Florida International University FIU Digital Commons

$6-2-2006$

\title{
Computational modeling of intermediate temperature proton exchange membrane (PEM) fuel cells
}

Denver Faron Cheddie

Florida International University

DOI: $10.25148 /$ etd.FI14060156

Follow this and additional works at: https://digitalcommons.fiu.edu/etd

Part of the Mechanical Engineering Commons

\section{Recommended Citation}

Cheddie, Denver Faron, "Computational modeling of intermediate temperature proton exchange membrane (PEM) fuel cells" (2006). FIU Electronic Theses and Dissertations. 2124.

https://digitalcommons.fiu.edu/etd/2124 


\section{FLORIDA INTERNATIONAL UNIVERSITY}

Miami, Florida

COMPUTATIONAL MODELING OF INTERMEDIATE TEMPERATURE

PROTON EXCHANGE MEMBRANE (PEM) FUEL CELLS

A dissertation submitted in partial fulfillment of the

requirements for the degree of

DOCTOR OF PHILOSOPHY

in

MECHANICAL ENGINEERING

by

Denver Faron Cheddie 
To: Dean Vish Prasad

College of Engineering and Computing

This dissertation, written by Denver Faron Cheddie, and entitled Computational Modeling of Intermediate Temperature Proton Exchange Membrane (PEM) Fuel Cells, having been approved in respect to style and intellectual content, is referred to you for judgment.

We have read this dissertation and recommend that it be approved.

Yiding Cao

Won Bong Choi

Berrin Tansel

Hongtan Liu

Xiang Yang Zhou

Norman Munroe, Major Professor

Date of Defense: June 2, 2006

The dissertation of Denver Faron Cheddie is approved.

\begin{tabular}{r} 
Dean Vish Prasad \\
College of Engineering and Computing \\
\hline Interim Dean Stephan Mintz \\
University Graduate School
\end{tabular}

Florida International University, 2006 


\section{DEDICATION}

I dedicate this dissertation to my parents, whose big idea it was for me to pursue graduate studies. I also dedicate it to my late grandparents, whose lives of self-sacrifice have left many doors open and many paths paved for subsequent generations, of which I am part. In similar vein, I do hope that through my accomplishments, I would have left a heritage for those who would follow in my footsteps. 


\section{ACKNOWLEDGMENTS}

During my four years at FIU, there are a number of individuals who have helped me along the way. First of all, I wish to acknowledge my Major Professor, Norman Munroe for introducing me to this research topic, of which I knew nothing prior to arriving at FIU. I am thankful for the guidance and mentoring he provided along the way, and the many opportunities with which he has presented me.

My gratitude is extended to my dissertation committee members for their willingness to participate in this process, and especially to Joe, who taught me how to use the fuel cell apparatus in the lab. Various other academic staff members have provided invaluable support and encouragement throughout my sojourn, and for this I am grateful.

Among my fellow students, there are a few who have assisted me along the way with advice and admonition - José and Srikanth, just to name two. I also wish to thank Roger for his help with the final preparation of some of the diagrams in this dissertation.

I would be remiss if I failed to acknowledge various sources of funding, which have enabled the completion of my degree:

- The Department of Mechanical Engineering, which offered me the Enhanced Research Assistant Award that covered my expenses during my first 2 years at FIU;

- Gas Technology Institute (GTI), who provided funds over the last 2 years of my study, which have enabled me to attend and present my work at numerous domestic and international conferences;

- The University Graduate School (UGS), who selected me for the Dissertation Year Fellowship, which covered my tuition fees and living expenses during my final year. 
Finally, I acknowledge my Lord and Savior Jesus Christ, who is my Strength when I am weak, who helps me, guides me, makes straight paths before me, and without whom I could do nothing. During the many times I felt like giving up, it was God's unceasing guidance that saw me through.

Hitherto Thy love has blessed me

Thou hast brought me to this place

And I know Thy hand will lead me

Safely home by Thy good grace 


\section{ABSTRACT OF THE DISSERTATION}

COMPUTATIONAL MODELING OF INTERMEDIATE TEMPERATURE

PROTON EXCHANGE MEMBRANE (PEM) FUEL CELLS

by

\section{Denver Faron Cheddie}

Florida International University, 2006

Miami, Florida

Professor Norman Munroe, Major Professor

A two-phase three-dimensional computational model of an intermediate

temperature $\left(120-190{ }^{\circ} \mathrm{C}\right)$ proton exchange membrane (PEM) fuel cell is presented. This represents the first attempt to model PEM fuel cells employing intermediate temperature membranes, in this case, phosphoric acid doped polybenzimidazole (PBI). To date, mathematical modeling of PEM fuel cells has been restricted to low temperature operation, especially to those employing Nafion ${ }^{\circledR}$ membranes; while research on PBI as an intermediate temperature membrane has been solely at the experimental level. This work is an advancement in the state of the art of both these fields of research. With a growing trend toward higher temperature operation of PEM fuel cells, mathematical modeling of such systems is necessary to help hasten the development of the technology and highlight areas where research should be focused.

This mathematical model accounted for all the major transport and polarization processes occurring inside the fuel cell, including the two phase phenomenon of gas dissolution in the polymer electrolyte. Results were presented for polarization performance, flux distributions, concentration variations in both the gaseous and aqueous 
phases, and temperature variations for various heat management strategies. The model predictions matched well with published experimental data, and were self-consistent.

The major finding of this research was that, due to the transport limitations imposed by the use of phosphoric acid as a doping agent, namely low solubility and diffusivity of dissolved gases and anion adsorption onto catalyst sites, the catalyst utilization is very low $(\sim 1-2 \%)$. Significant cost savings were predicted with the use of advanced catalyst deposition techniques that would greatly reduce the eventual thickness of the catalyst layer, and subsequently improve catalyst utilization. The model also predicted that an increase in power output in the order of $50 \%$ is expected if alternative doping agents to phosphoric acid can be found, which afford better transport properties of dissolved gases, reduced anion adsorption onto catalyst sites, and which maintain stability and conductive properties at elevated temperatures. 
1. INTRODUCTION 1

1.1. The Emergence of Fuel Cells 1

1.2. Limitations of Low Temperature Operation 1

1.3. The Need for Intermediate Temperature Membranes 3

1.4. The Need for Mathematical Modeling 3

1.5. Objectives of the Present Work 4

2. LITERATURE REVIEW 6

2.1. Review of PEM Fuel Cell Modeling $\quad 6$

2.2. Review of PBI Research 10

$\begin{array}{ll}\text { 2.2.1. } & \text { Methods to Improve Ionic Conductivity }\end{array}$

2.2.2. Mechanisms of Proton Conduction 16

2.2.3. Electro-Kinetic Studies 20

2.2.4. Fuel Cell Tests 22

2.3. Uniqueness of the Present Work 22

3. MODEL DEVELOPMENT 23

3.1. General Description of Phenomena 23

3.2. Phosphoric Acid Doped PBI Membrane 26

$\begin{array}{ll}\text { 3.3. Catalyst Layer } & 27\end{array}$

3.4. Computational Domain 29

3.5. Governing Equations $\quad 30$

3.5.1. Bulk Fluid Flow 30

$\begin{array}{ll}\text { 3.5.2. Gaseous Species Conservation } & 32\end{array}$

3.5.3. Dissolved Species Kinetics $\quad 32$

3.5.4. Two Phase Potential 33

3.5.5. Energy Conservation 36

$\begin{array}{lll}\text { 3.6. Source Terms } & 37\end{array}$

3.7. Constitutive Relations 38

$\begin{array}{lll}\text { 3.7.1. } & \text { Porous Media Corrections } & 38\end{array}$

3.7.2. Membrane Parameters $\quad 39$

3.7.3. Catalyst Parameters 41

$\begin{array}{lll}\text { 3.8. } & \text { Boundary Conditions } & 47\end{array}$

3.9. Solution Strategies and Methodologies $\quad 50$

3.9.1. Achieving Convergence 50

3.9.2. Solution Algorithm 52

3.9.3. Software, Hardware and Grid Independence 54 
$\begin{array}{ll}\text { 4. EXPERIMENTAL } & 57\end{array}$

5. RESULTS AND DISCUSSION 64

5.1. Model Validation $\quad 64$

5.1.1. Qingfeng et al [64] $\quad 64$

$\begin{array}{lll}\text { 5.1.2. } & 67\end{array}$

5.1.3. Wang et al [102] $\quad 69$

5.2. Base Case Solution $\quad 71$

$\begin{array}{ll}\text { 5.2.1. Velocities and Fluxes } & 72\end{array}$

$\begin{array}{lll}\text { 5.2.2. } & \text { Mole Fraction } & 74\end{array}$

5.2.3. Concentration $\quad 82$

5.2.4. Overpotentials $\quad 94$

5.2.5. Temperature 99

5.3. Parametric Analyses 106

$\begin{array}{lll}\text { 5.3.1. Temperature } & 106\end{array}$

5.3.2. Acid Doping Level ' 107

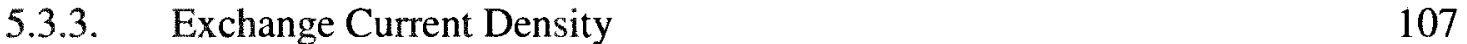

5.3.4. Transport Properties of Dissolved Gases $\quad 114$

$\begin{array}{lll}\text { 5.4. } & \text { Model Limitations } & 118\end{array}$

$\begin{array}{lr}\text { CONCLUSIONS } & 120\end{array}$

$\begin{array}{ll}\text { REFERENCES } & 124\end{array}$

$\begin{array}{lr}\text { APPENDICES } & 134\end{array}$

$\begin{array}{lr}\text { VITA } & 150\end{array}$ 


\section{LIST OF TABLES}

TABLE

PAGE

$\begin{array}{lr}\text { Table 2-1 Semi Empirical Models } & 8\end{array}$

Table 2-2 PBI Conductivity Results with Various Doping Agents 14

Table 2-3 Conductivity Results with Various PBI Composites 15

Table 2-4 PBI Fuel Cell Test Results 21

Table 3-1 Summary of Governing Equations and Applicable Sub-Domains 31

Table 3-2 Nominal Membrane and Diffusion Layer Properties 45

Table 3-3 Nominal Catalyst Layer Properties 46

Table 3-4 Nominal Fluid Properties [106] 46

Table 3-5 Nominal Gas Pair Diffusivities [110] 46

Table 3-6 Summary of Boundary Conditions 49

Table 5-1 Critical Numerical Values in Figure 5-1 66

$\begin{array}{lc}\text { Table 5-2 Critical Numerical Values in Figure 5-2 } & 68\end{array}$

Table 5-3 Critical Numerical Values in Figure 5-3 70

$\begin{array}{ll}\text { Table 5-4 Mass Balance Calculations } & 73\end{array}$

$\begin{array}{ll}\text { Table 5-5 Hydrogen Balance Calculations } & 76\end{array}$

$\begin{array}{ll}\text { Table 5-6 Oxygen Balance Calculations } & 76\end{array}$

Table 5-7 Water Balance Calculations $\quad 76$

$\begin{array}{ll}\text { Table 5-8 Energy Balance Calculations } & 100\end{array}$

$\begin{array}{ll}\text { Table 5-9 Critical Numerical Values in Figure 5-40 } & 108\end{array}$ 
Figure 2-1 Schematic of the PBI Repeat Unit

Figure 2-2 Proton Hopping along the PBI Backbone

Figure 2-3 Proton Hopping along Acid Anionic Chain

Figure 3-1 PEM Fuel Cell Schematic

Figure 3-2 Acid Doped PBI Membrane Schematic

Figure 3-3 Catalyst Layer Schematic

Figure 3-4 Computational Domain

Figure 3-5 Two Phase Potential Distribution

Figure 3-6 Two Phase Charge Transfers

Figure 3-7 Boundary Labels

Figure 3-8 Numerical Solutions

Figure 3-9 Solution Algorithm

Figure 3-10 Finite Element Mesh

Figure 3-11 Grid Independence Test

Figure 4-1 Fuel Cell Testing System Schematic

Figure 4-2 Arbin Instruments Fuel Cell Tester

Figure 4-3 Phosphoric Acid Doped ABPBI MEAs

Figure 4-4 Voltage vs. Time at $25^{\circ} \mathrm{C}$

Figure 4-5 Current Voltage (IV) Curves at $25{ }^{\circ} \mathrm{C}$

Figure 4-6 Voltage vs. Time Curve at Higher Temperatures

Figure 5-1 Model Comparison with Qingfeng et al [64] 
Figure 5-3 Model Comparison with Wang et al [102]

Figure 5-4 Velocity Distribution $\left(\mathrm{m} \mathrm{s}^{-1}\right)$

Figure 5-5 Hydrogen Flux $\left(\mathrm{kg} \mathrm{m}^{-2} \mathrm{~s}^{-1}\right)$

Figure 5-6 Oxygen Flux $\left(\mathrm{kg} \mathrm{m}^{-2} \mathrm{~s}^{-1}\right)$

Figure 5-7 Water Vapor Flux $\left(\mathrm{kg} \mathrm{m}^{-2} \mathrm{~s}^{-1}\right)$

Figure 5-8 Oxygen Mole Fraction, $0.4 \mathrm{~V}$

Figure 5-9 Oxygen Mole Fraction, $0.1 \mathrm{~V}$

Figure 5-10 Oxygen Mole Fraction, $0.65 \mathrm{~V}$

Figure 5-11 Oxygen Mole Fraction, $0.5 \mathrm{~L} \mathrm{~min}^{-1}$

Figure 5-12 Oxygen Mole Fraction, 1.6 $\mathrm{L} \mathrm{min}^{-1}$

Figure 5-13 Hydrogen Mole Fraction, $0.4 \mathrm{~V}$

Figure 5-14 Hydrogen Mole Fraction, $0.1 \mathrm{~V}$

Figure 5-15 Oxygen Concentration $\left(\mathrm{mol} \mathrm{m}^{-3}\right)$ on outer Surface of CCL

Figure 5-16 Hydrogen Concentration $\left(\mathrm{mol} \mathrm{m}^{-3}\right)$ on outer Surface of ACL

Figure 5-17 1D Oxygen Concentration in the CCL

Figure 5-18 1D Hydrogen Concentration in the ACL

Figure 5-19 x-z Oxygen Concentration $\left(\mathrm{mol} \mathrm{m}^{-3}\right)$ in outer $1 \%$ of the CCL

Figure 5-20 $\mathrm{x}-\mathrm{z}$ Hydrogen Concentration $\left(\mathrm{mol} \mathrm{m}^{-3}\right)$ in outer $1 \%$ of the ACL

Figure 5-21 Schematic of $x-z$ Transport Phenomena

Figure 5-22 $\mathrm{x}-\mathrm{y}$ Oxygen Concentration $\left(\mathrm{mol} \mathrm{m}^{-3}\right)$ in outer $1 \%$ of the CCL, $0.4 \mathrm{~V}$

Figure 5-23 x-y Hydrogen Concentration $\left(\mathrm{mol} \mathrm{m}^{-3}\right)$ in outer $1 \%$ of the ACL, 0.4 V 90

Figure 5-24 x-y Oxygen Concentration $\left(\mathrm{mol} \mathrm{m}^{-3}\right)$ in outer $1 \%$ of the CCL, $0.65 \mathrm{~V}$ 
Figure 5-25 x-y Hydrogen Concentration $\left(\mathrm{mol} \mathrm{m}^{-3}\right)$ in outer $1 \%$ of the ACL, $0.65 \mathrm{~V}$

Figure 5-26 Reaction Rate, $j\left(\mathrm{~A} \mathrm{~m}^{-3}\right)$ on outer surface of $\mathrm{CCL}$

Figure 5-27 Reaction Rate, $j\left(\mathrm{~A} \mathrm{~m}^{-3}\right)$ on outer surface of $\mathrm{ACL}$

Figure 5-28 Schematic of $x-y$ Transport Phenomena

Figure 5-29 Anode Overpotential (V)

Figure 5-30 Cathode Overpotential (V)

Figure 5-31 x-y Electrolyte Phase Potential (V)

Figure 5-32 x-z Electrolyte Phase Potential (V)

Figure 5-33 x-y Solid Phase Potential (V)

Figure 5-34 Temperature (K) Distribution

Figure 5-35 x-y Temperature (K) Distribution

Figure 5-36 Temperature (K), 1.6 $\mathrm{L} \mathrm{min}^{-1}$

Figure 5-37 Temperature (K), $\mathrm{h}=20 \mathrm{~W} \mathrm{~m}^{-2} \mathrm{~K}^{-1}$

Figure 5-38 Temperature (K), 0.16 $\mathrm{L} \mathrm{min}^{-1}$ counter-flow, $\mathrm{h}=10 \mathrm{~W} \mathrm{~m} \mathrm{~m}^{-2}$ 105

Figure 5-39 Temperature (K), 1.6 $\mathrm{L} \mathrm{min}^{-1}$ counter-flow, $\mathrm{h}=20 \mathrm{~W} \mathrm{~m}^{-2} \mathrm{~K}^{-1}$ 105

Figure 5-40 IV Curves as a Function of Doping Level, $X$ 108

Figure 5-41 IV Curves as a Function of Cathode Exchange Current Density

Figure 5-42 IV Curves as a Function of Anode Exchange Current Density

Figure 5-43 Anode Overpotential $(\mathrm{V})$ at $\mathrm{V}_{\text {cell }}=0.1 \mathrm{~V}$

Figure 5-44 Cathode Overpotential (V) at $\mathrm{V}_{\text {cell }}=0.1 \mathrm{~V}$

Figure 5-45 $\mathrm{x}-\mathrm{z}$ Oxygen Concentration $\left(\mathrm{mol} \mathrm{m}^{-3}\right)$ in outer $1 \%$ of the CCL, $0.1 \mathrm{~V} \quad 113$

Figure 5-46 $\mathrm{x}-\mathrm{z}$ Hydrogen Concentration $\left(\mathrm{mol} \mathrm{m}^{-3}\right)$ in outer $1 \%$ of the ACL, $0.1 \mathrm{~V} \quad 113$

Figure 5-47 IV Curves as a Function of Electrolyte Diffusivity and Solubility 
Figure 5-48 1D Hydrogen Concentration $\left(\mathrm{mol} \mathrm{m}^{-3}\right)$ in the ACL

Figure 5-49 1D Oxygen Concentration $\left(\mathrm{mol} \mathrm{m}^{-3}\right)$ in the CCL

Figure A-1 Thermodynamic Schematic of the Fuel Cell 
a

$c_{p}$

C

$d$

$D$

$D_{T}$

$f$

F

$h$

H

$i$

$i_{0}$

$j$

$k$

$k_{p}$

$m$

M

$P$

$R$

$S$

$T$

Effective surface area $\left(\mathrm{m}^{-1}\right)$

Specific heat capacity at constant pressure $\left(\mathrm{J} \mathrm{kg}^{-1} \mathrm{~K}^{-1}\right)$

Concentration $\left(\mathrm{mol} \mathrm{m}^{-3}\right)$

Diameter (m)

Species diffusivity $\left(\mathrm{m}^{2} \mathrm{~s}^{-1}\right)$

Effective thermal diffusivity $\left(\mathrm{m}^{2} \mathrm{~s}^{-1}\right)$

Mass ratio of platinum to carbon in the catalyst layer

Faraday constant, $96487 \mathrm{C} \mathrm{mol}^{-1}$

Convective heat transfer co-efficient $\left(\mathrm{W} \mathrm{m}^{-2} \mathrm{~K}^{-1}\right)$

Henry's constant ( $\mathrm{mol} \mathrm{m}^{-3} \mathrm{~atm}^{-1}$ )

Current density $\left(\mathrm{A} \mathrm{m}^{-2}\right)$

Exchange current density $\left(\mathrm{A} \mathrm{m}^{-2}\right)$

Reaction rate or volumetric current generation $\left(\mathrm{A} \mathrm{m}^{-3}\right)$

Thermal conductivity $\left(\mathrm{W} \mathrm{m}^{-1} \mathrm{~K}^{-1}\right)$

Gas permeability $\left(\mathrm{m}^{2}\right)$

Mass fraction, mass loading $\left(\mathrm{kg} \mathrm{m}^{-2}\right)$

Molar mass $\left(\mathrm{kg} \mathrm{mol}^{-1}\right)$, molarity $\left(\mathrm{mol} \mathrm{L}^{-1}\right)$

Pressure $(\mathrm{Pa})$

Universal gas constant, $8.3143 \mathrm{~J} \mathrm{~mol}^{-1} \mathrm{~K}^{-1}$

Source $\left(\mathrm{mol} \mathrm{m}^{-3} \mathrm{~s}^{-1}, \mathrm{~W} \mathrm{~m} \mathrm{~m}^{-3}\right)$, Entropy $\left(\mathrm{J} \mathrm{mol}^{-1} \mathrm{~K}^{-1}\right)$

Temperature (K) 


$\begin{array}{ll}u & \text { Velocity }\left(\mathrm{m} \mathrm{s}^{-1}\right) \\ V & \text { Potential (V) } \\ x & \text { Mole fraction } \\ X & \text { Doping level (dimensionless) }\end{array}$

\section{GREEK LETTERS}

$\alpha$

$\gamma$

$\varepsilon$

$\eta$

$\theta$

$\mu$

$\rho$

$\sigma$

$\phi$
Thermal diffusivity $\left(\mathrm{m}^{2} \mathrm{~s}^{-1}\right)$, Charge transfer coefficient

Concentration parameter

Porosity, volume fraction

Overpotential (V)

Blockage factor

Dynamic viscosity (Pa s)

Density $\left(\mathrm{kg} \mathrm{m}^{-3}\right)$

Electrical or ionic conductivity $\left(\mathrm{S} \mathrm{m}^{-1}\right)$

Electrical or ionic potential (V)

\section{SUBSCRIPTS \& SUPERSCRIPTS}

$$
a
$$

$c$

$d$

$e$

eff

$f$

$i, j$
Anode

Cathode

Dispersion

Electrolyte phase

Effective

Fluid property

Species $i, j$ 
Mass quantity

$s$

Solid property

sat

Saturation

$T$

Thermal

\section{ABBREVIATIONS}

ACL Anode catalyst layer

ADL Anode diffusion layer

AGC Anode gas channel

CCL Cathode catalyst layer

CDL Cathode diffusion layer

CGC Cathode gas channel

DMFC Direct methanol fuel cell

IV Current-voltage

MEA Membrane electrode assembly

OCV Open circuit voltage

PA Phosphoric acid

PAFC Phosphoric acid fuel cell

PBI Polybenzimidazole

PEM Proton exchange membrane or polymer electrolyte membrane 


\section{CHAPTER 1}

\section{INTRODUCTION}

\subsection{The Emergence of Fuel Cells}

It is believed that there will be a time in the future when global energy demands will be met by sources other than fossil fuels. It is believed that hydrogen will play a major role in such a future, a concept known as the hydrogen economy [1-4]. Fuel cells, in particular, proton exchange membrane (PEM) fuel cells are expected to play a major role in a future hydrogen economy, and are particularly attractive for use in portable, vehicular and stationary applications. The relatively low operational temperature of a PEM fuel cell allows for easy start up and quick response to changes in load and operating conditions.

\subsection{Limitations of Low Temperature Operation}

The PEM fuel cell has long been considered a prime candidate for future energy systems. However, a number of debilitating factors - low electrode kinetics, catalyst poisoning, and membrane material limitations - have hindered its development.

PEM fuel cells presently operate at temperatures below $90{ }^{\circ} \mathrm{C}$. Such low temperatures are necessary since the $\mathrm{Nafion}{ }^{\circledR}$ membrane, typically employed in PEM fuel cells requires a sufficiently high degree of hydration for effective proton conductivity. The presence of liquid water, however, dictates against higher temperature operation, and poses water management problems. Nafion's proton conducting ability decreases when it 
dehydrates. On the other extreme, excessive water produced at the cathode may result in flooding of the electrode, thereby blocking the gas pores via which oxygen is transported to the catalyst sites. Proper water management is therefore needed to simultaneously avoid membrane dehydration and electrode flooding, which is difficult to achieve under the variable load conditions associated with vehicular applications, and becomes increasingly cumbersome as individual fuel cells are assembled in stacks.

In order to maintain sufficiently low temperatures necessary for effective functioning of the Nafion ${ }^{\circledR}$ membrane, external cooling and humidification are required. This adds volume, weight and complexity to the fuel cell system [5]. At low temperatures, carbon monoxide $(\mathrm{CO})$ poisoning of the platinum $(\mathrm{Pt})$ catalyst also presents a problem. Traces of $\mathrm{CO}$, present in the hydrogen feed, are preferentially adsorbed on catalyst sites resulting in a reduced active catalyst surface area for hydrogen dissociation, and possibly permanent poisoning of the catalyst. This poisoning effect is less significant at higher temperatures. Generally, electrode kinetics, especially for oxygen reduction, are more sluggish at low temperatures.

These problems can all be resolved by operating the fuel cell at intermediate temperatures $\left(>120{ }^{\circ} \mathrm{C}\right.$ ). At intermediate temperatures, CO poisoning becomes less prominent, electrode kinetics are faster, and water exists primarily in the vapor phase, precluding problems associated with liquid water management. However, since Nafion ${ }^{\circledR}$ requires a high water content to maintain proton conductivity, its effectiveness diminishes above the boiling point of water. Therefore, alternative proton conducting membranes, which maintain mechanical strength and chemical stability at elevated temperatures, are needed. 


\subsection{The Need for Intermediate Temperature Membranes}

There has been growing interest in intermediate temperature $\left(120-190{ }^{\circ} \mathrm{C}\right)$, low humidity (25-50\% RH) PEM fuel cells. The US Department of Energy (DOE) has planned to invest USD $\$ 100$ million into research in such fuel cells over the next 4 years [5].

Alternative membranes are needed for intermediate temperature PEM fuel cells, which are mechanically, thermally and chemically stable at the desired temperatures. Many such membranes have been investigated, which include fluorinated polymers e.g. Nafion ${ }^{\circledR}$, Flemion ${ }^{\circledR}$, Aciplex ${ }^{\circledR}$; partially fluorinated polymers e.g. trifluostyrene monomers; and non-fluorinated aromatic polymers e.g. polyimide, poly (phenylquinoxaline), poly (phenylene) oxide, poly (arylether) sulfone, poly (arylether) ketone, and polybenzimidazole (PBI) [6]. Of these membranes, PBI has received considerable attention in the literature. Much effort has been directed into determining the conductivity characteristics and conduction mechanisms of PBI. Researchers have considered a variety of means for increasing its conductivity. Investigations have also been conducted to understand the electro-kinetics at the PBI/Pt interface. Section 2.2 presents a literature review of research conducted on PEM fuel cells with PBI as a membrane.

\subsection{The Need for Mathematical Modeling}

Fuel cell modeling has received much attention over the past 15 years in an attempt to better understand the phenomena occurring within the cell [7]. Parametric models allow engineers and designers to predict the performance of the fuel cell given 
geometric parameters, material properties, and operating conditions such as temperature, pressure and humidity. Such models are advantageous because experimentation is costly and time consuming. Furthermore, experimentation is limited to designs which already exist, thus does not facilitate innovative design. Given the highly reactive environment within the fuel cell, it is often impossible to measure critical parameters such as temperature, pressure and potential gradients, or species concentrations within the cell. Thus, detailed transport models are needed. Section 2.1 reviews some of the developments in PEM fuel cell modeling over the past 15 years.

\subsection{Objectives of the Present Work}

Most of the work done on the modeling of PEM fuel cells has considered low temperature fuel cells equipped with Nafion $^{\circledR}$ membranes. Very few models have been developed for other types of PEM fuel cells. This scarcity of intermediate temperature models in the literature is surprising given the DOE's long term interest in such fuel cells. The DOE represents the major funding agency for fuel cell research, so their long term interest in intermediate temperature PEM fuel cells is a strong indicator of the future for the industry. To the author's knowledge, the only mathematical models developed for intermediate temperature PEM fuel cells were by Cheddie and Munroe [8-17].

This work presents a 3-D 2-phase model of an intermediate temperature PEM fuel cell equipped with a PBI membrane. This model is intended to illicit a greater fundamental understanding of the transport phenomena occurring inside the fuel cell, highlight critical features which limit the cell performance, and specify areas where further research is needed. As such, it represents the first modeling effort of intermediate 
temperature PEM fuel cells (or the first application of modeling techniques to such systems), and is intended to serve as a foundational development for future work in the field. 


\section{CHAPTER 2}

\section{LITERATURE REVIEW}

\subsection{Review of PEM Fuel Cell Modeling}

The fuel cell and the hydrogen economy are two concepts which have always complemented each other. Commercial interest in the technology was piqued with the emergence of solid polymer electrolytes. The Nafion ${ }^{\circledR}$ membrane, being commercially produced by DuPont ${ }^{\circledR}$, became one of the main default choices of solid polymer electrolytes considered for PEM fuel cells.

Much experimental work and fuel cell tests were conducted on Nafion ${ }^{\circledR}$ membranes, and it was determined that a major parameter affecting its performance was the level of hydration in the membrane. Nafion ${ }^{\circledR}$ requires a high level of liquid water, absorbed in its structure, in order to effectively conduct protons. Thus, the conductivity and fuel cell performance declines when dehydration occurs in the membrane. It was further discovered, that at high current densities, excessive production of liquid water resulted in mass transport limitations at the cathode, thereby diminishing the performance of the cell. It became critical to operate the fuel cell in a manner that would maintain proper membrane hydration at all times, while simultaneously allowing for effective water removal at the cathode.

With the limitations in experimental techniques, induced by the size dimensions and the highly reactive environment inside the fuel cell, attention was turned to fuel cell modeling to obtain a better understanding of fuel cell phenomena. Mathematical 
modeling is important in that it is able to predict phenomena which simply cannot be experimentally determined. Modeling is also versatile in that it can evaluate the feasibility of innovative designs.

A model may fall into one of three categories: analytical, semi-empirical, or mechanistic. Analytical models (e.g. Standaert et al $[18,19]$ ) involve great simplifications of the physical phenomena in order to facilitate approximate analytical solutions. Usually analytical models are useful for providing quick calculations on current-voltage (IV) performance for simple cell designs. But they are limited in their ability to model the water management phenomena, which is so crucial to $\mathrm{Nafion}^{\circledR}$ fuel cells.

Semi-empirical modeling combines theoretically derived differential and algebraic equations with empirically determined relationships. Empirical relationships are employed when the physical phenomena are difficult to model or the theory governing the phenomena is not well understood. Examples of semi-empirical models are shown in Table 2-1.

Semi-empirical models are, however, limited to a narrow corridor of operating conditions, outside of which their predictive ability diminishes. They are very useful for making quick predictions for designs that already exist. They cannot be used to predict the performance of innovative designs, or the response of the fuel cell to parameter changes outside of the conditions under which the empirical relationships were developed. Empirical relationships also do not provide an adequate physical understanding of the phenomena inside the cell. They only correlate output with input. 
Table 2-1 Semi Empirical Models

\section{Authors Phenomena studied}

Springer et al [20]

Developed the conductivity-hydration relation for the Nafion membrane

Amphlett et al. [21] Estimated potential losses and fit coefficients in a formula to predict the current voltage characteristics

Pisani et al [22]

Estimated activation and ohmic losses, as well and transport limitations at the cathode reactive region

Maggio et al [23]

Related the cathode gas porosity as an empirical function of current density (indirectly related to the water production)

Chan et al [24]

Empirically determined the fraction of the anode catalyst occupied by carbon monoxide

Maxoulis et al [25] Modeled fuel cell stacks during automobile driving conditions

Mechanistic modeling involves the derivation of differential and algebraic equations based on the physics and electro-chemistry governing the phenomena internal to the cell. These equations are solved using some sort of computational method, which may involve a multi-domain or single (unified) domain approach [7].

One of the earliest works on PEM fuel cell modeling was by Bernardi and Verbrugge $[26,27]$. Theirs was a $1 \mathrm{D}$ isothermal model, which assumed fully hydrated conditions in the Nafion ${ }^{\circledR}$ membrane at all times. Thus, it was very limited in its ability to predict the hydration effects, noting that temperature and heat generation have significant effects on hydration levels. Nevertheless, this classic work was foundational to the modeling efforts which followed. 
Some subsequent 1D models were developed. The model by Baschuk and Li [28] allowed for variable degrees of hydration of the membrane, even though the isothermal assumptions were maintained. Yan et al [29] and Wohr et al [30] included non-isothermal effects, the former for single fuel cells, and the latter for fuel cell stacks. They reported temperature variations of $2-3 \mathrm{~K}$ in single cells and $8 \mathrm{~K}$ in a 4-cell stack. However, these values are 1D variations, or the temperature variations in the direction perpendicular to the membrane electrode assembly (MEA). The major temperature variations in fuel cells actually occur in the direction parallel to the gas channels, thus limiting the ability of 1D models to accurately simulate water and thermal effects.

One of the first 2D models developed was by Gurau et al [31]. In this work, the authors introduced the concept of unified domains by incorporating the gas channel and diffusion layer into one computational sub-domain. This concept was further developed by Wang et al [32] and Zhou and Liu [33], who first applied the principles of computational fluid dynamics (CFD) [34] to fuel cell modeling. The concept of the unified domain enabled the implementation of fuel cell models into commercial CFD codes, which facilitated the more complex models later developed.

Other 2D models developed were by Um et al [35], who studied transient effects; and Ge et al [36] who studied the effect of flow mode (co-flow vs. counter-flow) on the hydration of the Nafion ${ }^{\circledR}$ membrane. The development of 3D models quickly followed. Wang et al [37] studied the effect of inlet gas humidification on the hydration level of the membrane and fuel cell performance. Zhou et al [38] studied the effect of CO kinetics in the anode stream. Berning et al $[39,40]$ developed non-isothermal models which predicted the temperature variations within the cell. Clearly such models are much more 
accurate in predicting water management effects. Temperature variations in the order of $10 \mathrm{~K}$ were predicted, although not much discussion was given on any cooling strategies employed.

Strategies developed to enhance water management in fuel cells involved innovative gas flow fields. Because of the advanced state of the art in fuel cell modeling at this point, the geometric complexities of serpentine gas flow fields $[41,42]$ and interdigitated flow fields $[43,44]$ were incorporated into contemporary modeling. Modeling has also been used to optimize the design parameters in the serpentine flow fields [45]. Kumar and Reddy [46] numerically investigated the innovative design of including metal foam in the flow fields of the bi-polar plates. This reinforces the fact that modeling can be used to evaluate innovative designs, and greatly speed up the development of the technology.

In most of the early models, the co-existence of liquid water and water vapor was accounted for by assuming that each phase flowed in separate pores without mixing. $\mathrm{Hu}$ et al [47] and Sun et al [48] considered two-phase mixtures of gaseous and liquid species. Such methods are more effective in predicting the concentration overpotential effects, since they can account for the reduced porosity of the gas phase, due to the presence of liquid water, without resorting to semi-empirical relations.

\subsection{Review of PBI Research}

It is evident that much progress has been made in the modeling of Nafion ${ }^{\circledR}$ fuel cells. Recently however, there has been a shift toward operating PEM fuel cells at elevated temperatures. Since Nafion ${ }^{\circledR}$ suffers performance degradation above $100{ }^{\circ} \mathrm{C}$, 
alternative membranes are needed for intermediate temperature PEM fuel cells, which are not as dependent on liquid hydration.

Of the many alternatives considered, the PBL/phosphoric acid system is among the best candidates for higher temperature operation [49]. In fact, it is the phosphoric acid impregnation which enables proton exchange characteristics at elevated temperatures. Different factors now become critical to fuel cell performance, such as the doping level of the acid, the mechanisms of proton conduction, the effects of ambient humidity on the acid concentration and viscosity inside the membrane, and the transport properties of dissolved gases through the electrolyte. Research into PBI membranes has encompassed a broad range of topics, including means of improving its ionic conductivity, the study of water characteristics, and electro-kinetic studies.

PBI is an amorphous polymer with a glass transition temperature of $420^{\circ} \mathrm{C}$ [50]. It is very stable against mechanical stresses [51], which implies that membrane specimens of lower thicknesses than Nafion ${ }^{\circledR}$ are permissible. It was first suggested for use in fuel cell systems by Wainright et al [52]. Although the typical conductivities of acid doped PBI are lower than that of water impregnated Nafion ${ }^{\circledR}$ [53], the lower membrane thicknesses result in membrane resistances of the same order of magnitude as Nafion ${ }^{\circledR}[8]$. PBI is also a very promising membrane for direct methanol systems because of its lower permeability to methanol than Nafion ${ }^{(B)}$, especially at intermediate temperatures [54]. PBI has been reported to allow over 10 times less methanol crossover than Nafion ${ }^{\circledR}[52,55-57]$.

By itself, PBI has very little ionic conductivity $\left(\sim 1 \times 10^{-12} \mathrm{~S} \mathrm{~cm}^{-1}\right.$ at $\left.25^{0} \mathrm{C}[58]\right)$. However, when doped with a strong acid or alkali, it attains reasonable proton 
conductivity $[52,59]$, even at low humidities [60]. Also, because of the presence of the acid, as opposed to water, absorbed in the polymer structure, the PBI system is thermally stable at much higher temperatures than Nafion ${ }^{\circledR}$ [61-63]. PBI easily lends itself to acid impregnation because it has donor and acceptor hydrogen bonding sites which are capable of participating in specific interactions. A schematic of PBI is shown in Figure $2-1$.



Figure 2-1 Schematic of the PBI Repeat Unit

\subsubsection{Methods to Improve Ionic Conductivity}

The most common method of enhancing PBI's ionic conductivity is doping with an electrolyte active species (acid or base) [64], particularly phosphoric or sulfuric acid. The PBI membrane is formed by dissolving the PBI powder in a suitable organic solvent such as dimethylacetamide (DMAc) or methanesulfonic acid (MSA) [65], and heating the resulting solution over a glass plate until the solvent evaporates, leaving a thin film of PBI residue. For acid doping, the membranes are immersed in a concentrated acid solution, during which time it absorbs the acid into its structure until an equilibrium is established between the absorbed acid and the acid in solution. The reaction between the basic PBI polymer and the strong acid results in a single phase polymer electrolyte [52]. 
An alternative method of doping the membrane is the direct casting method, where the phosphoric acid is applied during the membrane casting stage i.e. the PBI powder is dissolved in a solvent consisting of phosphoric acid and either MSA or DMAc. Thus, there is no need for subsequent immersion doping. This method may increase the conductivity $[56,66]$, and has been reported to allow for better retention of the acid in the membrane structure [66].

The doping level is defined as the number of molecules of the doping agent absorbed by the membrane per repeat PBI unit i.e. it is the molar ratio between the absorbed agent and the PBI. The absorbed acid falls into 2 categories: bonded acid and non-bonded (free) acid. The bonded acid refers to that quantity of acid which forms bonds with the N-H groups of PBI. Since PBI contains 2 hydrogen bonding sites per repeat unit, a maximum of 2 acid molecules can be bonded to each PBI unit. For doping levels higher than 2, some of the acid will not be able to form bonds with PBI, and hence will be free. The amount of free (excess) acid increases with doping level, while the amount of bonded acid remains constant $[53,67]$.

For phosphoric acid doping, the membrane conductivity is observed to increase with temperature and doping level, since there is an increase in the concentration and/or mobility of charge carriers. However, increasing the doping level also decreases the mechanical strength of the membrane, so an upper limit of doping level exists which produces high conductivity membranes without sacrificing mechanical properties. Phosphoric acid doped PBI is thermally stable up to $200{ }^{\circ} \mathrm{C}$, above which the absorbed acid begins to decompose $[61,68]$. Sulfuric acid doped membranes were observed to dehydrate above $70^{\circ} \mathrm{C}$, which may dictate against their feasibility for high temperature 
operation $[60,69]$. Alkali $(\mathrm{KOH}$ and $\mathrm{NaOH})$ doped membranes were studied at $50{ }^{\circ} \mathrm{C}$, with no conductivity or fuel cell test results reported at higher temperatures [70]. Table 2-2 lists some typical conductivity values reported for the various doping systems.

Table 2-2 PBI Conductivity Results with Various Doping Agents

\begin{tabular}{lll}
\hline Dopant & Cell Conditions & Conductivity $\left(\mathrm{S} \mathrm{cm}^{-1}\right)$ \\
\hline & $160{ }^{\circ} \mathrm{C}$, doping level 5 & $0.1[51]$ \\
$\mathrm{H}_{3} \mathrm{PO}_{4}$ & Room temperature, doping level 6 & $4.5 \times 10^{-5}[71]$ \\
& $150{ }^{\circ} \mathrm{C}$, dry atmosphere, doping level 5 & $5 \times 10^{-3}[57]$ \\
& $150{ }^{\circ} \mathrm{C}, \mathrm{RH} 20 \%$, doping level 5 & $3 \times 10^{-2}[57]$ \\
\hline & $50{ }^{\circ} \mathrm{C}, 8 \mathrm{M}$ doping solution & $3.6 \times 10^{-3}[60,69]$ \\
$\mathrm{H}_{2} \mathrm{SO}_{4}$ & $50{ }^{\circ} \mathrm{C}, 12 \mathrm{M}$ solution & $8 \times 10^{-3}[60,69]$ \\
& $50{ }^{\circ} \mathrm{C}, 16 \mathrm{M}$ solution & $6 \times 10^{-2}[60,69]$ \\
\hline $\mathrm{KOH}$ & $50{ }^{\circ} \mathrm{C}, 6 \mathrm{M} \mathrm{KOH}$ doping solution & $9.5 \times 10^{-2}[70]$ \\
\hline $\mathrm{NaOH}$ & $50{ }^{\circ} \mathrm{C}, 8 \mathrm{M} \mathrm{NaOH}$ & $4.5 \times 10^{-2}[70]$ \\
\hline
\end{tabular}

Other methods for improving the PBI characteristics are the addition of side chains to the PBI ring, and inorganic composite incorporation into the PBI structure. Bae et al [72] produced PBI-PS and PBI-BS by adding propane-sultone and butane-sultone side chains to the PBI rings. Hasiotis et al [53] found that blends of PBI with sulfonated polysulfones (SPSF) showed excellent miscibility characteristics, which is expected to aid in the membrane preparation, and which they attributed to hydrogen bonding between the sulfate groups and the N-H groups in PBI $[73,74]$. Pu et al [50] synthesized PNMBI 
and PNEBI by replacing the imidazole hydrogen of PBI, respectively by methylate and ethylate groups. The only favorable result was that the addition of the methyl group may have enhanced the solubility of the membrane during preparation. Otherwise, there was no noticeable improvement in conductivity, whereas the methanol permeability actually increased with the addition of the organic side chains. Among the inorganic composite materials considered are imidazolium phosphate $\left(\mathrm{Me}-\mathrm{Im} \mathrm{H}_{2} \mathrm{PO}_{4}\right)$ [75], silicotungstic acid absorbed on silica $\left(\mathrm{SiWA}_{\mathrm{SiO}}\right)$, and zirconium phosphate $\left(\mathrm{ZrP}\right.$ or $\left.\mathrm{Zr}\left[\mathrm{HPO}_{4}\right]_{2} \cdot \mathrm{nH}_{2} \mathrm{O}\right)$. Hybrids of PBI with other polymers, such as PPY(50)coPSF [76, 77] and sulfonated poly(etheretherketone) (sPEEK) [78] have also been considered, and have been shown to display good conductivities and high stability at elevated temperatures. A summary of the significant findings is shown in Table 2-3.

Table 2-3 Conductivity Results with Various PBI Composites

\begin{tabular}{lll}
\hline Composites & Conditions & Conductivity $\left(\mathbf{S ~ c m}^{-1}\right)$ \\
\hline PBI-BS [72] & $160^{\circ} \mathrm{C}$ & $10^{-3}$ to $10^{-2}$ \\
\hline $22.5 \%$ SiWA, 27.5 $\mathrm{SiO}_{2}$ and & $160^{\circ} \mathrm{C}$, no doping & $1.2 \times 10^{-3}$ \\
$50 \%$ PBI [79-81] & $160{ }^{\circ} \mathrm{C}$, doped with PA & $2.23 \times 10^{-3}$ \\
\hline & $200^{\circ} \mathrm{C}, 0.15 \%$ rh & $3.2 \times 10^{-2}$ \\
& $200^{\circ} \mathrm{C}, 1 \%$ rh. & $4 \times 10^{-2}$ \\
PBI/ZrP doped with & $200^{\circ} \mathrm{C}, 5 \%$ rh & $6.8 \times 10^{-2}$ \\
phosphoric acid [82, 83] & $140^{\circ} \mathrm{C}, 5.6 \%$ rh & $3 \times 10^{-2}$ \\
& $140^{\circ} \mathrm{C}, 20 \% \mathrm{rh}$ & $4 \times 10^{-2}$ \\
\hline PBI and PPY(50)coPSF & Room temperature & 1 to $3 \times 10^{-2}$ \\
copolymer [76-78] & $150^{\circ} \mathrm{C}, 30 \%$ rh & $7 \times 10^{-2}$ \\
\hline
\end{tabular}




\subsubsection{Mechanisms of Proton Conduction}

In addition to developing high conductivity membranes, it is also necessary to determine the modes of proton conduction across the PBI membrane, because liquid water dependence militates against high temperature operation. The mechanism of proton conduction through a polymer can be either a vehicle mechanism, a Grotthus mechanism, or a combination of both [68]. The vehicle mechanism entails segmental motion of the polymer/electrolyte, which acts as a vehicle that transports protons with it. The conduction of protons in the Nafion $/$ water system occurs via the vehicle mechanism, water acting as the vehicle which transports the protons. The Grotthus mechanism involves proton hopping via hydrogen bond rearrangement. Under the Grotthus mechanism, there is no net translation of the electrolyte species. This is also referred to as an activated mechanism because it requires some sort of activation energy to break and re-form the hydrogen bonds.

$\mathrm{Pu}$ et al $[50,84]$ studied the conduction mechanism in phosphoric acid doped PBI. Their FTIR studies showed that strong hydrogen bonding existed between the polymer and the acid, whereby polymer complexes are formed due to the interaction of the imidazole ring and the acid [85]. This is interpreted to mean that the acid induces the protonation of the imidazole ring of PBI and forms anions, which interact with PBI by strong hydrogen bonding. The acid becomes ionized in the process, the dominant anions associated with phosphoric acid being $\mathrm{HPO}_{4}{ }^{2-}$ and $\mathrm{H}_{2} \mathrm{PO}_{4}^{-}$.

They used measurements of the activation volumes to lend insight into the conduction mechanism, activation volume being defined as the measure of volume dilatation required for ions or molecules to move through material $[84,86]$. The observed 
activation volumes for phosphoric acid doped PBI were between $3.8-5.8 \mathrm{~cm}^{3} \mathrm{~mol}^{-1}$, while activation volumes of $20-60 \mathrm{~cm}^{3} \mathrm{~mol}^{-1}$ are consistent with the generally accepted paradigm of ion motion by segmental movements of polymer $[87,88]$. They interpreted this order of magnitude difference to mean that large scale molecular motion does not occur in the glassy state of the polymer i.e. below $420^{\circ} \mathrm{C}$ for PBI. PBI's macromolecular chains are frozen below this temperature [89], which implies that the only possible vehicle is the doping acid, not the PBI. Bouchet et al [68] conclude that a Grotthus mechanism of proton conduction in acid doped PBI is more likely. Fontanella et al [71] concurred that a hopping mechanism, as opposed to segmental motion, is more likely the mode of proton transport through acid doped PBI.

The mechanism of proton conduction may depend on the acid doping level as well as the humidity. For low acid doping levels, the imide sites of PBI are not completely protonated, since there are more vacant $\mathrm{N}-\mathrm{H}$ bonding sites than acid molecules present. Ionic transport results from the transfer of protons from a protonated imide site to a vacant one, as shown in Figure 2-2. So at low doping levels, the PBI backbone plays a significant role in proton conduction [90].

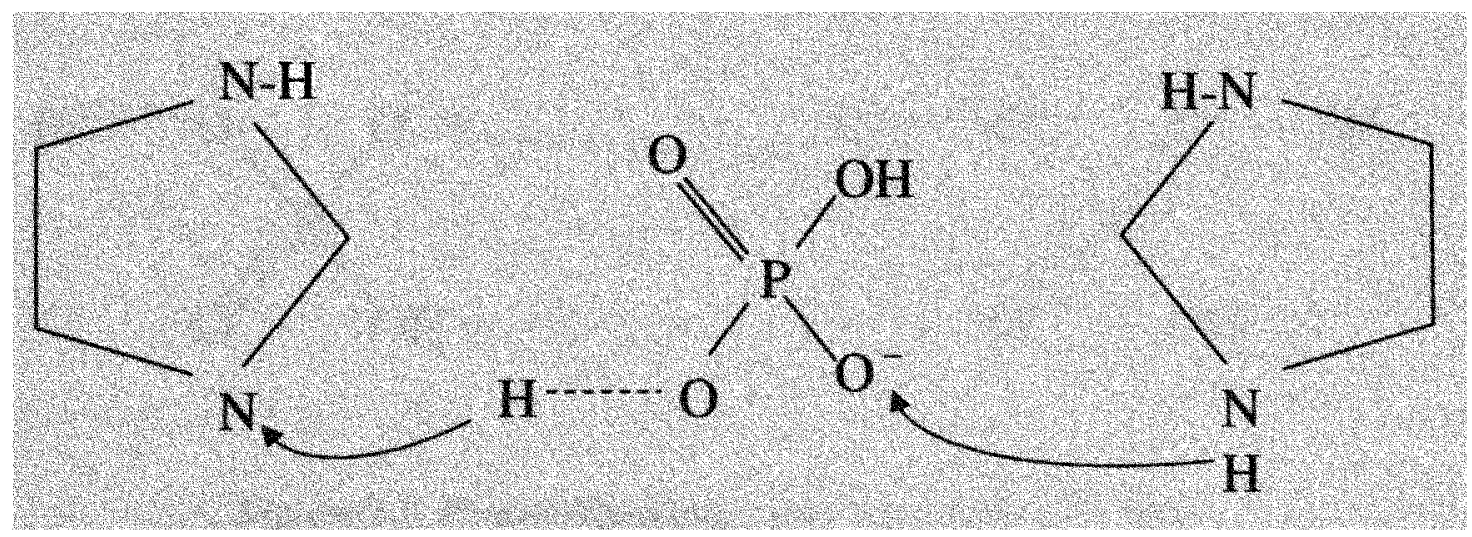

Figure 2-2 Proton Hopping along the PBI Backbone 
At higher doping levels, there is more free or non-bonded acid present, and different theories exist regarding the mechanism of proton conduction. As the doping level increases, the mobility of charge carriers increase, hence higher conductivities are observed [90]. One theory suggests that the proton hopping occurs along the anionic chains of the acid, with the PBI polymer acting as a matrix within which the acid is contained [90] (Figure 2-3). The zero water drag co-efficient of acid doped PBI [57, 91, 92] is said to favor this finding. Another theory is that proton transport is partially due to the diffusion of phosphate moieties (i.e. vehicle mechanism), and partially due to rapid proton exchanges between the phosphates acting as proton solvents (i.e. hopping). Pulsed-field gradient NMR proton and phosphorous diffusion data analysis showed that the ratio between the diffusion and hopping contribution to the proton transport increased with the acid content [93], which may suggest that at higher doping levels, the vehicle mechanism becomes increasingly prominent. Pu et al [84] concur that a combination of both mechanisms may be at work. This is confirmed by the fact that at higher acid concentrations, the activation volume increases, suggesting a greater influence of the vehicle mechanism [84].

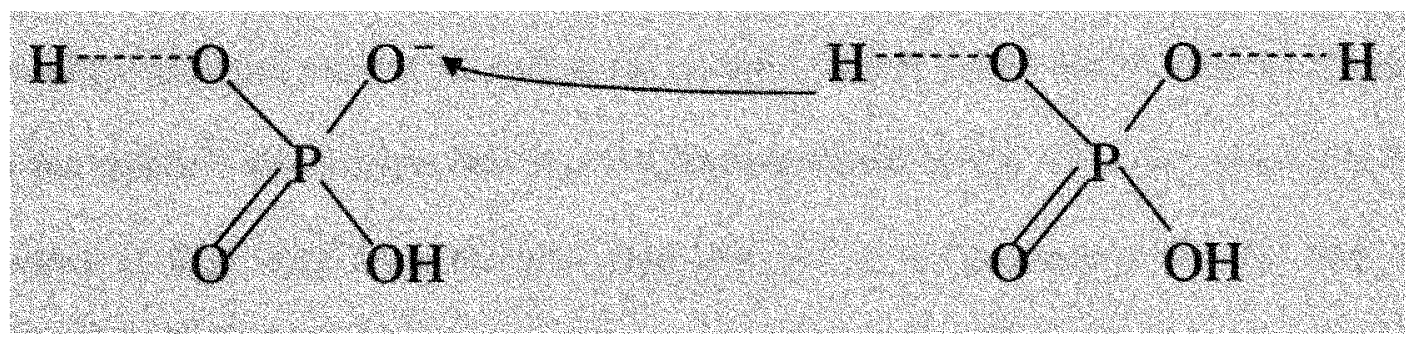

Figure 2-3 Proton Hopping along Acid Anionic Chain 
The role of humidity in the conduction mechanism has also been given attention in the literature, since there are differences in the reported conductivities of acid doped PBI for hydrous and anhydrous systems $[52,65,89,90]$. PBI can absorb up to 15 weight $\%$ water in equilibrium [94], and $\mathrm{Pu}$ et al [78] suggest that this absorbed water acts as a proton solvent and contributes to the proton transport either by self diffusion (vehicle) or by rapid exchange of protons via hydrogen bridges (hopping). Schechter et al [74] postulate that increasing the humidity increases the conductivity for numerous reasons. One is because conduction is assisted by water via the vehicle mechanism. Another is the reduction of viscosity of free acid (due to water dilution), which increases its mobility. Increasing the humidity also prevents the ortho-phosphoric acid from decomposing into pyro-phosphoric acid.

$$
2 \mathrm{H}_{3} \mathrm{PO}_{4} \leftrightarrow \mathrm{H}_{4} \mathrm{P}_{2} \mathrm{O}_{7}+\mathrm{H}_{2} \mathrm{O}
$$

He et al [95] concur that at high doping levels, there is increased water uptake, and the presence of strongly absorbed water molecules contributes to the ionization of the acid. Essentially, the absorbed water can act as a vehicle for proton transport, or can modify the phosphoric acid properties to better facilitate proton hopping. If indeed the vehicle mechanism were a means of proton transport in PBI, then there must be phosphate moieties exiting the cell at the cathode, which would not be difficult to detect. To the author's knowledge, this has not been reported in the literature. What has been reported is that, over time, the acid may leak out of the membrane $[63,66,96]$. This would suggest a state of mechanical degradation rather than a regular mode of operation. So it is more likely that for most doping levels and humidities, the Grothus mechanism is the mode of proton conduction through phosphoric acid doped PBI. 


\subsubsection{Electro-Kinetic Studies}

In addition to achieving high conductivity and understanding the conduction mechanism, the effects of the acid doped electrolyte on the electro-kinetics are also essential to fuel cell performance. The electrolyte "wets" the catalyst during assembly, and allows for adequate transport of protons and reactants to the catalyst sites. Studies were conducted on the electro-kinetics of oxygen reduction at the surface of $\mathrm{Pt}$ in the presence of phosphoric acid doped PBI. Cyclic voltammetry results suggested that the reaction mechanism is unaltered by the presence of the polymer, however there may be catalyst blockage due to the presence of the PBI [97]. One reported problem concerns the preferential adsorption of phosphoric acid anions onto the catalyst surface, which reduces the effective surface area for oxygen reduction. The blockage associated with this adsorption effect increases with acid concentration and electrode polarization, but decreases with temperature [98].

Another factor found to affect the reactivity of the electrode was the transport of reactants to the catalyst sites. Oxygen gas must first dissolve in the acid doped electrolyte and diffuse to the catalyst sites. It is found that the solubility and diffusivity of phosphoric acid systems are relatively low, leading to transport limitations. Typical oxygen diffusivities reported for phosphoric acid doped PBI range from $2.8-8.0 \times 10^{-10}$ $\mathrm{m}^{2} \mathrm{~s}^{-1}$ at $150^{\circ} \mathrm{C}$ for doping levels $4.5-10$, compared with $2.0 \times 10^{-8} \mathrm{~m}^{2} \mathrm{~s}^{-1}$ for a hydrated Nafion ${ }^{\circledR}$ membrane at $80{ }^{\circ} \mathrm{C}$ [43]. Typical oxygen solubility values for acid doped PBI are $0.56-1.13 \mathrm{~mol} \mathrm{~m}^{-3} \mathrm{~atm}^{-1}$, compared with $1.18 \mathrm{~mol} \mathrm{~m}^{-3} \mathrm{~atm}^{-1}$ for Nafion ${ }^{\circledR}$ [43] for the respective conditions given above. Gubbins et al [99] also show that the oxygen solubility 
and diffusivity values are an order of magnitude higher in water than in pure phosphoric acid at $25^{\circ} \mathrm{C}$.

Liu et al $[100,101]$ showed that the presence of PBI further reduces the transport properties of oxygen in acid doped PBI. Their results showed that as the acid doping level increases (relative PBI content decreases), the solubility, diffusivity and exchange current density values approached those of $\mathrm{Pt}$ in phosphoric acid. It should be noted though that the PBI polymer is necessary to contain the acid in a solid structure. No electro-kinetic studies were reported for the hydrogen reaction at a $\mathrm{Pt} / \mathrm{PBL} /$ phosphoric acid interface.

Table 2-4 PBI Fuel Cell Test Results

Fuel, Membrane System

Hydrogen, $\mathrm{H}_{3} \mathrm{PO}_{4}$ doped PBI membrane [102]

Hydrogen, $\mathrm{H}_{3} \mathrm{PO}_{4}$ doped PBI membrane [103]

Hydrogen, $\mathrm{H}_{3} \mathrm{PO}_{4}$ doped PBI membrane [69]

Hydrogen, $\mathrm{H}_{2} \mathrm{SO}_{4}$ doped PBI membrane [69]

Hydrogen, KOH doped PBI membrane [70]

Hydrogen, PBI-BS membrane [72]

DMFC, $\mathrm{H}_{3} \mathrm{PO}_{4}$ doped PBI membrane [55]

DMFC, sPEEK/PBI/PSU composite membrane [51]

Quasi-DMFC, $\mathrm{H}_{3} \mathrm{PO}_{4}$ doped PBI membrane [104]

Ethanol, $\mathrm{H}_{3} \mathrm{PO}_{4}$ doped PBI membrane [105]
Temperature

Peak Power

Density

$\left(\mathrm{mW} \mathrm{cm}^{-2}\right)$ 


\subsubsection{Fuel Cell Tests}

PBI membranes have also been implemented in laboratory fuel cells for testing purposes. The reported peak power densities for various membranes at different operating conditions are shown in Table 2-4. The best fuel cell results for PBI systems are comparable to Nafion ${ }^{\circledR}$ systems.

\subsection{Uniqueness of the Present Work}

A significant amount of effort has been devoted to the modeling of Nafion ${ }^{\circledR}$ fuel cells, and much experimental work has been conducted on the use of PBI systems in intermediate temperature PEM fuel cells. However, modeling of intermediate temperature fuel cells has been scarce, in fact, only the group at FIU has indulged in such work [8-17]. Our models range from $1 \mathrm{D}$ to $3 \mathrm{D}$, while our latest models include two phase effects due to reactant dissolution in the electrolyte phase $[13,17]$. This work presents the most up to date developments in our modeling efforts of intermediate temperature fuel cells using (although not restricted to) PBI membranes. PEM fuel cell modeling has been limited to Nafion ${ }^{\circledR}$ fuel cells at low temperature operation, while work on PBI has only been conducted at the experimental level. The present work is essentially the next step in the development of both PEM fuel cell modeling and intermediate temperature membrane research. 


\section{CHAPTER 3}

\section{MODEL DEVELOPMENT}

\subsection{General Description of Phenomena}

Figure 3-1 shows a schematic of the fuel cell operation. (a) shows the $x-y$ plane while (b) shows the $x-z$ plane. Hydrogen is supplied in the anode gas channel, and flows through the diffusion layer to the catalyst layer. On the surface of the Pt particles, the following half cell reaction occurs spontaneously.

$$
H_{2}(a q) \longrightarrow 2 H^{+}(a q)+2 e^{-}
$$

The proton conducting membrane is such that only protons can flow through, and not electrons. So protons flow through the membrane, while electrons flow around in an external circuit. Thus a criteria for proton exchange membranes is that they be electrical insulators. The diffusion layer must allow gases and electrons to flow. Typical diffusion layers for fuel cells are porous electrically conducting materials e.g. carbon cloth. Gases

flow in the pores while electrons flow in the solid regions. The electrons flow out of the cell through the ribs to the current collector plate.

At the cathode, oxygen is supplied in the gas channels, and diffuses to the cathode catalyst layer. Electrons, flowing around the external circuit, re-enter the cell through the ribs at the cathode and also flow through the diffusion layer to the catalyst layer. At the catalyst layer, oxygen, electrons and protons (flowing through the membrane) all react on the surface of the Pt according to Equation (2). 


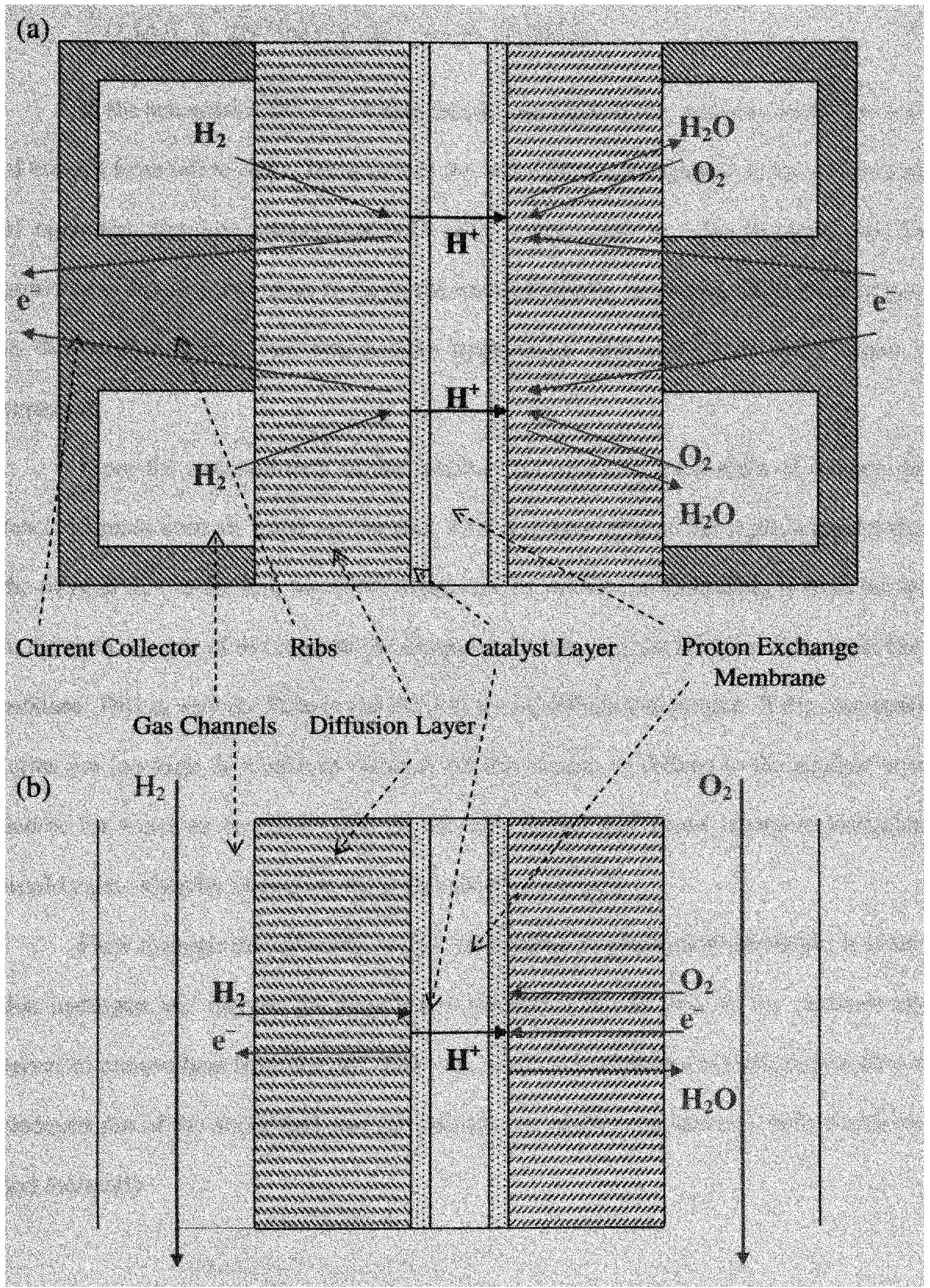

Figure 3-1 PEM Fuel Cell Schematic 


$$
\frac{1}{2} \mathrm{O}_{2}(a q)+2 \mathrm{H}^{+}(a q)+2 e^{-} \longrightarrow \mathrm{H}_{2} \mathrm{O}(a q)
$$

In the schematics shown, oxygen flows from right to left, whereas water flows out of the cell from left to right. The phase of the water produced depends on the temperature of operation. For low temperature fuel cells, water exists in a liquid phase, and the presence of liquid water tends to block the electrode pores, restricting the flow of oxygen to the catalyst layers. For intermediate temperature fuel cells, only water vapor is expected.

From the stoichiometry of the reaction, for every 16 mass units of oxygen that react, 18 mass units of water are formed. Thus the water flux to the right is greater than the oxygen flux to the left, the result being that the net flux of fluid mass is from the left to the right, i.e. out of the cathode. So oxygen must flow against the flow of the bulk fluid mixture. This is why the flow in the MEA must be diffusion dominant. If the convection terms are too high, it would be difficult for the oxygen to diffuse to the catalyst sites, and/or for water to be removed from the cell. Either way, mass transport limitations would exist, whereby increasing the polarization of the cell.

Flow through the channels, on the other hand, is convection dominant. It is here that hydrogen and oxygen are supplied to the cell. The gas flow in the channels also serves to remove heat from the cell. The ribs, which are necessary to facilitate the flow of electrons out of the anode and into the cathode, are highly conductive - both electrically and thermally. 


\subsection{Phosphoric Acid Doped PBI Membrane}

Figure 3-2 shows a schematic of proton transport through the acid doped PBI membrane. It consists of some acid bonded to the PBI, and some non-bonded or free or amorphous acid [90]. It is believed that the protons and dissolved gases flow through the amorphous acid phase, with the bonded acid and PBI structure contributing very little (if any at all) to the transport process [101]. The PBI acts as a matrix which contains the phosphoric acid, and together they form a single phase solid electrolyte [52]. A major difference between an acid doped PBI fuel cell and a phosphoric acid fuel cell (PAFC) is that the former employs a solid electrolyte while the latter, a liquid electrolyte.

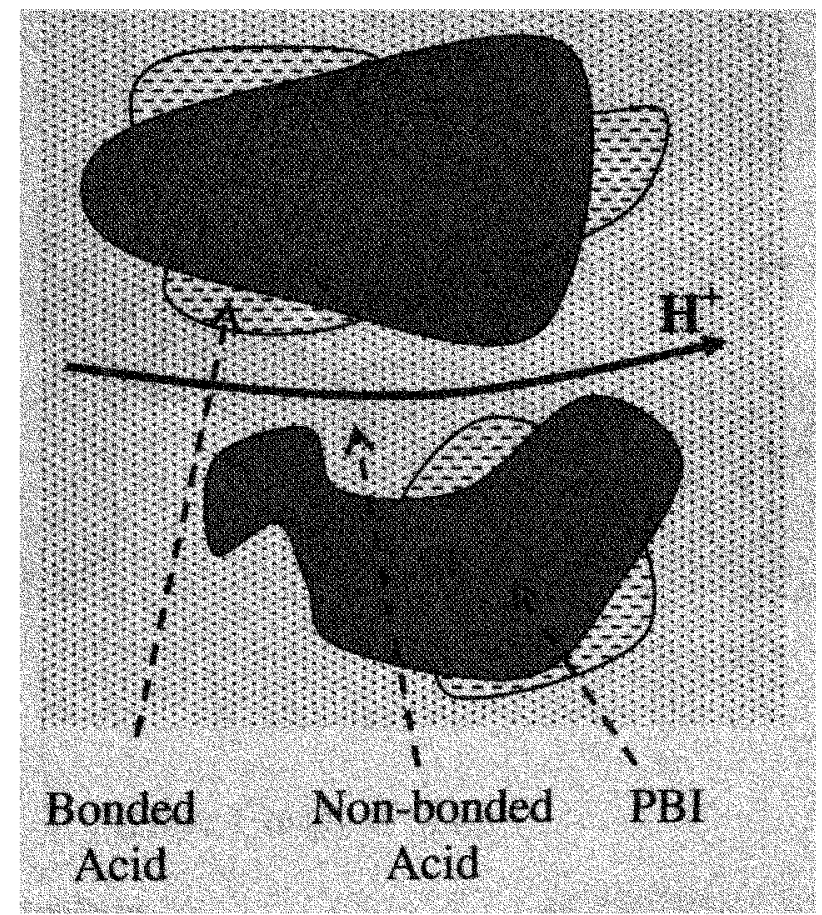

Figure 3-2 Acid Doped PBI Membrane Schematic 
The protons are assumed to flow via a Grotthus mechanism [68], and there is no net translation of the electrolyte species - a major difference between the PBI/acid system and Nafion ${ }^{\circledR} /$ water system. It has been reported that acid leaches out of the membrane over time $[63,66,96]$, however the fact that this occurs "over time" indicates that the process is very slow, and does not significantly affect the immediate performance of the fuel cell.

\subsection{Catalyst Layer}

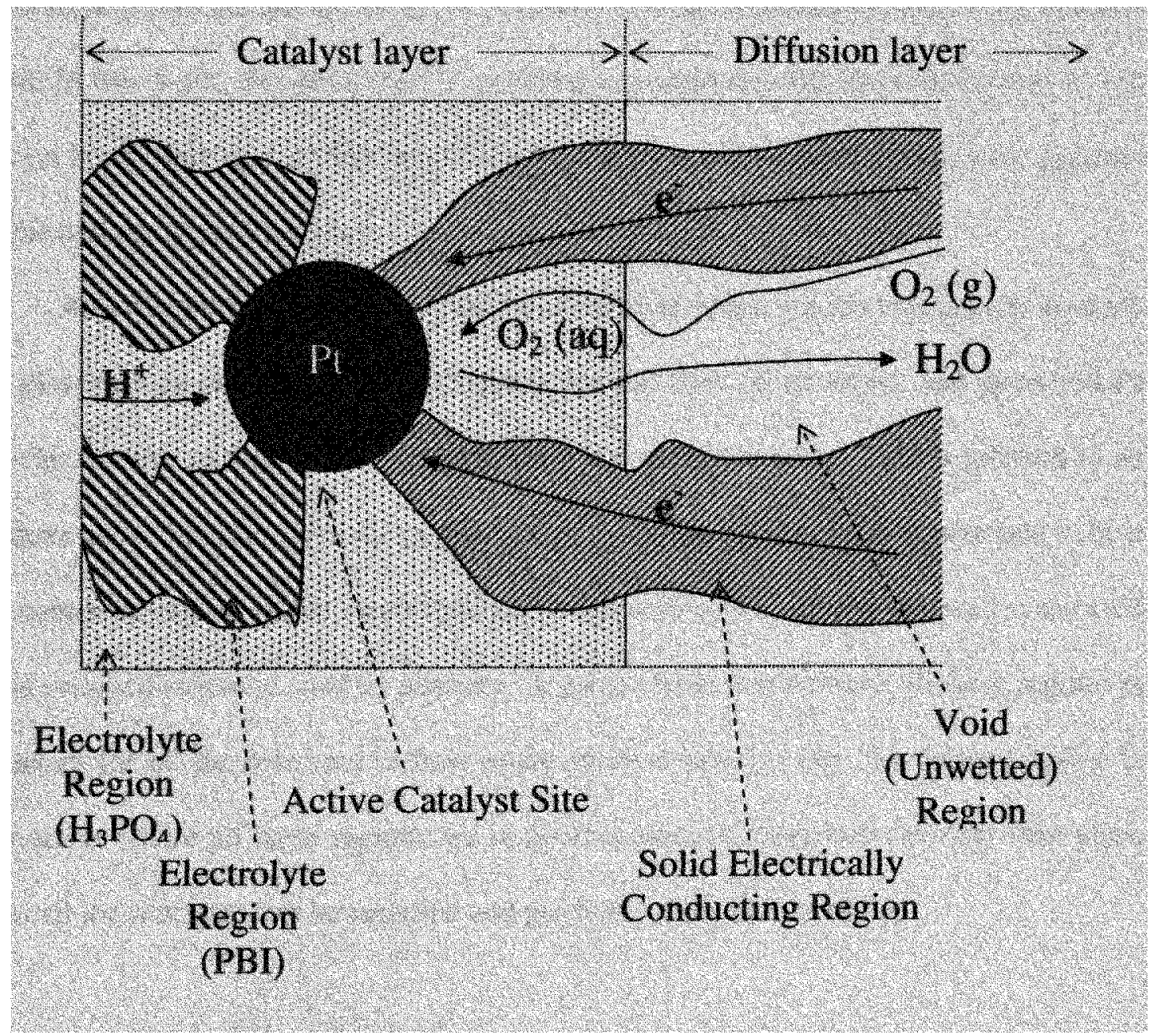

Figure 3-3 Catalyst Layer Schematic 
Figure 3-3 shows a schematic of the catalyst layer. The catalyst layer is a fused region of sputtered $\mathrm{Pt}$ particles between the membrane and the diffusion layer. The catalyst particles are deposited on either the electrode or the membrane, subsequent to which, the membrane and electrode are assembled with the catalyst particles sandwiched in between. In the process, some of the electrolyte flows into the pores of the catalyst region, "wetting" the catalyst particles. This is necessary in order for protons and reactant gases to be supplied to the catalyst surface. The reactant gases must first dissolve in the electrolyte phase before diffusing to the catalyst sites (Figure 3-3). The electrochemical reactions occur on the surface of the Pt particles, with the reactants existing in an aqueous phase. In this work, the electrolyte is assumed to completely fill the void regions in the catalyst layer. This way, a clear macro-level distinction can be made between the gaseous regime and the aqueous regime.

An effective catalyst layer contains electrolyte phase for the transport of protons and dissolved gases, solid (carbon) regions for the flow of electrons, and sputtered $\mathrm{Pt}$ particles, on the surface of which electrochemical reactions occur. This is referred to as the three-phase interface. For the purpose of analysis, the catalyst layer is assumed to be a homogeneous region where electrolyte and solid conductive regions are well connected to the evenly distributed catalyst particles. A good connection between all these regions is necessary for all the reactants to flow to the catalyst sites. In fact, the catalyst region is only active where all these regions are in good contact i.e. reactions can only take place when all the reactants can be supplied and products of reaction removed. 


\subsection{Computational Domain}

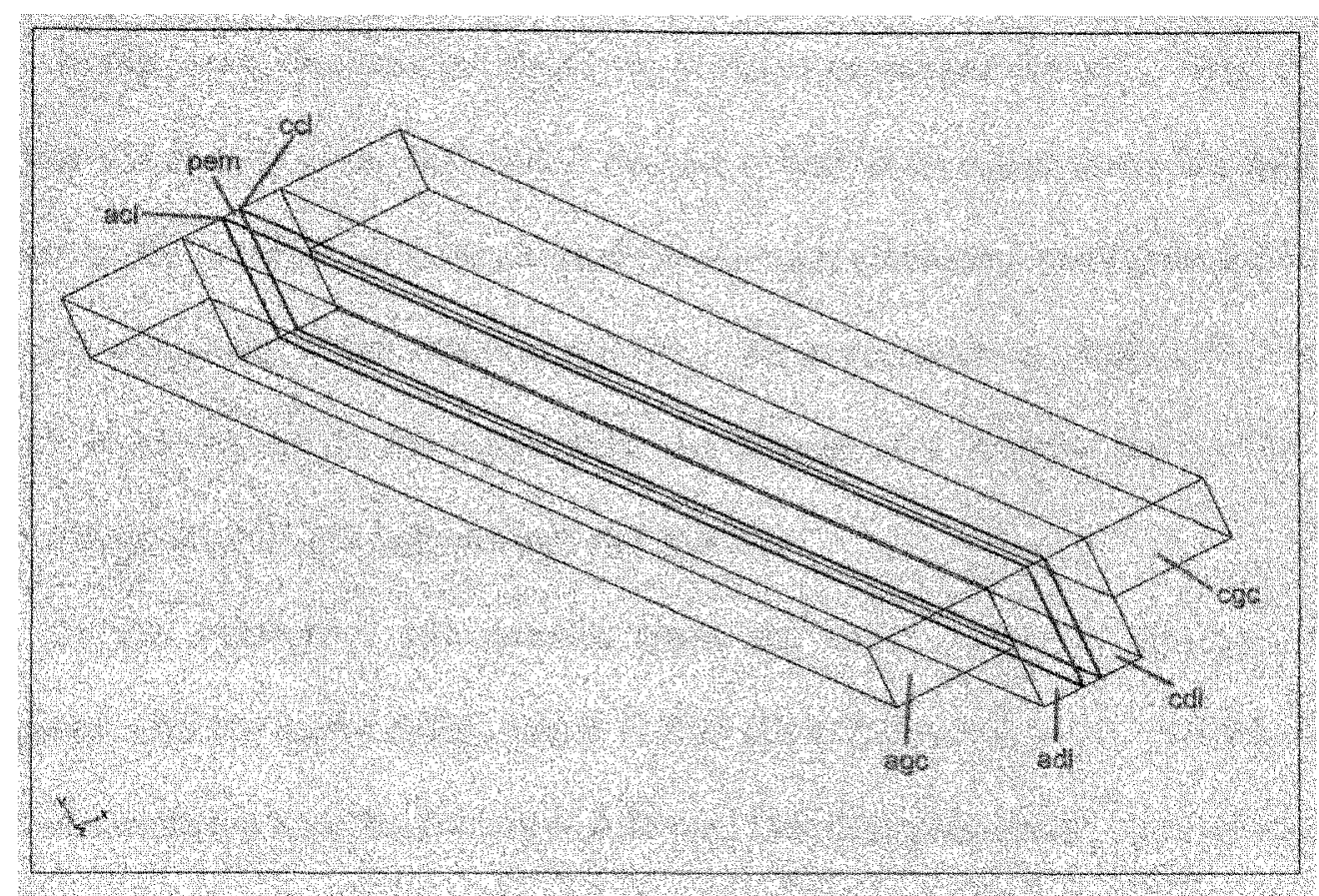

Figure 3-4 Computational Domain

Figure 3-4 shows the computational domain used in this model, as well as the coordinate system (see the Nomenclature for the definition of terms). In the x-direction, the domain spans the anode gas channel and rib to the cathode gas channel and rib. The ribs are actually not included in the computational domain. The ribs are considered to be perfect conductors of heat and electricity, and therefore equipotential and isothermal conditions are expected. So there is no need to include them in the computations. But it should be known that the ribs are located in the vacant regions "below" (in a y-direction sense) the channels. The domain includes the channels, and the membrane electrode assembly (MEA), with catalyst layers treated as finite sized regions, as opposed to 
vanishing interfaces. The anode is the left of the domain (or the lower values on the $\mathrm{x}$ scale), and the cathode is the right of the domain.

In this work, the gas flow fields are modeled as straight channels. Thus, in the ydirection, the domain spans half of one channel to half of an adjacent rib. Because of the structure of the fuel cell, with the channel-rib network, symmetry conditions are expected across the mid points of the channels and ribs. This is necessary to simplify the computer memory requirements. In the y-direction, the domain also includes the portion of the MEA contiguous with the half channel and half rib.

In the z-direction, the domain spans the entire length of the gas channel contiguous with the active MEA, which is $2.25 \mathrm{~cm} \times 2.25 \mathrm{~cm}$ in cross section. Thus the length of the channels in the domain is $2.25 \mathrm{~cm}$. This dimension is an order of magnitude larger than those in the $\mathrm{x}$ and $\mathrm{y}$ directions. The hydrogen and oxygen inlets are at $\mathrm{z}=0$ i.e. the back of the domain, while the outlets are at $\mathrm{z}=2.25 \times 10^{-2} \mathrm{~m}$.

\subsection{Governing Equations}

All the governing equations, discussed in this section, are summarized in Table 3-1, which also shows the applicable sub-domains for each governing equation.

\subsubsection{Bulk Fluid Flow}

Humidified hydrogen is supplied at the anode, while humidified oxygen or air is supplied at the cathode. It is assumed that each individual gas, as well as the gas mixture behave ideally. Due to the low velocities typically employed in fuel cells, the flow is 
considered laminar, and the bulk flow of the gas mixture in the gas channels is governed by the Navier-Stokes Equations.

$$
\begin{aligned}
& \rho u \cdot \nabla u=-\nabla P+\nabla \cdot(\mu \nabla u) \\
& \nabla \cdot(\rho u)=0
\end{aligned}
$$

Table 3-1 Summary of Governing Equations and Applicable Sub-Domains

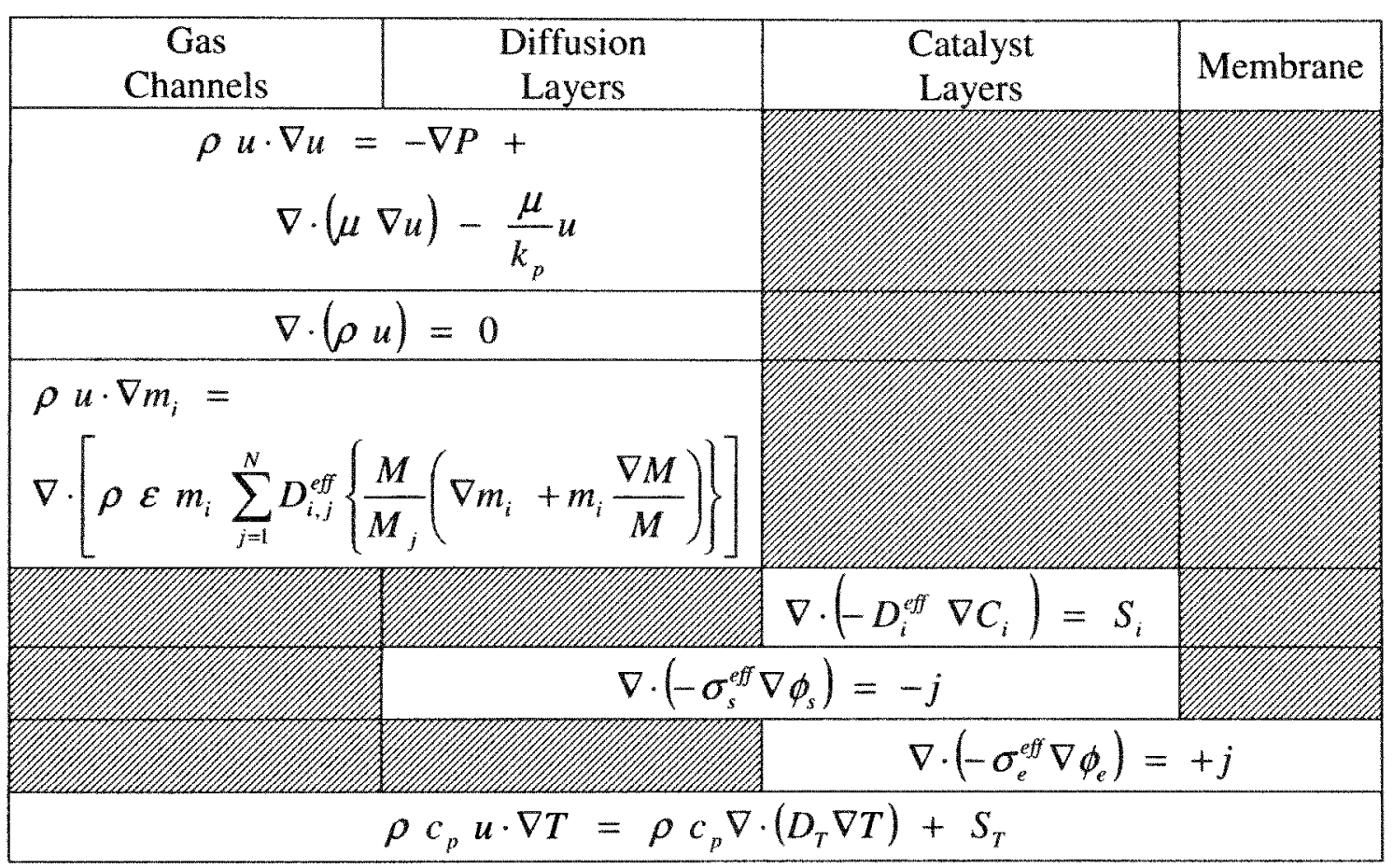

In the diffusion layers, the flow velocities are significantly smaller than in the gas channels, and flow is categorized as creeping flow, hence Darcy's law is used.

$$
\nabla P=-\frac{\mu}{k_{p}} u
$$


For convenience, the governing equations in the gas channels and diffusion layers can be combined, such that the Darcy's law term is incorporated into the Navier-Stokes Equations.

$$
\rho u \cdot \nabla u=-\nabla P+\nabla \cdot(\mu \nabla u)-\frac{\mu}{k_{p}} u
$$

\subsubsection{Gaseous Species Conservation}

The bulk flow consists of individual gas species: hydrogen, oxygen, water vapor, and nitrogen in the case where air is used in place of oxygen. Conservation of individual species is governed by the Stefan-Maxwell equations.

$$
\rho u \cdot \nabla m_{i}=\nabla \cdot\left[\rho \varepsilon m_{i} \sum_{j=1}^{N} D_{i, j}^{e f f}\left\{\frac{M}{M_{j}}\left(\nabla m_{i}+m_{i} \frac{\nabla M}{M}\right)\right\}\right]
$$

This equation governs individual gas species, and therefore applies in the gas channels and diffusion layers. In this work, unlike some of our previous single-phase models $[9-11,14,16]$, no reactions are considered to take place in the gaseous phase. Consequently, no reaction term is included in Equation (7).

\subsubsection{Dissolved Species Kinetics}

Before electrochemical reactions take place, the gas species must dissolve in the acid doped electrolyte, which wets the catalyst. This dissolution process is assumed to be governed by Henry's law. This implies that the model is only valid for steady state operation, since Henry's law pertains to the equilibrium existing between a species in the 
dissolved and the gaseous states, and relates the dissolved concentration with the partial pressure of the gas at the gas/liquid interface.

$$
C_{i}=P_{i} H_{i}
$$

The quantity $H$ is Henry's constant, and is dependent on the gas/liquid system as well as temperature. This is discussed further in Section 3.7.3. The dissolved gases then diffuse through the electrolyte and react on the surface of the Pt particles. Fick's law of diffusion is used to govern this phenomenon.

$$
\nabla \cdot\left(-D_{i}^{\text {eff }} \nabla C_{i}\right)=S_{i}
$$

\subsubsection{Two Phase Potential}

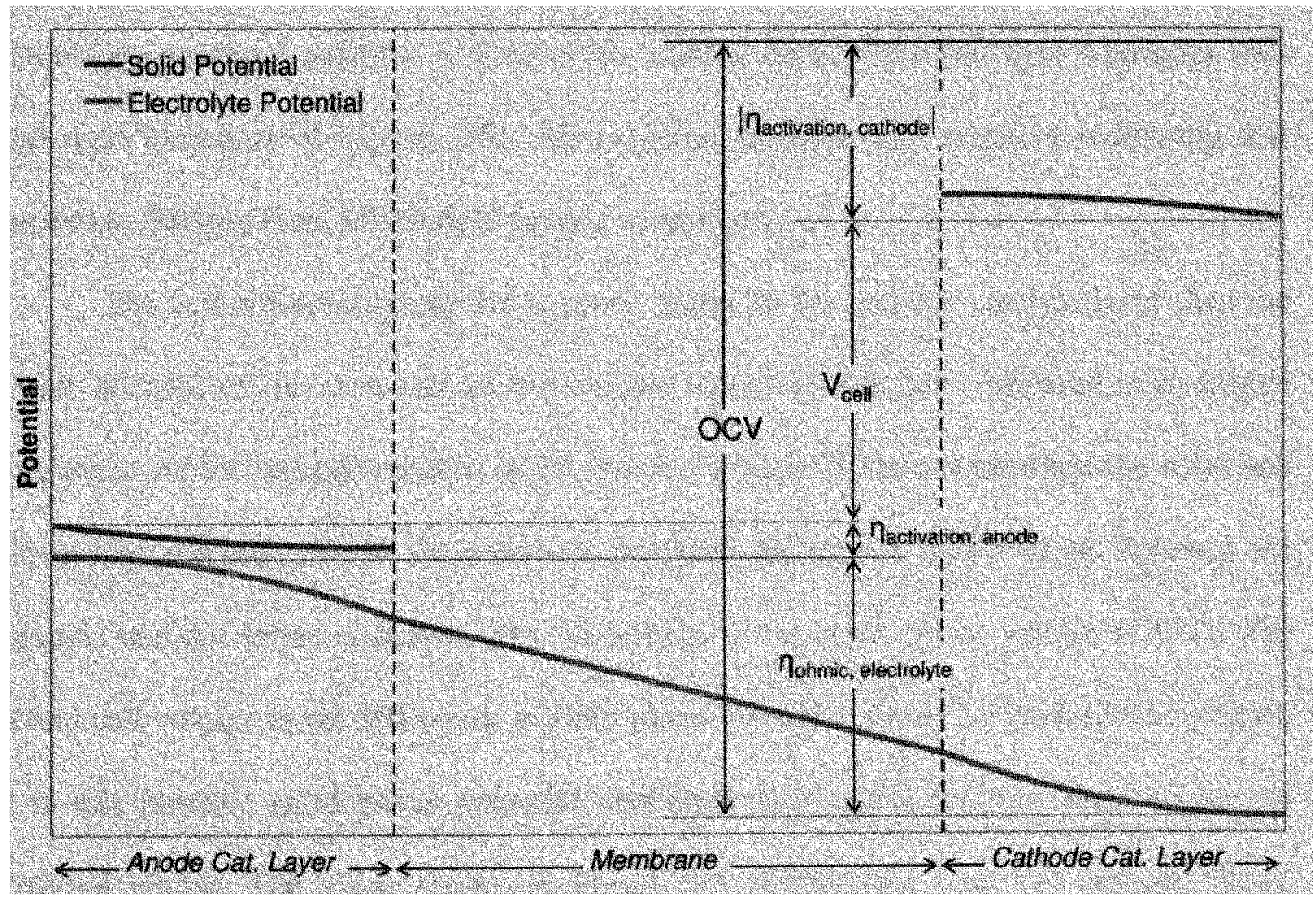

Figure 3-5 Two Phase Potential Distribution 
The concept of two phase potential and current flow, often overlooked by most fuel cell modelers, is critical to fully analyze the fuel cell. Figure 3-5 (not drawn to scale) shows the typical 1D (x-direction) potential variation across the catalyst layers and membrane.

In a PEM fuel cell, there are two charged species - protons and electrons. There are current flows due to the movement of electrons in the solid regions (solid phase current), as well as due to the movement of protons in the electrolyte region (electrolyte current). Associated with each current is a phase potential. The current densities are defined by the gradient of the respective potential curves in Figure 3-5. Since electrons cannot flow through the proton exchange membrane, the solid potential gradient is zero at the membrane/catalyst layer interfaces. Since protons cannot flow in the solid regions, the electrolyte potential gradient is zero at the catalyst layer/diffusion layer interfaces (left and right extremes of Figure 3-5). All potential gradients are negative indicating that current is flowing from left to right (anode to cathode).

The activation overpotential is much higher at the cathode catalyst layer than the anode because of the slow rate of the oxygen reduction reaction compared to hydrogen oxidation. At the cathode catalyst layer, there is a large difference between the solid and electrolyte potential due to the electrode potential difference, which exists between the cathode and the anode reactions. This difference is the open circuit voltage (OCV). The actual cell voltage is the difference in solid phase potential across the entire fuel cell unit. It is this positive solid phase potential difference that drives electron flow across the external circuit. The value shown in Figure 3-5 deliberately does not include ohmic potential drops in the diffusion layers for the purpose of simplifying the diagram. The 
electrolyte potential drop is the driving force for proton conduction across the membrane.

For the PBI membrane, the electrolyte potential difference across the membrane is the only driving force for proton conduction. There is no net translation of electrolyte species, therefore there is no proton transport via convection.

The charge conservation equation for each phase is given by,

$$
\begin{aligned}
& \nabla \cdot i_{s}=\nabla \cdot\left(-\sigma_{s}^{e f f} \nabla \phi_{s}\right)=-j \\
& \nabla \cdot i_{e}=\nabla \cdot\left(-\sigma_{e}^{e f f} \nabla \phi_{e}\right)=+j \\
& j=a i_{0}^{\text {ref }}\left(\frac{C_{i}}{C_{\text {ref }}}\right)^{\gamma_{i}}\left\{\exp \left[\frac{\alpha_{a} F}{R T} \eta\right]-\exp \left[-\frac{\alpha_{c} F}{R T} \eta\right]\right\}
\end{aligned}
$$

where the activation overpotential, $\eta=\left\{\begin{array}{cc}\phi_{s}-\phi_{e} & (\text { anode }) \\ \phi_{s}-\phi_{e}-V_{\text {rev }} & \text { (cathode) })\end{array}\right\}$

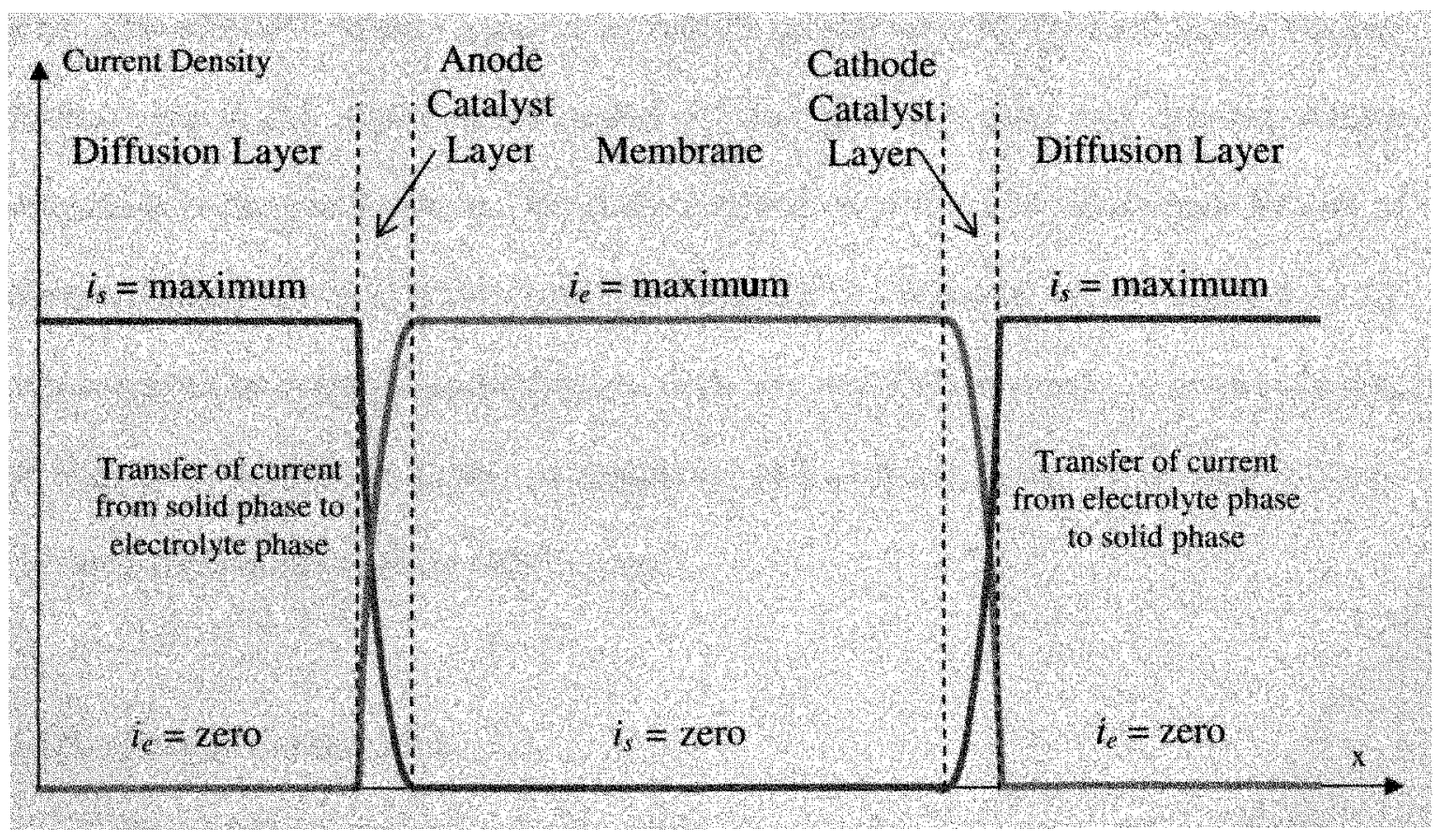

Figure 3-6 Two Phase Charge Transfers 
The reaction terms only exist in the catalyst layers. These equations include the transfer of charge between the electrolyte and solid regions during electrochemical reaction (Figure 3-6). Consider the cathode reaction, where protons, electrons and oxygen react to produce water. The protons flow through the membrane, while the electrons flow through the solid diffusion layers. In the membrane, only the protons flow (and its associated electrolyte current). In the diffusion layers, only electrons flow, therefore there is no electrolyte current. In the catalyst layer, where both of these regions are in contact, the electrolyte current decreases from left to right as protons are consumed. The solid current decreases from right to left (increases from left to right) as electrons are consumed. For total charge conservation, the current source terms in Equations (10) and (11) must sum to zero, hence the positive and negative $j$ terms.

The exchange current density, $i_{0}$, is defined in terms of the active catalyst surface area. The effective surface area, $a$, is defined as the ratio of the total active catalyst surface area to the total catalyst region volume, and thus takes into account surface roughness in the catalyst layer. The Butler-Volmer Equation (12) states that the rate of electrochemical reaction is driven by the electrode overpotential, and is affected by the concentration of reactants at the catalyst sites. The local reaction rate, $j$, defines the rate of transfer of solid state current to electrolyte phase current in the anode catalyst layer, and vice versa in the cathode catalyst layer.

\subsubsection{Energy Conservation}

There is heat generation in the cell due to the flow of current (ohmic heating) as well as the exothermic nature of the electrochemical reactions (reactive heating). The 
energy conservation equation balances the heat transfers, via convection and conduction, with heat generation.

$$
\rho c_{p} u \cdot \nabla T=\rho c_{p} \nabla \cdot\left(D_{T} \nabla T\right)+S_{T}
$$

\subsection{Source Terms}

The source terms depend on the reaction rate in each catalyst layer and the stoichiometry of the overall cell reaction. With the exception of the ohmic heating term, all other source terms are only non-zero in the catalyst layers. The reaction rate, $j$, is positive in the anode catalyst layer and negative in the cathode. Thus, the following equations define the local rates of oxygen consumption, water vapor production, and hydrogen consumption $\left(\mathrm{mol} \mathrm{m} \mathrm{m}^{-3}\right)$.

$$
\begin{aligned}
& S_{O_{2}}=\frac{j_{c}}{4 F} \\
& S_{H_{2} O}=-\frac{j_{c}}{2 F} \\
& S_{H_{2}}=-\frac{j_{a}}{2 F}
\end{aligned}
$$

The heat of reaction $\left(\mathrm{W} \mathrm{m}^{-3}\right)$ is due to irreversibilities associated with activation losses and entropy changes. This equation is derived in Appendix A.

$$
S_{r x n}=-j\left(\eta-\frac{T \Delta S}{n F}\right)
$$

The ohmic heating $\left(\mathrm{W} \mathrm{m}^{-3}\right)$ is given by,

$$
S_{o h m}=\frac{i_{s}^{2}}{\sigma_{s}^{e f f}}+\frac{i_{e}^{2}}{\sigma_{e}^{e f f}}
$$


The entropy term $\left(\mathrm{J} \mathrm{mol}^{-1} \mathrm{~K}^{-1}\right)$ is correlated from thermodynamics tables [106].

$$
\frac{\Delta S}{n}=-18.449-0.01283 T
$$

\subsection{Constitutive Relations}

\subsubsection{Porous Media Corrections}

This section provides a list of constitutive relations necessary to correct the plain media fluid and material properties for the porous media. It also lists the ideal gas relations used in this work. The geometric average of the solid and fluid thermal conductivity is used to determine the effective thermal conductivity.

$$
\frac{k^{e f f}}{k_{f}}=\left(\frac{k_{s}}{k_{f}}\right)^{1-\varepsilon}[107]
$$

The thermal dispersion diffusivity is given by the following relationship, valid for low Peclet number flows.

$$
\frac{D^{d}}{\alpha_{f}}=3(1-\varepsilon)\left(\frac{k_{s}-k_{f}}{k_{s}+2 k_{f}}\right)[108]
$$

The total effective thermal diffusivity is given by,

$$
\frac{D_{T}}{\alpha_{f}}=\frac{k^{e f f}}{k_{f}}+\frac{\varepsilon D^{d}}{\alpha_{f}}[109]
$$

This value depends on solid and fluid properties and compositions, as well as porous media characteristics. The effective gas diffusivity is related to the plain media diffusivity. 


$$
\frac{D_{i, j}^{e f f}}{D_{i, j}}=\frac{2 \varepsilon}{3-\varepsilon}[110]
$$

The electrical and ionic conductivities are corrected for porous media using the Bruggemann correlation, where $\varepsilon_{\text {phase }}$ is the volume fraction occupied by the phase through which the respective current flows.

$$
\sigma^{\text {eff }}=\sigma \varepsilon_{\text {phase }}^{1.5}[111]
$$

The gas mixture (mass) density and molar mass are derived from the ideal gas law.

$$
\begin{aligned}
& \rho=\frac{P M}{R T} \\
& M=\left(\sum \frac{m_{i}}{M_{i}}\right)^{-1}=\sum x_{i} M_{i}
\end{aligned}
$$

All other fluid properties are mass averaged for the gas mixture. The plain media gas pair diffusivity is assumed constant at a given temperature and pressure, and independent of composition.

\subsubsection{Membrane Parameters}

The most significant factor affecting the performance of a PBI membrane is the acid doping level. When PBI is doped or immersed in phosphoric acid, the latter is absorbed into the polymer matrix, forming a single phase material [52]. The doping level, $X$, is defined as the number of moles of acid absorbed per PBI repeat unit. The PBI repeat unit contains two bonding sites for phosphoric acid, thus two moles of acid per repeat unit can be bonded to PBI. However, it is possible for the doping level to exceed 2. Any additional absorbed acid is termed free or non-bonded acid, which forms an amorphous 
phase within the polymer matrix. It is believed that the transport of protons and dissolved gases takes place through the free acid inside the PBI matrix [101].

The doping level is a function of the concentration of acid used in the doping process, where an equilibrium is established between the acid absorbed into the polymer matrix and the acid in the immersion solution. The volume fraction of amorphous phosphoric acid in the membrane is related to the number of moles of free acid present in accordance with the following equation,

$$
\varepsilon_{P A}=\left(\frac{4.81}{X-2}+1\right)^{-1}[101]
$$

The amount of phosphoric acid within the membrane is determined by the concentration of the acid solution used during the doping procedure. Water is also absorbed by the membrane, which has a diluting effect on the phosphoric acid within the membrane. The concentration of the acid within the membrane depends on the operating conditions i.e. an equilibrium is established between the humidity in the environment and the water inside the membrane. It is shown that for most fuel cell applications, the acid concentration within the membrane ranges from $85-95$ weight $\%$ phosphoric acid [91, 101, 103]. Changes in acid concentration inside the membrane may affect proton conductivity and transport properties of dissolved gases. These phenomena were not accounted for in this model. In reality, water production, especially at high current densities, may dilute the absorbed phosphoric acid, thus enhancing the conductivity and transport properties of dissolved gases. This process is not as yet well understood, and requires further research before it can be incorporated into a mathematical model. 
The membrane ionic conductivity is related to both the temperature and the doping level. The conductivity may also depend on the humidity, in as much as the humidity affects the acid concentration and viscosity inside the membrane. Equation (28) is used in this work to determine the membrane conductivity because it is empirically obtained from conductivity data published by the same authors whose fuel cell results are used for model validation.

$$
\sigma_{m}=\frac{100}{T} \exp \left[8.0219-\left(\frac{2605.6-70.1 X}{T}\right)\right] \mathrm{S} \mathrm{m}^{-1}[64]
$$

\subsubsection{Catalyst Parameters}

The transport and electro-kinetic properties of the electrolyte are also related to the doping level. Liu et al [101] suggested that the effective diffusivity of oxygen in the acid doped electrolyte is related to its diffusivity in the amorphous phosphoric acid by a Bruggeman relation with the exponent of 1.8 , which provides the best fit with the experimental data.

$$
D_{O_{2}}^{(P B L)}=D_{O_{2}}^{(P A)} \varepsilon_{P A}^{1.8}[101]
$$

The Henry's constant pertaining to oxygen solubility in acid doped PBI is also related to its solubility in the amorphous phosphoric acid. The following relation is empirically determined from data presented by Liu et al [101].

$$
H_{O_{2}}^{(P B I)}=\varepsilon_{P A}^{1.945}\left[H_{O_{2}}^{(P A)}+5.79\left(1-\varepsilon_{P A}^{1.8}\right)\right] \mathrm{mol} \mathrm{m}^{-3} \mathrm{~atm}^{-1}[101]
$$


The transport properties of oxygen in concentrated phosphoric acid are related to the temperature and the acid concentration (mass fraction). These expressions were empirically obtained from the experimental data published in ref [112].

$$
\begin{aligned}
\ln \left(10^{9} D_{O_{2}}^{P_{A}}\right) & =\left(-192.55 m_{P A}^{2}+323.55 m_{P A}-125.61\right) \\
& +\frac{62010 m_{P A}^{2}-105503 m_{P A}+40929}{T} \mathrm{~m}^{2} \mathrm{~s}^{-1} \\
\ln \left(10 H_{O_{2}}^{P A}\right) & =\left(257.13 m_{P A}^{2}-431.08 m_{P A}+178.45\right) \\
& +\frac{-93500 m_{P A}^{2}+156646 m_{P A}-64288}{T} \mathrm{~mol} \mathrm{~m}^{-3} \mathrm{~atm}^{-1}
\end{aligned}
$$

The exchange current density for the oxygen reduction reaction over a smooth Pt surface in an acid doped PBI electrolyte is related to that in a phosphoric acid electrolyte of the equivalent concentration. The following relation is empirically determined from data published by Liu et al [101].

$$
\log \left(i_{0}^{(P B I)}\right)=\log \left(i_{0}^{(P A)}\right)-4.16\left(1-\varepsilon_{P A}\right) \mathrm{A} \mathrm{m}^{-2}[101]
$$

The exchange current density on $\mathrm{Pt}$ in an $85 \mathrm{wt}$. \% phosphoric acid electrolyte is empirically quantified, base on results presented by Huang et al [113].

$$
\log \left(i_{0}^{(P A)}\right)=3.509-\frac{2193}{T} \mathrm{~A} \mathrm{~m}^{-2}[113]
$$

Although much attention has been given to properties affecting the oxygen reduction reaction at the cathode, not much has been devoted to the oxidation of hydrogen at the anode. It has been traditionally assumed that the hydrogen reaction is fast, and hence does not warrant much research. As a result, data for the transport properties of hydrogen in phosphoric acid systems are not readily available. It is assumed, in this work, that the solubility of hydrogen in phosphoric acid is 4.4 times that 
of oxygen, and its diffusivity is twice as much, as is the case with water systems [27, 114]. It will also be assumed that the exchange current density for the anode reaction is $10^{8}$ times that at the cathode, since the ratio of the anode to cathode exchange current densities is typically in the range $10^{6}[33]$ to $10^{10}[27]$.

It can be shown geometrically that the effective surface area per unit volume of the catalyst region (or per agglomerate volume) is given by the following expression, where $\theta$ is a blockage factor [13].

$$
a=\frac{6 m_{P t}}{\rho_{P t} d_{P t} L_{c a t}}(1-\theta)
$$

There are two kinds of concentration overpotentials. The first is due to dilution effects. This refers to the reduction in the concentration of the reactant, which results in reduced reaction rates and increased electrode polarization. This phenomenon is particularly evident when air is used as the oxidant at the cathode. The concentration of oxygen decreases as it is consumed in the electrochemical reactions, resulting in relatively dilute oxygen content toward the outlet of the cell. In this work, the dilution effects are taken into account in the Butler-Volmer Equation (12). It is modeled as the increase in electrode polarization due to reactant dilution.

The other kind of concentration overpotential is due to mass transport limitations. This refers to a physical blockage of reactants restricting their access to catalyst sites. There are numerous causes of catalyst blockage. $\mathrm{CO}$ adsorbed onto the catalyst may inhibit the adsorption of hydrogen, while liquid water may block the passage of oxygen. But at elevated temperatures, $\mathrm{CO}$ poisoning becomes less significant and liquid water does not exist. The only cause of blockage considered in this model is the adsorption of 
phosphoric acid anions onto the catalyst sites. This reduces the effective surface area of the catalyst, thus reducing its activity. This blockage is not as yet quantitatively understood, nevertheless it is believed to be a function of acid concentration, temperature, and electrode potential. The following relation is empirically obtained from data presented by Zelanay et al [98] to quantify the acid anion blockage factor in this work.

$$
\theta=-0.893 \eta^{2}+1.714 \eta[98]
$$

This is based on experiments performed at $25^{\circ} \mathrm{C}$ in a $0.02 \mathrm{M}$ phosphoric acid solution. The blockage decreases with temperature, but increases with acid concentration. Therefore, in the absence of other experimental data, this correlation will be used in this model.

It can be shown that the volume of the catalyst region occupied by $\mathrm{Pt}$ is given by,

$$
\varepsilon_{P t}=\frac{m_{P t}}{\rho_{P t} t_{c a t}}
$$

where $m_{P t}$ is the mass loading of catalyst per unit cross sectional area, distributed over the catalyst thickness, $t_{\text {cat }}$. The Pt catalyst is usually contained in a carbon matrix, with a $10-20 \% \mathrm{Pt}$ weight ratio. Thus the volume fraction of the carbon phase, which is the solid electron conducting phase, is

$$
\varepsilon_{C}=\frac{\varepsilon_{P_{t}}}{f_{P_{t}}} \frac{\rho_{P_{t}}}{\rho_{C}}
$$

It is assumed that the remainder of the catalyst region is occupied by electrolyte phase,

$$
\varepsilon_{\text {elect }}=1-\varepsilon_{P t}-\varepsilon_{C}
$$


Membrane [64]

Thermal conductivity, $k_{m}[115]$

Ionic conductivity, $\sigma_{m}$ (eqn 28)

Thickness

Doping level, $\mathrm{X}$

Cross Section
40

4.25

$8 \times 10^{-5}$

6.2
$\mathrm{W} \mathrm{m} \mathrm{m}^{-1} \mathrm{~K}^{-1}$

$\mathrm{S} \mathrm{m}^{-1}$

$\mathrm{m}$

\begin{tabular}{lcc}
\hline \multicolumn{3}{c}{ Diffusion Layer (Graphite) [27] } \\
\hline Thermal conductivity, $k_{d}[116]$ & 1.15 & $\mathrm{~W} \mathrm{~m}^{-1} \mathrm{~K}^{-1}$ \\
Electrical conductivity, $\sigma_{d}$ & 120 & $\mathrm{~S} \mathrm{~m}^{-1}$ \\
Porosity, $\varepsilon$ & 0.4 & \\
Permeability, $k_{p}$ & $1.8 \times 10^{-11}$ & $\mathrm{~m}^{2}$ \\
Thickness & $2.5 \times 10^{-4}$ & $\mathrm{~m}$ \\
\hline & Channels [64] & \\
\hline Channel length & $2.25 \times 10^{-2}$ & $\mathrm{~m}$ \\
Rib and channel cross section (deduced) & $\left(7.5 \times 10^{-4}\right)^{2}$ & $\mathrm{~m}^{2}$ \\
Gas flow rates at channel inlet & $2.67 \times 10^{-6}$ & $\mathrm{~m}^{3} \mathrm{~s}^{-1}$ \\
\hline
\end{tabular}

The value of $\varepsilon_{P_{A}}$ used in Equation (29) must be modified by multiplying by $\varepsilon_{\text {elect }}$ in order to correct for the porous nature of the catalyst region. Other numerical values are listed in Table 3-2 to Table 3-5. These values are valid for $\mathrm{T}=150{ }^{\circ} \mathrm{C}(423 \mathrm{~K})$ and $1 \mathrm{~atm}$. The operating condition, represented by these numerical values, is called the base or nominal condition. It will be used as the basis for comparison in later sections. 
Table 3-3 Nominal Catalyst Layer Properties

\begin{tabular}{lccc}
\hline & Anode & Cathode & \\
\hline$a i_{0}{ }^{\text {ref }}$ (cell voltage $=0.4 \mathrm{~V}$ ) (eqns 27,33,34) & $7.69 \times 10^{11}$ & $7.69 \times 10^{3}$ & $\mathrm{~A} \mathrm{~m}^{-3}$ \\
Transfer co-efficient, $\alpha[27]$ & 0.5 & 1 & \\
Concentration parameter, $\gamma[27]$ & 0.5 & 1 & \\
Catalyst layer thickness & $1 \times 10^{-5}$ & $\mathrm{~m}$ \\
\hline
\end{tabular}

Table 3-4 Nominal Fluid Properties [106]

\begin{tabular}{cccccc}
\hline & Oxygen & Nitrogen & Water Vapor & Hydrogen & \\
\hline$M$ & $32 \times 10^{-3}$ & $28.16 \times 10^{-3}$ & $18 \times 10^{-3}$ & $2 \times 10^{-3}$ & $\mathrm{~kg} \mathrm{~mol}^{-1}$ \\
$k$ & 0.036 & 0.034 & 0.030 & 0.239 & $\mathrm{~W} \mathrm{~m}^{-1} \mathrm{~K}^{-1}$ \\
$c_{p}$ & 956 & 1050 & 1980 & 14500 & $\mathrm{~J} \mathrm{~kg}^{-1} \mathrm{~K}^{-1}$ \\
$\mu$ & $27 \times 10^{-6}$ & $23 \times 10^{-6}$ & $14 \times 10^{-6}$ & $1.1 \times 10^{-6}$ & $\mathrm{~Pa} \mathrm{~s}$ \\
$\alpha$ & $44.4 \times 10^{-6}$ & $41.0 \times 10^{-6}$ & $30.8 \times 10^{-6}$ & $217 \times 10^{-6}$ & $\mathrm{~m}^{2} \mathrm{~s}^{-1}$ \\
\hline
\end{tabular}

Table 3-5 Nominal Gas Pair Diffusivities [110]

Gas Pair Diffusivity

\begin{tabular}{lcc}
\hline $\mathrm{O}_{2}-\mathrm{H}_{2} \mathrm{O}$ & $41.9 \times 10^{-6}$ & $\mathrm{~m}^{2} \mathrm{~s}^{-1}$ \\
$\mathrm{O}_{2}-\mathrm{N}_{2}$ & $34.2 \times 10^{-6}$ & $\mathrm{~m}^{2} \mathrm{~s}^{-1}$ \\
$\mathrm{~N}_{2}-\mathrm{H}_{2} \mathrm{O}$ & $49.2 \times 10^{-6}$ & $\mathrm{~m}^{2} \mathrm{~s}^{-1}$ \\
$\mathrm{H}_{2}-\mathrm{H}_{2} \mathrm{O}$ & $144 \times 10^{-6}$ & $\mathrm{~m}^{2} \mathrm{~s}^{-1}$ \\
\hline
\end{tabular}




\subsection{Boundary Conditions}

Figure 3-7 shows the computational domain with the major boundaries numbered. The boundary conditions used in this work are summarized in Table 3-6.

Symmetry conditions are applied for all variables across boundaries 7 and 8 , because that was the assumption in the selection of the computational domain. At the channel inlets; the velocity, mass fraction and temperature are specified; while at the outlets; the equivalent conditions are pressure and convective flux. The convective flux condition simply states that the diffusive flux is zero while the convective flux is non zero i.e. because species or heat is carried out of the domain in the bulk flow. Insulation conditions, on the other hand, state that the total flux across a boundary is zero. Across solid boundaries, where there is no normal velocity, insulation conditions are equivalent to convective flux conditions. On all solid boundaries, no slip conditions exist for the fluid flow, and insulation conditions for the species flow, since species cannot flow through a solid boundary. On boundaries 9 and 10 , there must be mass continuity between the gas flow and the aqueous flow. Thus, the gas species flux (Stefan-Maxwell Equations) was set equal to the dissolved species flux (Fick's Law) at those boundaries, with the necessary conversion from mass to molar units.

The boundary conditions in the Navier-Stokes equation involved setting the gas mixture flux to the sum of all species flux. At the cathode, this would include the vector sum of the oxygen and water vapor flux. At the anode, it would only involve the hydrogen flux. 

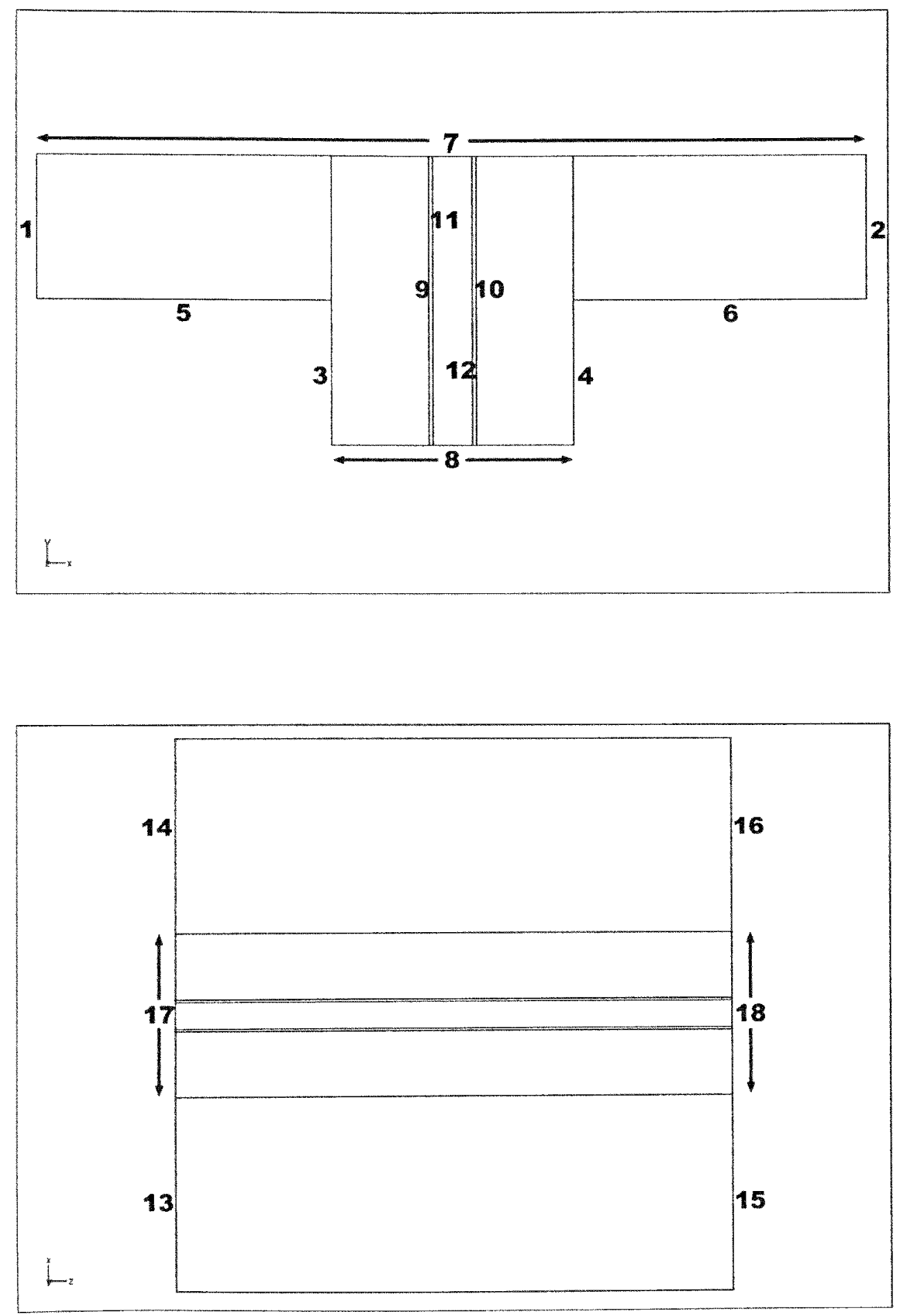

Figure 3-7 Boundary Labels 
Table 3-6 Summary of Boundary Conditions

\begin{tabular}{|c|c|c|c|c|c|c|}
\hline Boundary & Fluid Flow & Gas Species & $\begin{array}{c}\text { Dissolved } \\
\text { Species }\end{array}$ & Energy & $\begin{array}{c}\text { Solid } \\
\text { Potential }\end{array}$ & $\begin{array}{c}\text { Electrolyte } \\
\text { Potential }\end{array}$ \\
\hline $17-18$ & \multirow{4}{*}{$u=0$} & \multirow{4}{*}{$n \cdot\left[\begin{array}{ll}-\rho & D_{i} \nabla m_{i} \\
+\rho & u m_{i}\end{array}\right]^{\prime}=0$} & $n \bullet \nabla C_{i}=0$ & \multirow{3}{*}{$\begin{array}{l}n \bullet\left[\begin{array}{ll}D_{T} & 1 \\
+u T & \end{array}\right] \\
-h\left(T-T_{\text {surr }}\right)\end{array}$} & $n \cdot \nabla \phi_{s}=0$ & $n \bullet \nabla \phi_{e}=0$ \\
\hline $1-2$ & & & \multirow{3}{*}{ NA } & & $\mathrm{NA}$ & \multirow{3}{*}{ NA } \\
\hline $3-4$ & & & & & $\begin{array}{c}\phi_{s}=0 \\
\phi_{s}=V_{\text {tell }}\end{array}$ & \\
\hline $5-6$ & & & & $n \cdot\left[\begin{array}{l}-D_{T} \nabla T \\
+u T\end{array}\right]=0$ & NA & \\
\hline $7-8$ & $n \bullet u=0$ & $n \cdot\left[\begin{array}{ll}-\rho & D_{i} \nabla m_{i} \\
+\rho & u m_{i}\end{array}\right]^{\prime}=0$ & $n \bullet \nabla C_{i}=0$ & $n \cdot\left[\begin{array}{l}-D_{T} \nabla T \\
+u T\end{array}\right]=0$ & $n \bullet \nabla \phi_{s}=0$ & $n \bullet \nabla \phi_{e}=0$ \\
\hline $9-10$ & $\begin{array}{l}n \cdot \rho u= \\
n \cdot \sum\left(-M_{i} D_{i} \nabla C_{i}\right)\end{array}$ & $\begin{array}{l}n \bullet\left[\begin{array}{ll}-\rho & D_{i j} \nabla m_{i} \\
+\rho & u m_{i}\end{array}\right]^{\prime} \\
=-n \bullet\left[M_{i} D_{i} \nabla C_{i}\right]\end{array}$ & $C_{i}=x_{i} P H_{i}$ & Internal & Internal & $n \bullet \nabla \phi_{e}=0$ \\
\hline $11-12$ & $\mathrm{NA}$ & $\mathrm{NA}$ & $n \bullet \nabla C_{i}=0$ & Internal & $n \bullet \nabla \phi_{s}=0$ & \\
\hline $13-14$ & $n \bullet u=v_{0}$ & $m_{i}=m_{i, 0}$ & $M_{T}$ & $T=T_{0}$ & $\Delta$ & NA \\
\hline $15-16$ & $P=P_{0}$ & $n \cdot\left[\begin{array}{lll}-\rho & D_{i} \nabla m_{i}\end{array}\right]=0$ & NA & $n \cdot\left[-D_{T} \nabla T\right]=0$ & NA & \\
\hline
\end{tabular}


For the energy equation, heat flux conditions were set at the solid boundaries in the extremities of the $x$ and $z$-directions. This represents heat loss to the environment at temperature $T_{\text {surr }}(=298 \mathrm{~K})$ with heat removal co-efficient, $h$. The heat removal coefficient has a base value of $10 \mathrm{~W} \mathrm{~m}^{-2} \mathrm{~K}^{-1}$, which is a measure of the effectiveness of the heat removal scheme.

The handling of boundaries $3-6$ presented a slight problem with regard to the thermal analysis. With the rib present, these would have been internal boundaries, and heat flux conditions would have been specified on the sides and ends of the ribs ( $x$ and $z$ extremities). However, with the ribs omitted from the computational domain, the following assumption was made. It is assumed that all of the heat flowing out of the diffusion layer via boundary 3 would have exited the fuel cell through the ribs and none of it would have been transferred to the fluid stream via boundary 5 . Thus heat flux conditions were set at boundary 3 , while insulation conditions set at boundary 5 . This assumption may result in an underestimation of the actual heat "pickup" by the gas streams.

\subsection{Solution Strategies and Methodologies}

\subsubsection{Achieving Convergence}

The computational problem consists of 12 independent variables: $u, v, w, P, m_{H_{2}}, m_{O_{2}}, m_{H_{2} O}, C_{H_{2}}, C_{O_{2}}, \phi_{s}, \phi_{e}, T$

The multi-physics equations are highly coupled at the catalyst layers. The major source of coupling are the source terms in the catalyst layers which are proportional to 
the reaction rate, $j$. The reaction rate is itself a very unstable term involving functions of other independent variables even in the exponential argument (Equation 12). Thus, careful consideration had to be made to achieve convergence. There is a better chance of obtaining a convergent solution if the more unstable aspects of the model are solved first. Good initial guesses for all variables are also critical.

The unstable elements in the solution are the potential variables and the dissolved concentration variables. The equation for the electrolyte potential, as can be seen from Table 3-6, has no Dirichlet boundary conditions, only Neumann. As a result, by itself, it has no unique solution. It only has a unique solution when coupled with the solid potential. The electrolyte potential equation has insulation and symmetry conditions on every boundary. This means that no electrolyte current leaves the domain. This ensures that all of the electrolyte current generated at the anode is consumed at the cathode, and as a result, the quantity, $j$, when integrated over each catalyst layer, gives the same value in magnitude, but with opposite sign. This value is the cell current.

The other unstable variables are the dissolved concentrations, $C_{i}$. The reason for this is that high concentration gradients are expected on the outer layer of the catalyst region. Figure 3-8 shows the instability associated with this phenomenon. The reaction term, $j$, is dependent on $C_{i}$, and heavily dependent on the electrode overpotential. So if the overpotential is too high, numerical instabilities would arise since these quantities are in the exponential terms. Figure 3-8 shows a typical divergent solution, which is easy to obtain if the reaction term "gets out of hand". Therefore, good initial guesses, which are close to the expected solution, are needed for the potential and concentration terms. 


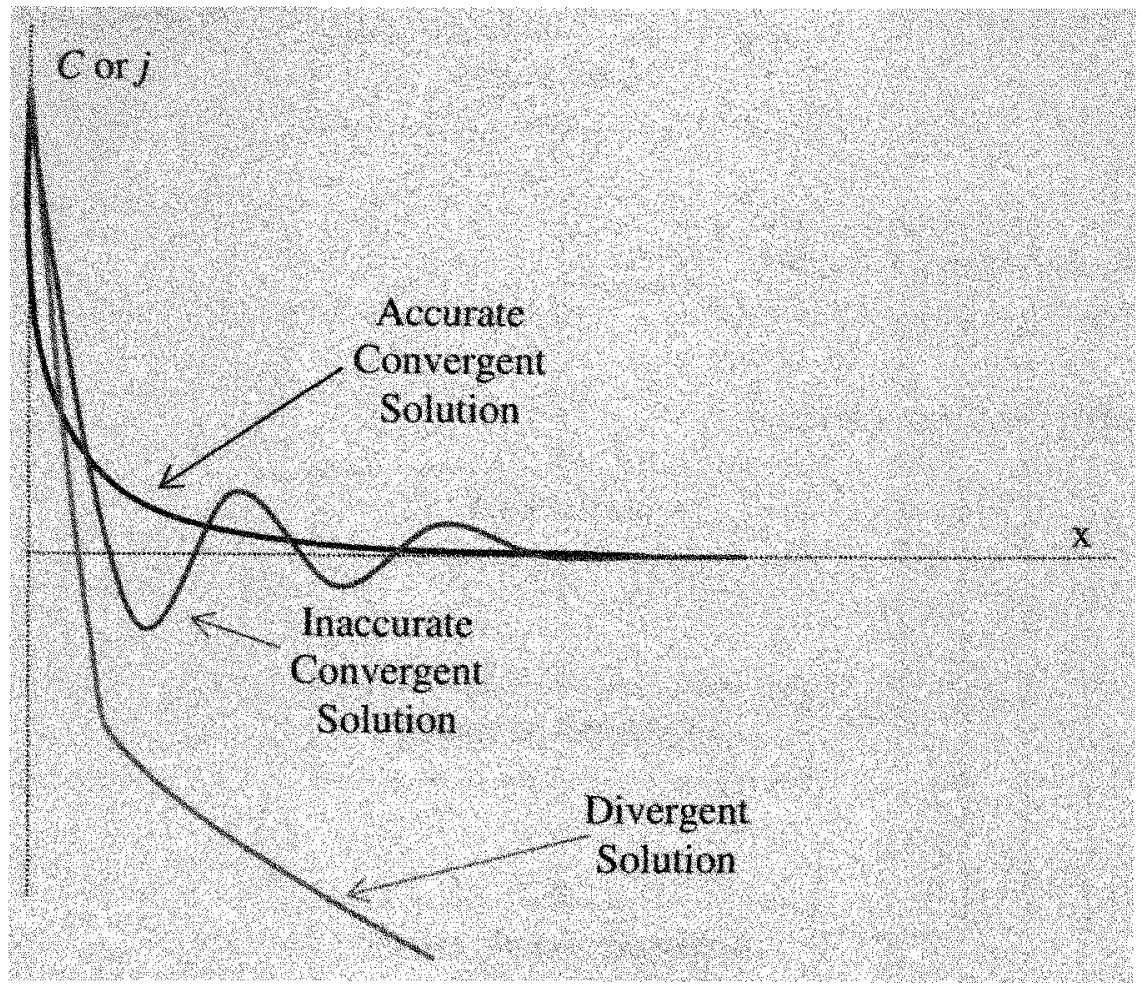

Figure 3-8 Numerical Solutions

\subsubsection{Solution Algorithm}

The algorithm used for solving the problem is shown in Figure 3-9. The concentration variables are solved first. Good initial guesses are needed to ensure convergence. Once the concentration problem is solved, only the dissolved concentration variables have a solution (not the correct solution as yet, but a convergent solution). All other variables remain at the initially guessed values. Secondly, the solid and electrolyte potentials are solved, using the existing solution as the new initial guess. This enables smoother convergence. Once convergence is obtained with these variables, the remainder of the problem is less demanding. 


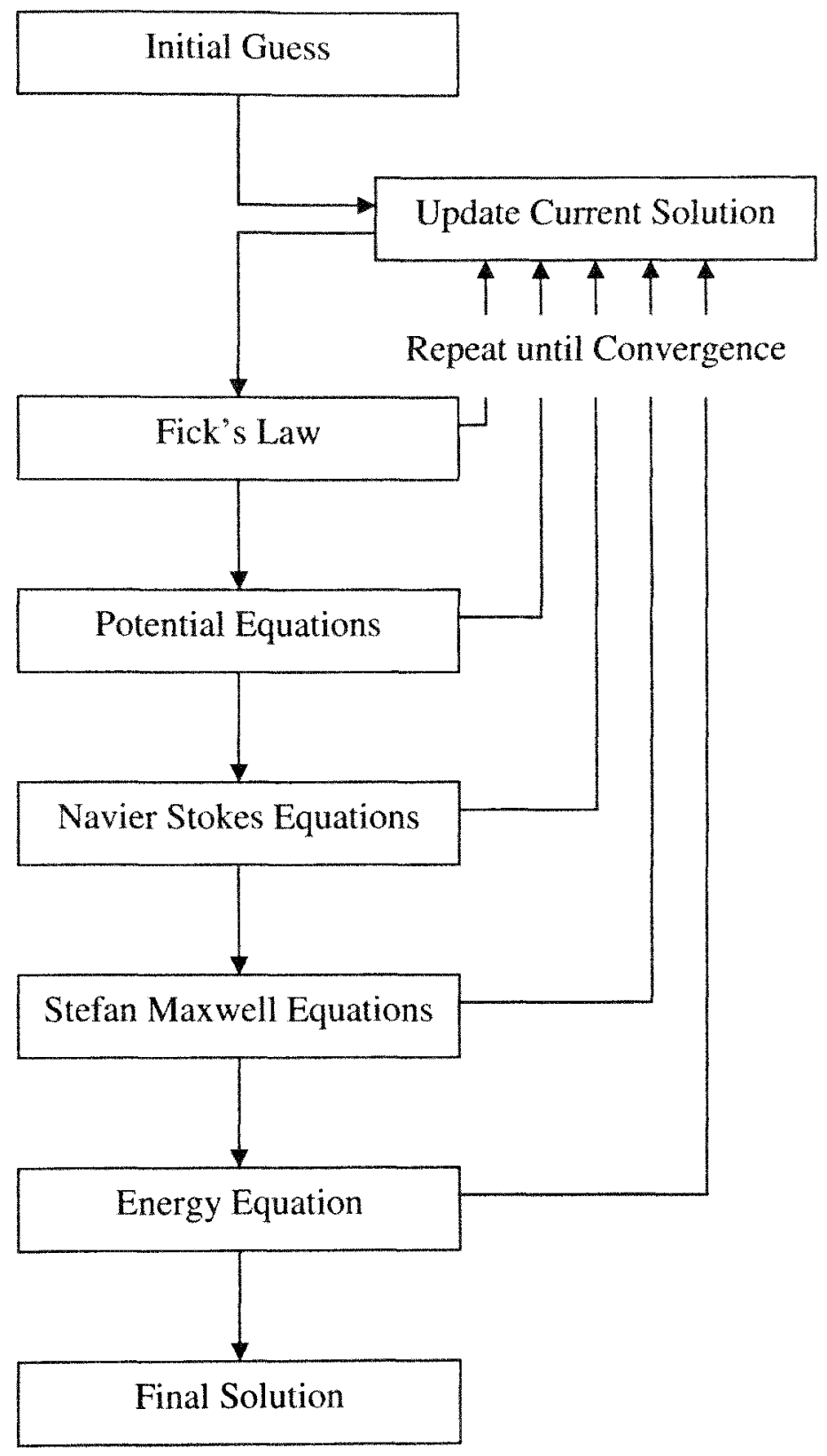

Figure 3-9 Solution Algorithm

The next instability concerns the coupling of the Stefan-Maxwell equations and the Navier-Stokes equations with Fick's law. However, once the concentration profiles 
were solved, a smooth coupling of these two equations resulted. The Navier-Stokes equations were solved before the Stefan-Maxwell equations because the latter needed an established velocity field to return a valid solution. Once again, the same technique of using the existing solution as the initial guess for the next set of iterations was employed. Finally the thermal problem was added, after which the full final convergent solution was obtained.

This did not guarantee that the solution was accurate. Because of the high reaction terms and the low diffusivities in the electrolyte, very sharp concentration gradients were expected on the outer layer of the catalyst. This required a very fine computational mesh to capture this phenomenon. Figure 3-8 also shows a typical solution obtained using a mesh which is not sufficiently dense on the outer surface of the catalyst layer. Instead of a smooth asymptotic decrease in concentration to zero, it overshoots and then finally levels off at zero. A fine mesh is required to resolve this inaccuracy.

\subsubsection{Software, Hardware and Grid Independence}

The governing equations with appropriate boundary conditions were inputted into the graphical interface of the commercial coupled multi-physics software, FEMLAB ${ }^{\circledR}$ 3.1i. The input data is shown in Appendix B. The finite element mesh, using second order tetrahedral elements, $\mathrm{O}\left(\mathrm{h}^{3}\right)$, is shown in Figure 3-10. The finite element matrix was solved using the Unsymmetric MultiFrontal (UMF) method [117-123]. This was one of the default solvers that came with the software, and which proved to be the most robust. It did not depend on the quality of the elements, which was low because of the large aspect ratios present in this problem. 

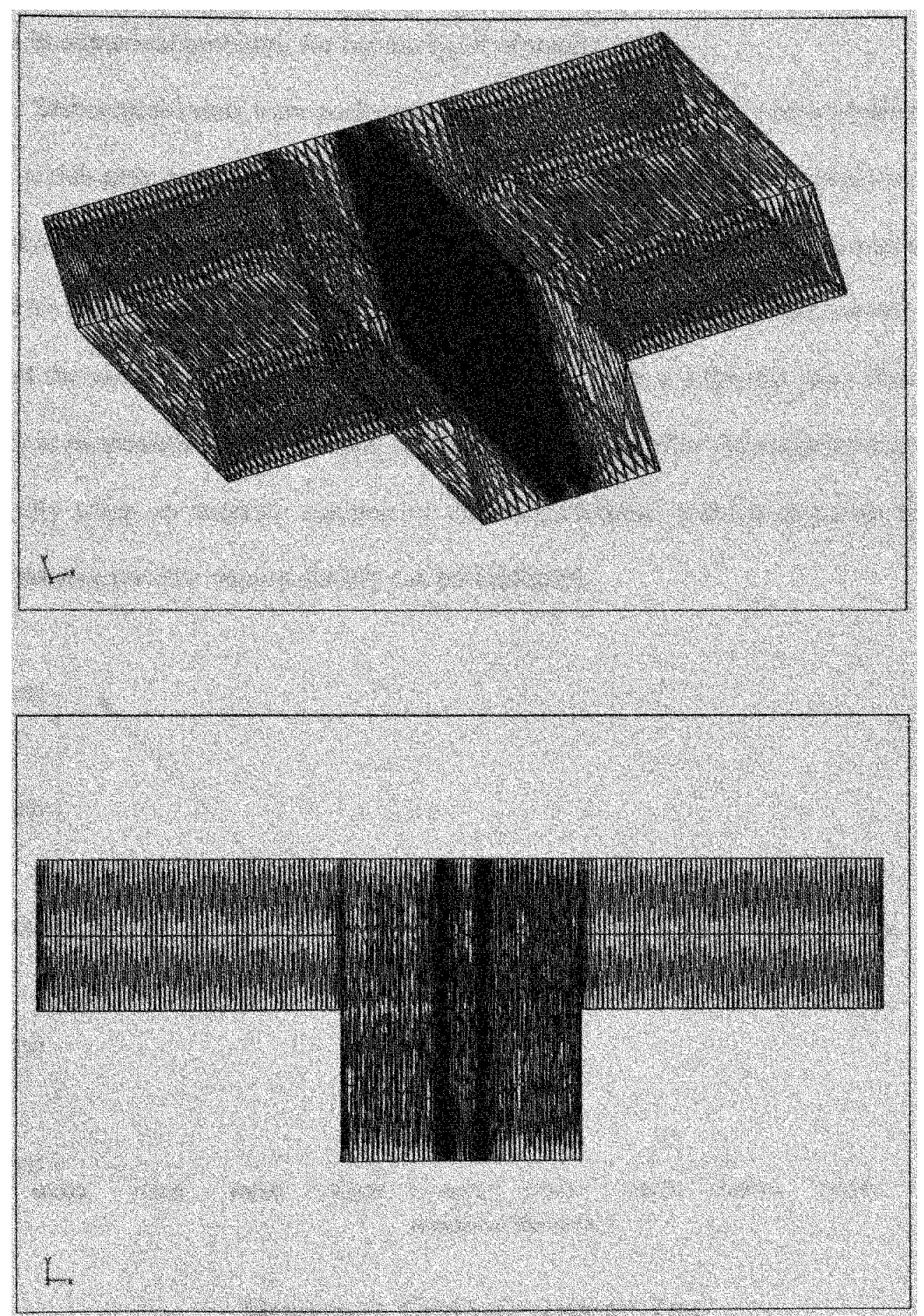

Figure 3-10 Finite Element Mesh 
A low mesh quality, it must be noted, does not produce an inaccurate solution, but rather results in numerical problems for certain types of matrix solvers.

The computations were performed on a $64 \mathrm{bit}, 4 \mathrm{~GB}, 3.8 \mathrm{GHz}$ Linux platform. The mesh, which gave accurate grid independent solutions, contained 86,865 elements. Figure 3-11 shows the test for grid independence. This figure shows how the cell current density (at $0.4 \mathrm{~V}$ ) changes with the number of elements. It was found that the cell current density showed the most variation with the mesh refinement. This is expected since the current density is proportional to the integral of the reaction rate, $j$, over the entire catalyst layer. It is only when an accurate solution of the concentrations and the reactions terms is obtained, that the true current density can be evaluated.

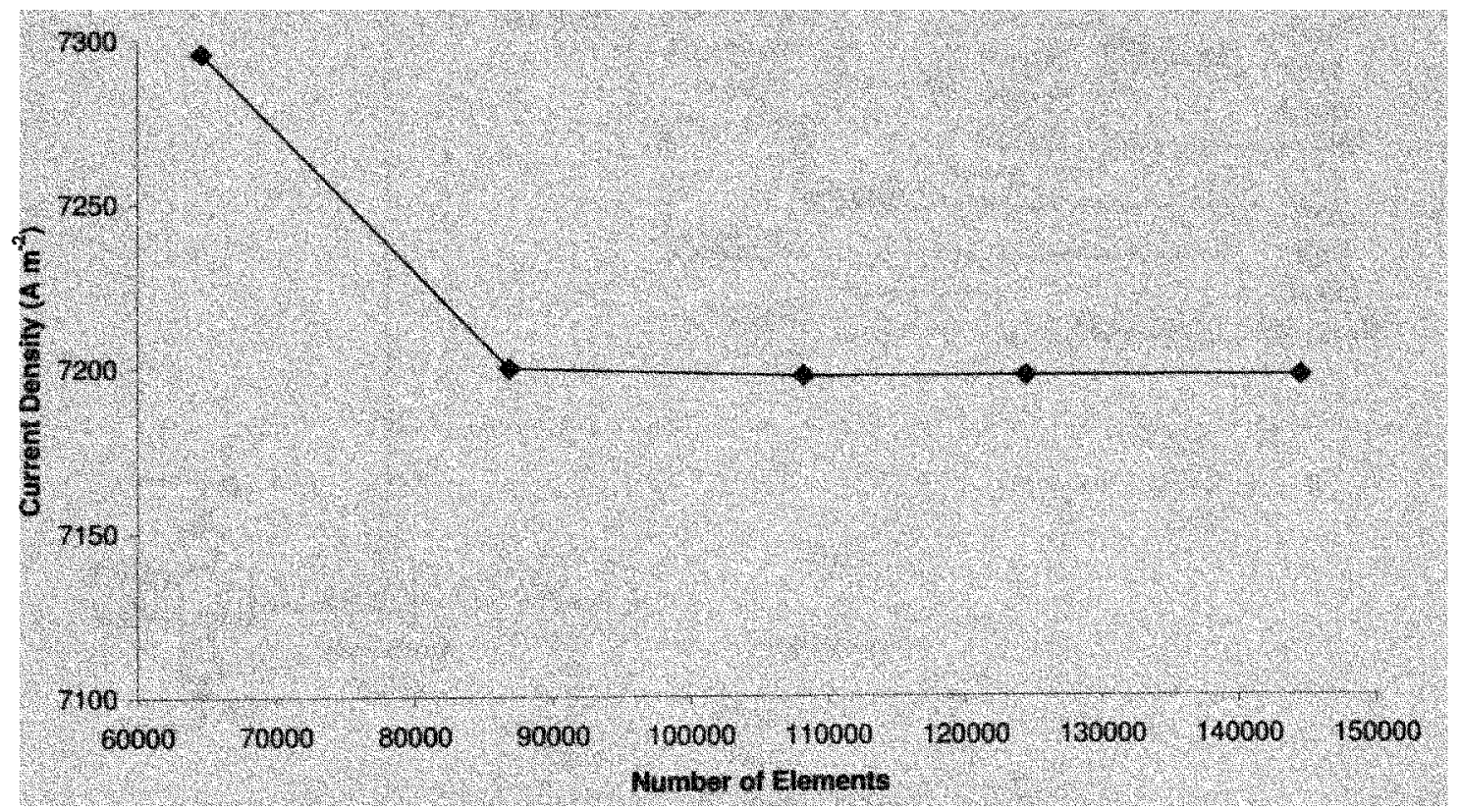

Figure 3-11 Grid Independence Test 


\section{CHAPTER 4}

\section{EXPERIMENTAL}

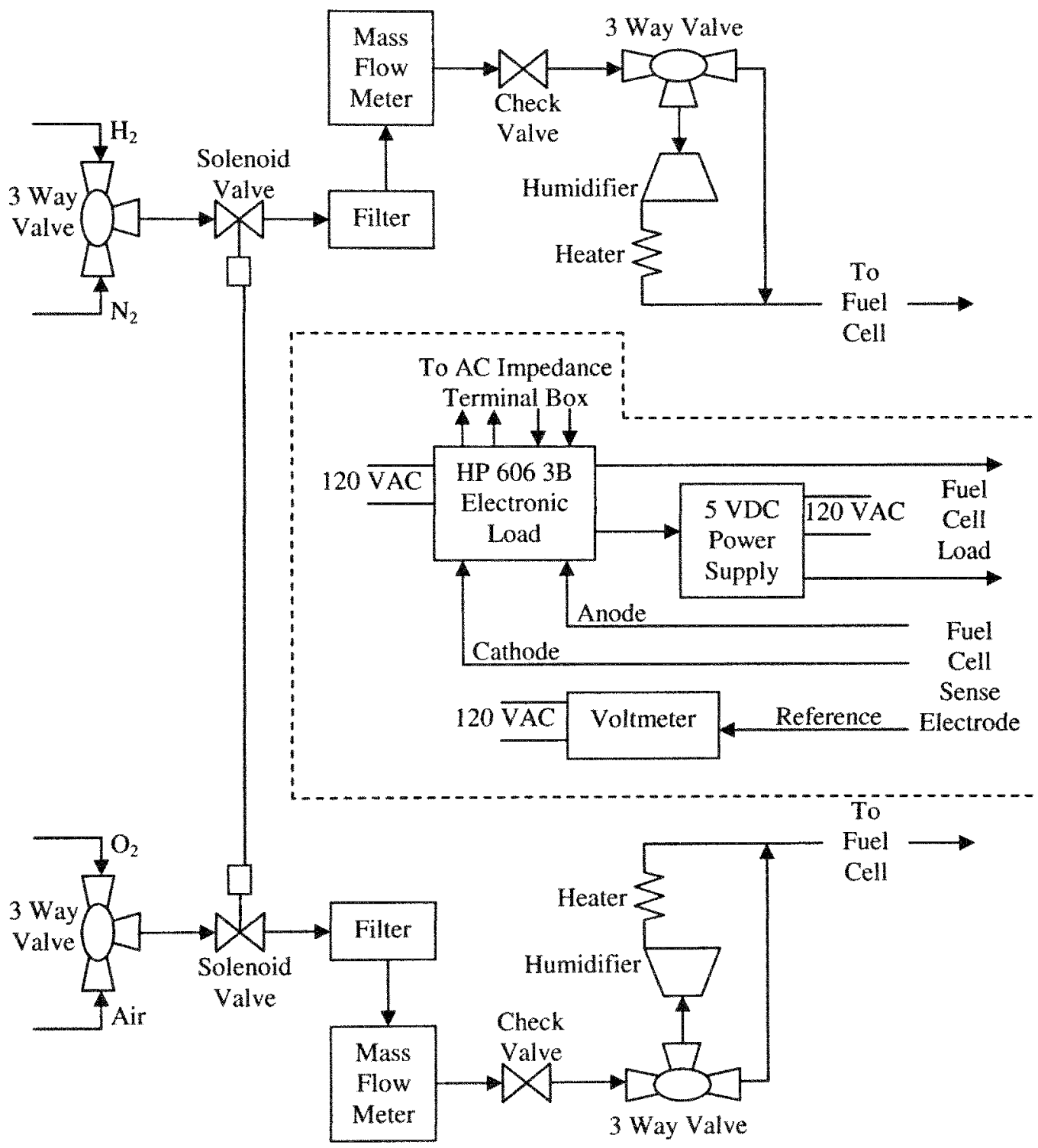

Figure 4-1 Fuel Cell Testing System Schematic 
Fuel cell tests were conducted in our laboratory at the Applied Research Center (ARC) of Florida International University (FIU), with the intention of using the experimental results for model validation. A schematic of the experimental set up is shown in Figure 4-1. An Arbin Instruments fuel cell tester was used (Figure 4-2), which was controlled by the MITs-PRO software, which allowed for variation of flow rates, pressure, temperature, and for the monitoring of critical fuel cell parameters e.g. cell voltage, current density, actual cell temperature etc.
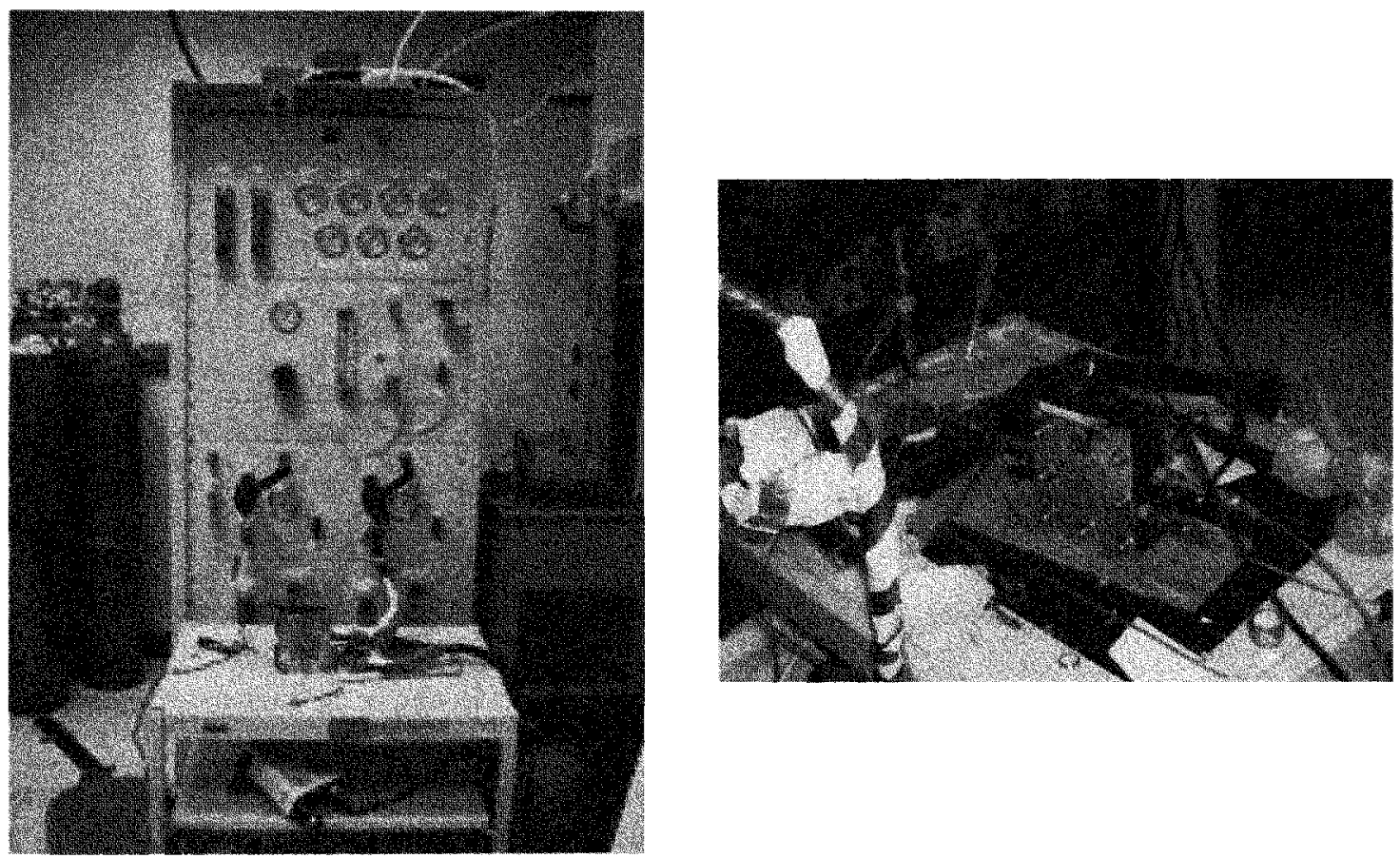

Figure 4-2 Arbin Instruments Fuel Cell Tester

ABPBI membranes, doped with phosphoric acid, were obtained from Gas Technology Institute (GTI), Des Plains, IL. The membrane thickness was $100 \mu \mathrm{m}$, and 
the already assembled MEAs had a cross sectional electrode area of $5 \mathrm{~cm}^{2}$. The MEAs were loaded with $0.5 \mathrm{mg} \mathrm{cm}^{-2}$ of Pt catalyst. Unfortunately the doping levels of the membranes were not reported, neither was the concentration of phosphoric acid used in the doping procedure. Very little is known of the actual preparation procedure. Photographs of the MEAs, before (left) and after (right) use, are shown in Figure 4-3.
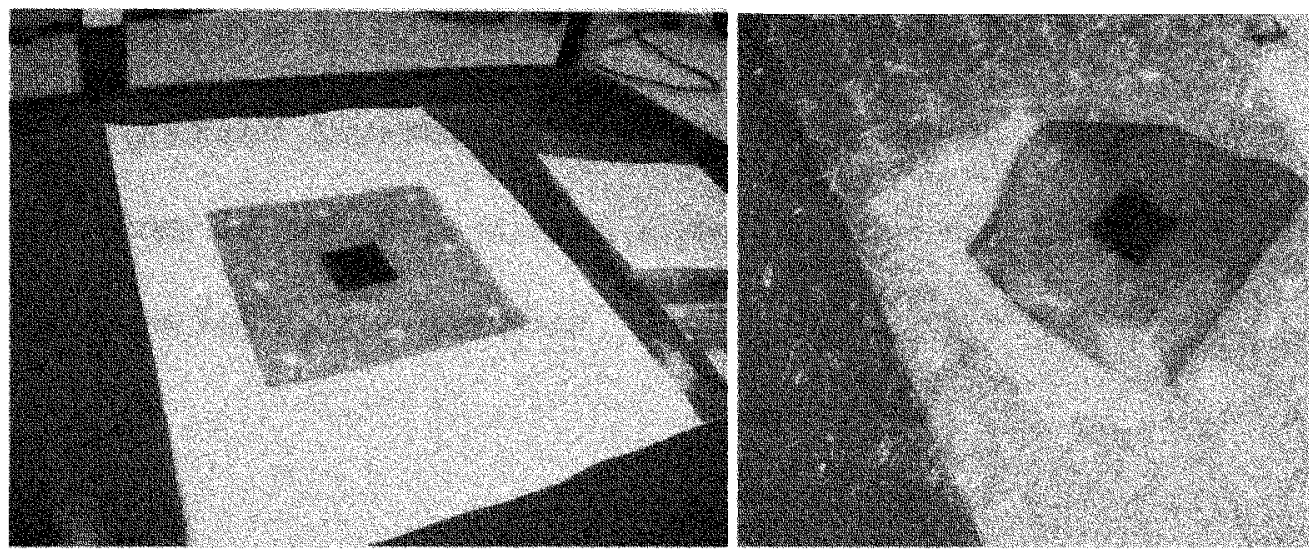

Figure 4-3 Phosphoric Acid Doped ABPBI MEAs

The first stage of the testing involved running the fuel cell at room temperature, with gases supplied at atmospheric pressure. Hydrogen and oxygen were humidified at room temperature, and were assumed to be saturated at the inlet to the fuel cell. This was confirmed by visible condensation of water in the inlet and outlet tubes. The software was setup to run the cell on open circuit for 20 minutes, subsequent to purging with nitrogen. Afterward, the current density was increased gradually in a stepwise fashion, until the voltage dropped to nearly zero (limiting conditions). Then the cell would return to open circuit conditions. One schedule consisted of 4 such cycles. The results of our 
room temperature tests are shown in Figure 4-4 and Figure 4-5. Figure 4-5, which arranges the current and voltage data in order to obtain IV plots, show that limiting current densities of just over $200 \mathrm{~mA} \mathrm{~cm}^{-2}$ were observed. The maximum power density was approximately $32 \mathrm{~mW} \mathrm{~cm}$. This value is very low, considering that fuel cells with PBI membranes have achieved power densities of over $500 \mathrm{~mW} \mathrm{~cm}^{-2}$. Very noticeable in the IV plots, is that for each subsequent cycle, the performance diminished (evident by a downward shift in the curves). This is also evident in Figure 4-4, where the open circuit voltage gradually decreases over time. The spikes indicate the times when current is drawn from the cell. Even at room temperature, this may have suggested that some degradation had begun to take place.

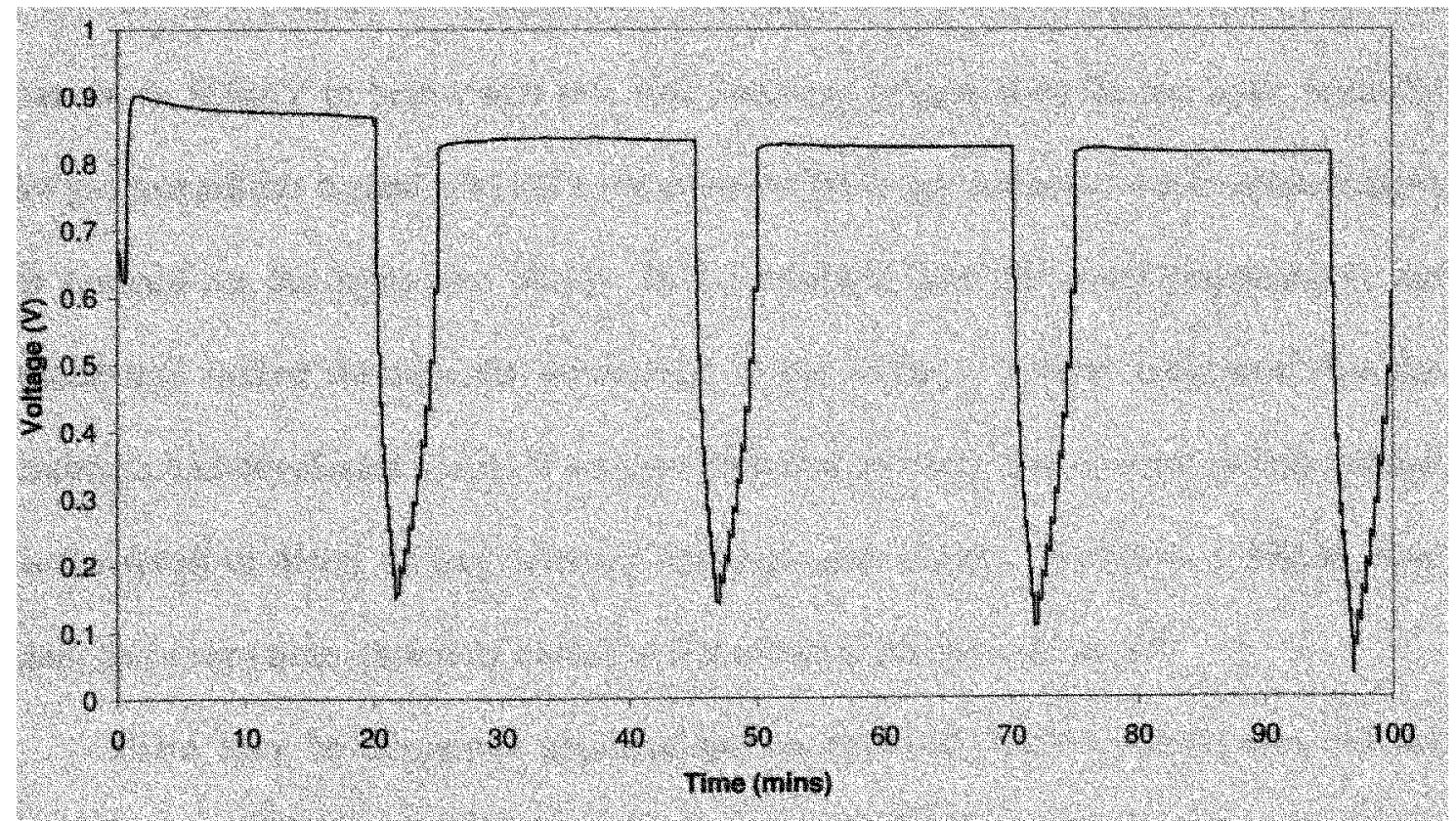

Figure 4-4 Voltage vs. Time at $25^{\circ} \mathrm{C}$ 


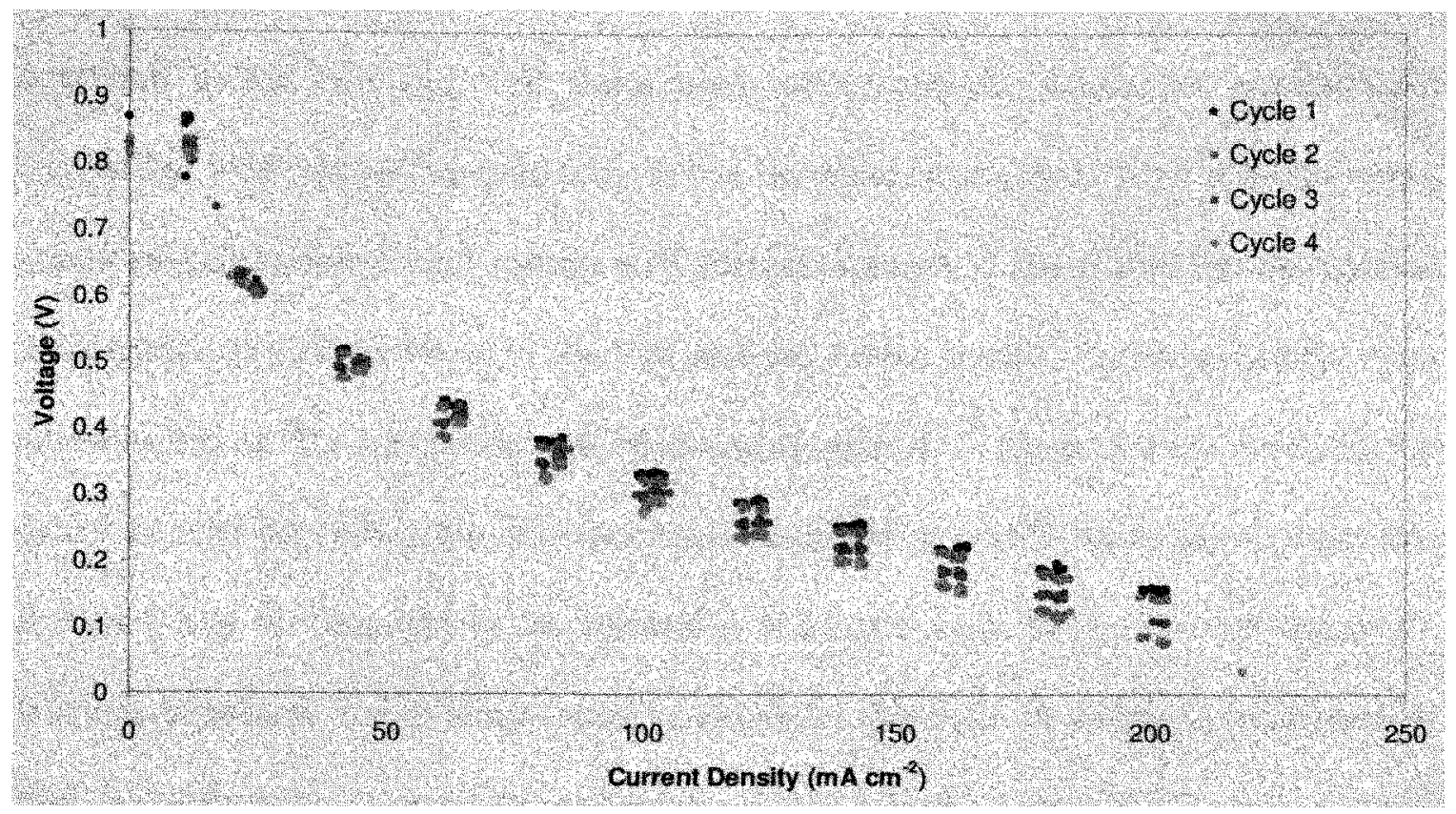

Figure 4-5 Current Voltage (IV) Curves at $25^{\circ} \mathrm{C}$

As we increased the temperature, a noticeable decrease in open circuit potential from above $800 \mathrm{mV}$ to below $600 \mathrm{mV}$ was observed (Figure 4-6). In one case, with the inlet gas humidifier turned off (i.e. with un-humidified gas streams), water condensation was noticed on the hydrogen outlet. This confirmed that the water produced at the cathode had leaked through the membrane to the anode - a clear indication that the membrane had developed a leak. It was possible that the reduction in open circuit voltage was the result of direct mixing between hydrogen and oxygen. A total of 6 MEAs were tested, and every time, failure occurred as the temperature was increased.

There may be numerous explanations on why our ABPBI membranes did not perform well at high temperatures. It was possible that the membranes developed physical deformities during manufacture or assembly, or maybe even during 
transportation or storage. It is possible that the deformities were developed during operation in the fuel cell. Our tester used rubber gaskets, which are mechanically compatible with Nafion ${ }^{\circledR}$ membranes. In the literature, researchers have reported using aluminum and stainless steel gaskets with PBI membranes. It is possible that mechanical incompatibility existed between the PBI and the rubber gasket. On disassembly, vivid delamination of the membrane was observed (Figure 4-3). Delamination refers to the detachment of the membrane and the carbon electrode. It is difficult to say whether this occurred only on disassembly, or whether it had begun even during the cell operation. Uneven expansion, due to temperature variations of thermally incompatible materials, or uneven swelling due to water absorption, may result in such delamination.

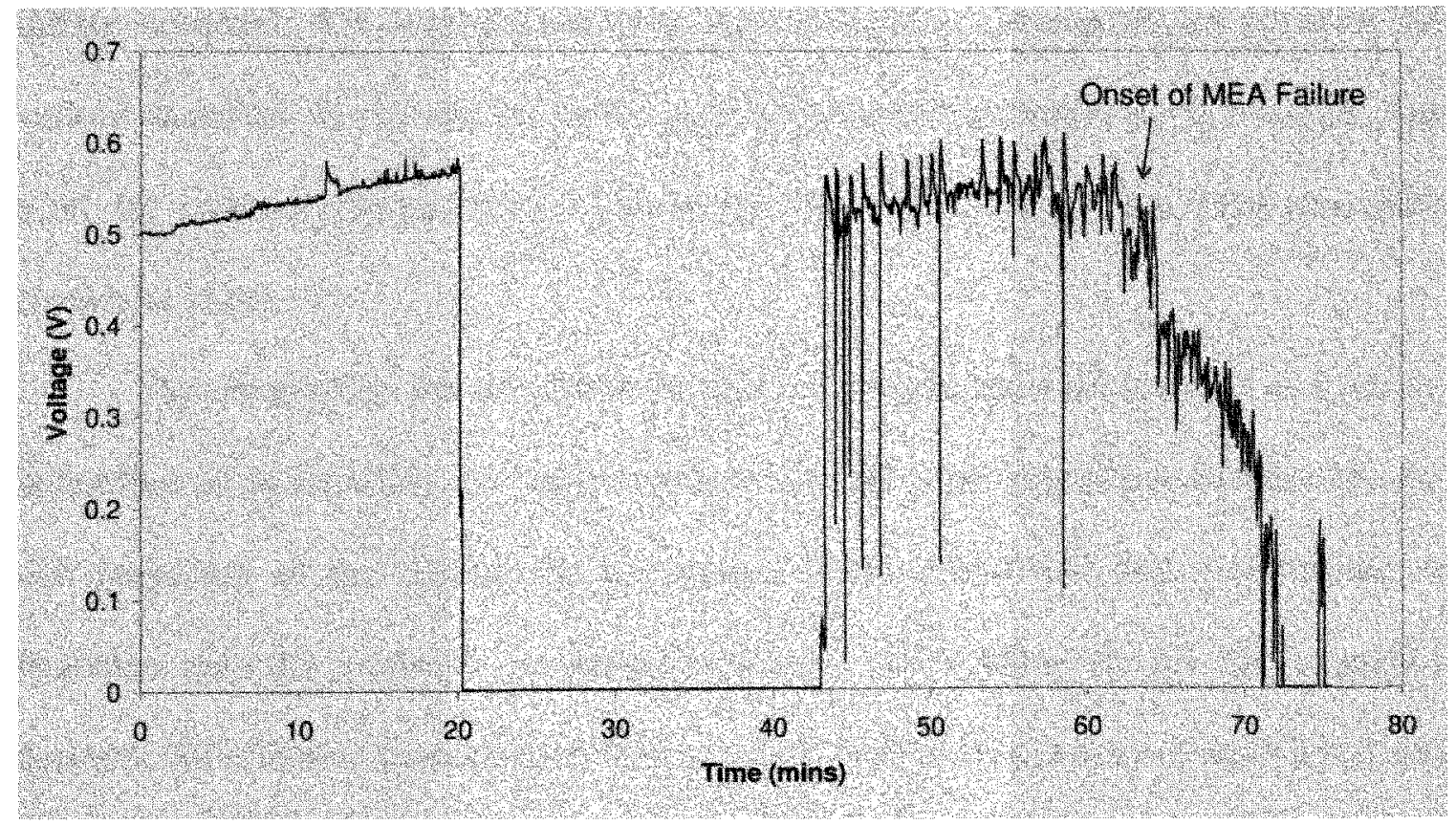

Figure 4-6 Voltage vs. Time Curve at Higher Temperatures 
We were therefore, not able to obtain meaningful intermediate temperature results. Our final recourse was to use experimental results from the literature for model validation. Three papers by independent authors were used, which presented intermediate temperature results of fuel cell tests using PBI membranes - Qingfeng et al [64], Savadogo et al [69], and Wang et al [102].

The fact that promising intermediate temperature results for ABPBI were obtained in the literature $[63,66]$, while we were unable to produce satisfactory high temperature results in our lab, reveals that results for intermediate temperature PEM fuel cells are not repeatable. This is partly due to the fact that there is, as yet, no standard procedure for fabrication of membranes and assembling of MEAs. In some cases, the MEAs looked very promising on inspection, however, during intermediate temperature operation, failure occurred. It is strongly believed that mechanical incompatibility between the various materials in the cell assembly may have been responsible for the failure. The need for material compatibility between the fuel cell materials has been discussed elsewhere [124].

This re-enforces the belief that the fuel cell system must be designed as a whole, rather than as an assembly of compartments [125]. Our experiments revealed how the exsitu properties of the ABPBI do not equate to the in-situ fuel cell performance. It behooves material scientists to design materials, which allow for all the properties desirable for effective fuel cell performance, while maintaining chemical, mechanical and morphological compatibility under a wide range of operating conditions. 


\section{CHAPTER 5}

\section{RESULTS AND DISCUSSION}

The results in this section are divided into three categories. The first involves model validation where theoretical predictions are compared to experimental results for identical operating conditions. Secondly, results are presented, which are difficult or impossible to measure experimentally. Finally, some parametric analyses are performed, which predict and explain the fuel cell performance when critical parameters are varied from their base values.

\subsection{Model Validation}

We were unable to obtain intermediate temperature results in our lab, primarily because of mechanical failure of our MEAs, as discussed in the previous section. In order to validate our model, we used experimental results published in the literature. In this section, our model predictions are compared with three sets of experimental data, published independently by different authors.

\subsubsection{Qingfeng et al [64]}

Figure 5-1 shows the current-voltage (IV) comparisons between the model and the experimental work of Qingfeng et al [64]. In their tests, hydrogen and oxygen are supplied at atmospheric pressure and flow rates of $0.16 \mathrm{~L} \mathrm{~min}^{-1}\left(32 \mathrm{~mL} \mathrm{~min}^{-1} \mathrm{~cm}^{-2}\right)$. Since no specific humidification of the gas streams were reported, we assumed that the gases 
were humidified at room temperature, and hence the partial vapor pressure was set to the saturation vapor pressure at $25{ }^{\circ} \mathrm{C}$. This does not make a significant difference in the computational results since the effects of ambient humidity on membrane performance were not considered. In reality, it may affect the conductivity and transport properties of the acid in the membrane. The authors report a membrane doping level of 6.2 , and the conductivity relation given by Equation (28) is used. Table 5-1 shows the numerical values of some of the critical parameters for these computations.

Their test results at 150 and $170{ }^{\circ} \mathrm{C}$ are shown, where it can be seen that the model predictions are accurate for these two temperatures. For the $150{ }^{\circ} \mathrm{C}$ data, the model slightly underestimates the performance in the activation overpotential region, though it does predict a reasonable open circuit voltage between 0.8 and $0.9 \mathrm{~V}$. The fit in the ohmic region is particularly good, noting that this is the region where the optimum fuel cell performance is obtained. In the experimental data, there appears to be a concentration overpotential region, although the data is not given below $0.2 \mathrm{~V}$. The model predicts sharp concentration overpotential regions around $0.2 \mathrm{~V}$, and limiting current densities of 10480 and $13200 \mathrm{~A} \mathrm{~m}^{-2}$, respectively at 150 and $170{ }^{\circ} \mathrm{C}$. The reason for these limiting regions is the catalyst blockage due to the phosphoric acid anion adsorption onto $\mathrm{Pt}$, which becomes increasingly significant as the electrode polarization increases. Qingfeng et al [64] did use a relatively low flow rate $\left(0.16 \mathrm{~L} \mathrm{~min}^{-1}\right)$, and this results in a sizeable concentration drop in the z-direction (as will be seen later). However, this is not sufficient to cause such a significant concentration region in the IV curve, especially with oxygen (vs. air) used as the oxidant. It is primarily the catalyst blockage that is responsible for the concentration region. 


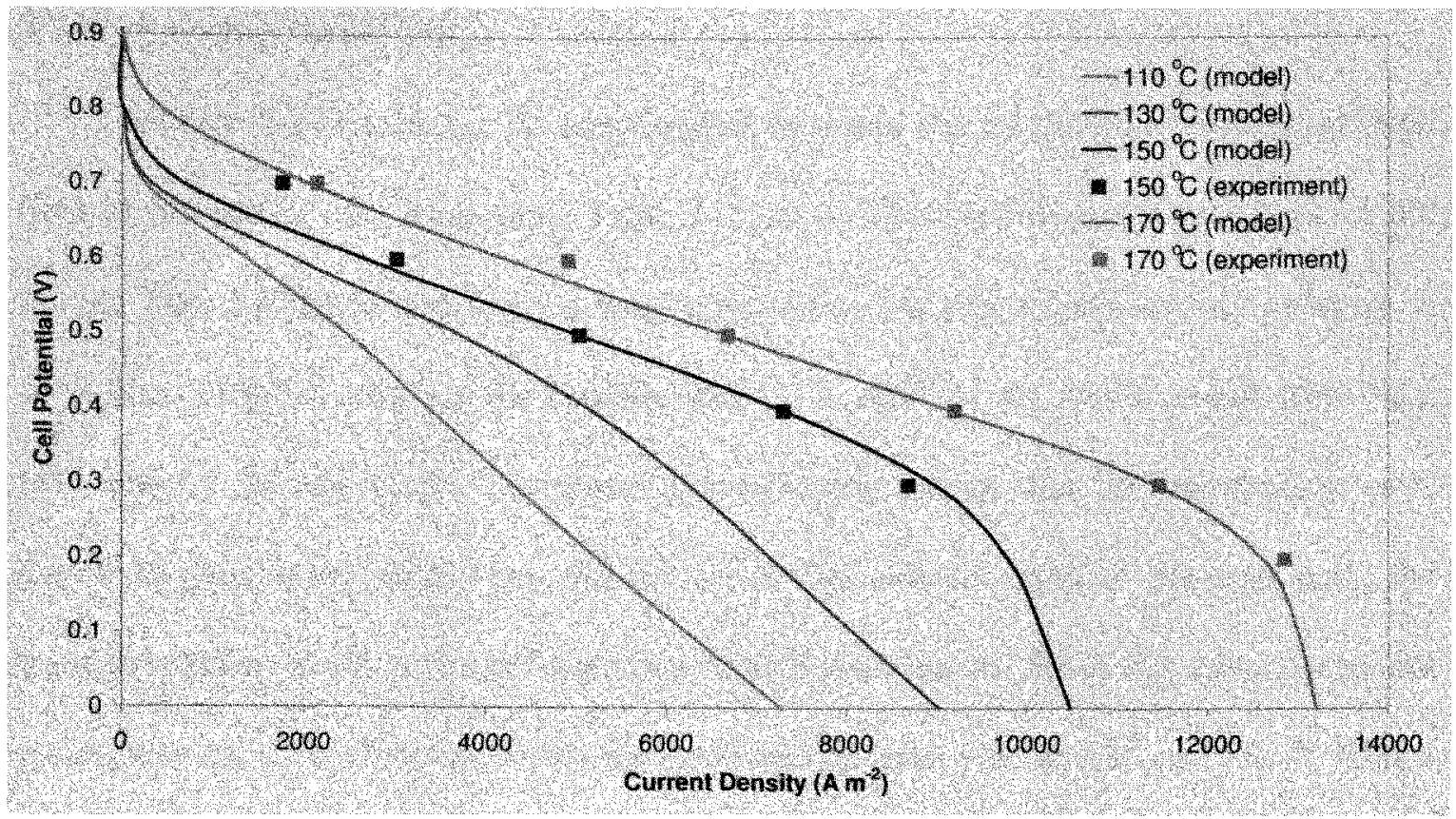

Figure 5-1 Model Comparison with Qingfeng et al [64]

Table 5-1 Critical Numerical Values in Figure 5-1

\begin{tabular}{lccccc}
\hline & $\mathbf{T}=110^{\circ} \mathbf{C}$ & $\mathbf{T}=\mathbf{1 3 0}^{\circ} \mathbf{C}$ & $\mathbf{T}=150^{\circ} \mathbf{C}$ & $\mathbf{T}=1700^{\circ} \mathbf{C}$ & \\
\hline$\sigma_{m}$ (eqn 28) & 2.75 & 3.46 & 4.25 & 5.12 & $\mathrm{~S} \mathrm{~m}^{-1}$ \\
$i_{0, c}($ eqns 27,33,34) & $6.95 \times 10^{-4}$ & $1.26 \times 10^{-3}$ & $2.80 \times 10^{-3}$ & $8.01 \times 10^{-3}$ & $\mathrm{~A} \mathrm{~m}^{-2}$ \\
$i_{0, a}$ & $6.95 \times 10^{4}$ & $1.26 \times 10^{5}$ & $2.80 \times 10^{5}$ & $8.01 \times 10^{5}$ & $\mathrm{~A} \mathrm{~m}^{-2}$ \\
$D_{O_{2}}$ (eqns 27,29,31) & $7.04 \times 10^{-11}$ & $1.15 \times 10^{-10}$ & $1.80 \times 10^{-10}$ & $2.69 \times 10^{-10}$ & $\mathrm{~m}^{2} \mathrm{~s}^{-1}$ \\
$D_{H_{2}}$ & $1.41 \times 10^{-10}$ & $2.30 \times 10^{-10}$ & $3.59 \times 10^{-10}$ & $5.39 \times 10^{-10}$ & $\mathrm{~m}^{2} \mathrm{~s}^{-1}$ \\
$H_{O_{2}}$ (eqns 27,30,32) & 0.78 & 0.77 & 0.76 & 0.76 & $\mathrm{~mol} \mathrm{~m}^{-3} \mathrm{~atm}^{-1}$ \\
$H_{H_{2}}$ & 3.47 & 3.43 & 3.39 & 3.37 & $\mathrm{~mol} \mathrm{~m}^{-3} \mathrm{~atm}^{-1}$ \\
\hline
\end{tabular}




\subsubsection{Savadogo et al [69]}

Figure 5-2 shows the IV comparisons between the model and the experimental data of Savadogo and Xing [69]. Table 5-2 shows the critical parameters used in the model. Pure hydrogen and oxygen were supplied to the cell at atmospheric pressure at flow rates of $0.8 \mathrm{~L} \mathrm{~min}^{-1}$ at the cathode and $1.2 \mathrm{~L} \mathrm{~min}^{-1}$ at the anode. Apart from this, very little is known of the experimental conditions, except that the membranes were doped in phosphoric acid. They did not report the concentration of the acid bath, the eventual doping level, or the conductivity of their membranes. So in this case, the model parameters had to be fitted to match the experimental data. For the 130 and $150{ }^{\circ} \mathrm{C}$ data, a doping level of 12 produced IV curves which closely match the experimental data. For the $185^{\circ} \mathrm{C}$ data, a doping level of 4 matches the data. Because of the higher temperature, the exchange current densities are higher for the $185^{\circ} \mathrm{C}$ cell than the 130 and $150{ }^{\circ} \mathrm{C}$, although it appears that the cell resistance is greater (judging from the larger slope in the IV curve). It is possible that the experimenters applied a smaller doping level to the membrane, used for the $185{ }^{\circ} \mathrm{C}$ data, to increase its mechanical stability at this higher temperature.

The experimental data is not given beyond $32000 \mathrm{~A} \mathrm{~m}^{-2}$, so it is difficult to tell exactly what takes place as the cell voltage approaches zero. From the data given, it does not appear that a significant concentration region exists for the high temperature curves. Notably, for the two low temperature curves shown in the figure $\left(50\right.$ and $\left.100{ }^{\circ} \mathrm{C}\right)$, a significant concentration region exists in the IV curves, which most likely is due to the presence of liquid water in the pores of the electrodes. This region is not evident in the high temperature curves. 


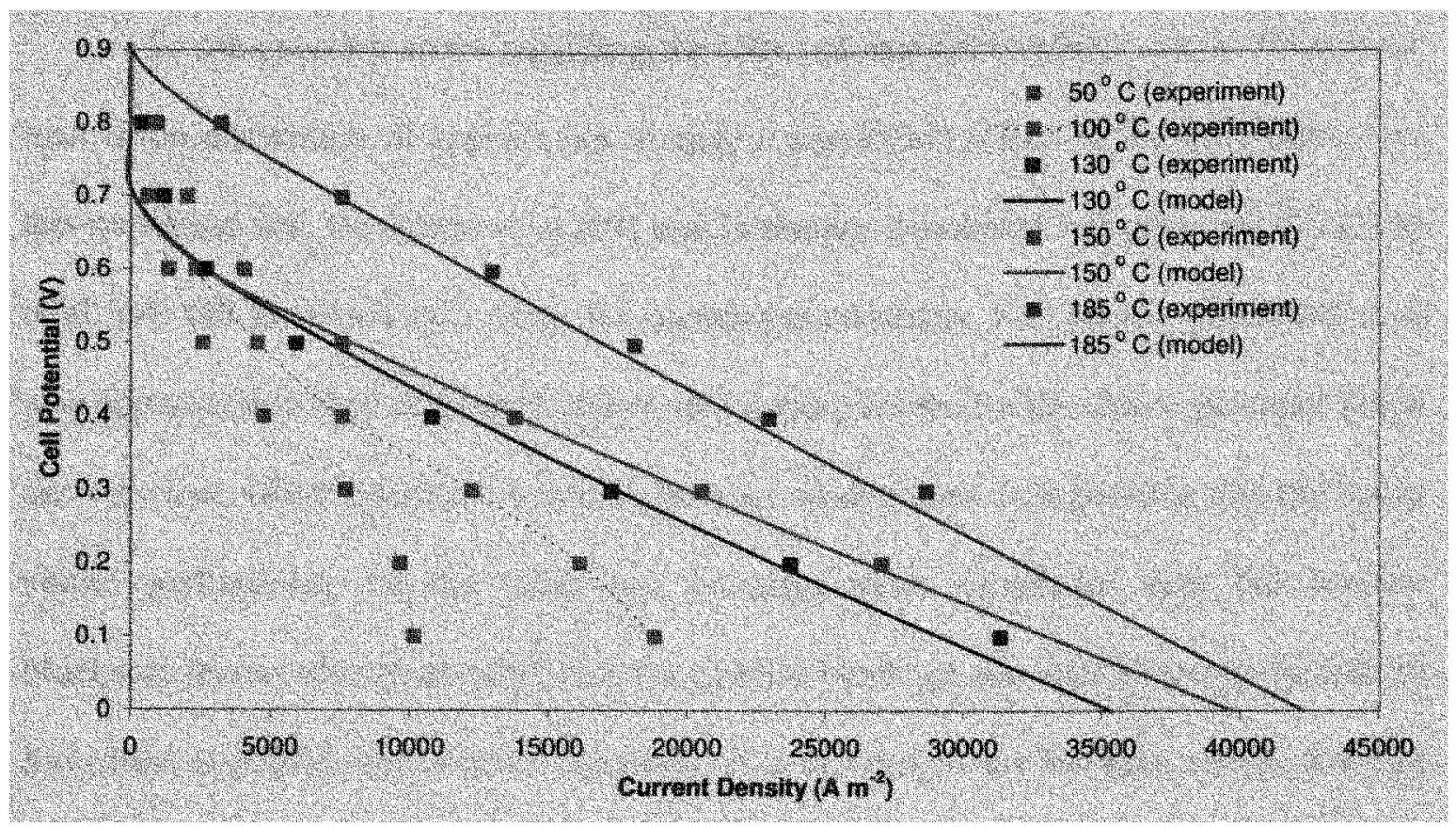

Figure 5-2 Model Comparison with Savadogo et al [69]

Table 5-2 Critical Numerical Values in Figure 5-2

\begin{tabular}{lcccc}
\hline & $\mathbf{T}=\mathbf{1 3 0}{ }^{\circ} \mathbf{C}$ & $\mathbf{T}=\mathbf{1 5 0}{ }^{\circ} \mathbf{C}$ & $\mathbf{T}=\mathbf{1 8 5}{ }^{\circ} \mathbf{C}$ & \\
\hline$X$ (fitted) & 12 & 12 & 4 & \\
$\sigma_{m}$ (eqn 28) & 9.49 & 11.12 & 4.15 & $\mathrm{~S} \mathrm{~m}^{-1}$ \\
$i_{0, c}$ (eqns 27,33,34) & $1.35 \times 10^{-2}$ & $3.01 \times 10^{-2}$ & $2.54 \times 10^{-1}$ & $\mathrm{~A} \mathrm{~m}^{-2}$ \\
$i_{0, a}$ & $1.35 \times 10^{6}$ & $3.01 \times 10^{6}$ & $2.54 \times 10^{7}$ & $\mathrm{~A} \mathrm{~m}^{-2}$ \\
$D_{O_{2}}$ (eqns 27,29,31) & $2.24 \times 10^{-10}$ & $3.50 \times 10^{-10}$ & $1.55 \times 10^{-10}$ & $\mathrm{~m}^{2} \mathrm{~s}^{-1}$ \\
$D_{H_{2}}$ & $4.48 \times 10^{-10}$ & $7.00 \times 10^{-10}$ & $3.11 \times 10^{-10}$ & $\mathrm{~m}^{2} \mathrm{~s}^{-1}$ \\
$H_{O_{2}}$ (eqns 27,30,32) & 1.02 & 1.01 & 0.40 & $\mathrm{~mol} \mathrm{~m}^{-3} \mathrm{~atm}^{-1}$ \\
$H_{H_{2}}$ & 4.54 & 4.47 & 1.77 & $\mathrm{~mol} \mathrm{~m}^{-3} \mathrm{~atm}^{-1}$ \\
\hline
\end{tabular}


So the question arises regarding the effect of catalyst blockage due to phosphoric acid anion adsorption. It appears not to have a significant effect on the performance of this particular cell. Savadogo et al [69] used a thinner membrane $(40 \mu \mathrm{m})$ than Qingfeng et al [64] $(80 \mu \mathrm{m})$, and as a result the membrane resistance was greatly decreased. It is also apparent that they employed higher acid doping levels. So the ohmic potential drops are very low, which results in much higher current densities. It is possible that the better ohmic performance of the membrane becomes more significant than the catalyst blockage. It may also be possible that the catalyst blockage was minimized in the cell by Savadogo et al [69] due to better assembly. It is difficult to say for sure, except that this blockage phenomenon is not very well quantified at present. The model used Equation (36) to quantify the blockage, and as a result the model curves do show a slight concentration overpotential region. Since the experimental data is not given beyond $32000 \mathrm{~A} \mathrm{~m}^{-2}$, it is difficult to say whether or not the model accurately predicts the experimental data during limiting conditions.

\subsubsection{Wang et al [102]}

Figure 5-3 shows the comparison between the model predictions and the experimental data of Wang et al [102]. Their results are only given at $150{ }^{\circ} \mathrm{C}$, but in this case, separate curves are given for oxygen and air as the oxidant. Their gas streams were humidified at room temperature, and supplied to the cell at atmospheric pressure, although the flow rates are not reported. In the model, the same flow rates used by Qingfeng et al [64] were assumed. Table 5-3 shows the critical cell parameter values. 


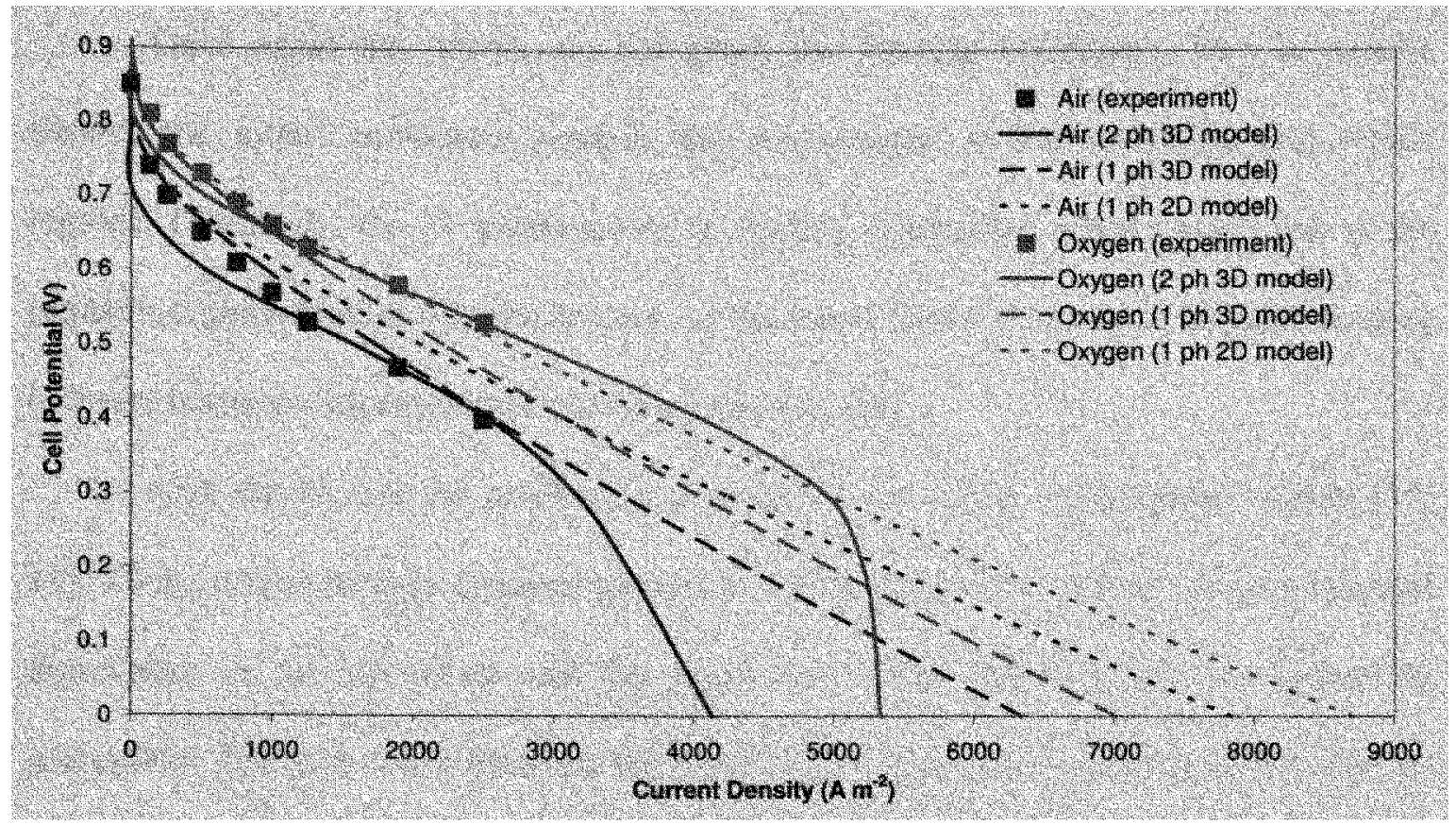

Figure 5-3 Model Comparison with Wang et al [102]

Table 5-3 Critical Numerical Values in Figure 5-3

\begin{tabular}{lcc}
\hline & $\mathbf{T}=\mathbf{1 5 0} \mathbf{0}^{\mathbf{C}} \mathrm{C}$ & \\
\hline$\sigma_{m,}[102]$ & 1.87 & $\mathrm{~S} \mathrm{~m}^{-1}$ \\
$i_{0, c}($ eqns $27,33,34)$ & $1.61 \times 10^{-5}$ & $\mathrm{~A} \mathrm{~m}^{-2}$ \\
$i_{0, a}$ & $1.61 \times 10^{3}$ & $\mathrm{~A} \mathrm{~m}^{-2}$ \\
$D_{\mathrm{O}_{2}}$ (eqns 27,29,31) & $1.01 \times 10^{-11}$ & $\mathrm{~m}^{2} \mathrm{~s}^{-1}$ \\
$D_{H_{2}}$ & $2.02 \times 10^{-11}$ & $\mathrm{~m}^{2} \mathrm{~s}^{-1}$ \\
$H_{O_{2}}$ (eqns 27,30,32) & 0.06 & $\mathrm{~mol} \mathrm{~m}^{-3} \mathrm{~atm}^{-1}$ \\
$H_{H_{2}}$ & 0.25 & $\mathrm{~mol} \mathrm{~m}^{-3} \mathrm{~atm}^{-1}$ \\
\hline
\end{tabular}


Once again the results are not given for limiting conditions. For the results shown, the model accurately predicts the performance in the activation and ohmic regions. Obviously, the IV performance is slightly diminished when air is used as the oxidant in place of pure oxygen, because of the lower partial pressure of oxygen, leading to lower reactant concentrations and lower reaction rates.

Also shown, are the predictions of some of our earlier single-phase models [10, 11]. Those earlier models assumed gas phase reactions, and did not account for reactant dissolution in the electrolyte and the associated catalyst blockage due to electrolyte adsorption. The difference between the $2 \mathrm{D}$ and $3 \mathrm{D}$ single phase models is that the $3 \mathrm{D}$ model accounted for dilution along the gas channels. That consideration resulted in limiting current densities that were $1000-2000 \mathrm{~A} \mathrm{~m}^{-2}$ less than the 2D models, although both matched the ohmic regions of the experimental curves fairly well. Taking two-phase phenomena into account resulted in a sharper concentration overpotential region, and much lower limiting current densities. It follows that neglecting the two-phase phenomena results in an overestimation of the limiting cell performance.

\subsection{Base Case Solution}

All the results in this section are for the base or nominal condition, represented in Table 3-2 to Table 3-5. For the base condition, inlet gases are supplied at $150{ }^{\circ} \mathrm{C}$ (which is referred to as the cell temperature), atmospheric pressure, and at flow rates of $0.16 \mathrm{~L}$ $\min ^{-1}\left(0.32 \mathrm{~m} \mathrm{~s}^{-1}\right)$. Occasionally comparisons will be made for other operating conditions. Unless otherwise stated, the base values apply for the results presented in the following 
sections. Peak power conditions were observed at a cell voltage of $0.4 \mathrm{~V}$, so unless otherwise stated, $0.4 \mathrm{~V}$ is the operating cell voltage for the results presented.

\subsubsection{Velocities and Fluxes}

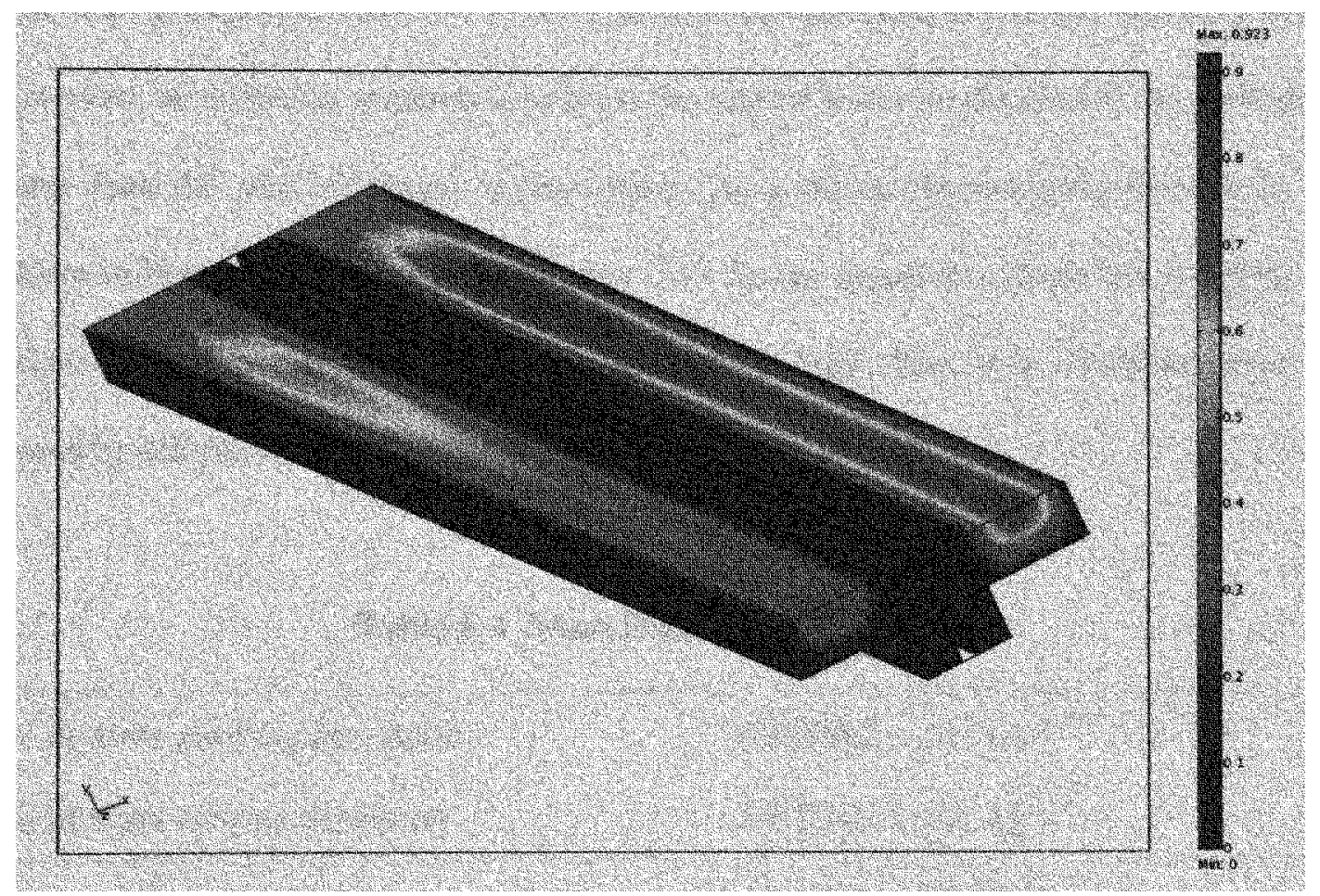

Figure 5-4 Velocity Distribution $\left(\mathrm{m} \mathrm{s}^{-1}\right)$

Figure 5-4 shows the velocity profile for the base condition. There appears to be an entrance length before fully developed conditions exist. This entrance length is not significant to the problem of fuel cell modeling since it is only the velocity distribution that is affected, and not the concentration of the gases in the mixture. Although, it is not evident in the figure, there is a decrease in velocity in the anode channel as hydrogen is consumed, and an increase in velocity along the cathode channel. Although oxygen is 
consumed in the cathode, the mass production of water vapor is greater, hence there is a fluid mass increase at the cathode. A mass balance, conducted to check the solution for self consistency, is shown in Table 5-4. It shows that the accuracy is within $0.5 \%$.

It is also evident that a much larger velocity exists in the gas channels than in the MEA. This is expected since the flow in the MEA is diffusion dominant. The flow in the MEA must be diffusion dominant, because the rate of water production at the cathode is greater than the rate of oxygen consumption. As a result, the net mass flow is in the positive $\mathrm{x}$-direction, whereas oxygen must flow in the negative $\mathrm{x}$-direction to get to the catalyst layer. Since oxygen must flow against the bulk flow, it is incumbent that the process be diffusion dominant.

Table 5-4 Mass Balance Calculations

\begin{tabular}{ll}
\hline $\begin{array}{l}\text { Rate of mass entering the anode } \\
\text { Rate of mass leaving the anode }\end{array}$ & $\begin{array}{l}6.658962 \times 10^{-9} \mathrm{~kg} \mathrm{~s}^{-1} \\
5.407202 \times 10^{-9} \mathrm{~kg} \mathrm{~s}^{-1}\end{array}$ \\
\hline Mass consumed at the anode & $1.25176 \times 10^{-9} \mathrm{~kg} \mathrm{~s}^{-1}$ \\
\hline Rate of mass entering the cathode & $8.039175 \times 10^{-8} \mathrm{~kg} \mathrm{~s}^{-1}$ \\
Rate of mass leaving the cathode & $8.165351 \times 10^{-8} \mathrm{~kg} \mathrm{~s}^{-1}$ \\
\hline Rate of mass produced at the cathode & $0.126176 \times 10^{-8} \mathrm{~kg} \mathrm{~s}^{-1}$ \\
\hline & $\frac{i A_{\text {mea }} M_{H_{2}}}{2 \mathrm{~F}}$ \\
\hline
\end{tabular}


Figure 5-5 shows the mass flux of hydrogen at the anode. There is a slight decrease in hydrogen flux along the anode channel as hydrogen is consumed in the reactions. Table 5-5 shows the hydrogen balance, which indicates a level of accuracy within $0.1 \%$. Figure 5-6 shows the mass flux of oxygen at the cathode. For the same reasons as above, there is a decrease in oxygen flux along the cathode. Table 5-6 shows the oxygen balance which indicates an error of $0.7 \%$.

Figure 5-7 shows the water vapor flux at the cathode, which is expected to increase in the z-direction as water is produced at the cathode catalyst layer. Table 5-7 shows the water vapor balance. This represents an error of $1 \%$. This error is not unexpected in numerical calculations when the flux is integrated over a boundary. This is because the flux is a first order derivative of a state variable, thus the error in the flux calculation is $\mathrm{O}\left(\mathrm{h}^{\mathrm{n}-1}\right)$. So it can be concluded that, within a reasonable error, the mass and species balance are self consistent. This, in addition to the model validation with experimental data, bolsters confidence in the accuracy of the numerical solution.

\subsubsection{Mole Fraction}

Figure 5-8 shows the variation of oxygen mole fraction in the gas flow regions for the base conditions at a cell voltage of $0.4 \mathrm{~V}$. It has already been shown that the water vapor and oxygen fluxes balance at the inlet and outlet of the cell. At the cathode outlet, the rate of oxygen removal is $6.735613 \times 10^{-8} \mathrm{~kg} \mathrm{~s}^{-1}$ (Table 5-6) while the total mass exiting the cathode is $8.165351 \times 10^{-8} \mathrm{~kg} \mathrm{~s}^{-1}$ (Table 5-4). This represents an oxygen mass fraction of 0.825 at the outlet (mole fraction of 0.726 ). The model predicts an average mole fraction of 0.724 (Figure 5-8) at the outlet, an error of less than $0.3 \%$. 

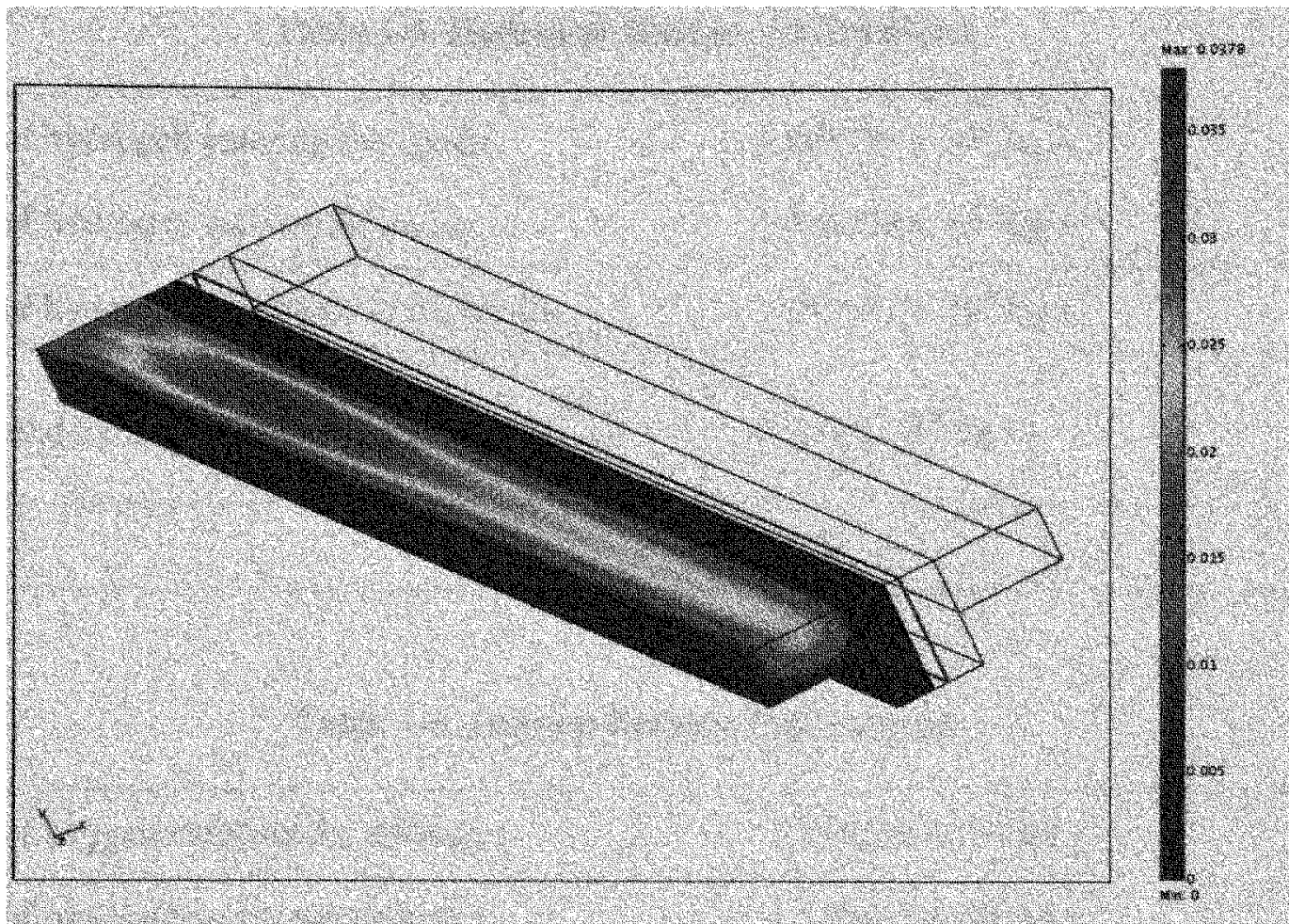

Figure 5-5 IIydrogen Flux $\left(\mathrm{kg} \mathrm{m}^{-2} \mathrm{~s}^{-1}\right)$
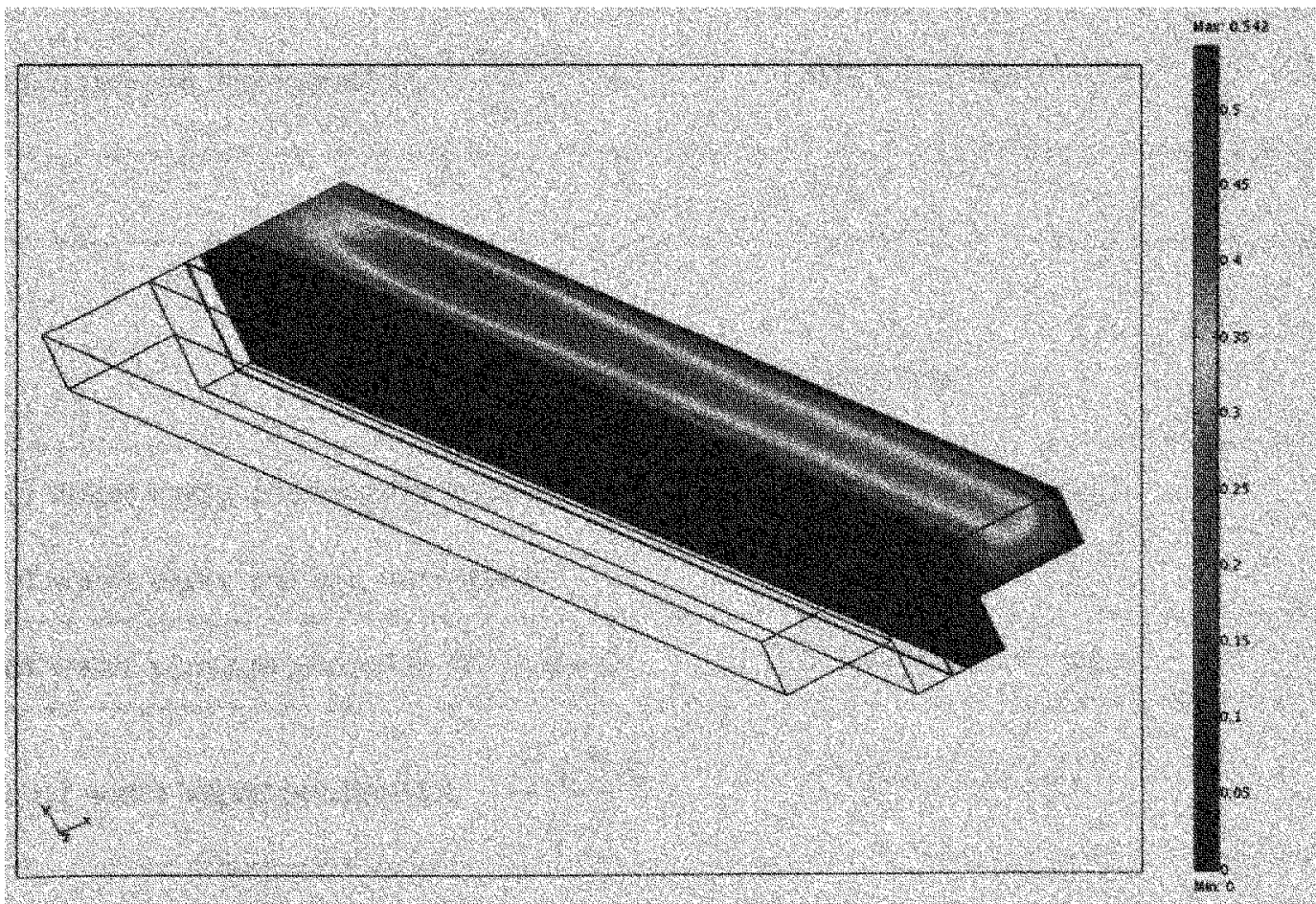

Figure 5-6 Oxygen Flux $\left(\mathrm{kg} \mathrm{m}^{-2} \mathrm{~s}^{-1}\right)$ 
Table 5-5 Hydrogen Balance Calculations

\begin{tabular}{ll}
$\begin{array}{l}\text { Rate of hydrogen entering the anode } \\
\text { Rate of hydrogen leaving the anode }\end{array}$ & $\begin{array}{l}5.005789 \times 10^{-9} \mathrm{~kg} \mathrm{~s}^{-1} \\
3.746738 \times 10^{-9} \mathrm{~kg} \mathrm{~s}^{-1}\end{array}$ \\
\hline Rate of hydrogen consumed at the anode & $1.259051 \times 10^{-9} \mathrm{~kg} \mathrm{~s}^{-1}$ \\
\hline Expected hydrogen consumption, $\frac{i A_{\text {mea }} M_{H_{2}}}{2 \mathrm{~F}}$ & $1.258 \times 10^{-9} \mathrm{~kg} \mathrm{~s}^{-1}$ \\
\hline Error & $0.1 \%$ \\
\hline
\end{tabular}

Table 5-6 Oxygen Balance Calculations

Rate of oxygen entering the cathode

$7.735732 \times 10^{-8} \mathrm{~kg} \mathrm{~s}^{-1}$

Rate of oxygen leaving the cathode

$6.735613 \times 10^{-8} \mathrm{~kg} \mathrm{~s}^{-1}$

Rate of oxygen consumed at the cathode

$1.000119 \times 10^{-8} \mathrm{~kg} \mathrm{~s}^{-1}$

Expected oxygen consumption, $\frac{i A_{\text {mea }} M_{O_{2}}}{4 F} \quad 1.007 \times 10^{-8} \mathrm{~kg} \mathrm{~s}^{-1}$

Error

$0.7 \%$

\section{Table 5-7 Water Balance Calculations}

Rate of water vapor entering the cathode

$0.3151914 \times 10^{-8} \mathrm{~kg} \mathrm{~s}^{-1}$

Rate of water vapor leaving the cathode

$1.436656 \times 10^{-8} \mathrm{~kg} \mathrm{~s}^{-1}$

Rate of water vapor produced at the cathode

$1.1214646 \times 10^{-8} \mathrm{~kg} \mathrm{~s}^{-1}$

Expected water vapor production, $\frac{i A_{\text {mea }} M_{\mathrm{H}_{2} \mathrm{O}}}{2 \mathrm{~F}} \quad 1.13284 \times 10^{-8} \mathrm{~kg} \mathrm{~s}^{-1}$ 


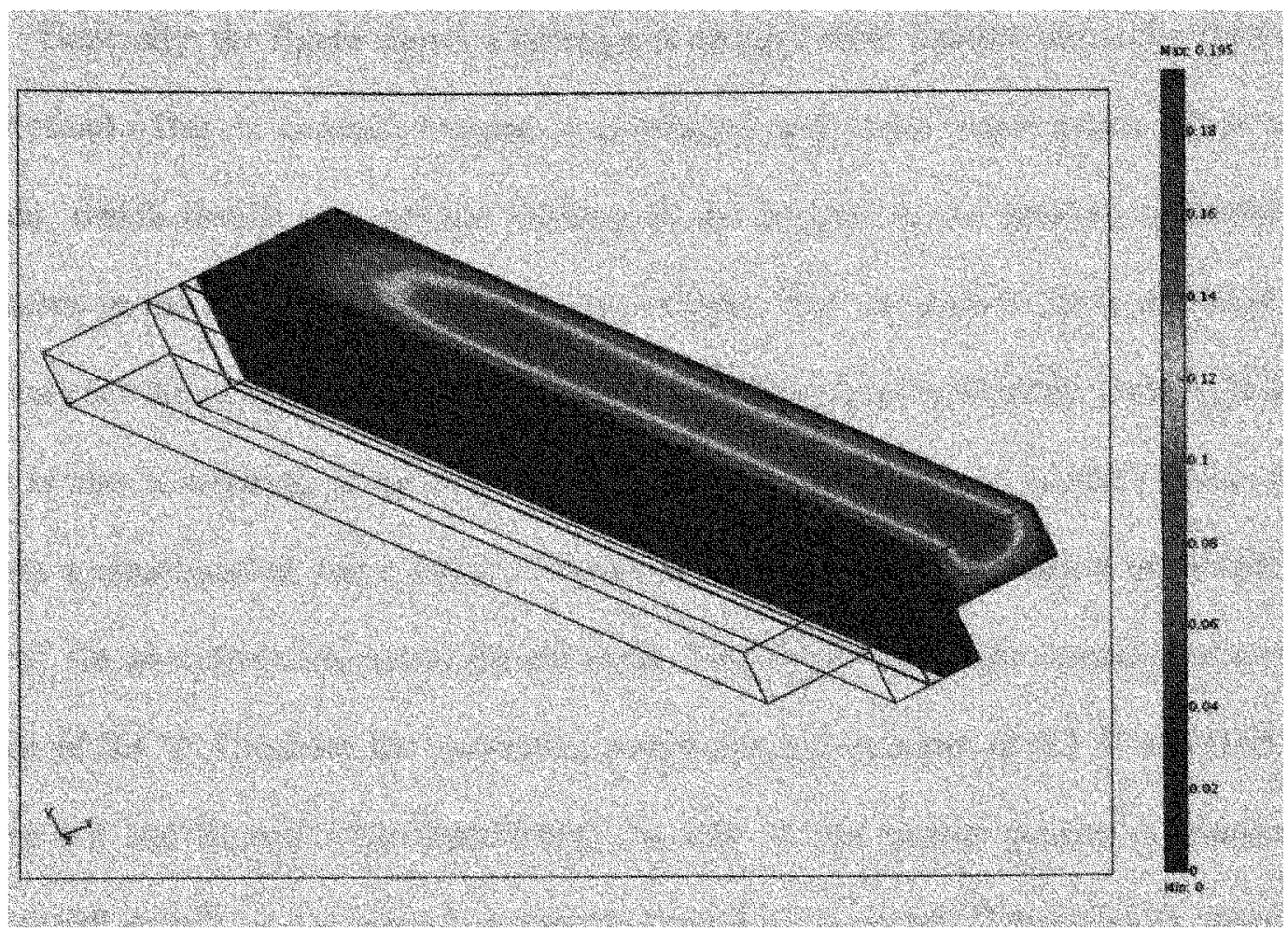

Figure 5-7 Water Vapor Flux $\left(\mathrm{kg} \mathrm{m}^{-2} \mathrm{~s}^{-1}\right)$

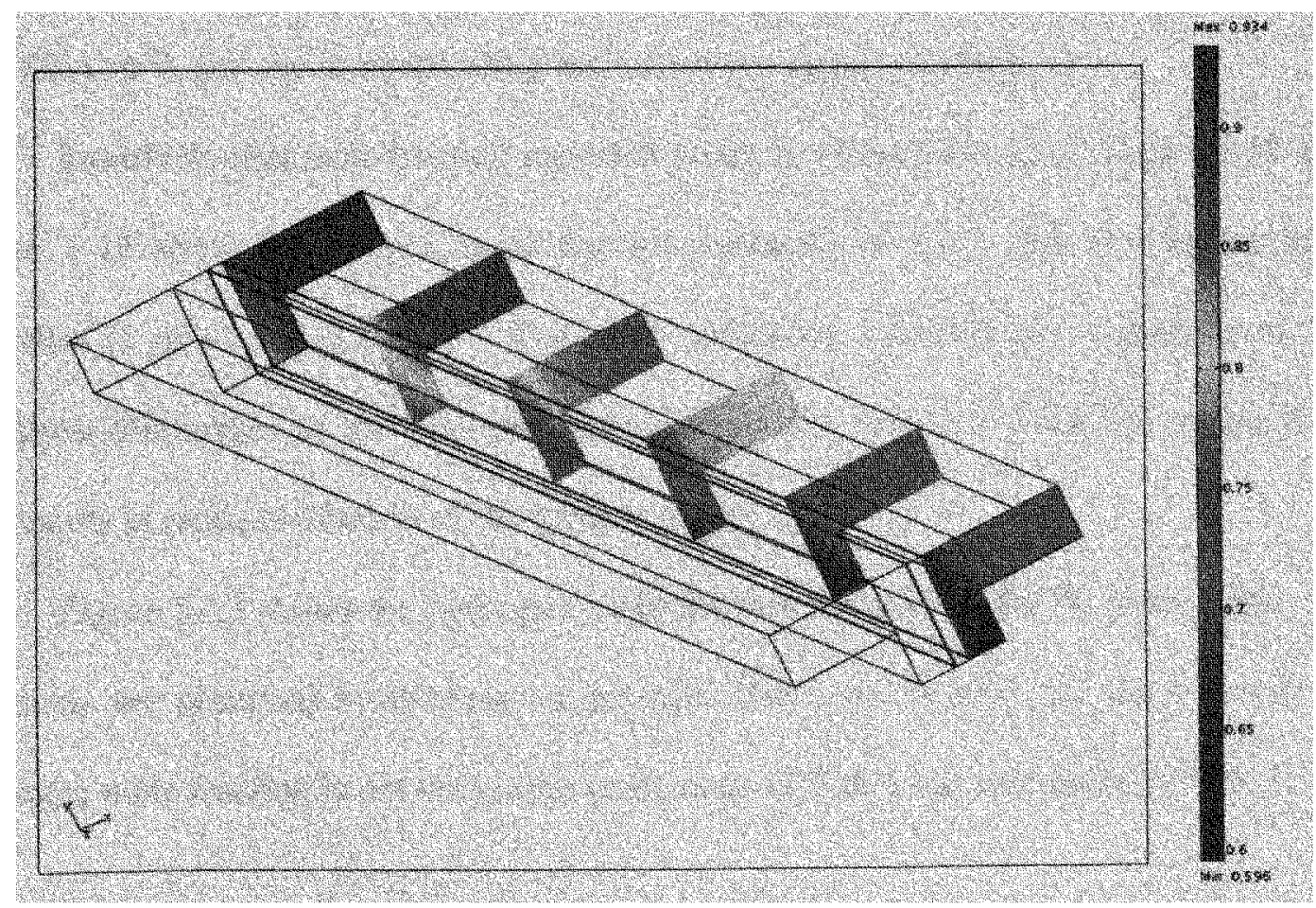

Figure 5-8 Oxygen Mole Fraction, 0.4 V 
Generally, the figure shows a decrease in oxygen mole fraction along the channel (z-direction). This is because oxygen is consumed and water vapor produced at the cathode, which results in a general diluting of the oxygen in the positive z-direction. Variations in the $\mathrm{x}$ and $\mathrm{y}$-directions are also evident. The variation in the $\mathrm{x}$-direction is necessary for the oxygen to diffuse (against the bulk fluid flow) toward the catalyst layer. There is also a variation in the y-direction, since there is an oxygen scarcity across the ribs. As a consequence, there exists a region of low oxygen concentration in the MEA "below" (in an x-direction sense) the rib areas. This figure shows the variation at a cell voltage of $0.4 \mathrm{~V}$. Consider the equivalent results for cell voltages of $0.1 \mathrm{~V}$ and $0.65 \mathrm{~V}$ (Figure 5-9 and Figure 5-10 respectively). At $0.65 \mathrm{~V}$, the current density is relatively small $\left(1670 \mathrm{~A} \mathrm{~m}^{-2}\right)$, and as a result not much oxygen is consumed. Consequently, there is a small variation in mole fraction. At $0.1 \mathrm{~V}$, on the other hand, the current density is high $\left(10,180 \mathrm{~A} \mathrm{~m}^{-2}\right)$, and the corresponding mole fraction variation is large.

Intuitively this mole fraction variation depends on the flow rates. Figure 5-11 and Figure 5-12 show the oxygen mole fraction variation at $0.4 \mathrm{~V}$ for two higher inlet velocities $\left(1 \mathrm{~m} \mathrm{~s}^{-1}\right.$ and $\left.3.2 \mathrm{~m} \mathrm{~s}^{-1}\right)$. The same variations exist, but the magnitude of the variations diminishes as the flow rate increases. This is expected since the greater flow rate results in reduced dilution of the oxygen stream.

Figure 5-13 shows the hydrogen mole fraction variation at $0.4 \mathrm{~V}$. Once again, the variations are observed in all three co-ordinate directions. In this case the variation in hydrogen mole fraction is not very large (maximum of 0.964 and minimum of 0.951 ). 


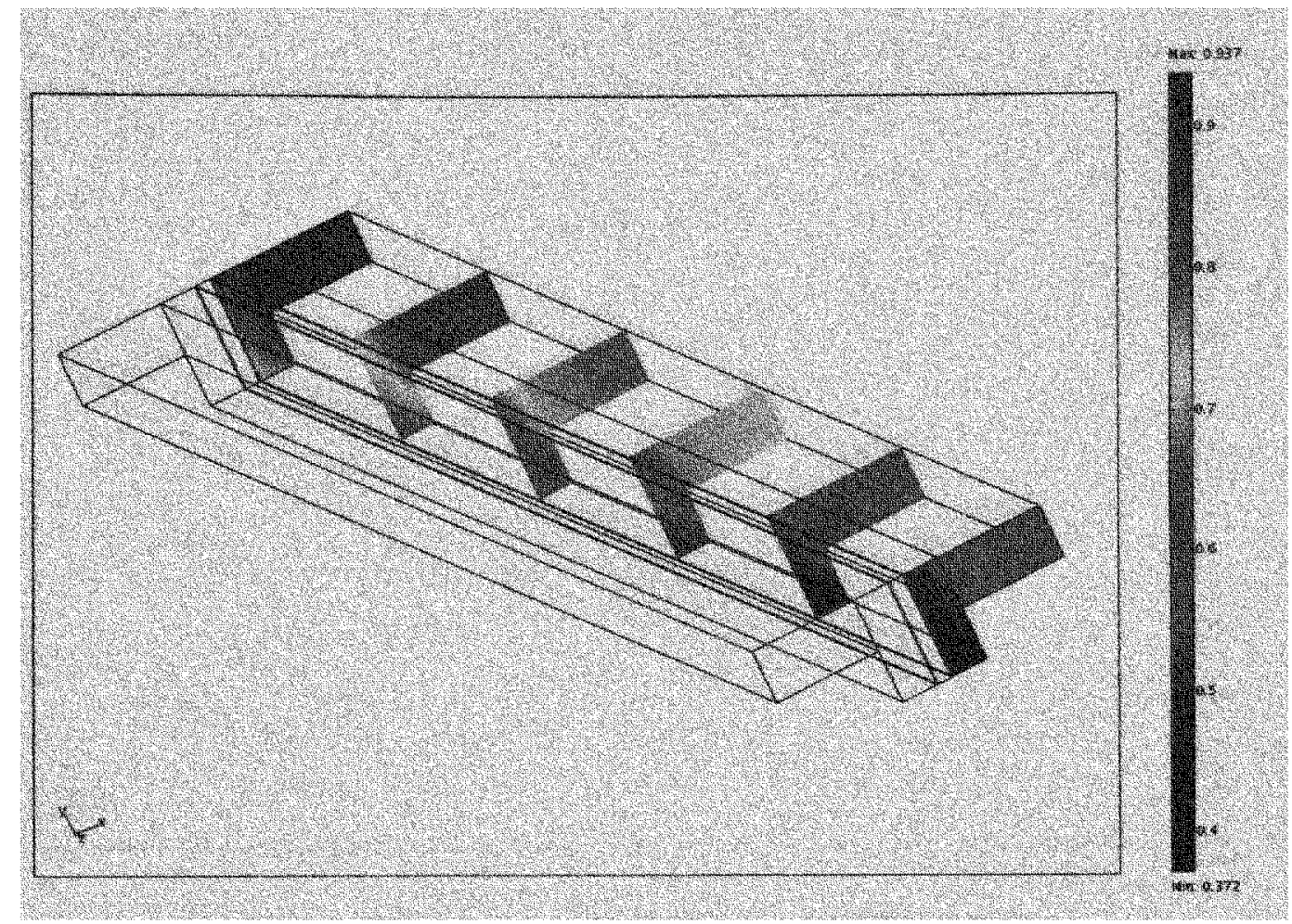

Figure 5-9 Oxygen Mole Fraction, $0.1 \mathrm{~V}$

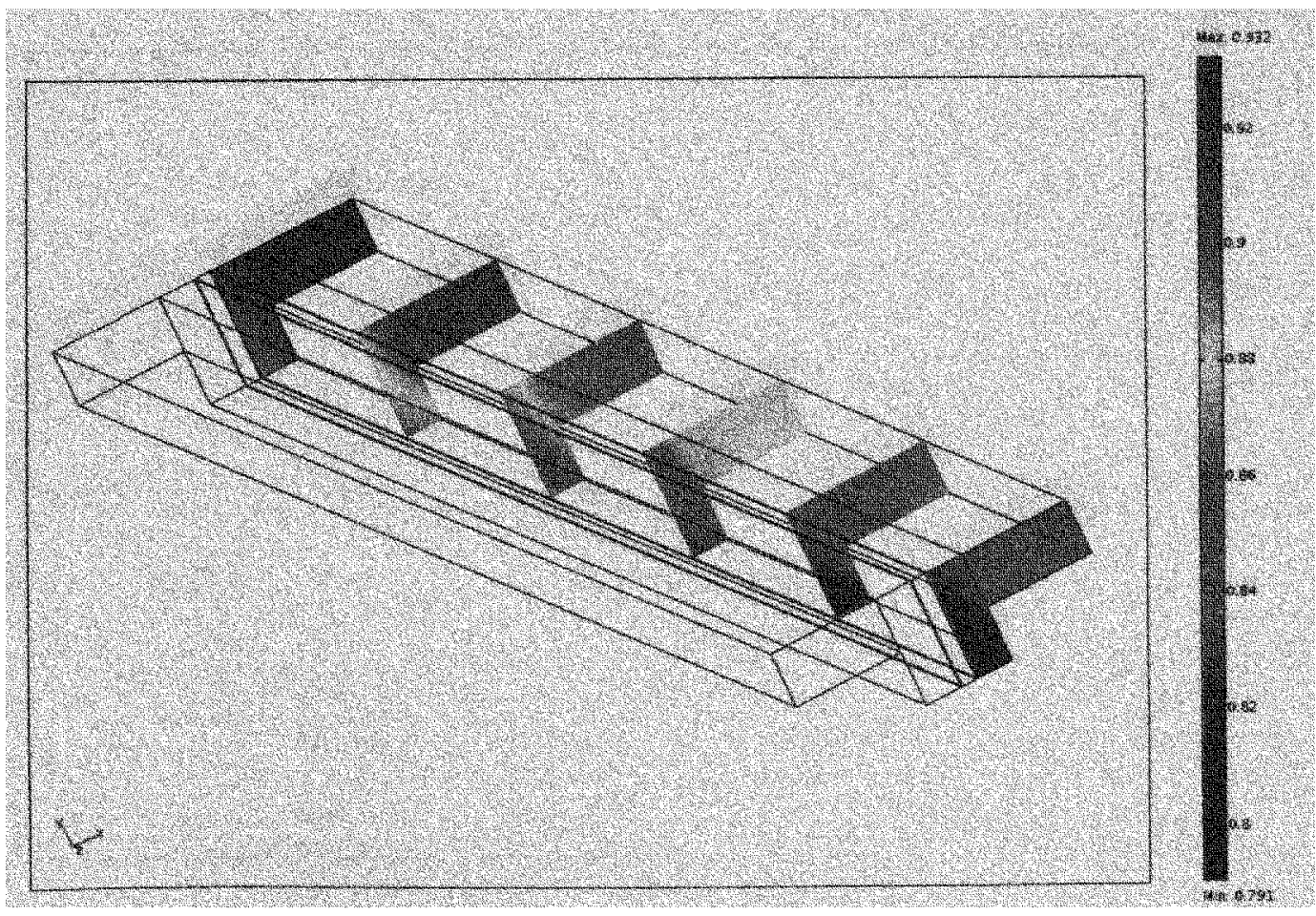

Figure 5-10 Oxygen Mole Fraction, 0.65 V 


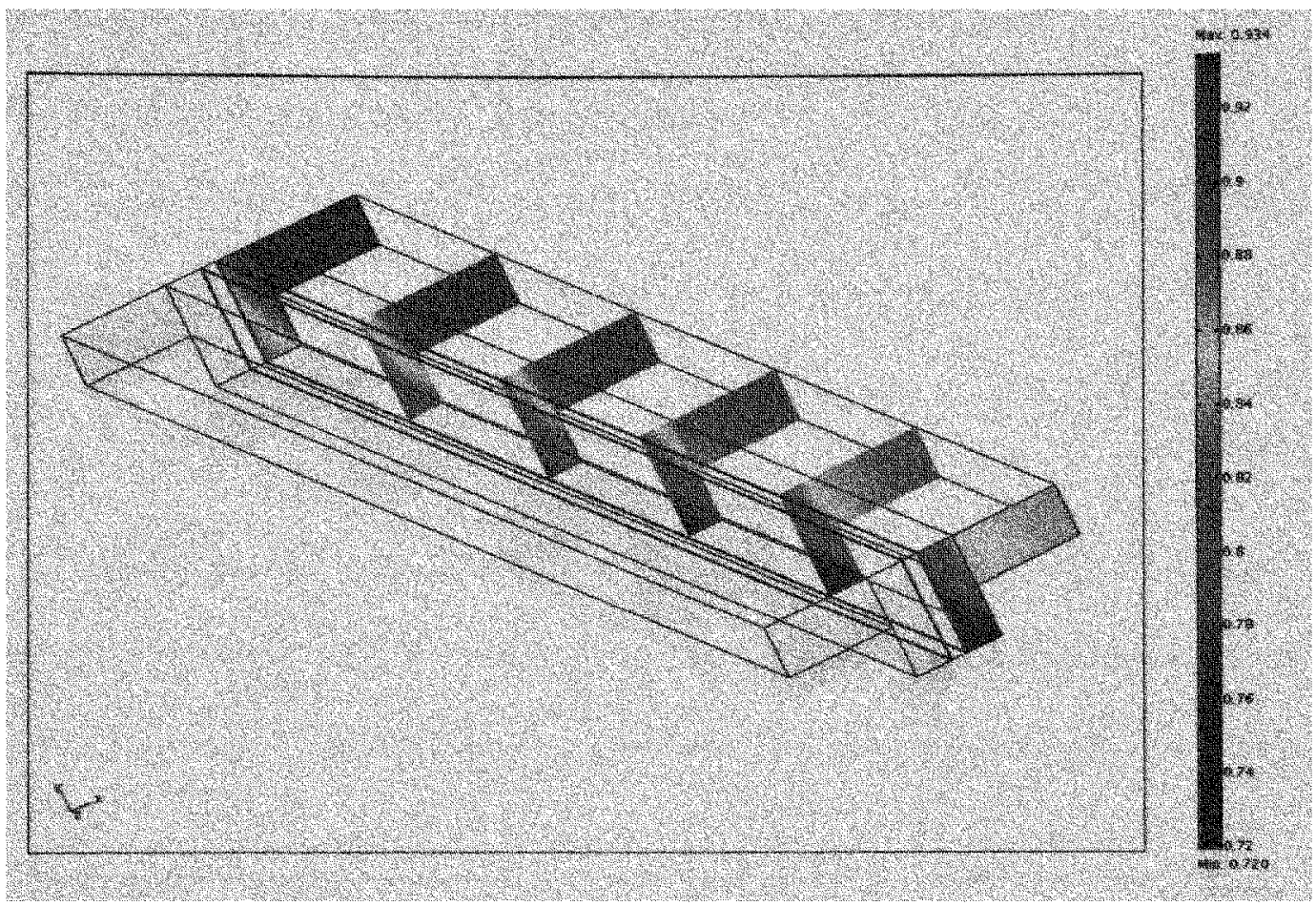

Figure 5-11 Oxygen Mole Fraction, $0.5 \mathrm{~L} \mathrm{~min}{ }^{-1}$

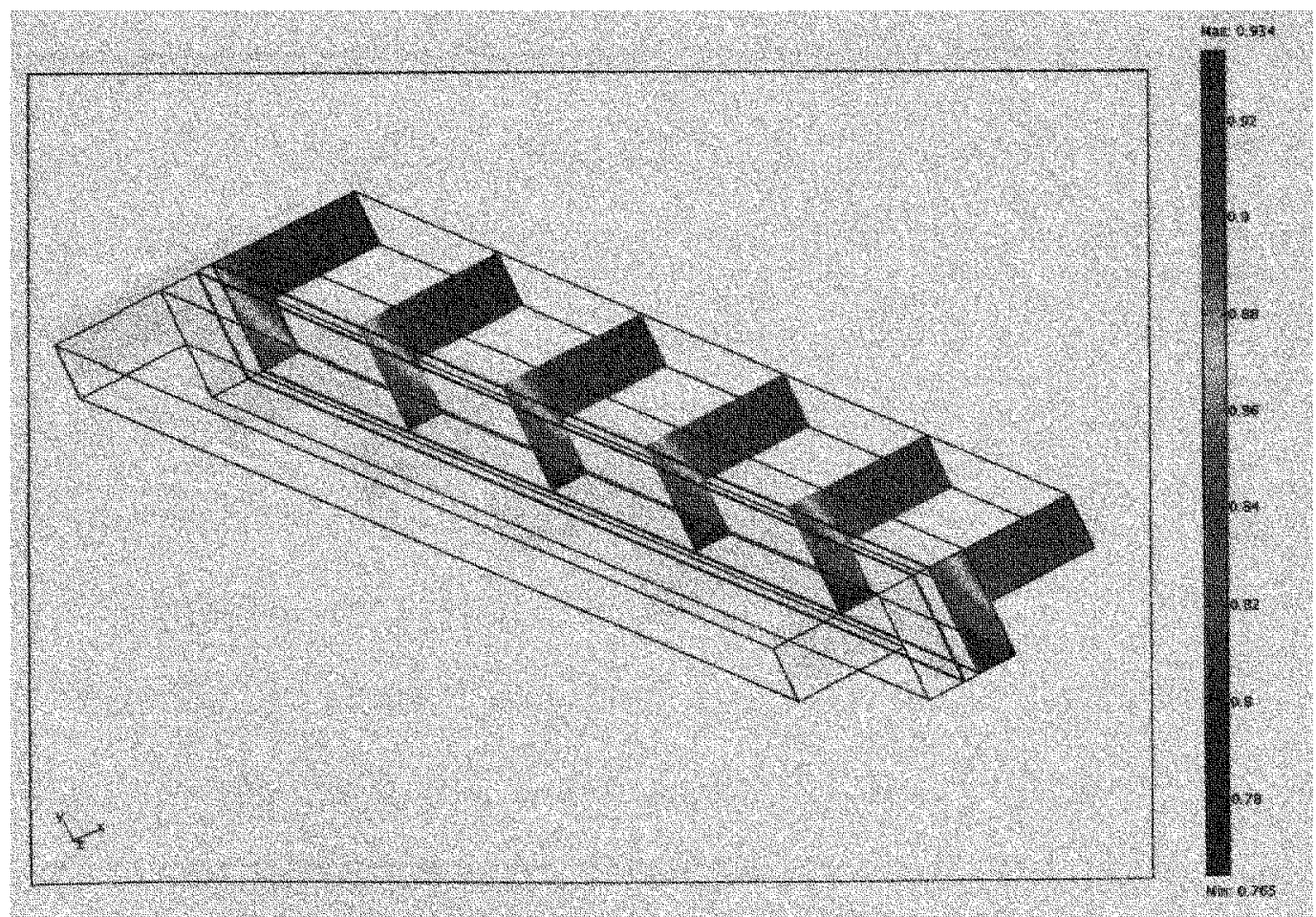

Figure 5-12 Oxygen Mole Fraction, 1.6 $\mathrm{L} \mathrm{min}{ }^{-1}$ 

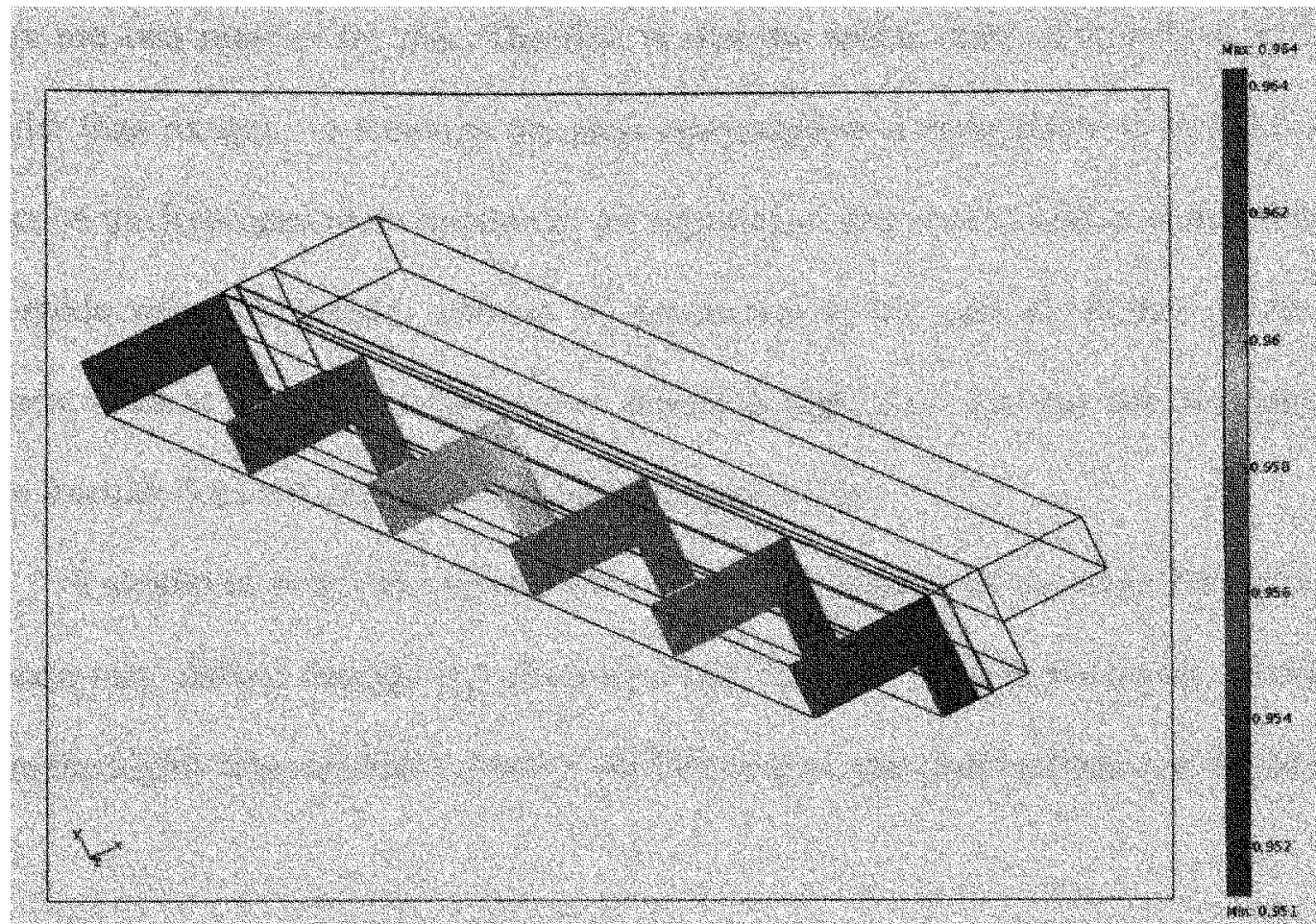

Figure 5-13 Hydrogen Mole Fraction, 0.4 V

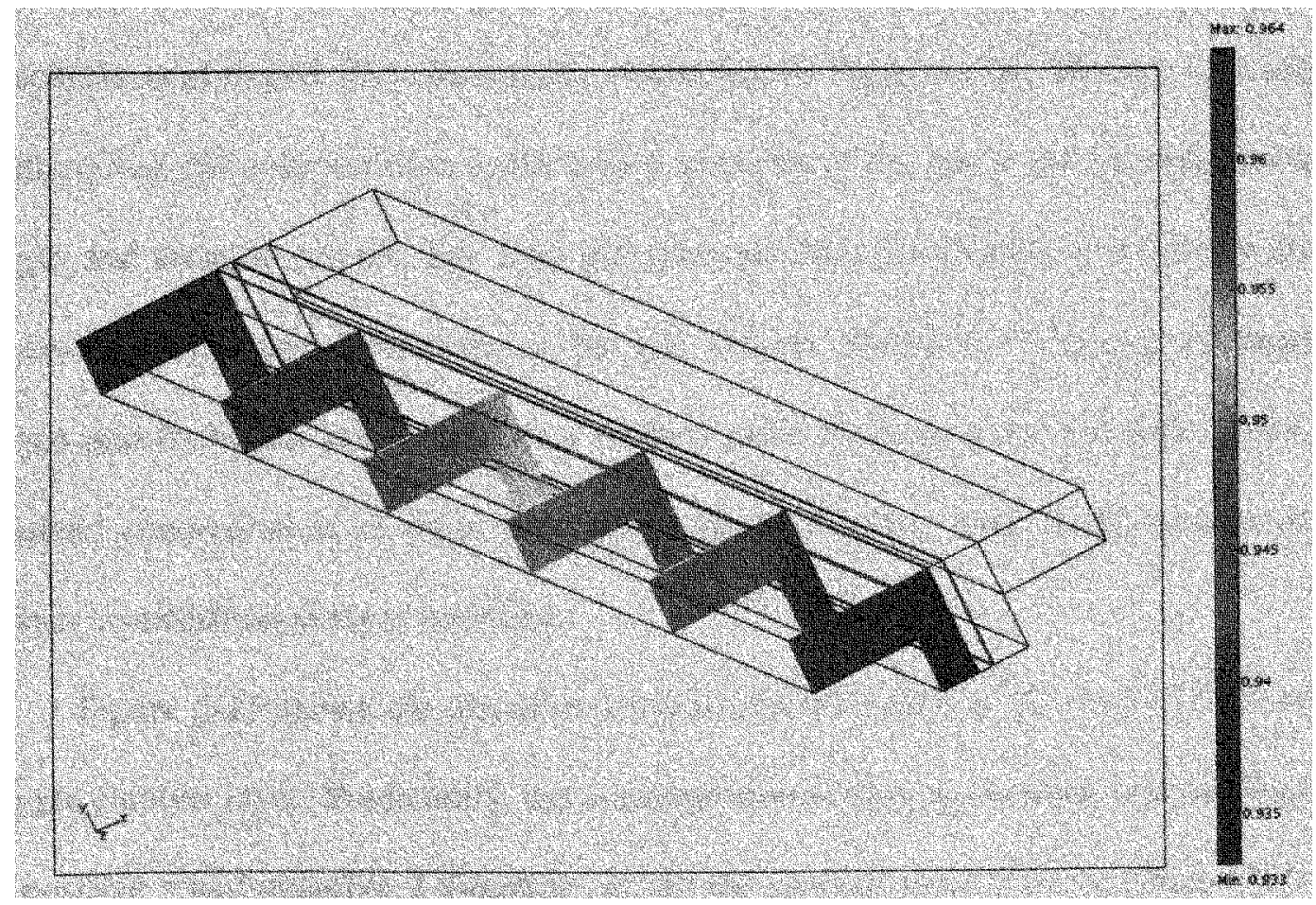

Figure 5-14 Hydrogen Mole Fraction, $0.1 \mathrm{~V}$ 
There are two reasons for this. The first is that the molar mass of hydrogen is much smaller than oxygen, so although the mass consumption is comparable to oxygen's, the effect on the hydrogen mole fraction is not significant. The second reason is that water is not produced at the anode, whereas its production at the cathode further dilutes the oxygen. Even at $0.1 \mathrm{~V}$, when the current density is high, it is observed that the hydrogen mole fraction does not change significantly (Figure 5-14).

It should be noted that there is the possibility that some of the water formed at the cathode may diffuse through the electrolyte and flow out through the anode. However, given the highly impermeable nature of the PBI system, this phenomenon was neglected.

\subsubsection{Concentration}

In this model, Henry's Law was assumed to govern the dissolution of gases in the phosphoric acid doped PBI electrolyte. According to Equation (8), Henry's law relates the dissolved gas concentration to the partial pressure of the gas at the interface between the gas and solution phases. The total gas pressure does not change significantly due to the low viscosity and flow rates of the gas species, therefore the partial pressure of oxygen and hydrogen are proportional to their mole fraction at the interface. Thus, the dissolved concentration of these reactants is proportional to their mole fraction at the catalyst layer/diffusion layer interface.

Figure 5-15 shows the dissolved oxygen concentration at the outer surface of the cathode catalyst layer. Predictably, the concentration is high at the inlet, and decreases in the positive $\mathrm{z}$ and negative $\mathrm{y}$-direction, as did the oxygen mole fraction (Figure 5-8, pp. 77). 


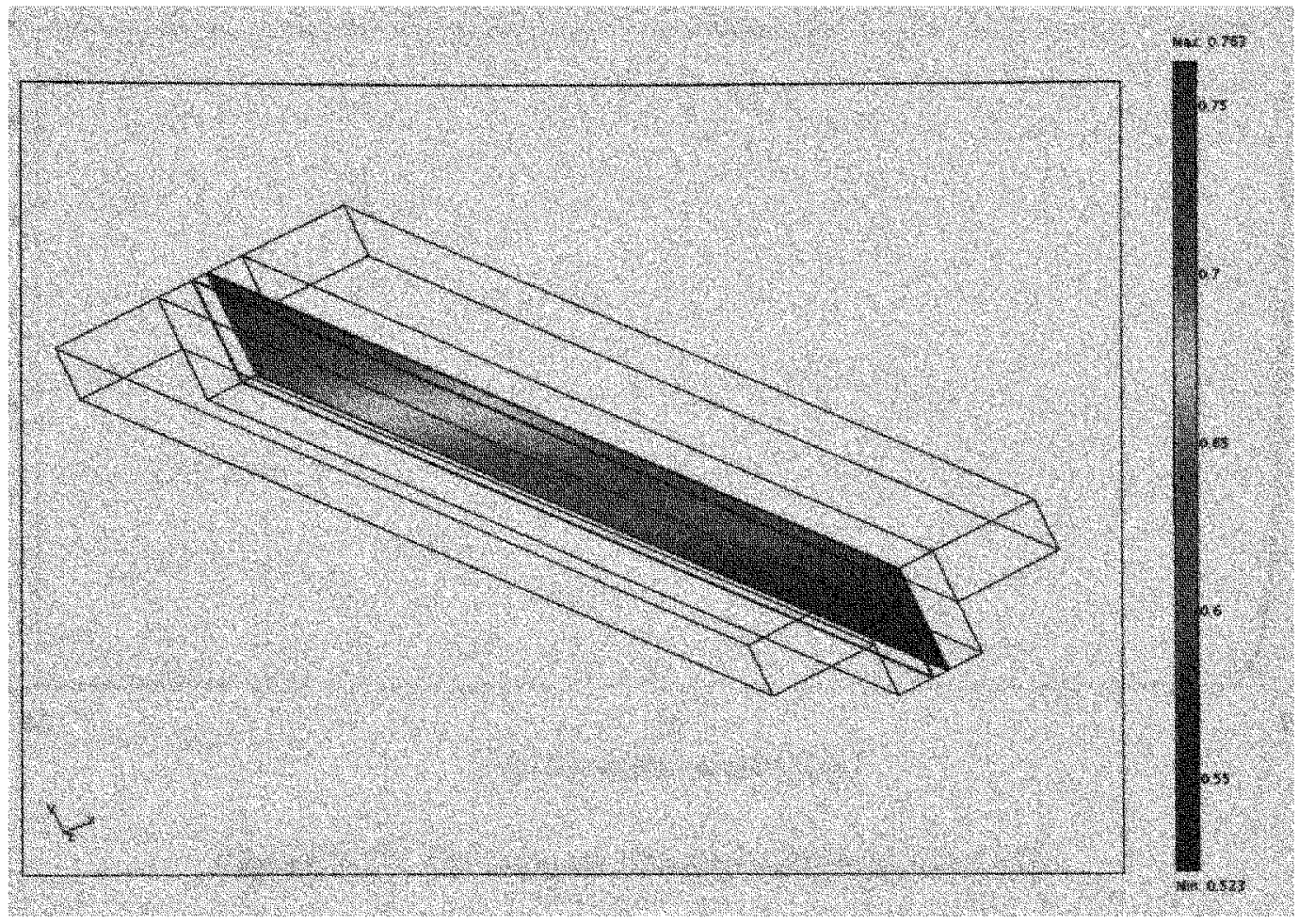

Figure 5-15 Oxygen Concentration $\left(\mathrm{mol} \mathrm{m}^{-3}\right)$ on outer Surface of CCL
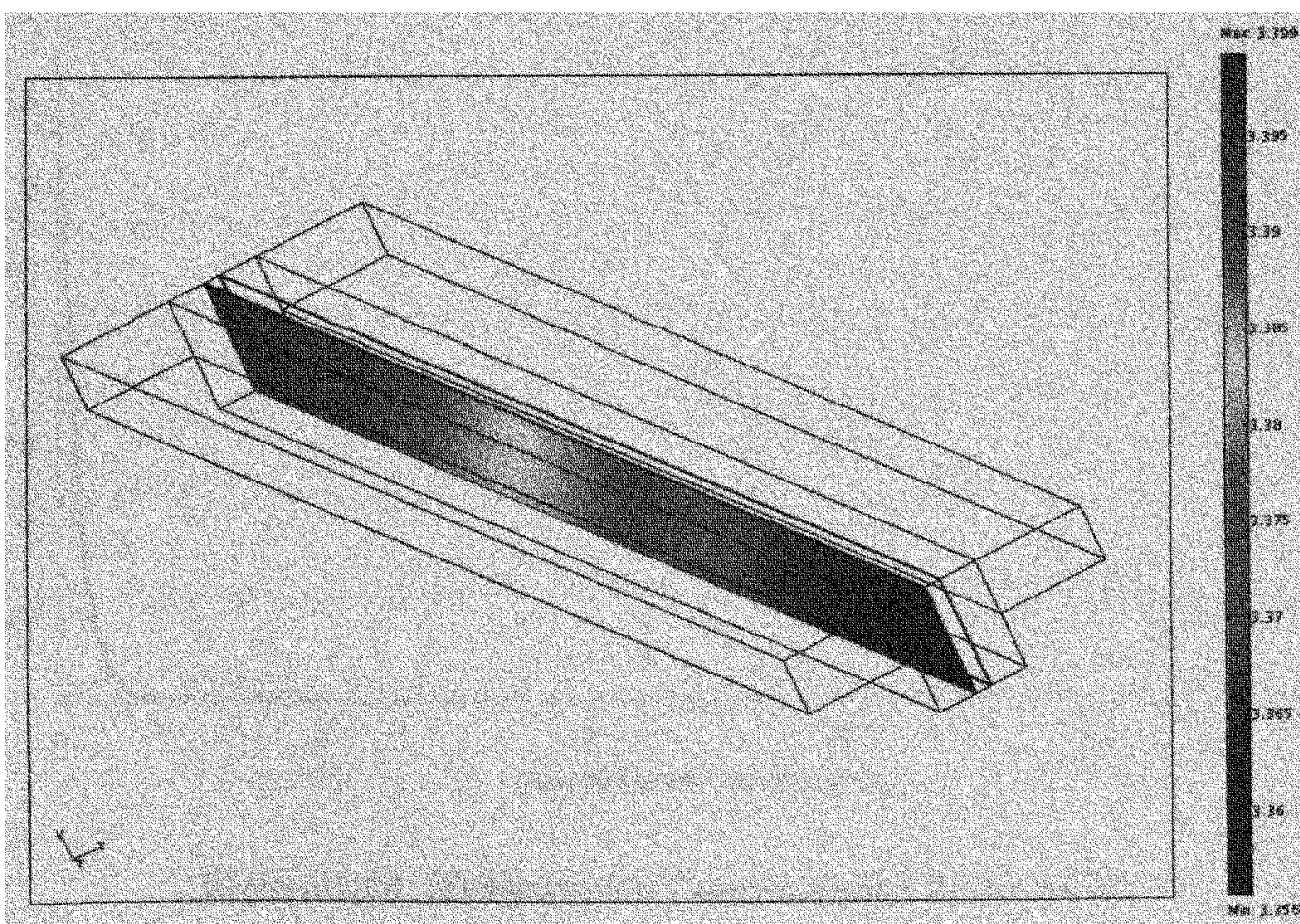

Figure 5-16 Hydrogen Concentration $\left(\mathrm{mol} \mathrm{m}^{-3}\right)$ on outer Surface of ACL 


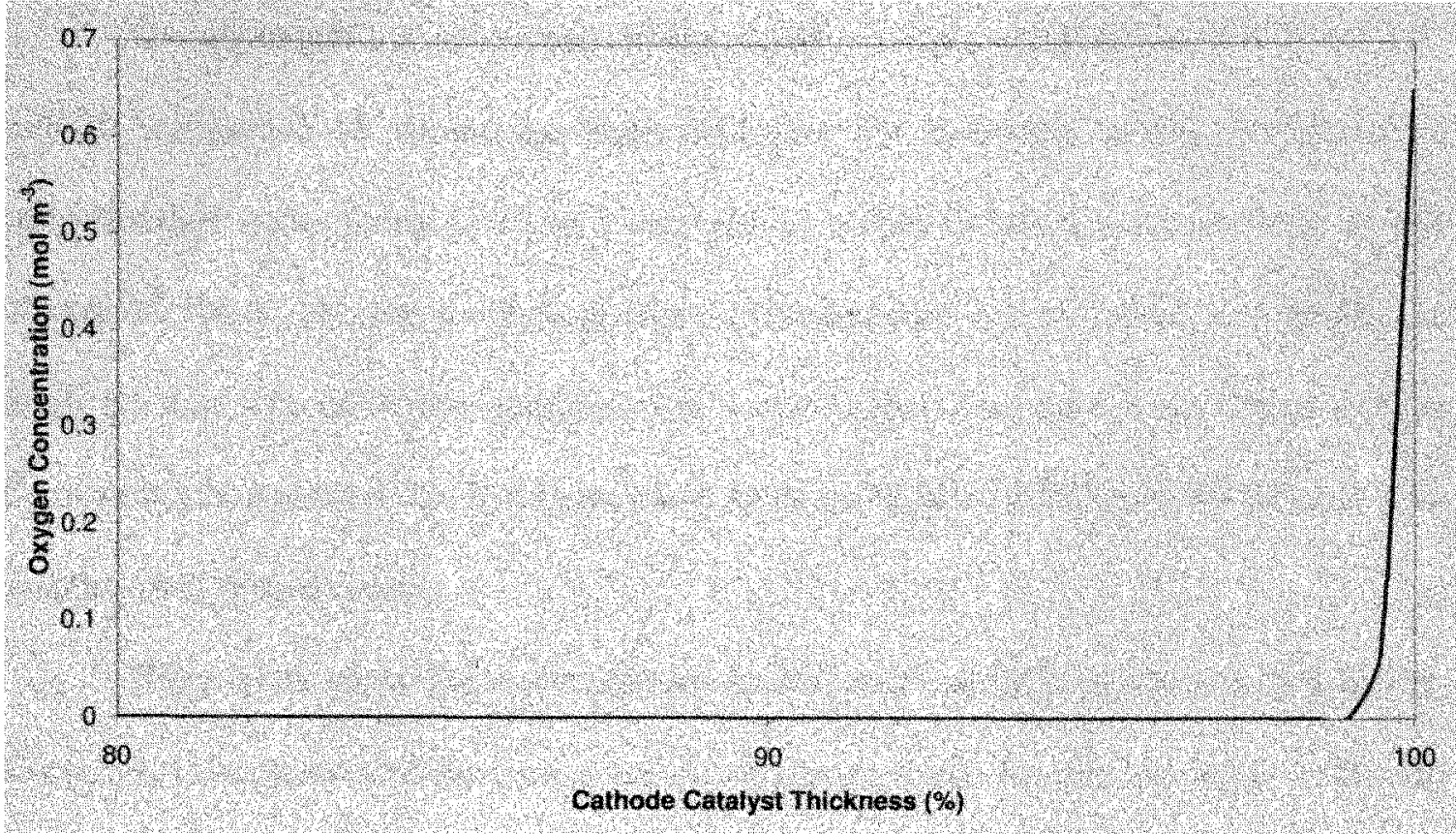

Figure 5-17 1D Oxygen Concentration in the CCL

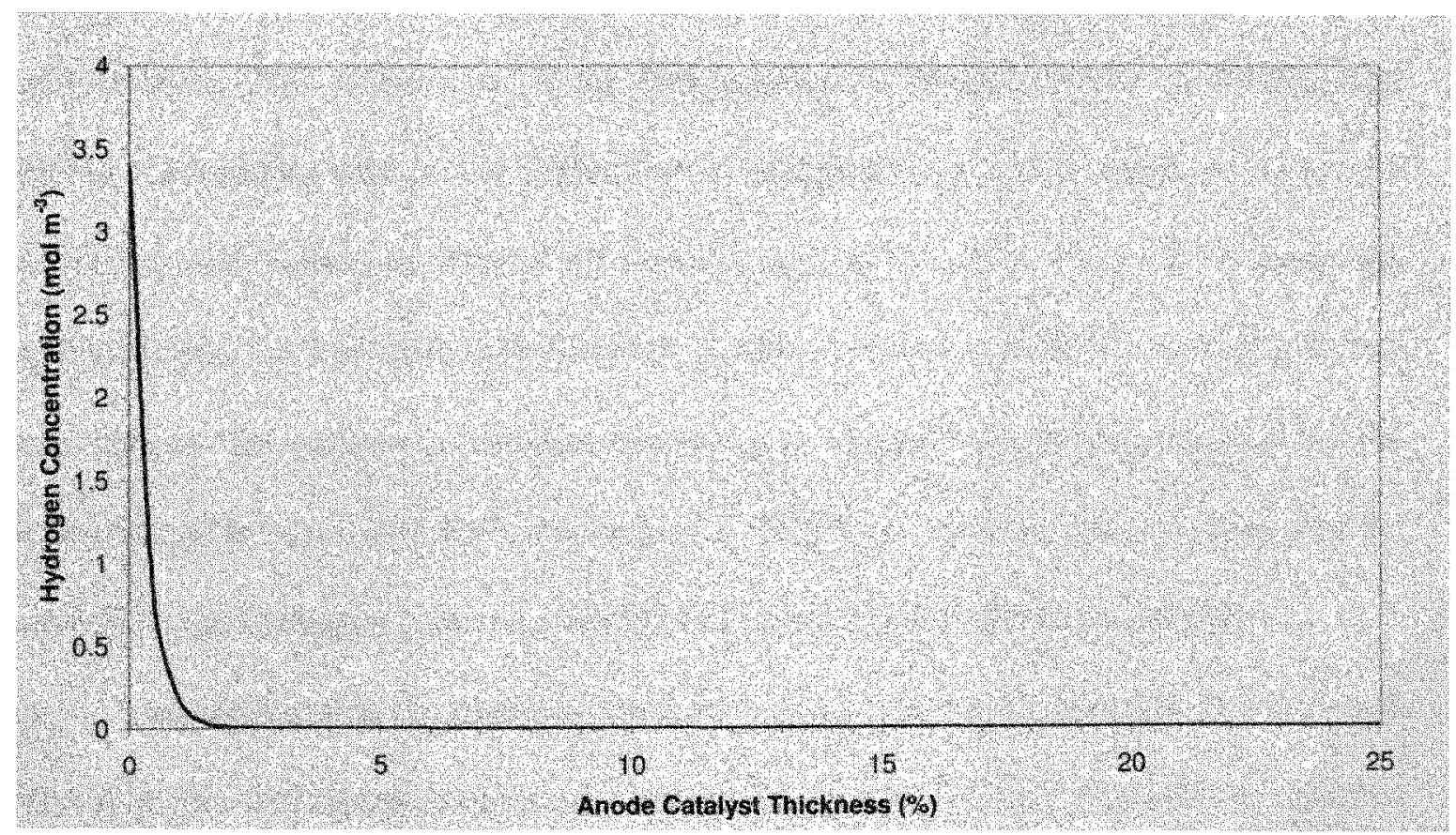

Figure 5-18 1D Hydrogen Concentration in the ACL 
The concentration of oxygen on the catalyst surface varies from 0.763 to 0.523 $\mathrm{mol} \mathrm{m}^{-3}$. Figure 5-16 shows the equivalent plot for hydrogen, where the dissolved concentration varies from 3.399 to $3.356 \mathrm{~mol} \mathrm{~m}^{-3}$. This variation is not as large as the oxygen variation, because the hydrogen mole fraction does not vary significantly (Figure $5-13$, pp. 81). The hydrogen concentration is also higher than the oxygen concentration because it was assumed that hydrogen has 4.44 times higher solubility in phosphoric acid systems than does oxygen.

These plots show the concentration on the outer surfaces of the catalyst layers. However, visualization of the concentration variations inside the catalyst layer is difficult in $3 \mathrm{D}$ because of the geometric aspect ratio. Figure 5-17 shows a 1D plot of the oxygen variation in the $\mathrm{x}$-direction across the catalyst layer at $0.4 \mathrm{~V}$ (oxygen flowing from right to left). It shows that the oxygen concentration falls to zero within the outer $1 \%$ of the catalyst layer. This is because of the consumption of oxygen in the electrochemical reactions, combined with its low diffusivity in phosphoric acid. This signifies that for the optimum power condition, $99 \%$ of the cathode catalyst is wasted. Figure 5-18 shows the equivalent plot for hydrogen concentration (hydrogen flowing from left to right). In this case, $2 \%$ of the catalyst is utilized, catalyst utilization being roughly defined as the percentage of the catalyst which experiences a "non-zero" reactant concentration. For the inner $98 \%$, the hydrogen concentration is zero, and hence no reaction takes place.

Considering that the platinum catalyst is one of the most expensive elements in a PEM fuel cell, this represents a major opportunity for cost savings. Typically the catalyst is loaded at $0.5 \mathrm{mg} \mathrm{cm}^{-2}$ of MEA, and this catalyst is spread out across the entire thickness (of $10 \mu \mathrm{m}$ ). That means, that at the cathode, only $0.005 \mathrm{mg} \mathrm{cm}^{-2}$ of catalyst is 
being utilized, and at the anode, $0.01 \mathrm{mg} \mathrm{cm}^{-2}$. Hypothetically, if the inner $90 \%$ of the catalyst layers were not present, i.e. if only $0.05 \mathrm{mg} \mathrm{cm}^{-2}$ of catalyst were loaded (over a thickness of $1 \mu \mathrm{m}$ ), then the performance of the fuel cell would be unaffected and $90 \%$ of the cost of the catalyst would be saved. In this hypothetical case, the catalyst utilization would now be 10 and $20 \%$ at the cathode and anode respectively. It should be noted that catalyst utilization of $100 \%$ is not desirable, because once the reactant is able to entirely permeate the catalyst, there is a likelihood of reactant crossover and direct mixing. Direct reaction between oxygen and hydrogen in the membrane would result in localized heating and eventually mechanical degradation.

The cost saving technique identified by the results in this section, involves distributing a lesser amount of catalyst over a thinner layer (say $1 \mu \mathrm{m}$ ). This would result in a $90 \%$ cost savings, without compromising the performance of the fuel cell. However, advanced manufacturing techniques are needed to deposit the catalyst over such a thin region. This may involve nano-deposition techniques (e.g. plasma sputtering or evaporation methods), or electro-deposition methods (e.g. pulsed electrodeposition [126]). Further research is needed in this area. Whatever the choice of method, it must not compromise the integrity of the polymer material components of the fuel cell. Note that other fuel cell models have reported thicker catalyst layers than $10 \mu \mathrm{m}$. Appendix $\mathrm{C}$ shows mathematically, that employing thicker catalyst layers results in even lower catalyst utilization.

Figure 5-19 and Figure 5-20 show the 2D (x-z) variation of oxygen and hydrogen concentration on the outer $1 \%$ of the cathode and anode catalyst layers respectively. These figures are greatly exaggerated in the $x$-direction to enhance visualization. These 
figures are shown in the $x-z$ plane at $y=3.75 \times 10^{-4} \mathrm{~m}$, i.e. in line with the rib/channel interface. In the case of oxygen, the initial contour lines are diagonally slanted, because 1) there is a concentration decrease on the outer surface (right side) in the positive zdirection, and 2) the concentration decreases in the negative $\mathrm{x}$-direction as oxygen is consumed in the electrochemical reactions. The contours show that the oxygen concentration falls to a negligibly low value within the outer $1 \%$.

For the case of hydrogen, the initial concentration on the surface (left side) is approximately constant, so the only variation is in the $\mathrm{x}$-direction as hydrogen is consumed. Within the outer $1 \%$ of the catalyst layer, the concentration falls from 3.4 to less than $0.25 \mathrm{~mol} \mathrm{~m}^{-3}$. The initial contour lines for hydrogen are parallel to the $\mathrm{z}$ direction, while as the reactant concentration decreases, the contour lines become more slanted. Species flux is perpendicular to the contour lines, thus it appears that there is a tendency for hydrogen to diffuse slightly in the negative z-direction. The oxygen concentration varies more significantly in the z-direction. Since the oxygen concentration is higher at the inlet $(z=0)$ than at the outlet, more of the electrochemical reactions take place on the inlet side at the cathode. So the protons must flow generally in a negative $z$ direction to reach the high reaction zones at the cathode. Figure 5-21 illustrates this tendency for the hydrogen to diffuse in the negative z-direction.

Figure 5-22 and Figure 5-23 show the $x-y$ variation of oxygen and hydrogen concentration in the catalyst layer, half way along the channels $\left(z=1.125 \times 10^{-2} \mathrm{~m}\right)$. Figure 5-22 shows the oxygen concentration falling to less than $0.01 \mathrm{~mol} \mathrm{~m} \mathrm{~m}^{-3}$ within the outer $1 \%$ of the catalyst layer. In this case, the initial concentration, at the channel midpoint, is less than $0.7 \mathrm{~mol} \mathrm{~m}^{-3}$. 


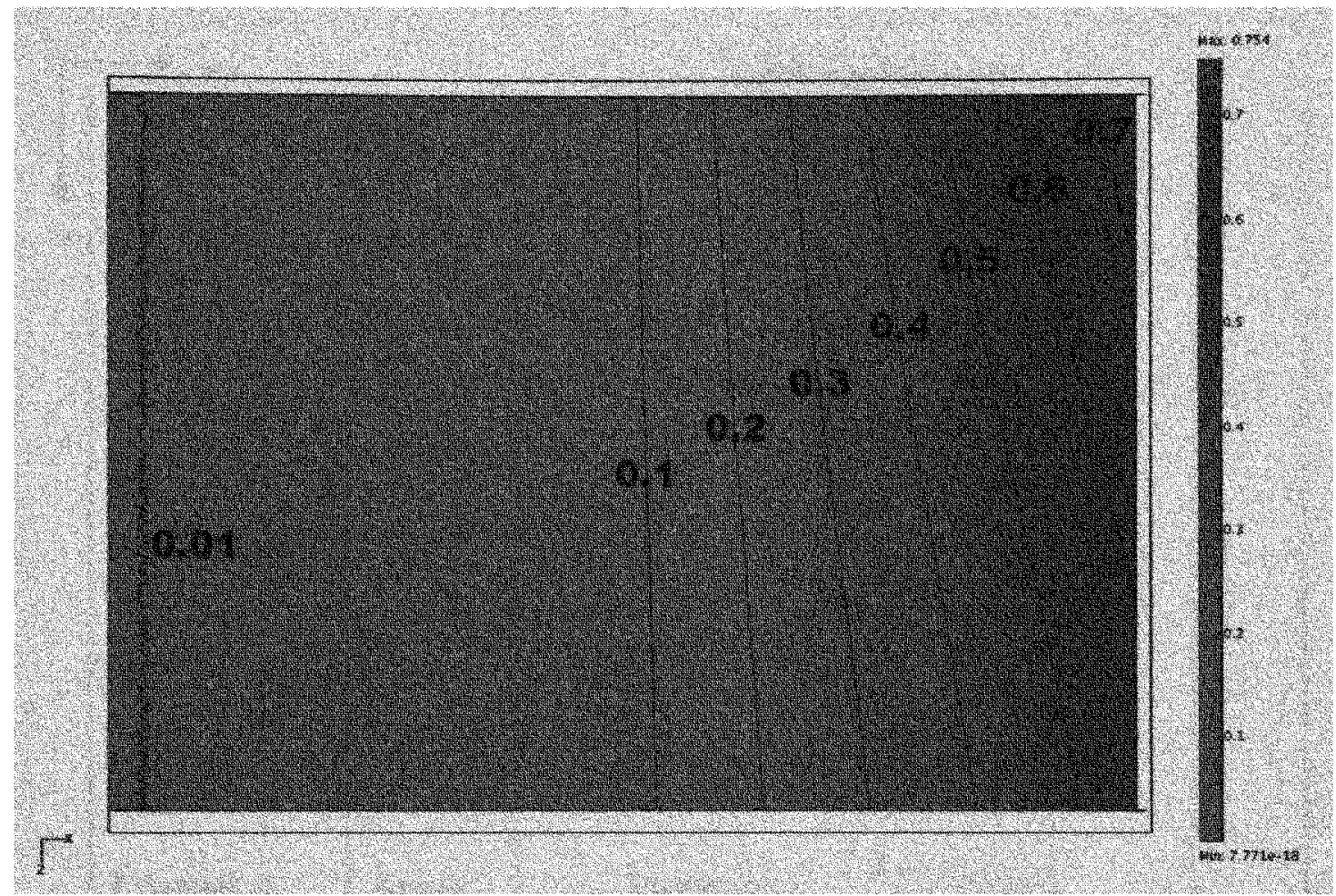

Figure 5-19 x-z Oxygen Concentration $\left(\mathrm{mol} \mathrm{m}^{-3}\right)$ in outer $1 \%$ of the CCL

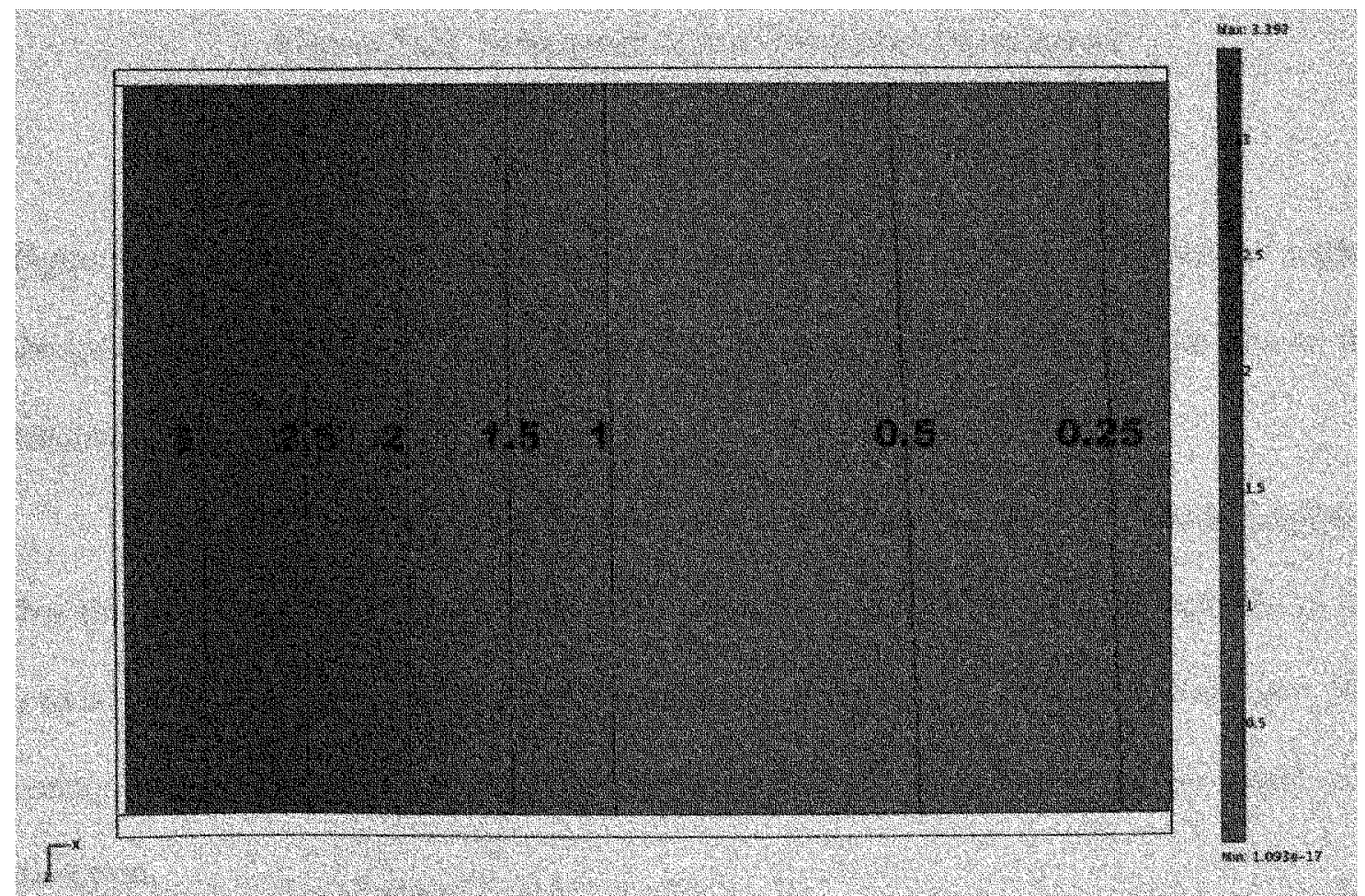

Figure 5-20 x-z Hydrogen Concentration $\left(\mathrm{mol} \mathrm{m}^{-3}\right)$ in outer $1 \%$ of the $\mathrm{ACL}$ 


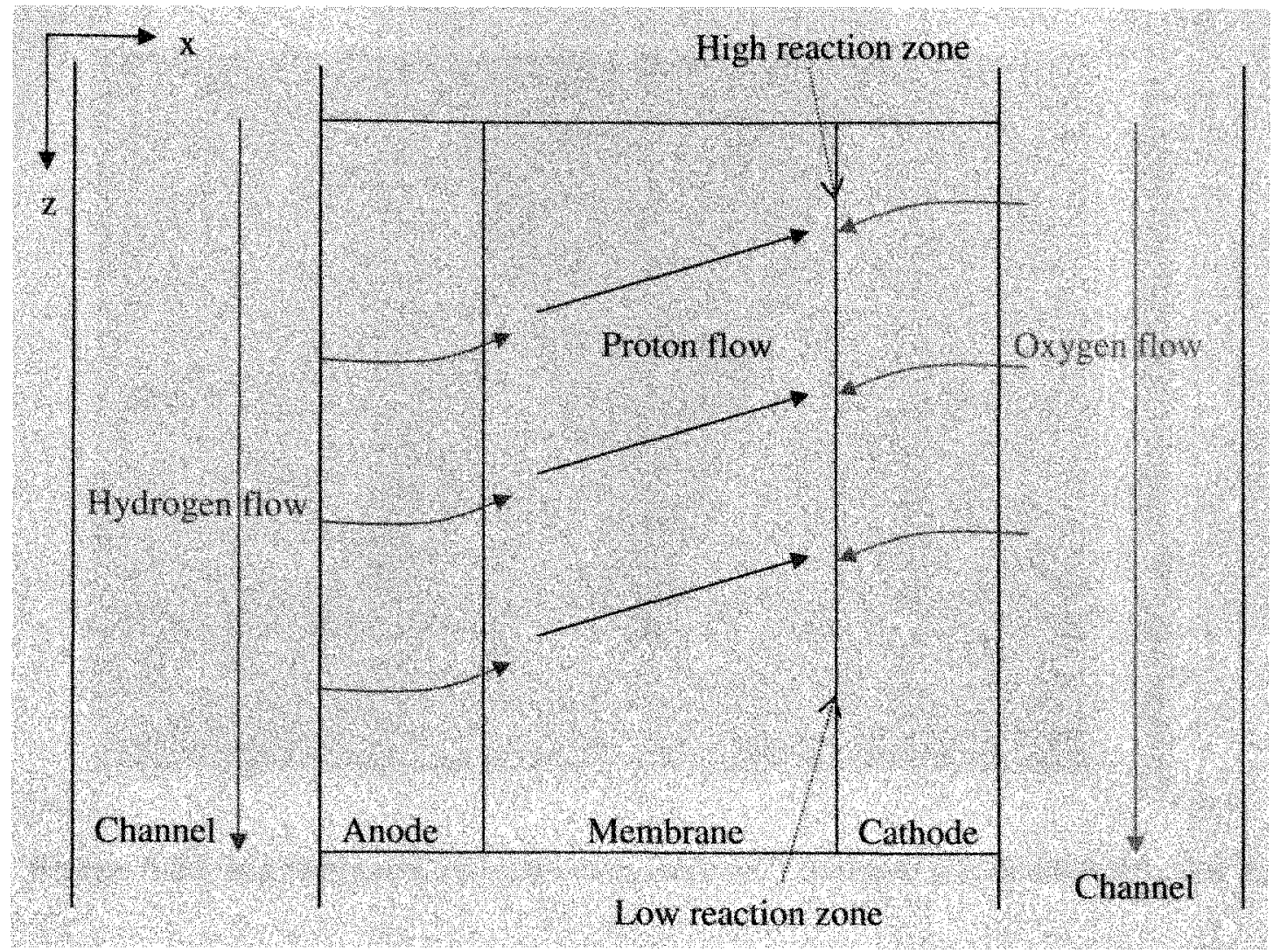

Figure 5-21 Schematic of x-z Transport Phenomena

Figure 5-23 shows the hydrogen concentration dropping to less than $0.25 \mathrm{~mol} \mathrm{~m}^{-3}$ within the outer $1 \%$ of the anode catalyst layer. These figures show the effect of the ribs on the reactant concentration.

The oxygen contour lines appear vertical and parallel with the y-axis, implying that the oxygen is diffusing through the catalyst layer in a direction perpendicular to the y-axis. The hydrogen contours on the other hand become slanted toward the low concentration region. This implies that hydrogen begins to diffuse toward the negative $y-$ direction. 


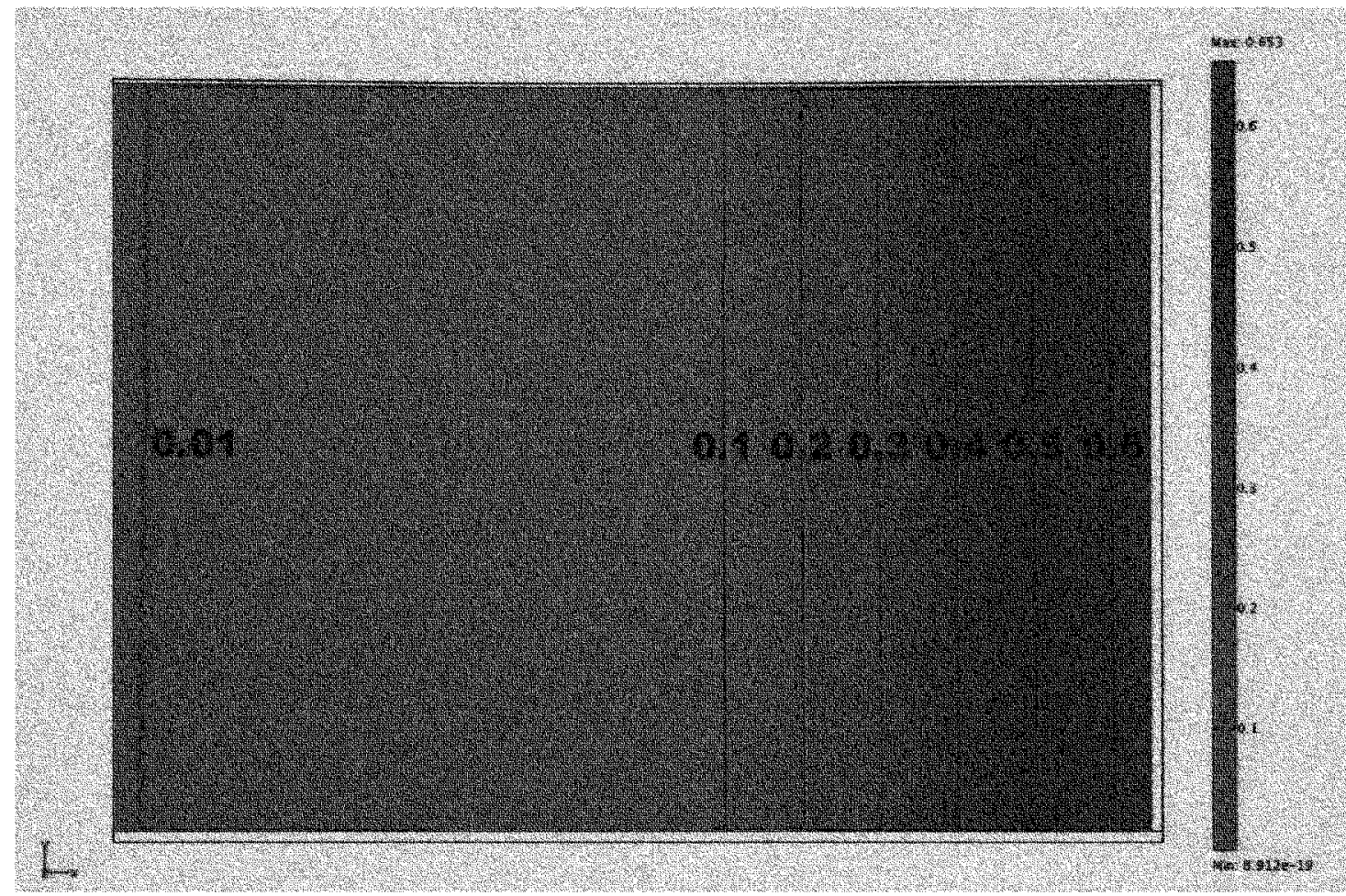

Figure 5-22 x-y Oxygen Concentration $\left(\mathrm{mol} \mathrm{m}^{-3}\right)$ in outer $1 \%$ of the CCL, $0.4 \mathrm{~V}$

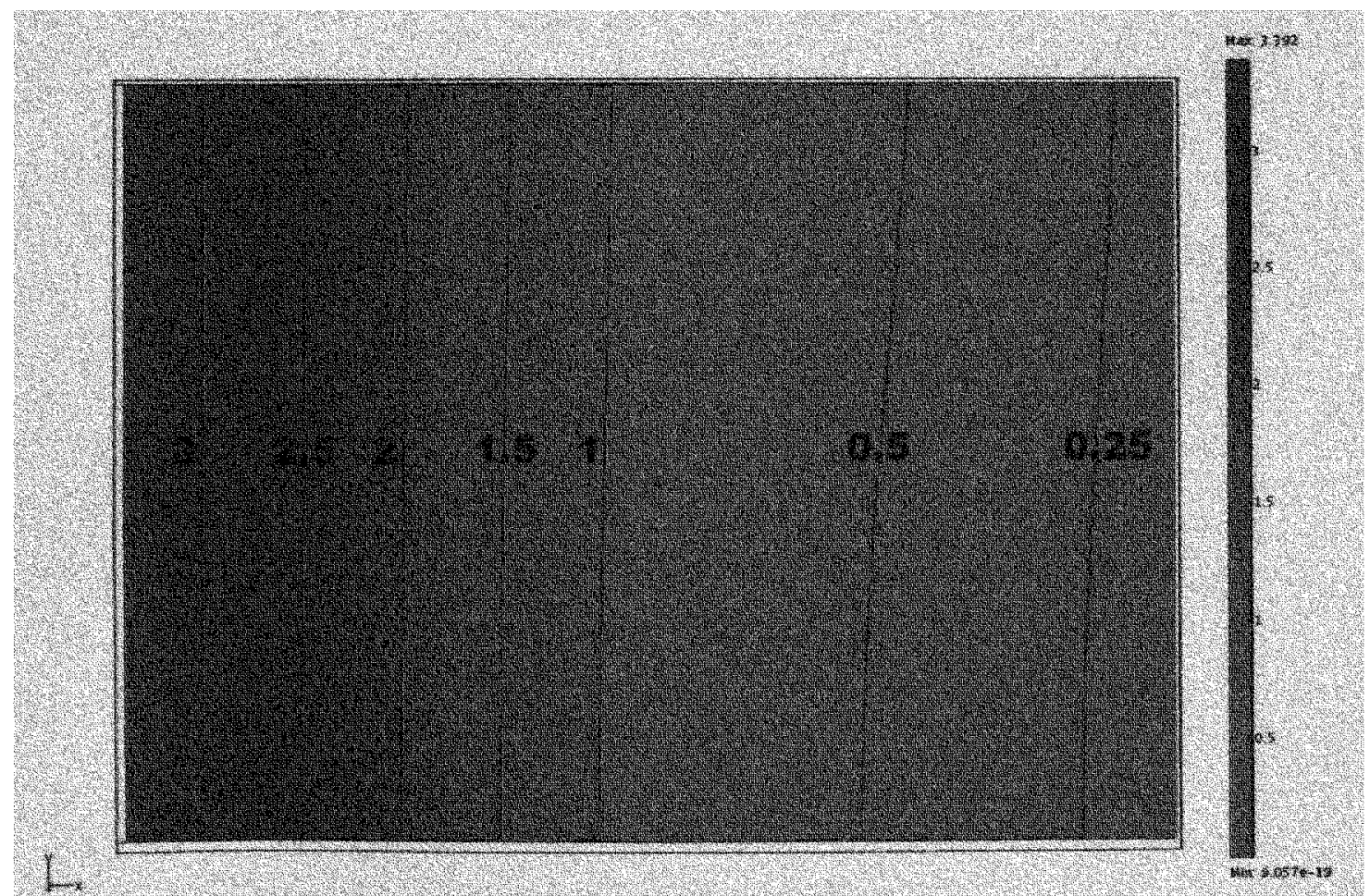

Figure 5-23 x-y Hydrogen Concentration $\left(\mathrm{mol} \mathrm{m}^{-3}\right)$ in outer $1 \%$ of the $\mathrm{ACL}, 0.4 \mathrm{~V}$ 


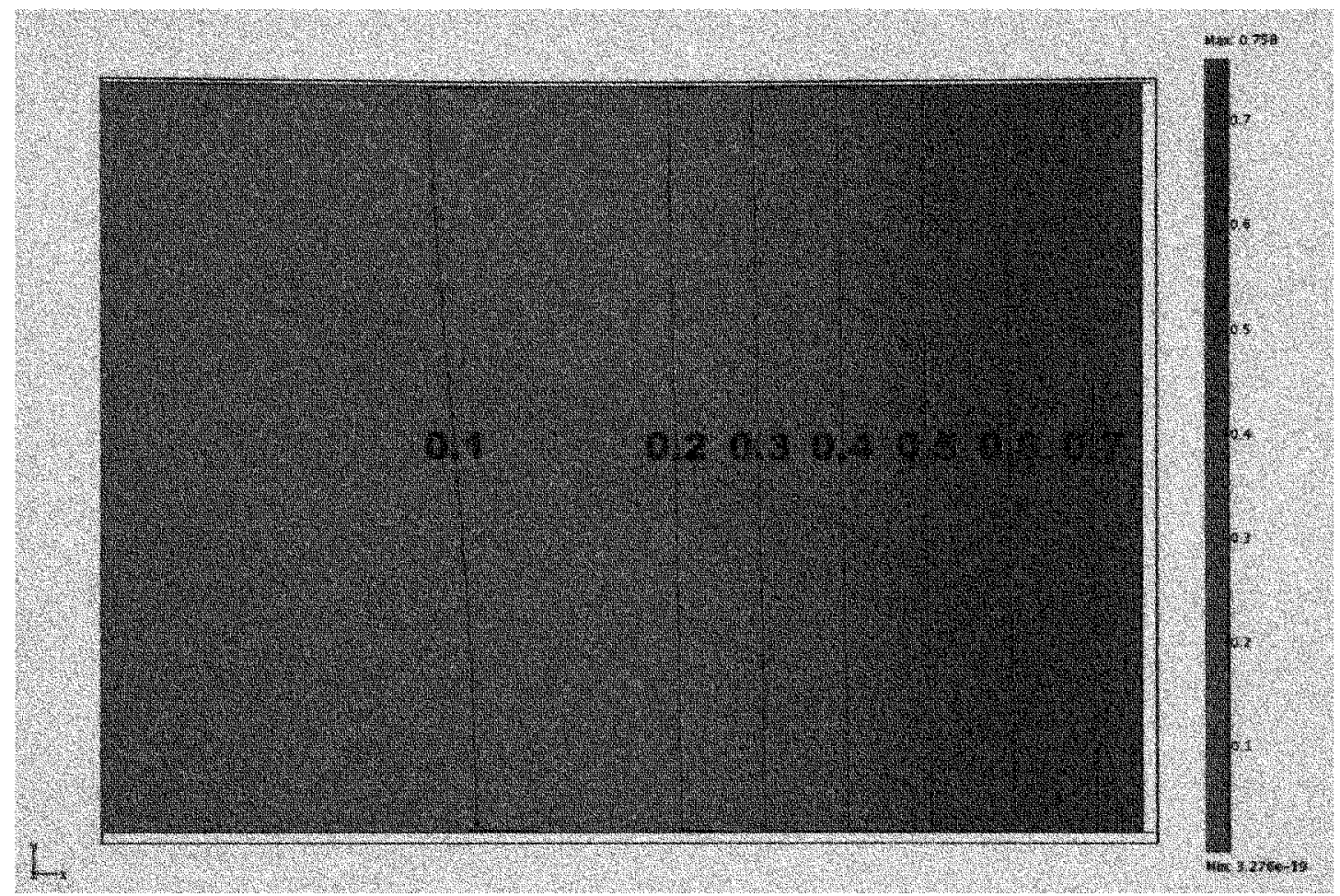

Figure 5-24 x-y Oxygen Concentration $\left(\mathrm{mol} \mathrm{m}^{-3}\right)$ in outer $1 \%$ of the CCL, $0.65 \mathrm{~V}$

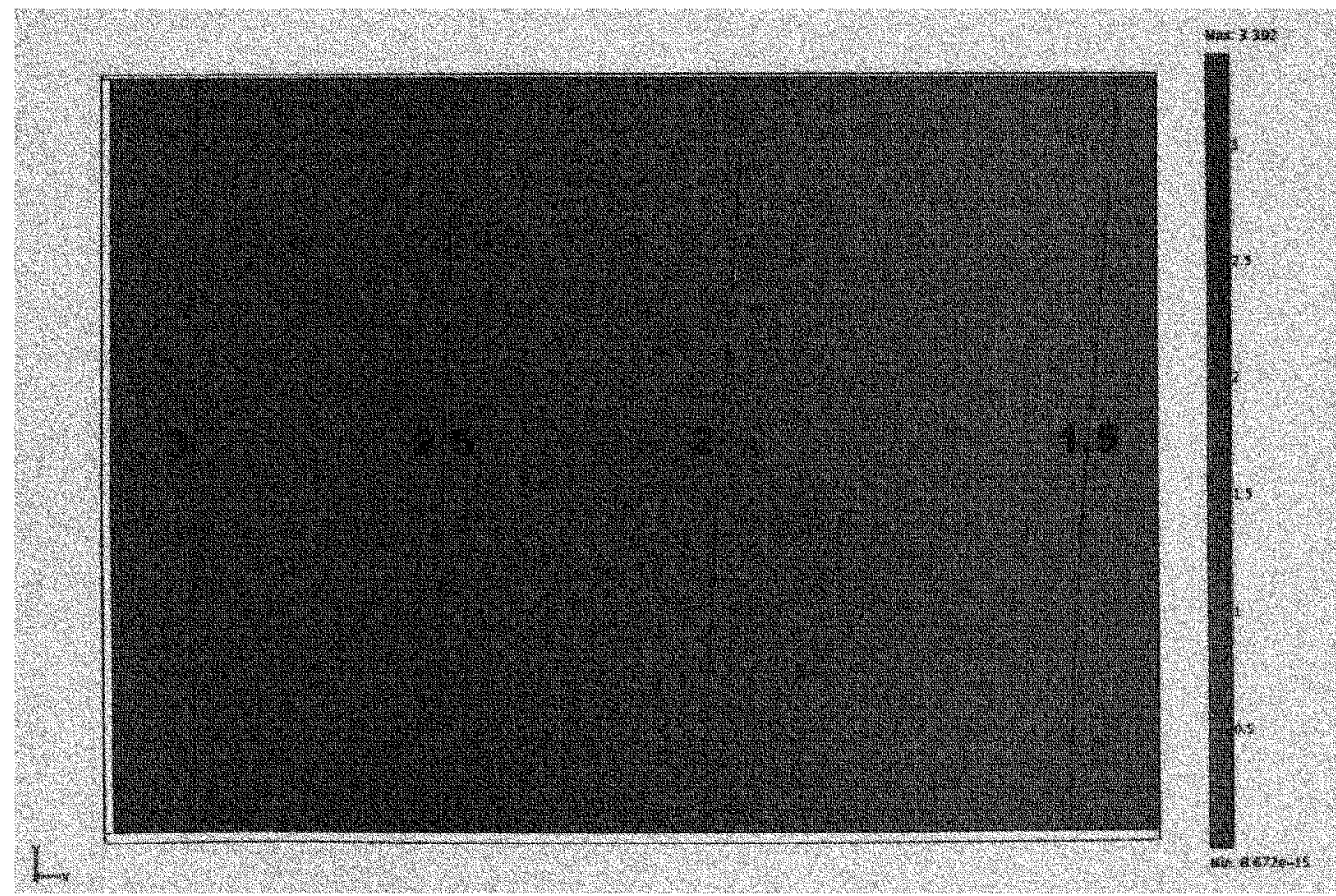

Figure 5-25 $x-y$ Hydrogen Concentration $\left(\mathrm{mol} \mathrm{m}^{-3}\right)$ in outer $1 \%$ of the $\mathrm{ACL}, 0.65 \mathrm{~V}$ 

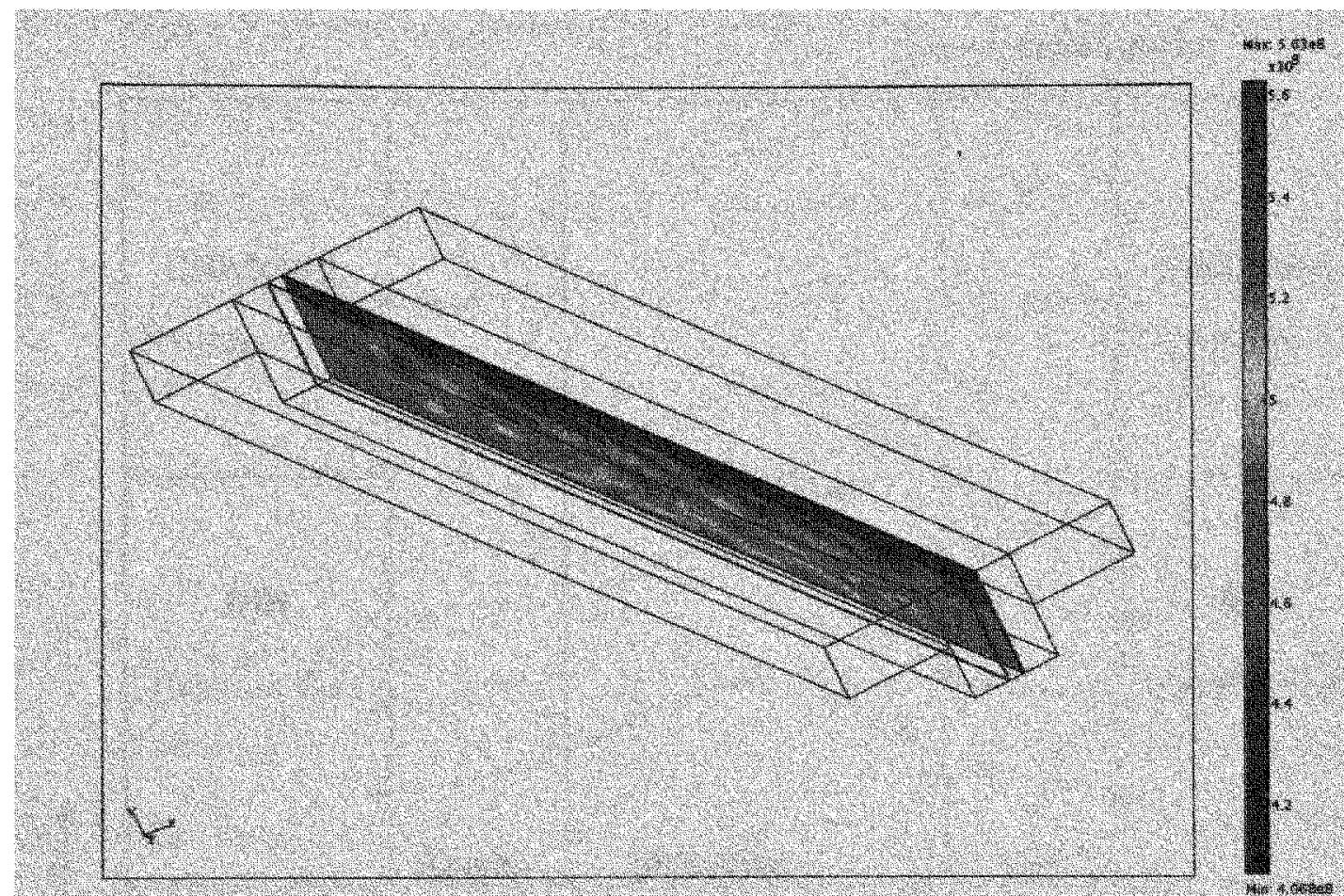

Figure 5-26 Reaction Rate, $j\left(\mathrm{~A} \mathrm{~m}^{-3}\right)$ on outer surface of $\mathrm{CCL}$
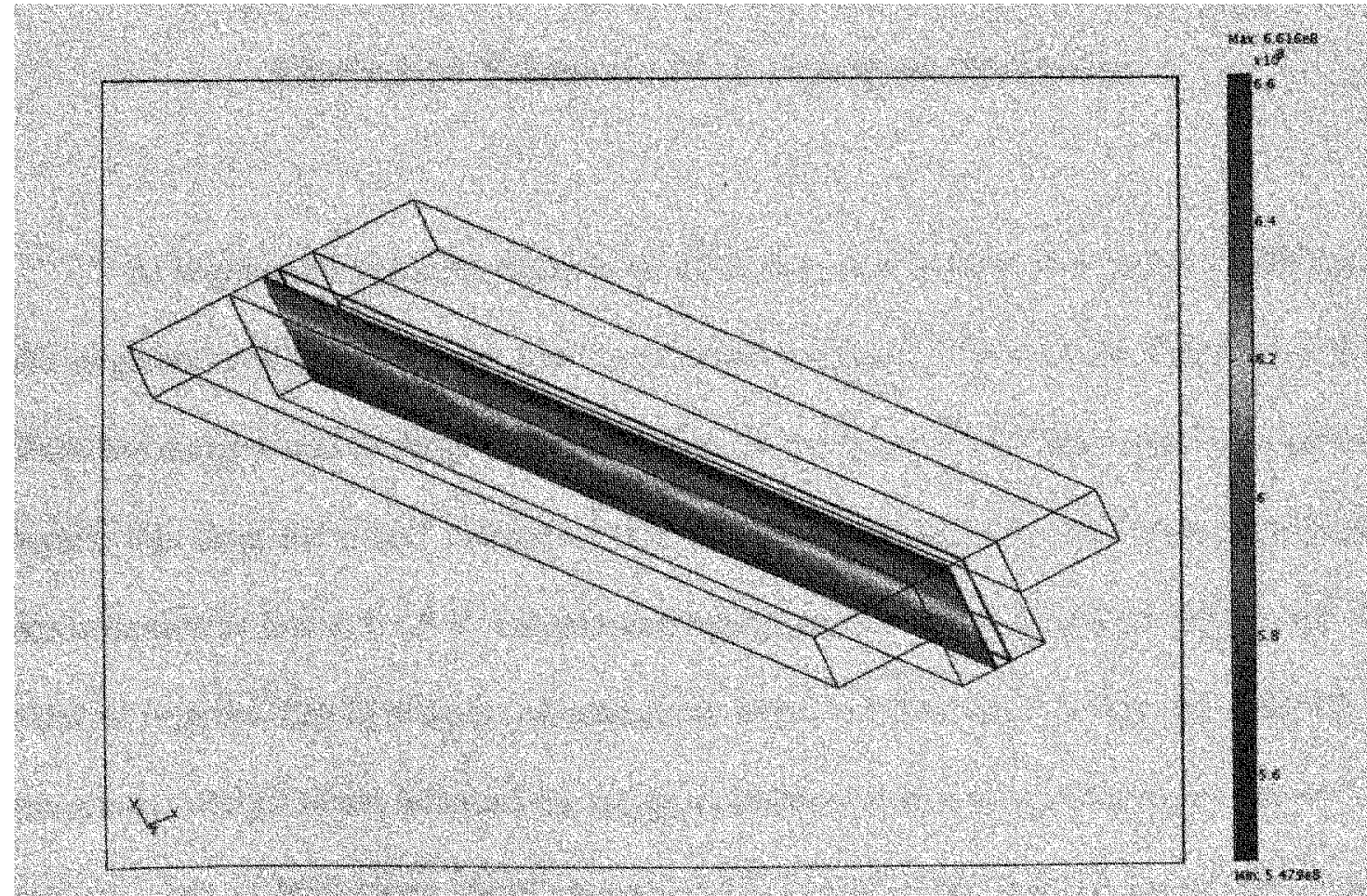

Figure 5-27 Reaction Rate, $j\left(\mathrm{~A} \mathrm{~m}^{-3}\right)$ on outer surface of $\mathrm{ACL}$ 


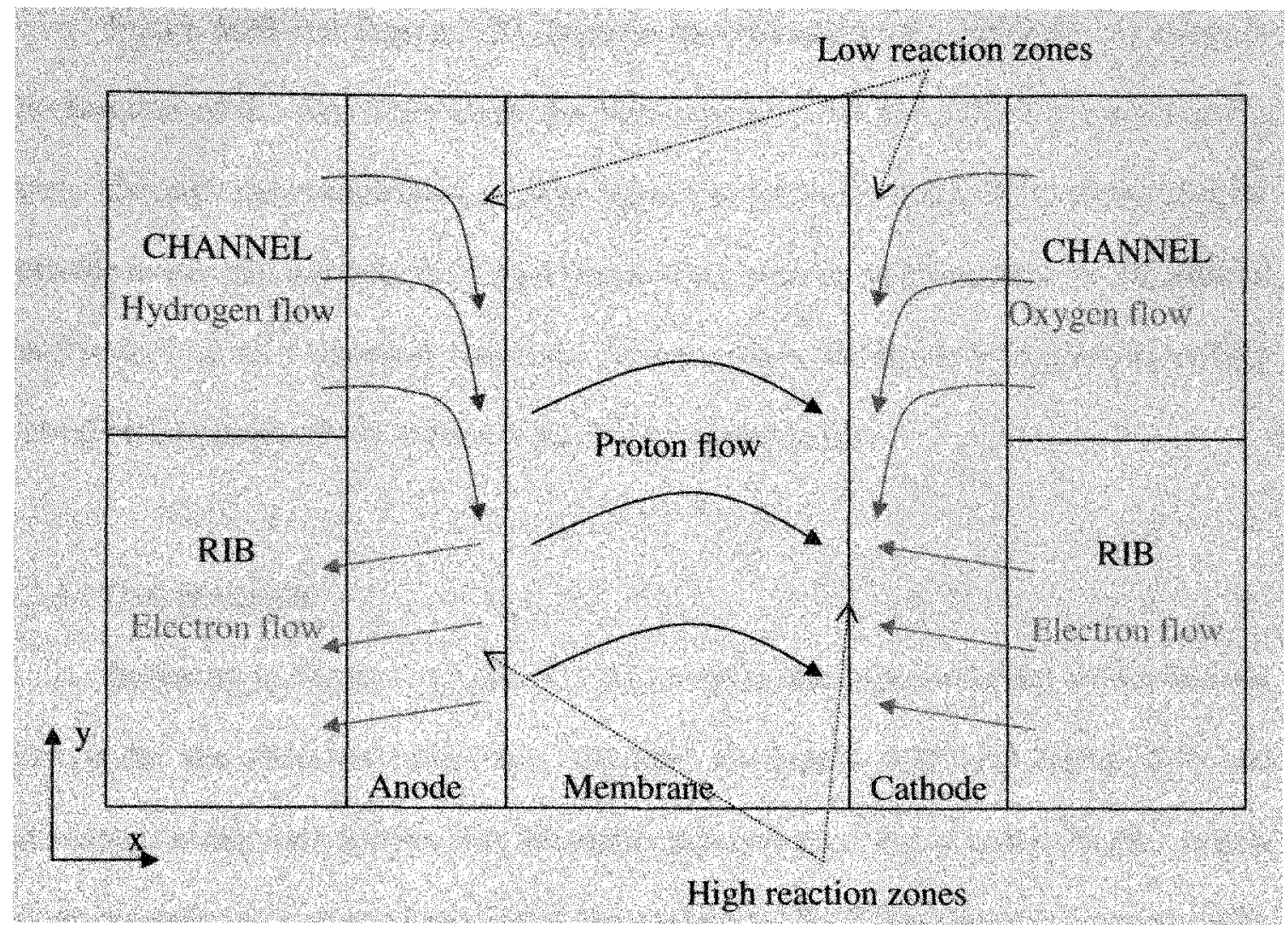

\section{Figure 5-28 Schematic of x-y Transport Phenomena}

At higher cell voltages, there is an indication that oxygen also begins to diffuse in the negative y-direction in the low concentration region. Figure 5-24 and Figure 5-25 show the oxygen and hydrogen concentration on the outer $1 \%$ of their respective catalyst layers, this time for a cell voltage of $0.65 \mathrm{~V}$. As would be expected, since the reactant consumption is less at $0.65 \mathrm{~V}$, oxygen and hydrogen are able to permeate further into the catalyst regions. The hydrogen concentration drops to $1.5 \mathrm{~mol} \mathrm{~m}^{-3}$ within the outer $1 \%$ of the anode catalyst layer, whereas the oxygen concentration falls to some value above 0.01 mol $\mathrm{m}^{-3}$. But in both cases, there appears to be a slant in the contour lines, indicating a flux of species in the negative y-direction. 
Figure 5-26 and Figure 5-27 illustrate the reason for this transport of species in the direction of the ribs. They show the reaction rate, $j$, on the surface of each catalyst layer. Although the visualization of these figures is not very smooth, it is evident that for both the anode and cathode, the higher reaction rates occur on the surface of the catalyst just "under" (in an x-direction sense) the rib rather than the channel. So there must be a curved path of proton flow in the x-y plane (see Figure 5-28).

\subsubsection{Overpotentials}

Referring to Figure 5-15 (pp. 83), it is evident that higher reactant concentrations exist under the channels rather than the ribs. So Figure 5-26 and Figure 5-27 are interesting in that they predict that the higher reaction rates occur under the ribs, where the lower reactant concentrations exist. According to the Butler-Volmer Equation (12), there are two variables which affect the reaction rate: 1) the reactant concentration, and 2) the activation overpotential. So it is indeed possible that the higher reaction rates occur under the ribs, even though the reactant concentration is higher under the channels.

Figure 5-29 and Figure 5-30 show the two-phase electrode overpotential distribution on the surface of the catalyst for the anode and cathode respectively. Recall that the electrode overpotential is defined as the magnitude of the difference between the solid and electrolyte phase potentials and the reversibly electrode potential. The figures show that at both electrodes, the overpotential is slightly higher under the ribs than under the channels. Although this difference does not appear to be large, in the Butler-Volmer equation (12), these values appear in the exponential argument, therefore small changes in the overpotential may result in large changes in the reaction rate. In this case, the larger 
overpotentials below the ribs result in higher reaction rates there, despite the low reactant concentrations.

From a physical point of view, there is an additional factor affecting the reaction rate. That is the facility of electron flow. Since the electrons flow through the ribs, in this particular case, the reaction rates are faster where the electrons are more readily available. But it would be misleading merely to conclude that the reaction rate is higher under the ribs even though the reactant concentrations are lower. There is a flip side to this argument. From another perspective, because the electrode overpotential is larger below the ribs, this represents a larger drop in voltage. So it could also be concluded that maintaining a high reaction rate despite the low reactant concentration, requires higher activation energies, and hence results in larger activation overpotentials under the ribs.

Figure 5-31 shows the distribution of the electrolyte potential in the $x-y$ plane. The most significant variation is in the $\mathrm{x}$-direction. The electrolyte potential is the sole driving force for proton conduction across a PBI membrane, since there is no vehicle translation, with proton flow perpendicular to the contour lines. The contour lines confirm what is postulated in Figure 5-28 (pp. 93). The protons, which flow perpendicular to the contour lines, move in a curved path across the membrane. Figure 5-32 shows the electrolyte potential variations in the $x-z$ plane, respectively. Note the direction of the contour lines. These figures verify what is shown in Figure 5-21 (pp. 89), that protons flow in a slightly negative $\mathrm{z}$ direction from anode to cathode. 


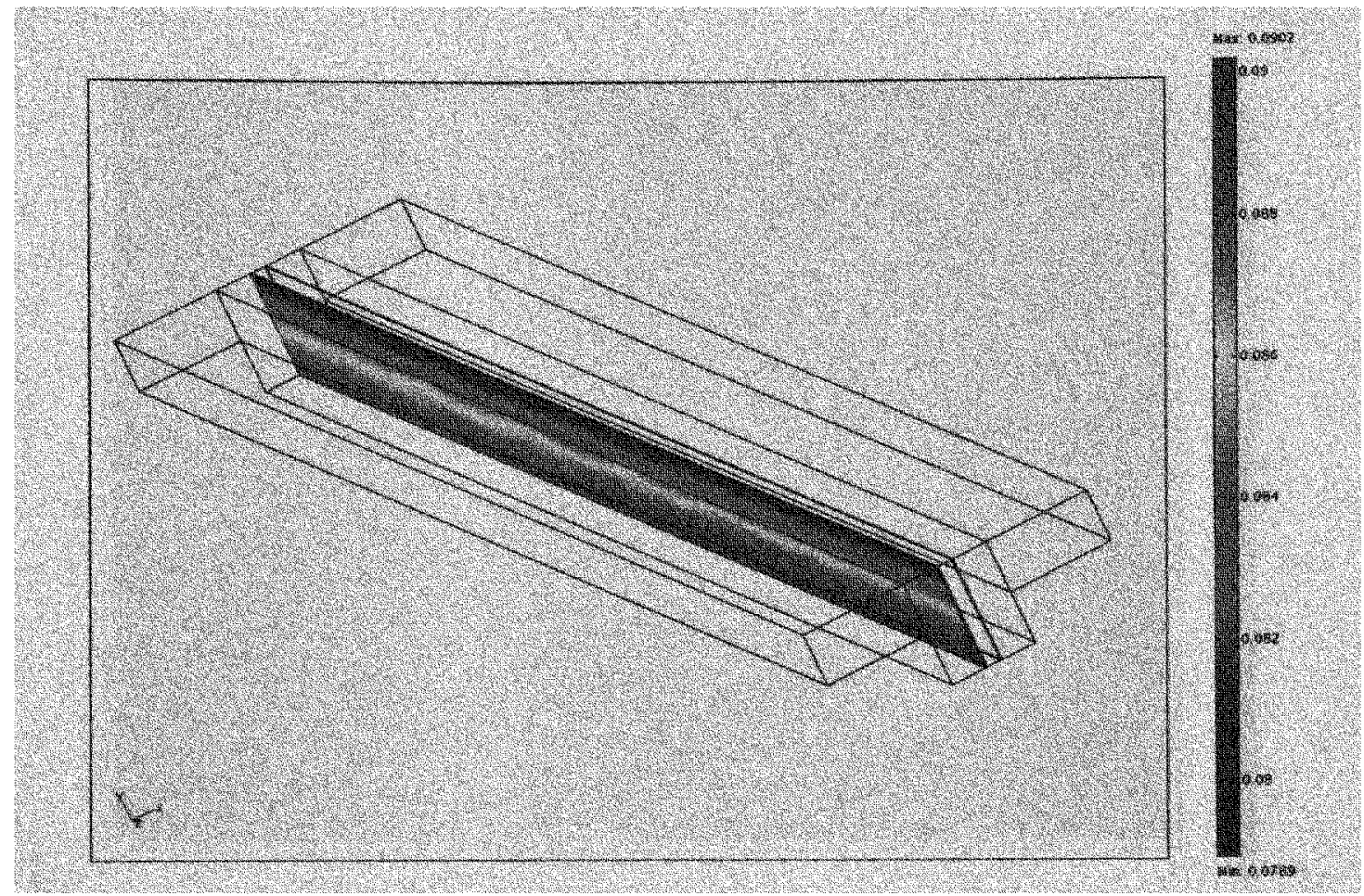

Figure 5-29 Anode Overpotential (V)
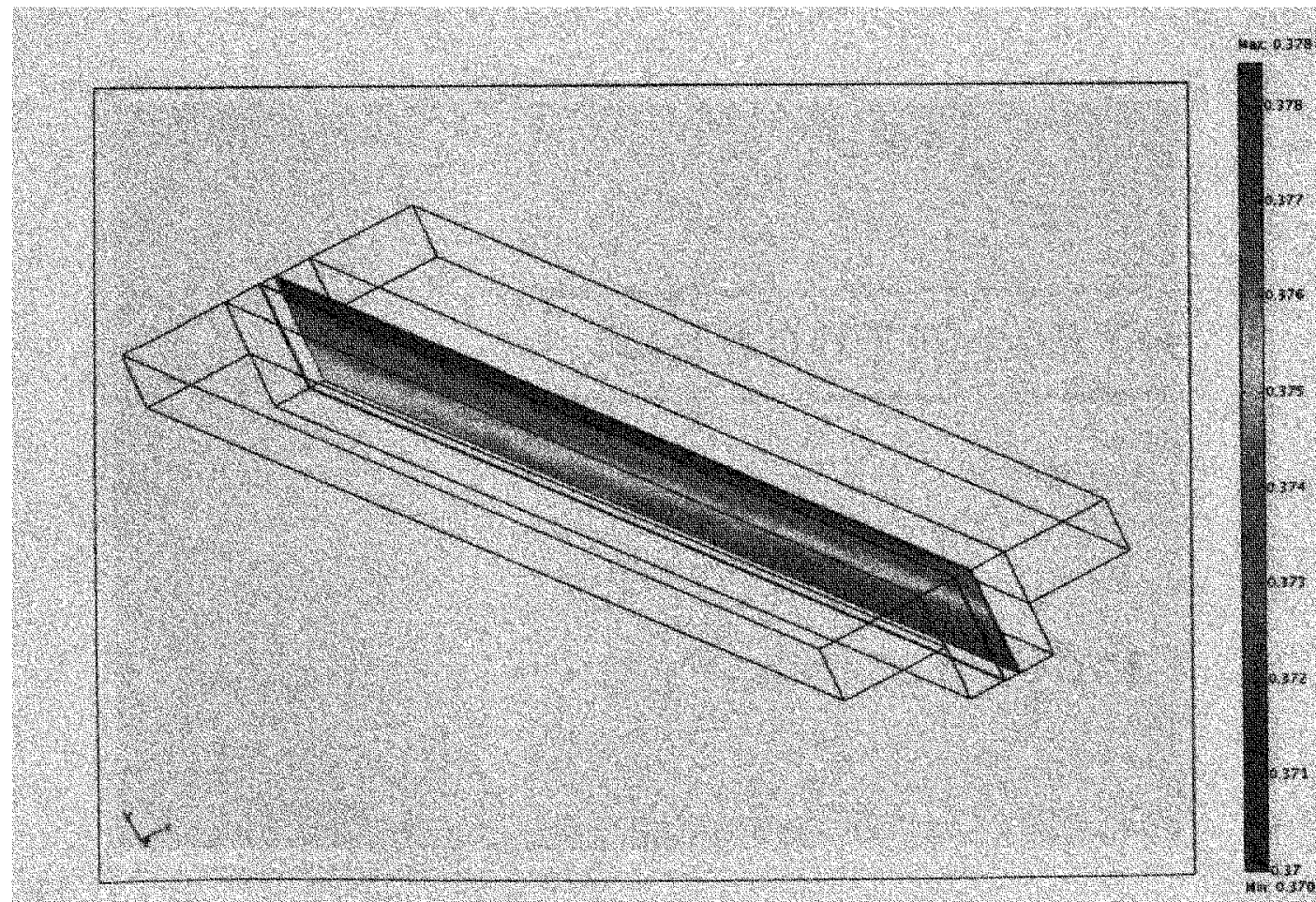

Figure 5-30 Cathode Overpotential (V) 


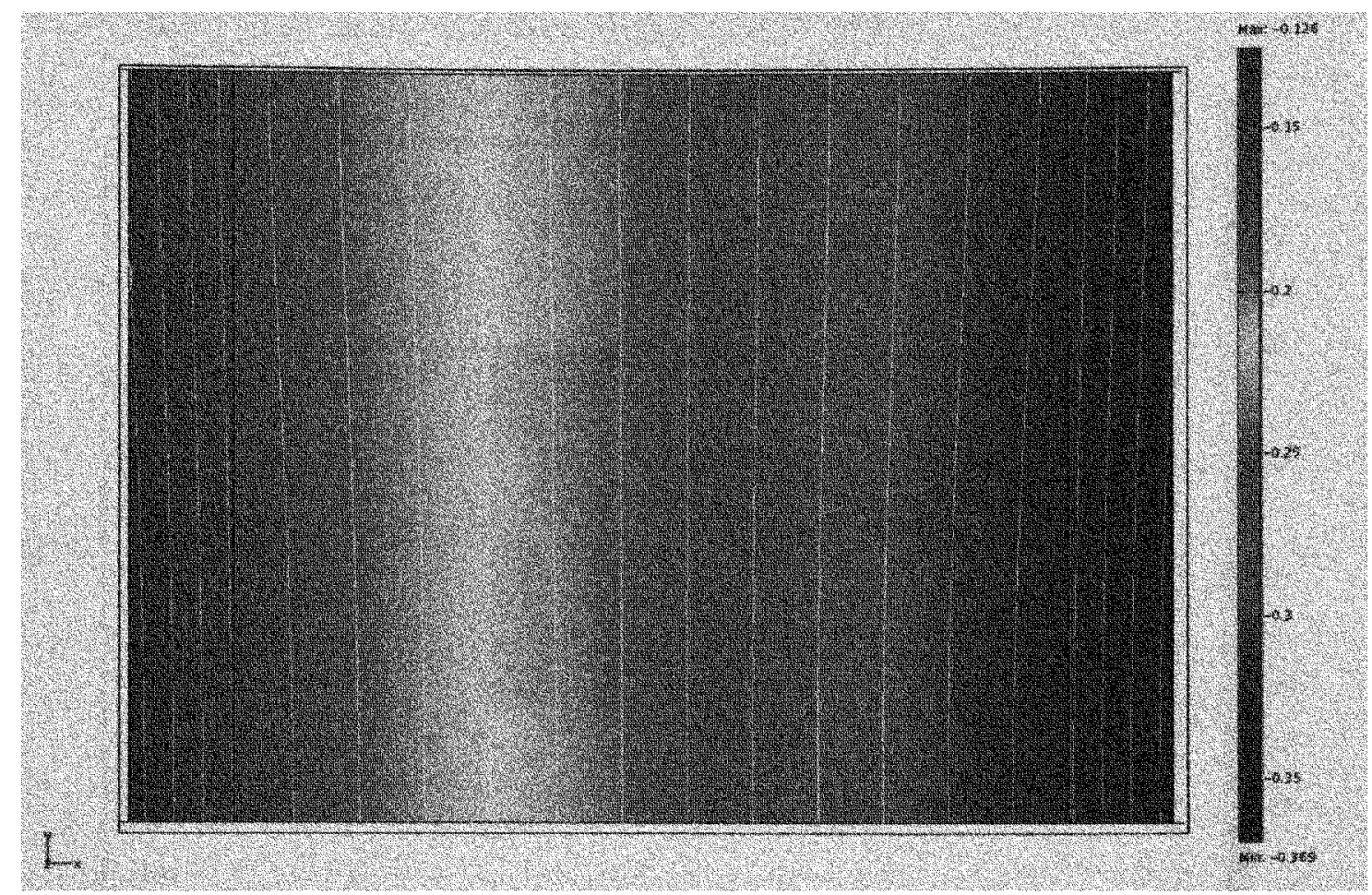

Figure 5-31 x-y Electrolyte Phase Potential (V)

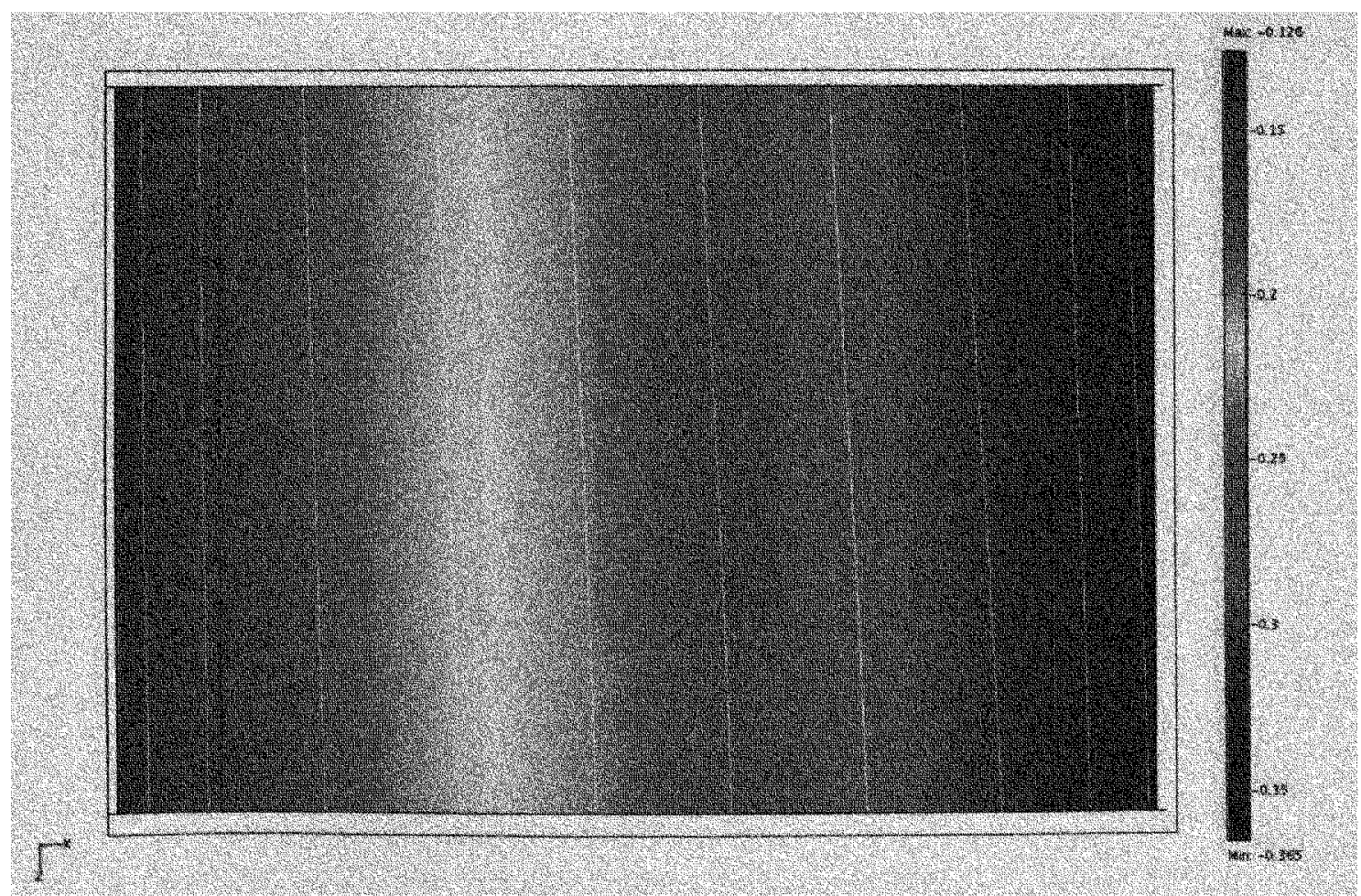

Figure 5-32 $x-z$ Electrolyte Phase Potential (V) 

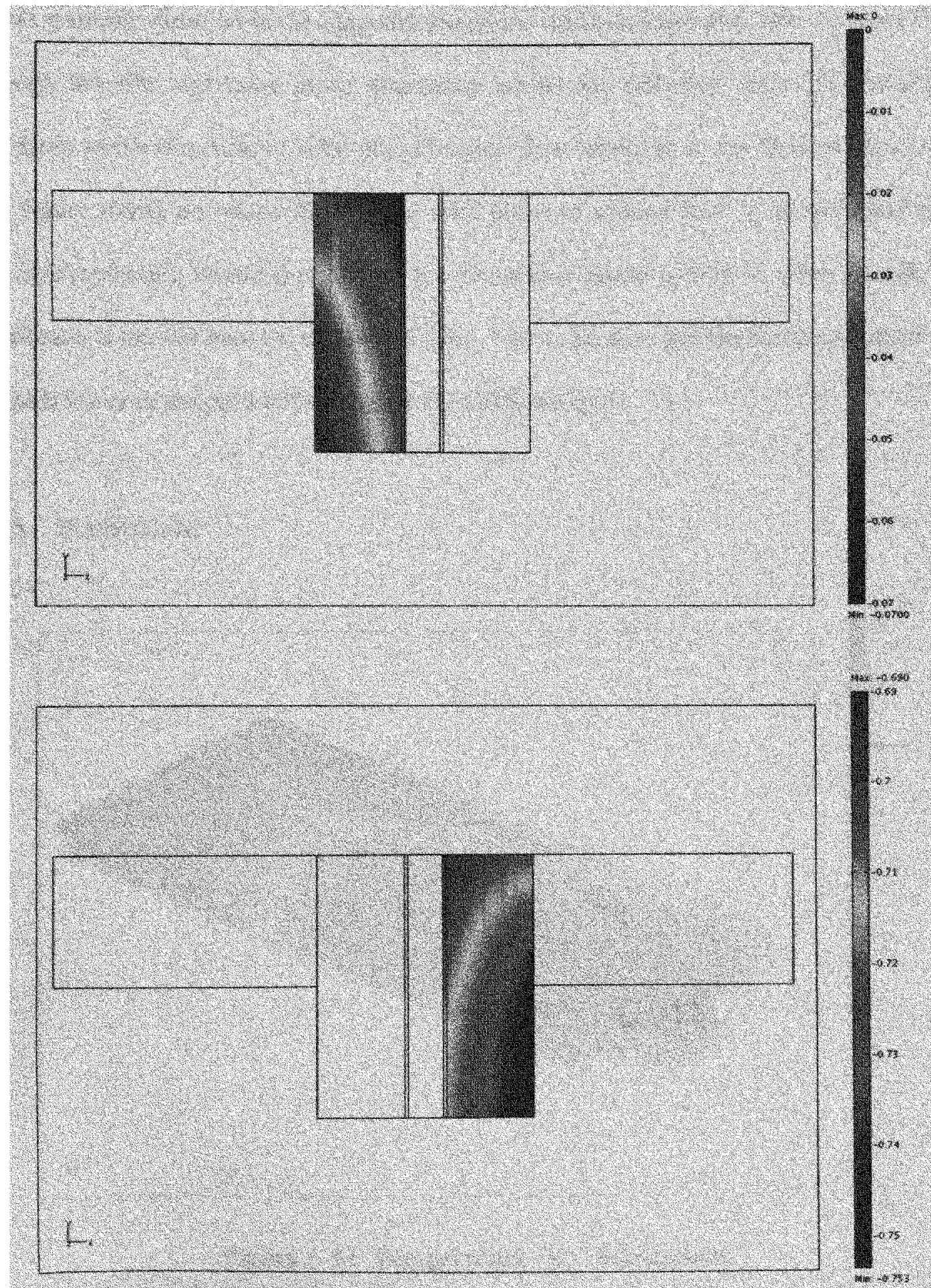

Figure 5-33 x-y Solid Phase Potential (V) 
Figure 5-33 shows the distribution of solid phase potential in the $x-y$ plane. It shows a strong variation in the diagonal directions which is expected. The electrons flow through the ribs and must move diagonally across the diffusion layer. The potential decreases in the direction of solid phase current flow (opposite to the flow of electrons). The figure shows an ohmic drop in the solid phase of around $0.07 \mathrm{~V}$ at each electrode. The corresponding ohmic drop across the electrolyte phase is $0.24 \mathrm{~V}$, even though the membrane is thinner than the diffusion layers. This is because the membrane conductivity is much lower in magnitude than that of the diffusion layer.

\subsubsection{Temperature}

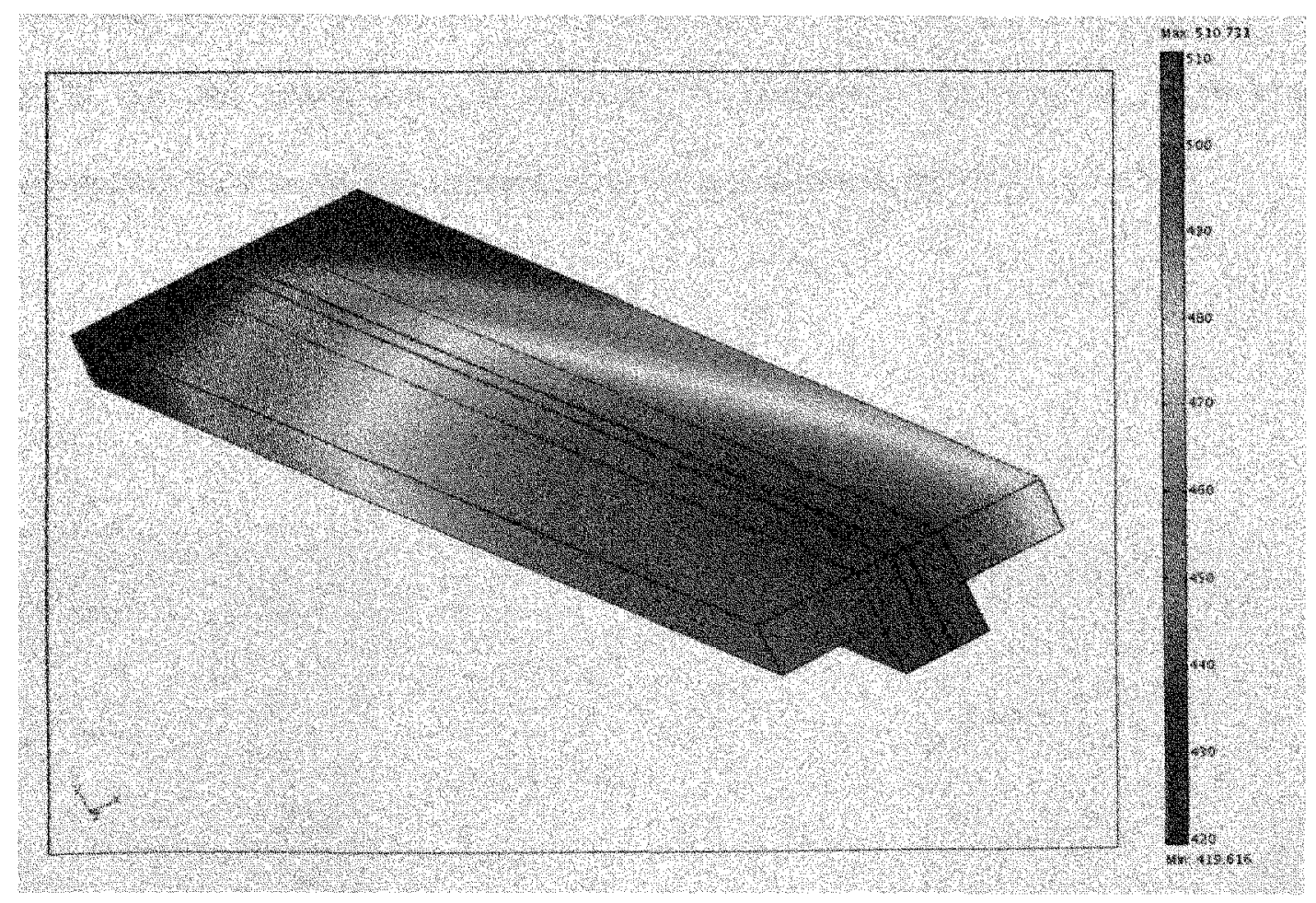

Figure 5-34 Temperature (K) Distribution 
Figure 5-34 shows the temperature variations at base conditions for a cell voltage of $0.4 \mathrm{~V}$. This is for a flow rate of $0.16 \mathrm{~L} \mathrm{~min}^{-1}$ (inlet velocities of $0.32 \mathrm{~m} \mathrm{~s}^{-1}$ ). This is also for the case, where heat is given off to the surroundings at $298 \mathrm{~K}$ via a heat transfer coefficient, $h=10 \mathrm{~W} \mathrm{~m}^{-2} \mathrm{~K}^{-1}$ from the sides (extremities in the $\mathrm{x}$-direction) and the ends (extremities in the z-direction). In the y-direction, there must be symmetry or insulation conditions, because the computational domain only considers the rib and channel half widths i.e. there is no physical external boundary at the extremities in the y-direction. It shows that under these conditions, the maximum temperature is expected to be $511 \mathrm{~K}$, which represents a temperature rise of $88 \mathrm{~K}$. This appears to be a very large temperature increase, but according to the energy balance in Table 5-8, this is very much realistic for this flow rate and cooling level. This table shows that the heat absorbed by the gas stream (0.26 W for the entire cell) is expected to produce a temperature increase of approximately $56 \mathrm{~K}$ in the gas streams, which is not inconsistent with Figure 5-34.

\section{Table 5-8 Energy Balance Calculations}

$$
\begin{array}{ll}
\rho c_{p} \stackrel{o}{V}_{\text {anode }} & 2.26 \times 10^{-3} \mathrm{~W} \mathrm{~K}^{-1} \\
\rho c_{p} \stackrel{o}{V}_{\text {cathode }} & 2.40 \times 10^{-3} \mathrm{~W} \mathrm{~K}^{-1} \\
Q_{\text {gen }}=\left(V_{\text {rev }}-V_{\text {cell }}+\frac{T \Delta S}{n F}\right) I_{\text {cell }} A_{M E A} & 2.81 \mathrm{~W}
\end{array}
$$

Heat losses to surroundings (boundary integration) $2.55 \mathrm{~W}$ 
Figure 5-35 shows the temperature variation in the $x-y$ plane in the middle of the domain $\left(\mathrm{z}=1.125 \times 10^{-2} \mathrm{~m}\right)$. It can be seen that the anode gas stream develops a higher temperature than the cathode. There may be a number of reasons for this. Firstly, the volumetric heat capacity of the anode gases is less than those of the cathode. Although hydrogen has a higher specific heat capacity, its density is very low, and the result is that the volumetric heat capacity is slightly lower than the cathode gases. Secondly and more significantly, the velocity of the anode gas stream decreases as it loses mass, whereas the velocity of the cathode gas stream increases as it gains mass. So the lower velocity at the anode contributes to the larger temperature rise. Figure 5-35 shows the temperature variation across the MEA is very small $(\sim 5 \mathrm{~K})$. This is the same magnitude of temperature variation predicted by some of our earlier $1 \mathrm{D}$ and $2 \mathrm{D}$ models $[8,10,12]$.

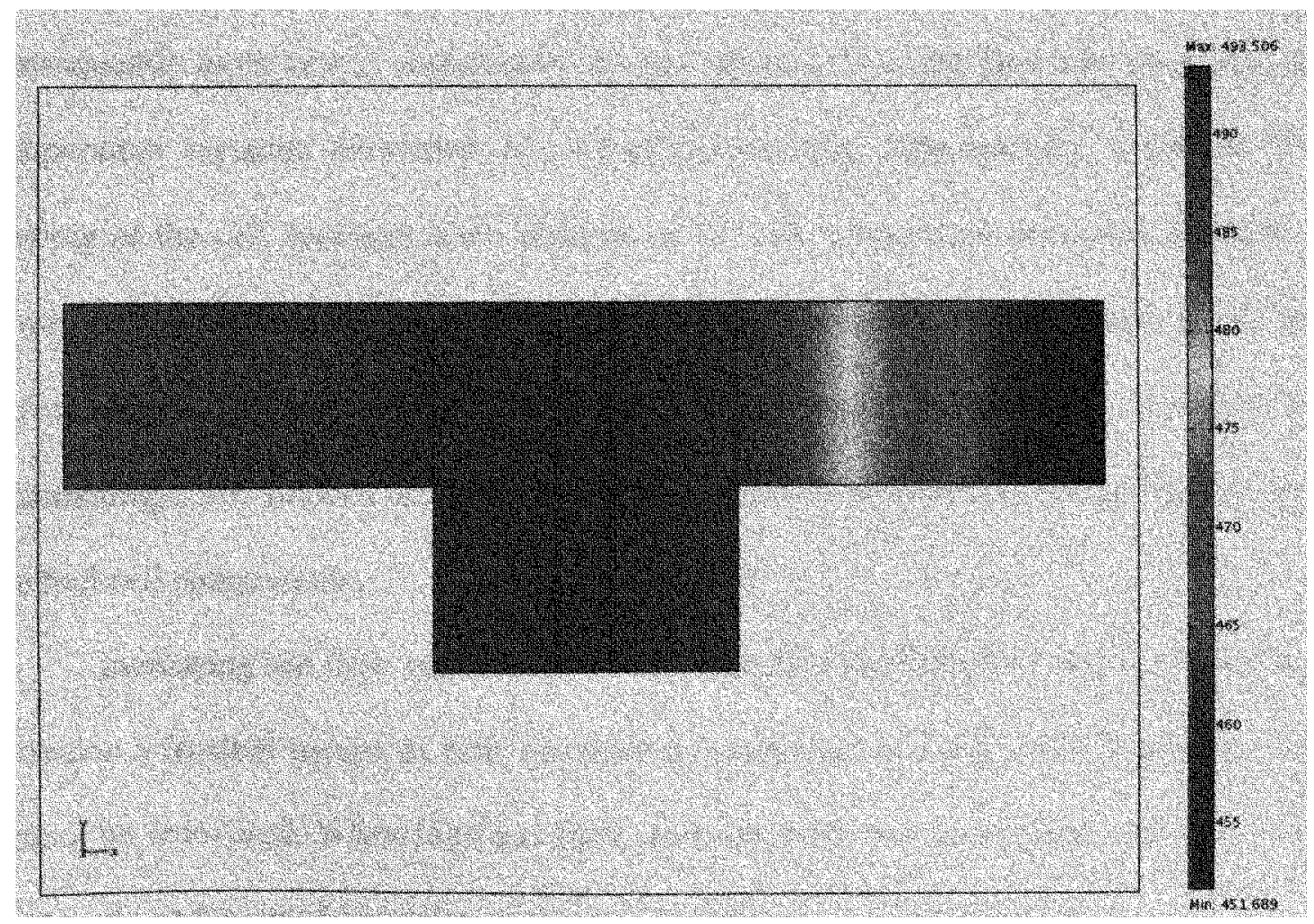

Figure 5-35 x-y Temperature (K) Distribution 
The temperature variation shown in Figure 5-34 is not acceptable, since it results in local temperatures, which are higher than $200{ }^{\circ} \mathrm{C}$. This may result in mechanical degradation of the acid doped PBI membrane $[61,68]$. Thus better cooling techniques must be employed. This fairly large temperature rise is due to two factors: 1) the low flow rates used in this experimental work [64], and 2) the fact that only minimal cooling is simulated.

Figure 5-36 shows the temperature variation (at $0.4 \mathrm{~V}$ ) for a higher flow rate. Since at higher flow rates, the effective co-efficient of convective heat transfer increases, the expected temperature variation decreases. For a flow rate of $1.6 \mathrm{~L} \mathrm{~min}{ }^{-1}$, the maximum temperature is $464 \mathrm{~K}$, which is a $41 \mathrm{~K}$ increase from the inlet temperature. Note that the temperature variation is not proportional to the flow rate. This is not surprising, because as the cell temperature drops, less heat is lost to the surroundings, and consequently more heat is absorbed by the gas streams. So as the flow rate increases, the temperature variation decreases, but not proportionately. Subsequently, it follows that cooling of the cell becomes more difficult as the cell temperature decreases, because at lower cell temperatures, there is a smaller temperature difference between it and the surroundings. This smaller temperature difference results in lower heat losses to the surroundings, and implies that a larger amount of heat is absorbed by the gas streams and the fuel cell components.

Increasing the flow rate can be a very attractive heat removal strategy because it provides a feasible means of heat recovery as compared to using a fan, where the heat cannot be recovered. When high gas flow rates are used, the outlet gases transport more heat, and can be recycled and/or used to pre-heat the incoming gas streams. 


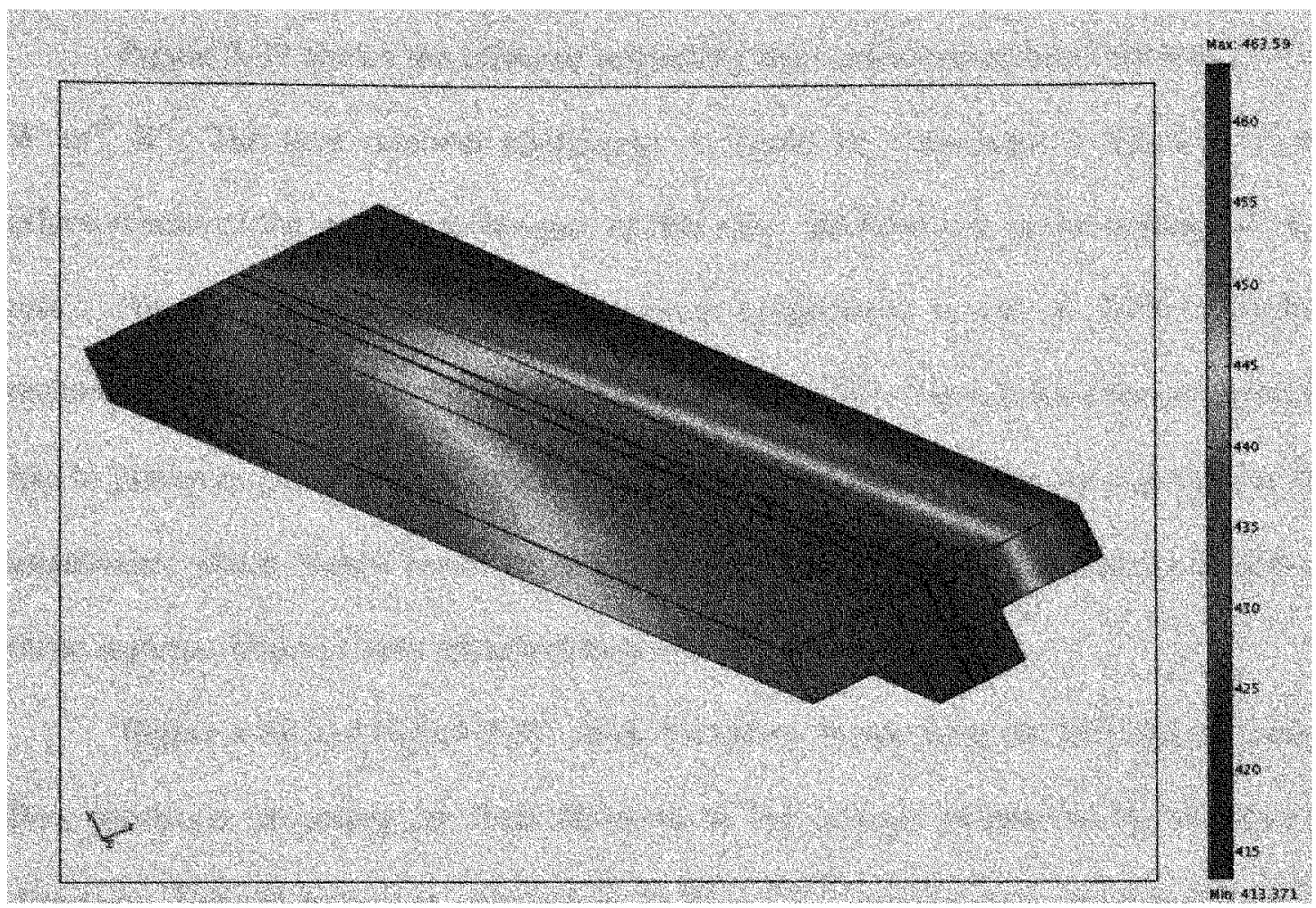

Figure 5-36 Temperature (K), $1.6 \mathrm{~L} \mathrm{~min}^{-1}$
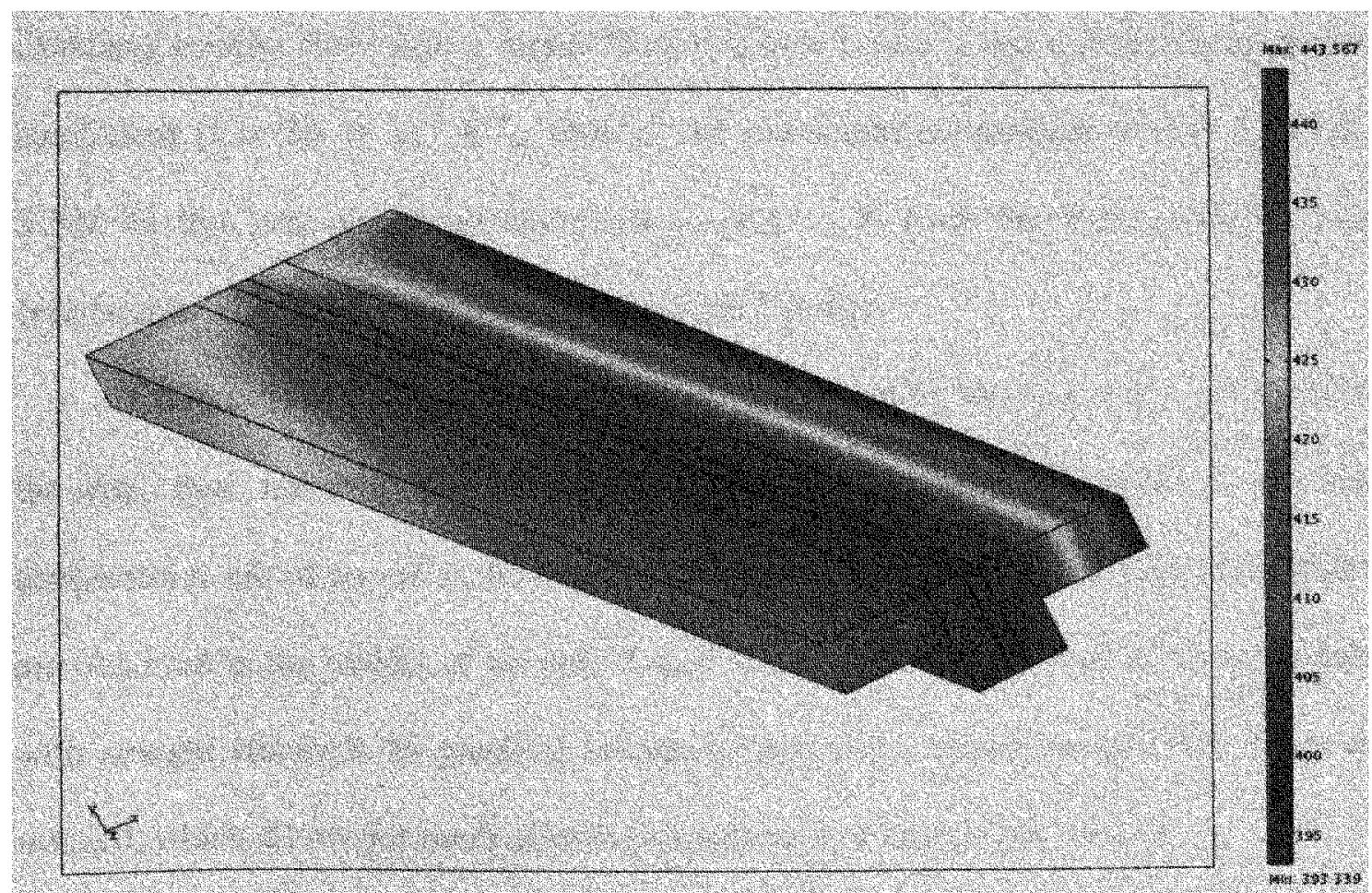

Figure 5 37 Temperature $(K), h=20 \mathrm{~W} \mathrm{~m}^{-2} K^{-1}$ 
Figure 5-37 shows the effect of increasing the coefficient of heat removal, $h$ to 20 $\mathrm{W} \mathrm{m} \mathrm{m}^{-2} \mathrm{~K}^{-1}$. The heat removal coefficient, $h$, could be considered a measure of the effectiveness of the cooling technique. In this case, the flow rate is the nominal $0.16 \mathrm{~L}$ $\min ^{-1}$. For $h=20 \mathrm{~W} \mathrm{~m}^{-2} \mathrm{~K}^{-1}$, the maximum temperature is $444 \mathrm{~K}$. Thus a cooling technique with a heat removal coefficient of $20 \mathrm{~W} \mathrm{~m}^{-2} \mathrm{~K}^{-1}$ would reduce the temperature rise to just over $20 \mathrm{~K}$. In such a case, it can be seen that the hot areas are restricted to the membrane, which would result in an increase in conductivity and catalytic activity in those regions. This is a very attractive heat removal scenario.

Figure 5-38 and Figure 5-39 show the effect of operating the fuel cell in counter flow mode i.e. reversing the flow direction of the cathode stream (to the negative $\mathrm{z}$ direction). For the base case, where $h=10 \mathrm{~W} \mathrm{~m}^{-2} \mathrm{~K}^{-1}$ and the flow rate $=0.16 \mathrm{~L} \mathrm{~min}^{-1}$ (Figure 5-38), counter flow operation reduces the peak temperature from $511 \mathrm{~K}$ to $478 \mathrm{~K}$. Combing counter flow with a higher flow rate $\left(1.6 \mathrm{~L} \mathrm{~min}^{-1}\right)$ and a higher heat removal coefficient $\left(h=20 \mathrm{~W} \mathrm{~m}^{-2} \mathrm{~K}^{-1}\right.$ ), reduces the maximum temperature to $439 \mathrm{~K}$ (Figure 5-39). In this case the temperature rise is just $16 \mathrm{~K}$ from the inlet, which is more comparable with predictions from other models [38-40].

Counter flow operation has the effect of distributing the heat more evenly across the cell, thus reducing the maximum temperature. In co-flow operation, the high temperatures are observed at the outlet. In counter flow operation, the high temperatures are observed in the middle of the cell. Recall that in this work, the fuel cell was modeled with straight channels. In practical laboratory fuel cells, serpentine gas flow fields are utilized, which allows for more effective distribution of heat across the cell. 


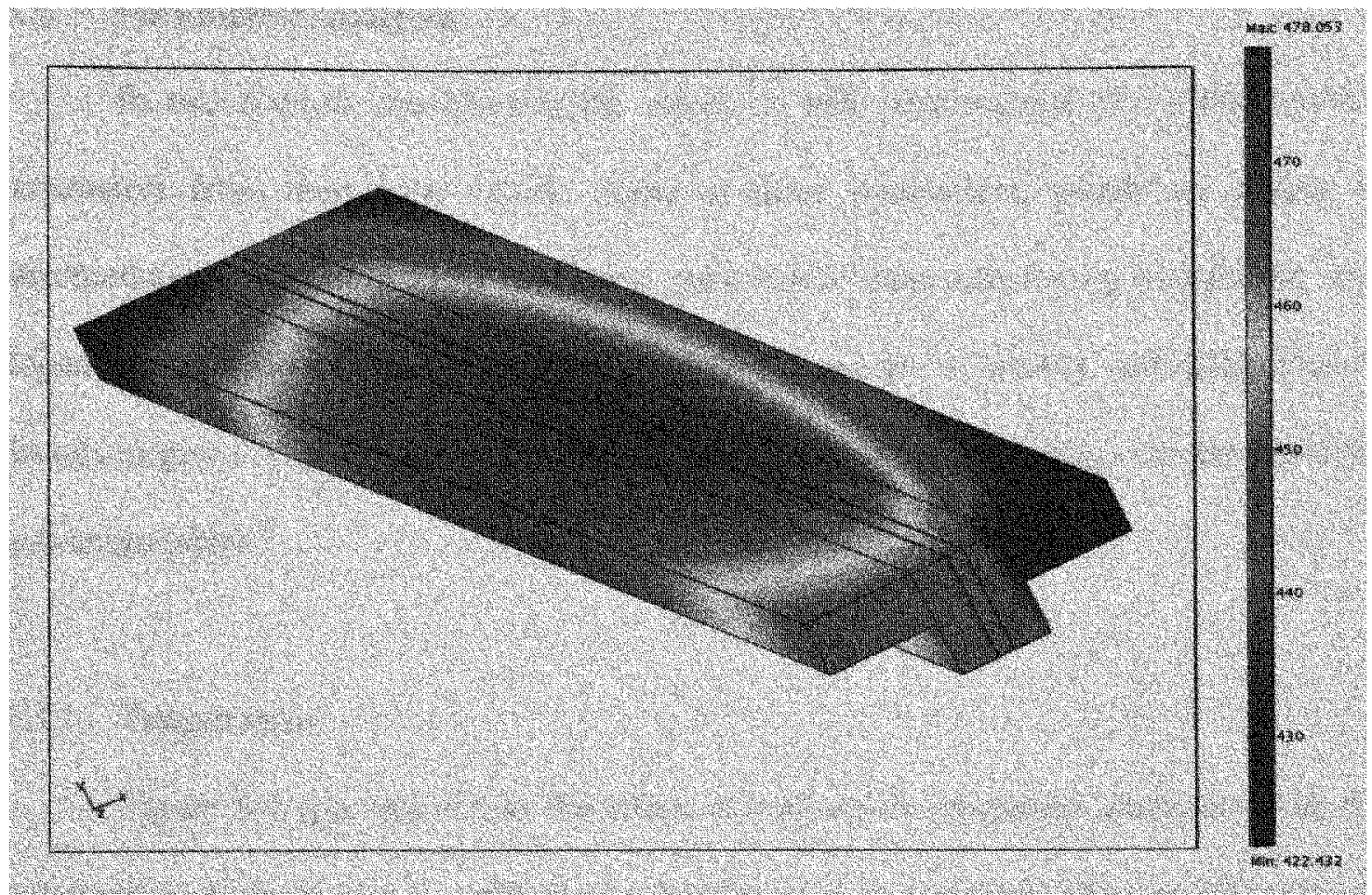

Figure 5-38 Temperature $(\mathrm{K}), 0.16 \mathrm{~L} \mathrm{~min} \mathrm{~m}^{-1}$ counter-flow, $\mathrm{h}=10 \mathrm{~W} \mathrm{~m} \mathrm{~m}^{-2} \mathrm{~K}^{-1}$
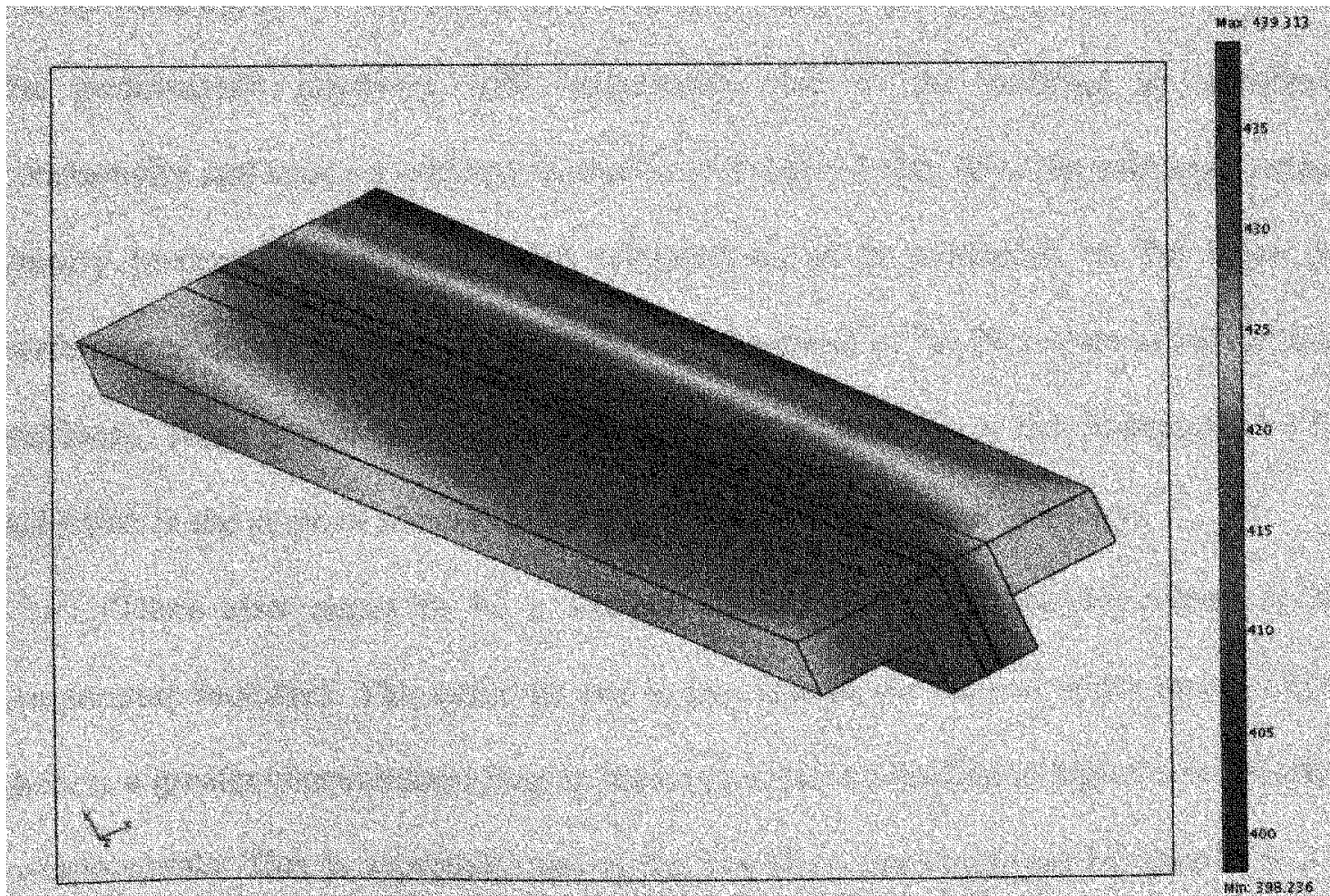

Figure 5-39 Temperature $(\mathrm{K}), 1.6 \mathrm{~L} \mathrm{~min}^{-1}$ counter-flow, $\mathrm{h}=20 \mathrm{~W} \mathrm{~m}^{-2} \mathrm{~K}^{-1}$ 


\subsection{Parametric Analyses}

In this section, we observe the effect on cell performance of varying critical parameters from their base values. Some of these parameters, which are unique to intermediate temperature PEM fuel cells, particularly those employing phosphoric acid doped polymer membranes, are the doping level, and the solubility and diffusivity of dissolved gases. We also investigate the effects of varying the exchange current densities and temperature.

\subsubsection{Temperature}

Figure 5-1 (pp. 66) shows the effect of varying the operating temperature on the polarization performance. In addition to matching the experimental data at 150 and 170 ${ }^{\circ} \mathrm{C}$, the model predictions are also extended to 110 and $130{ }^{\circ} \mathrm{C}$. Generally, as is expected, the performance improves with temperature due to the increase in membrane conductivity and catalyst activity, as shown in Table 5-1 (pp. 66). The exchange current density increases significantly with temperature, as is evidenced in the better IV performance during the activation overpotential regions of the IV curves as temperature increases. There is also an increase in membrane conductivity, which is depicted by the reduction in the slope of the curves during the ohmic overpotential regions.

There also seems to be a sharper concentration overpotential region as the temperature increases. This could be due to two factors. As the cell draws more current, there is a greater concentration drop in the oxygen stream leading to higher concentration overpotentials. This is especially true at the low flow rate employed by Qingfeng et al [64]. Further, the effect of catalyst blockage due to phosphoric acid anion adsorption may 
be more significant as the current density increases. Physically, there is a greater demand for catalyst sites as the current density increases, hence the effect of blockage is more "strongly felt".

\subsubsection{Acid Doping Level}

Figure 5-40 shows the IV curves for various acid doping levels. The doping level affects mainly the membrane conductivity and exchange current densities, and to a lesser degree, the reactant solubility and diffusivity in phosphoric acid. See Table 5-9.

Increasing the doping level increases the proportion of amorphous phosphoric acid inside the PBI structure, whereby increasing its effective diffusivity, solubility and conductivity. The curves show an increase in performance as the doping level increases. Figure 5-31 and Figure 5-32 show that the ohmic potential drop across the membrane was $0.24 \mathrm{~V}$ for a cell voltage of $0.4 \mathrm{~V}$ (total cell polarization of approximately $0.75 \mathrm{~V}$ ). Thus, a significant proportion of the overall cell polarization is due to membrane resistance, and this explains why the performance improves drastically as the membrane conductivity increases. There is a $70 \%$ increase in peak power as the doping level is increased from 4.5 to 6.2 , and $38 \%$ as it increases from 6.2 to 8 . It should also be noted, that as the doping level increases, the mechanical properties of the membrane may become degraded. Unless this can be quantified, it cannot be accounted for mathematically.

\subsubsection{Exchange Current Density}

Figure 5-41 shows the effect of increasing the cathode exchange current density. 


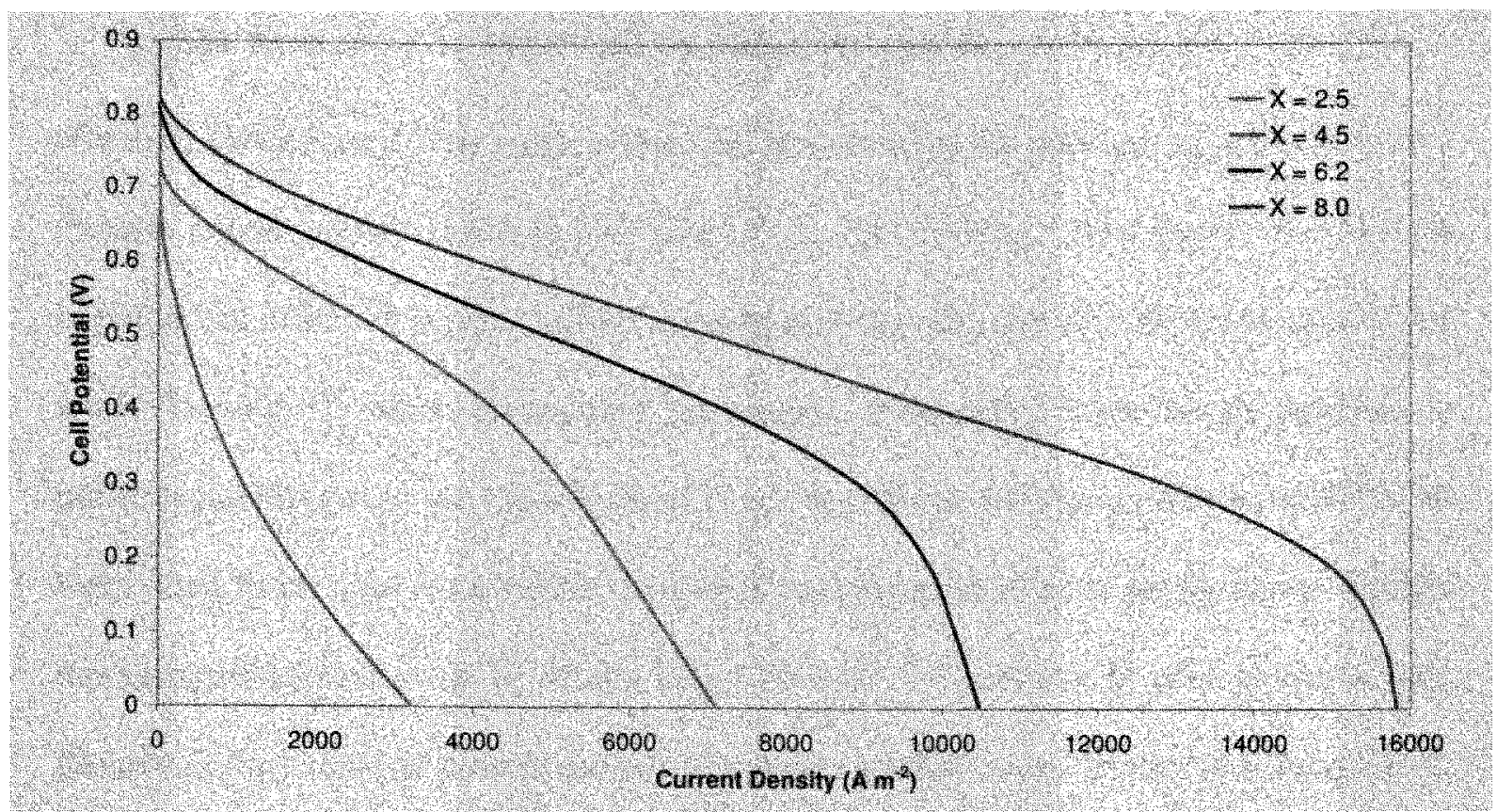

Figure 5-40 IV Curves as a Function of Doping Level, $X$

Table 5-9 Critical Numerical Values in Figure 5-40

\begin{tabular}{lccccc}
\hline & $\mathbf{X}=\mathbf{2 . 5}$ & $\mathbf{X}=\mathbf{4 . 5}$ & Base, $\mathbf{X}=6.2$ & $\mathbf{X}=8.0$ & \\
\hline$\sigma_{m}$ (eqn 28) & 2.30 & 3.21 & 4.25 & 5.73 & $\mathrm{~S} \mathrm{~m}^{-1}$ \\
$i_{0, c}$ (eqns 27,33,34) & $1.61 \times 10^{-5}$ & $6.26 \times 10^{-4}$ & $2.80 \times 10^{-3}$ & $7.82 \times 10^{-3}$ & $\mathrm{~A} \mathrm{~m}^{-2}$ \\
$i_{0, a}$ & $1.61 \times 10^{3}$ & $6.26 \times 10^{4}$ & $2.80 \times 10^{5}$ & $7.82 \times 10^{5}$ & $\mathrm{~A} \mathrm{~m}^{-2}$ \\
$D_{O_{2}}$ (eqns 27,29,31) & $1.01 \times 10^{-11}$ & $1.03 \times 10^{-10}$ & $1.80 \times 10^{-10}$ & $2.46 \times 10^{-10}$ & $\mathrm{~m}^{2} \mathrm{~s}^{-1}$ \\
$D_{H_{2}}$ & $2.02 \times 10^{-11}$ & $2.06 \times 10^{-10}$ & $3.59 \times 10^{-10}$ & $4.92 \times 10^{-10}$ & $\mathrm{~m}^{2} \mathrm{~s}^{-1}$ \\
$H_{O_{2}}$ (eqns 27,30,32) & 0.06 & 0.51 & 0.76 & 0.91 & $\mathrm{~mol} \mathrm{~m}^{-3} \mathrm{~atm}^{-1}$ \\
$H_{H_{2}}$ & 0.25 & 2.25 & 3.39 & 4.04 & $\mathrm{~mol} \mathrm{~m}^{-3} \mathrm{~atm}^{-1}$ \\
\hline
\end{tabular}


The term, $a i_{0}$, is influenced by numerous factors - temperature, doping level, effective surface area. The surface area can be increased by packing the catalyst over a thinner region, or by reducing the size of the Pt particles. This figure predicts the hypothetical effect of increasing the cathode exchange current density by factors of 10 , while leaving all other parameters unchanged. Predictably there is an increase in performance, however the improvement is not very large. Increasing it from $1 / 10^{\text {th }}$ of its base value to its base value results in a $16 \%$ improvement in peak performance. Further increasing it by factors of 10 results in a $13 \%$ and $11 \%$ increase in peak power output. Clearly as the exchange current density increases, the electrode overpotential decreases at the cathode, and thus the scope for improvement decreases (Equation 12). The scope for improvement is high when the relevant overpotential is high. This explains why the percentage increase diminishes as the exchange current density continues to increase. Figure 5-41 also shows similar concentration overpotential effects for all of the IV curves.

Figure 5-42 shows the effect of increasing the anode exchange current density while leaving all other parameters unchanged. Increasing this value from $1 / 10^{\text {th }}$ of its base value to its base value results in a $46 \%$ increase in peak performance. Further increasing it by factors of 10 results in an $8 \%$ and $1 \%$ increase in performance. In fact, the improvement is barely noticeable in the activation and ohmic overpotential regions. Figure 5-29 (pp. 96) shows that anode overpotential for the base case is approximately $0.08-0.09 \mathrm{~V}$. From the Butler-Volmer equation (12), increasing the exchange current density results in a decrease in electrode overpotential. If the electrode overpotential is already small, then there is little scope for improvement. Obviously, for the lowest 
exchange current density shown, the actual anode overpotential would have been much higher than $0.09 \mathrm{~V}$, and this presented a large scope for performance improvement. For the base case, an overpotential of $0.08-0.09 \mathrm{~V}$ is very much expected at the anode, so there is very little room for improvement beyond this. This is why the performance does not improve significantly as the exchange current density is further increased.

However, in the concentration overpotential region of the IV curves, there is a significant improvement in performance as the anode exchange current density increases. This suggests that a major source of mass limitation exists at the anode. Figure 5-43 sheds more light on this. It shows the anode overpotential, for the base case, at a cell voltage of $0.1 \mathrm{~V}$. In this case, the overpotential is $0.25-0.27 \mathrm{~V}$, which is extremely large for the anode. Figure 5-44 shows that the corresponding cathode overpotential is $0.42-$ $0.43 \mathrm{~V}$, which is normal. This large overpotential at the anode presents great scope for improving the limiting cell performance as the anode exchange current density increases, as is predicted by the model.

Figure 5-45 and Figure 5-46 show the hydrogen and oxygen concentration in the outer $1 \%$ of their respective catalyst layers for a cell voltage of $0.1 \mathrm{~V}$. The oxygen concentration profile does not change much from $0.4 \mathrm{~V}$ (Figure 5-19, pp. 88), while the hydrogen concentration plummets more quickly because of the higher reaction rate (compare with Figure 5-20, pp. 88). It appears as though the anode "feels" the concentration effect more strongly than the cathode as limiting conditions approach. This results in a large increase in anode overpotential as limiting conditions approach. 


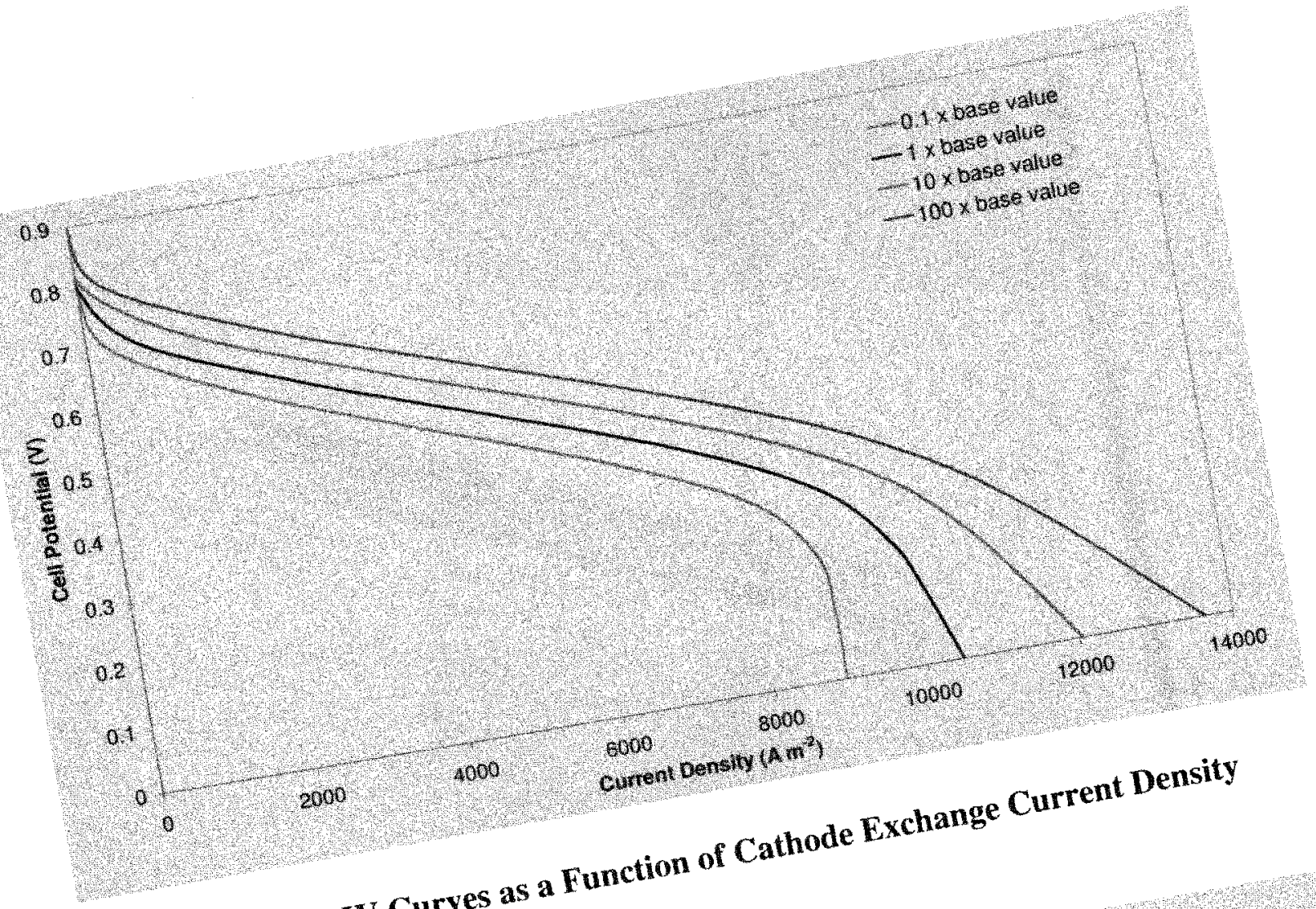

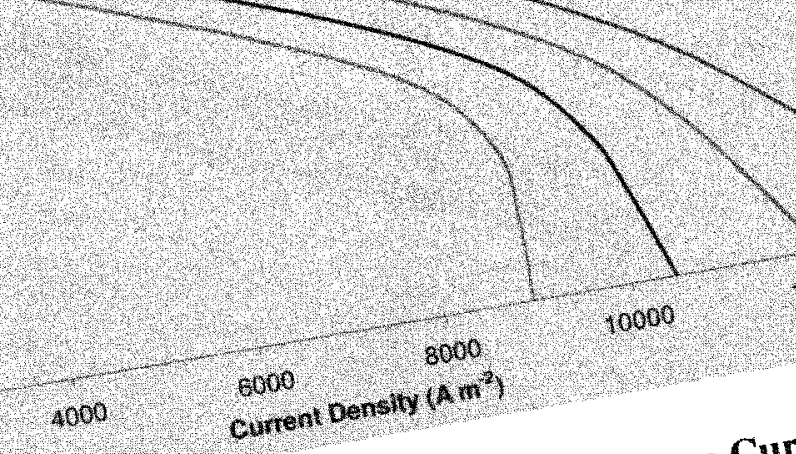

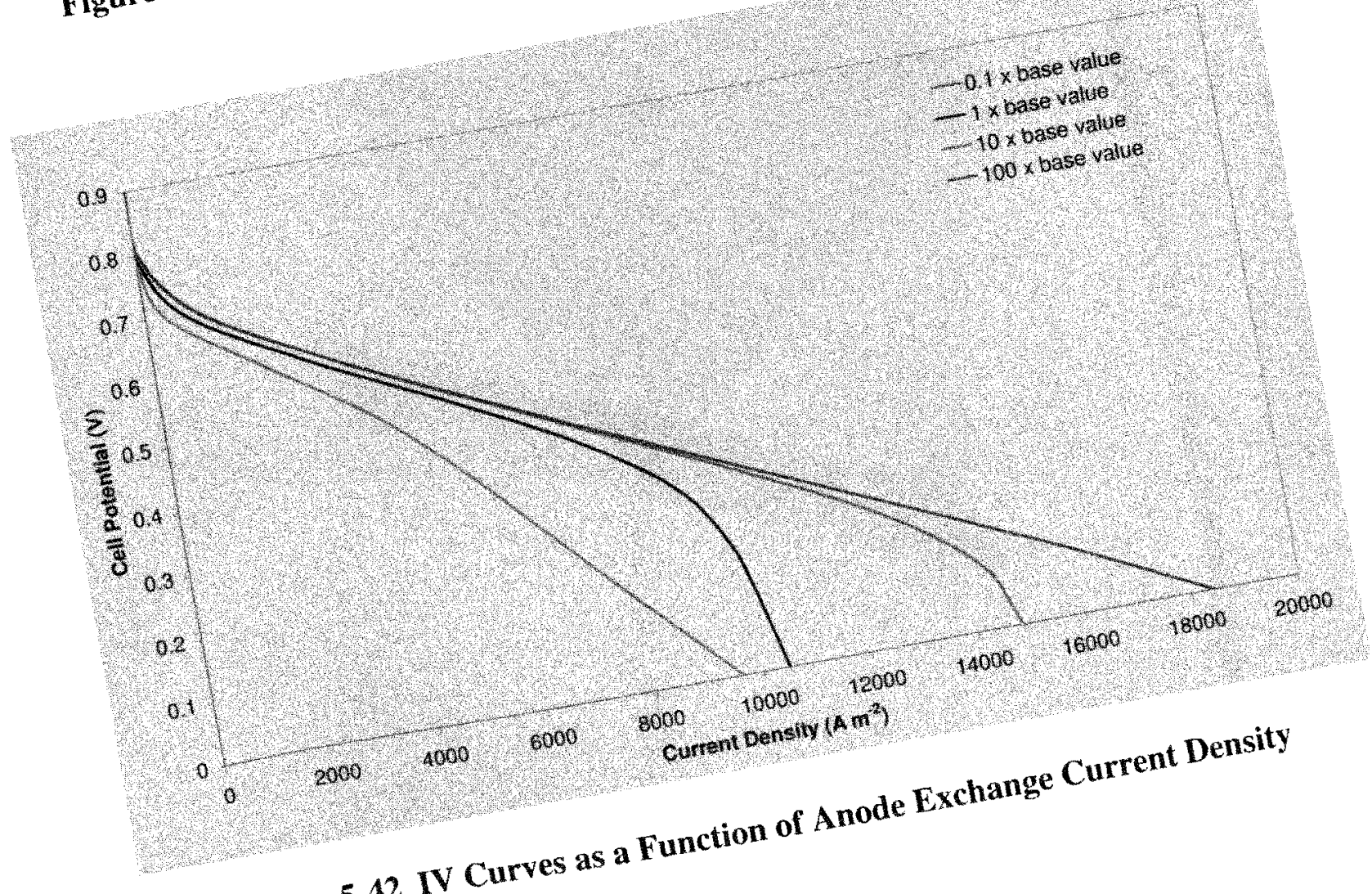



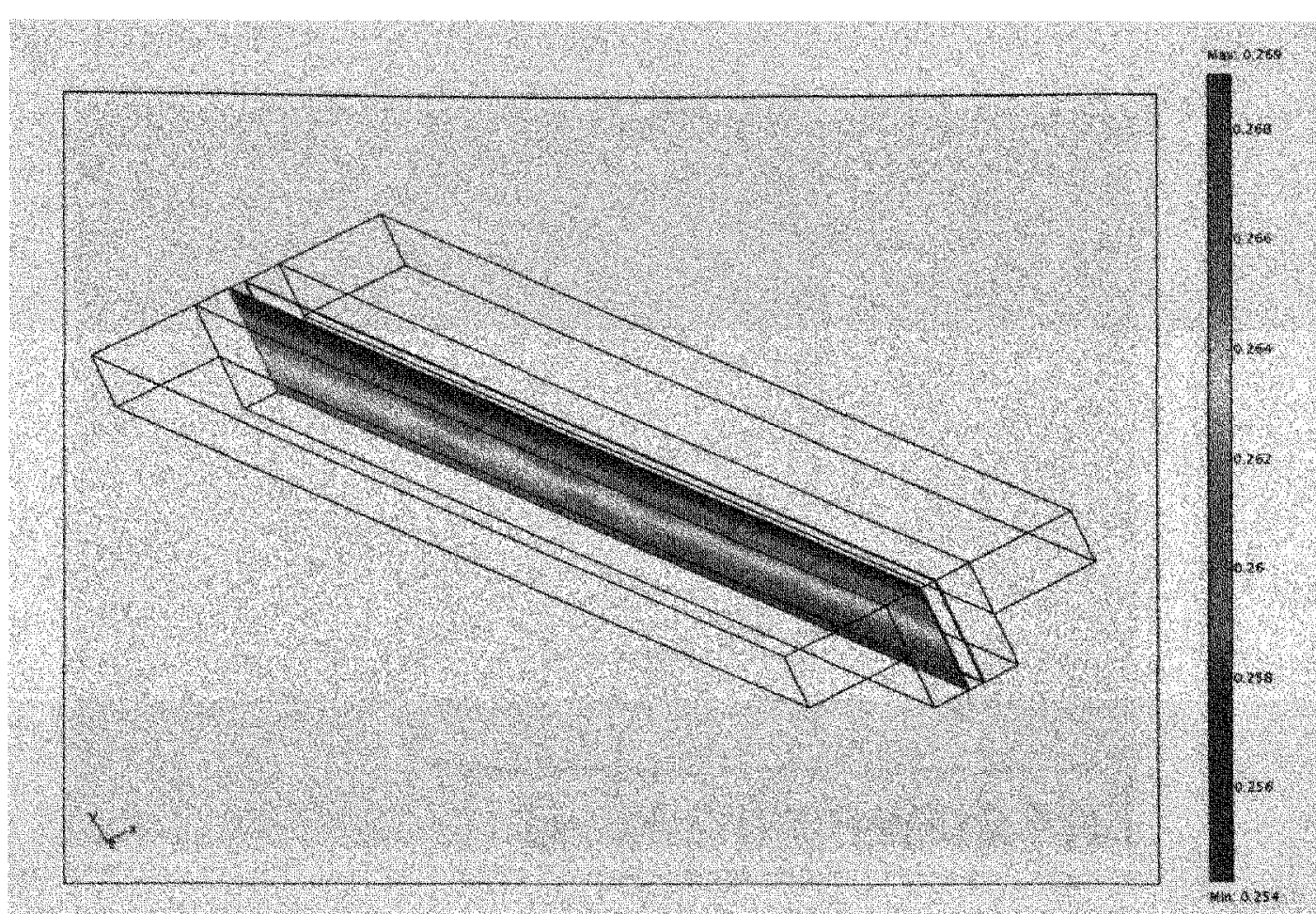

Figure 5-43 Anode Overpotential $(\mathrm{V})$ at $\mathrm{V}_{\text {cell }}=0.1 \mathrm{~V}$
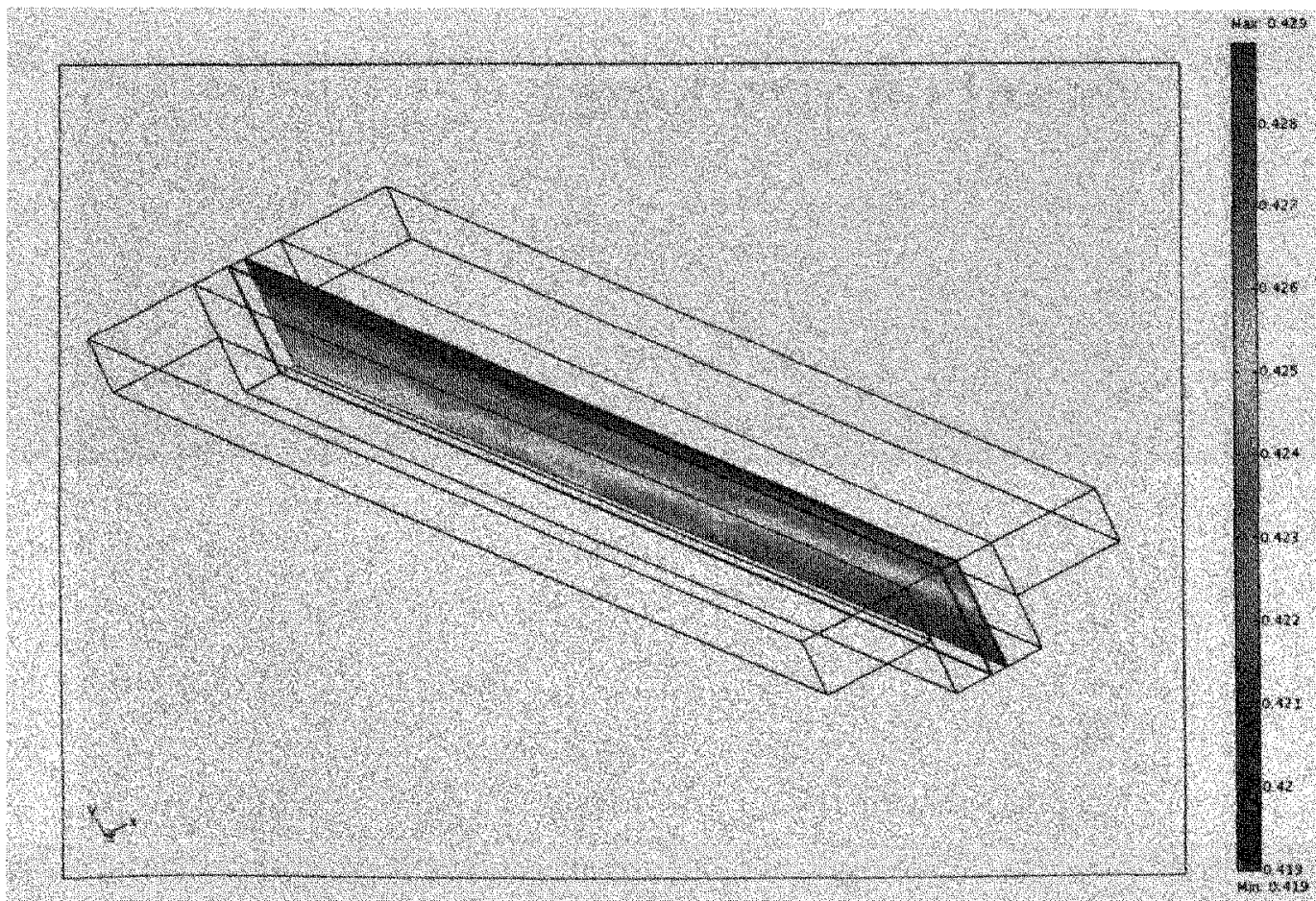

Figure 5-44 Cathode Overpotential (V) at $V_{\text {cell }}=0.1 \mathrm{~V}$ 


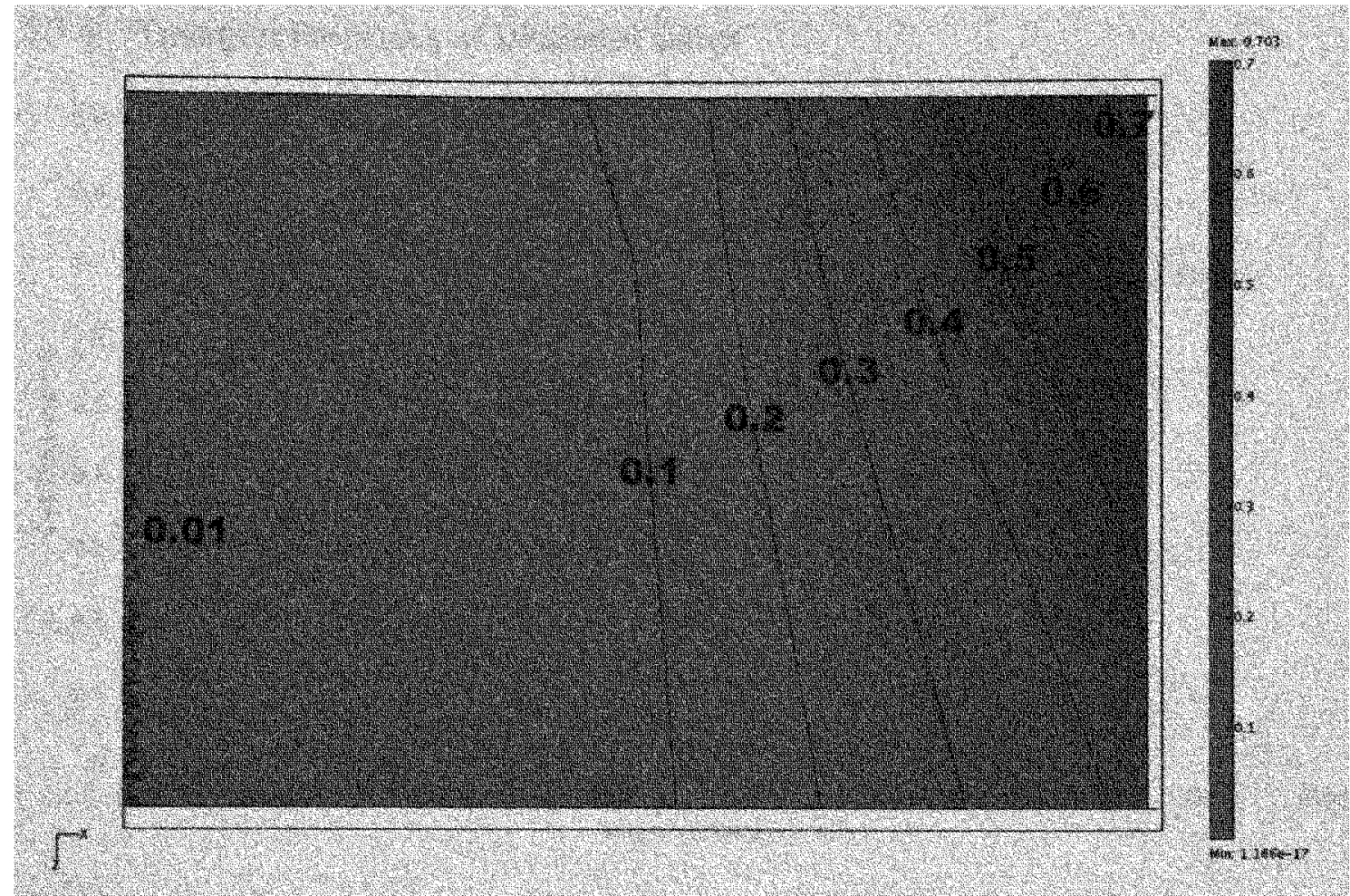

Figure 5-45 X-z Oxygen Concentration $\left(\mathrm{mol} \mathrm{m}^{-3}\right)$ in outer $1 \%$ of the CCL, 0.1 V

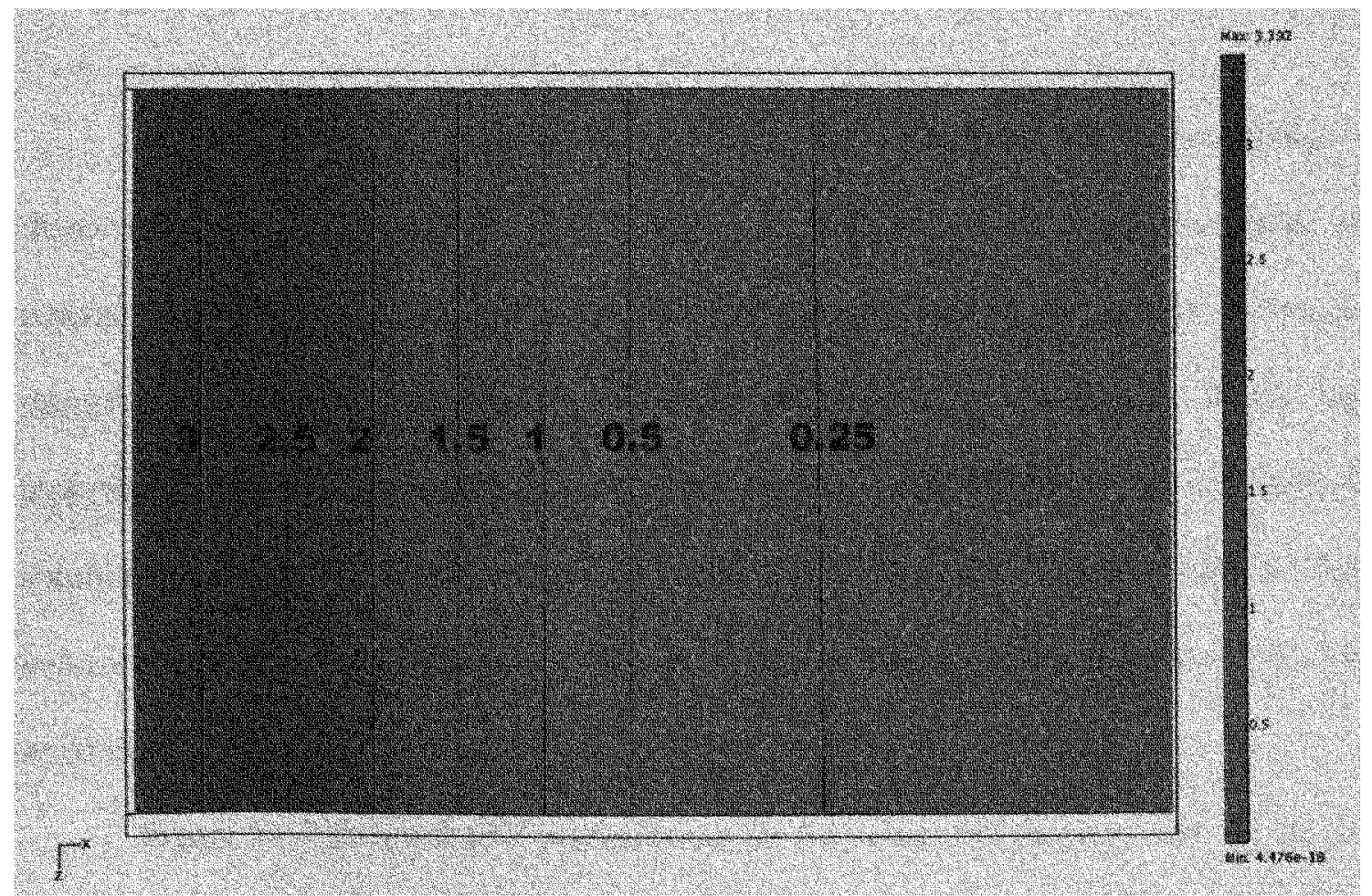

Figure 5-46 $\mathrm{x}-\mathrm{z}$ Hydrogen Concentration $\left(\mathrm{mol} \mathrm{m}^{-3}\right)$ in outer $1 \%$ of the $\mathrm{ACL}, 0.1 \mathrm{~V}$ 
5.3.4. Transport Properties of Dissolved Gases

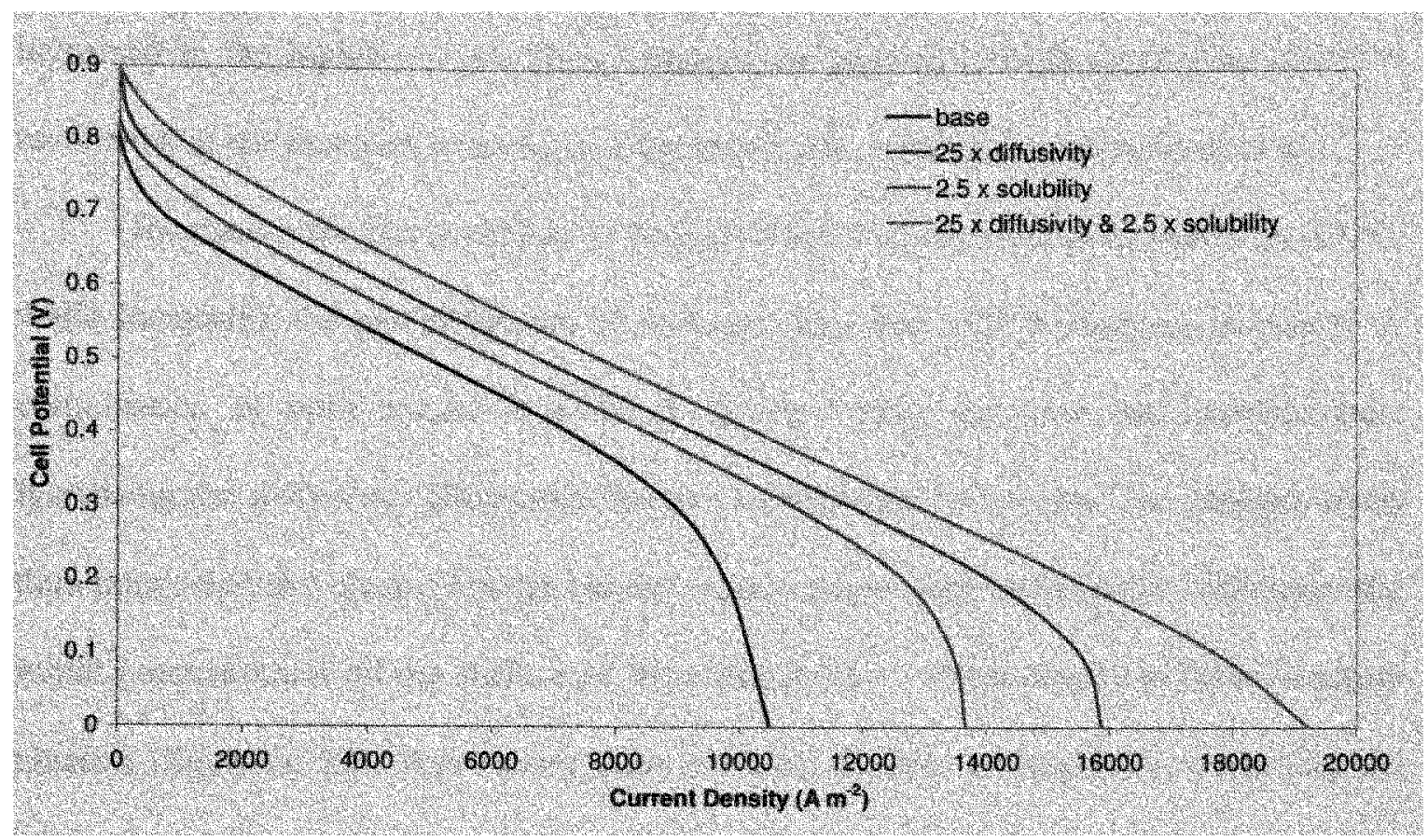

Figure 5-47 IV Curves as a Function of Electrolyte Diffusivity and Solubility

Previously it was observed that, due to the poor transport characteristics of dissolved gases in phosphoric acid systems as well as the high reaction rates, the reactants were only able to diffuse $1-2 \%$ into the catalyst layers. In this section, we observe the effect of varying the solubility and diffusivity parameters. It has been reported that trifluoromethanesulfonic acid $\left(\mathrm{CF}_{3} \mathrm{SO}_{3} \mathrm{H}\right.$ or TFMSA) affords 2.5 times the solubility of oxygen than does phosphoric acid, and 25 times the diffusivity [98]. So these values are used for comparison, with all other parameters unchanged from the base condition.

Figure 5-47 shows the IV performance for four cases: 1) the base case, 2) the case where the solubility is increased by a factor of $2.5,3$ ) the case where the diffusivity is 
increased by a factor of 25 , and 4 ) the case where both the solubility and diffusivity are increased to the higher values. These changes are applied to both electrodes, and it is assumed that the transport properties of hydrogen and oxygen maintain a fixed ratio.

Increasing the gas solubility to its high value increases the peak power by $17 \%$, while increasing the gas diffusivity to its high value has a $28 \%$ increase in power. A combination of both results in a $42 \%$ increase from the base case performance. Increasing the diffusivity allows the reactant to permeate further into the catalyst layer, thus improving the electro-kinetic characteristics. Increasing the solubility increases the initial concentration on the surface of the catalyst layer, which results in faster reaction kinetics (Equation 12). This clearly does not have as large an impact as increasing the diffusivity.

Figure 5-48 shows the 1D plot of the hydrogen concentration in the anode catalyst layer for each scenario. Generally, the area under the $C-x$ curves is a measure of the performance of the fuel cell. In the case of hydrogen, the higher diffusivity (alone) allows an increase in catalyst utilization from $2 \%$ to over $20 \%$. Increasing the solubility alone improves the utilization to $4 \%$. Because of the higher initial concentration, there is a larger area under the curve, which is seen by the improvement in the IV performance. Improving both the solubility and diffusivity results in a catalyst utilization of over $30 \%$ at the anode.

Figure 5-49 shows the equivalent 1D plots for oxygen at the cathode. It is seen that improving the oxygen solubility results in a very slight improvement in catalyst utilization, which is barely noticeable in the plot. A possible explanation is that the higher initial oxygen concentration results in higher reaction rates, and hence higher rates of 
oxygen consumption. It may be that this increase in oxygen consumption cancels out the effect of increasing solubility, and hence the catalyst utilization does not change significantly as the solubility increases. Improving the diffusivity increases the catalyst utilization from $1 \%$ to $6 \%$, while improving the diffusivity and solubility increases the catalyst utilization to approximately $15 \%$.

A noticeable feature of Figure $5-47$ is that for the higher diffusivity values, the concentration overpotential region of the IV curve becomes less sharp. Previously it was seen that this region became sharper as the current density increased (Figure 5-1, pp. 66), presumably because of the greater demand for catalyst sites combined with the increased blockage of catalyst sites. In this case, the higher diffusivity allows increased access to the catalyst sites, especially to catalyst sites further into the catalyst layer, which at the low diffusivity value, were unreachable. So this compensates for the blockage of catalyst sites, and thus the effect of blockage is less strongly felt. This is reflected in the IV curves.

For the purpose of comparison, increasing the solubility by a factor of 2.5 has a similar effect on IV performance to increasing the operating temperature by $20 \mathrm{~K}$. Increasing the diffusivity by a factor of 25 has a similar effect to increasing the doping level from 6.2 to 8 . Increasing both the solubility and diffusivity to the higher values has the same effect of increasing the exchange current density by a factor of 100 .

It must be noted that, although it is desirable to increase the diffusivity of the doping agent, there is an upper limit of diffusivity, which results in acceptable fuel cell performance. Higher diffusivities result in high catalyst utilization, however $100 \%$ catalyst utilization is not desirable. $100 \%$ utilization implies that some reactant permeates 


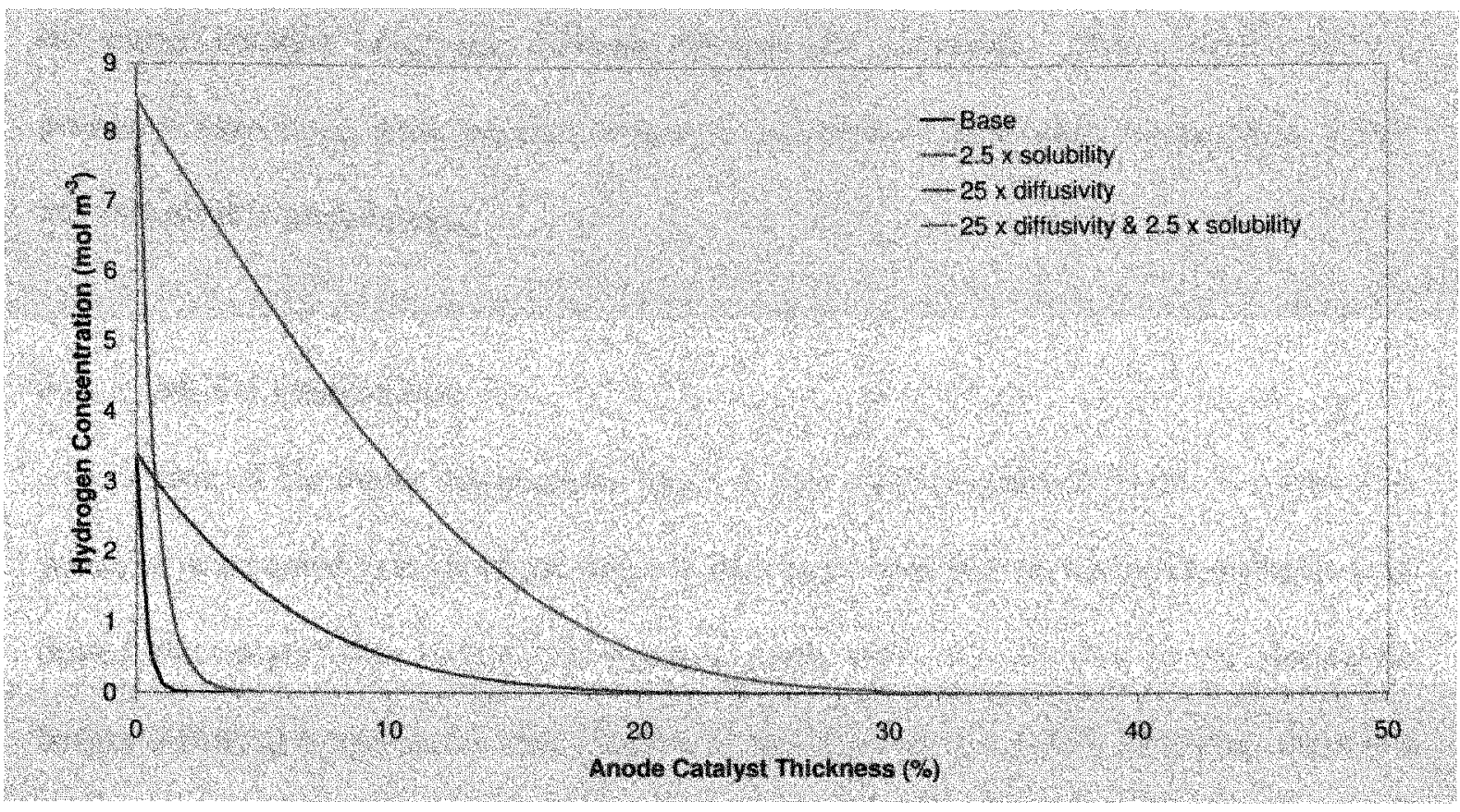

Figure 5-48 1D Hydrogen Concentration $\left(\mathrm{mol} \mathrm{m}^{-3}\right)$ in the ACL

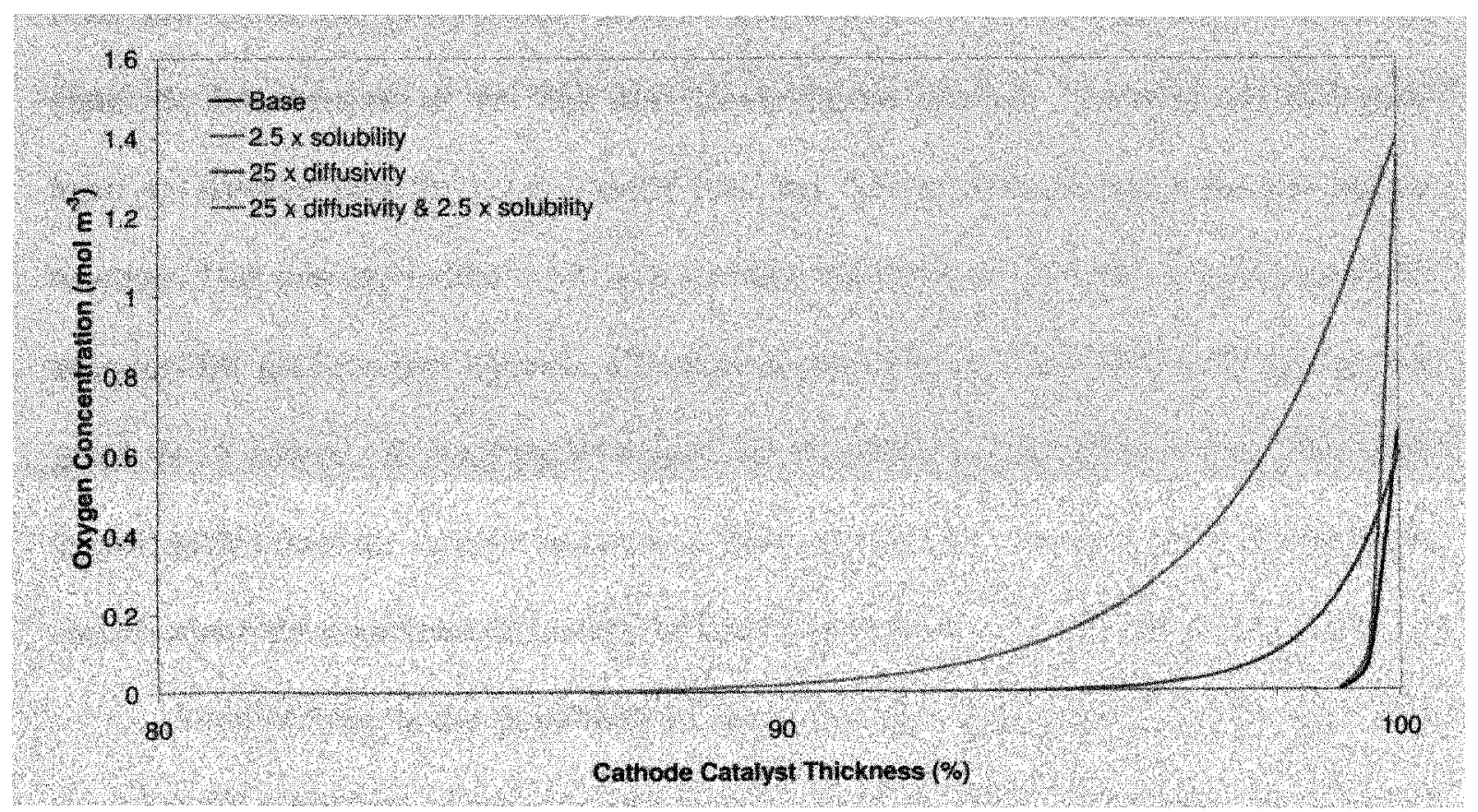

Figure 5-49 1D Oxygen Concentration $\left(\mathrm{mol} \mathrm{m}^{-3}\right)$ in the $\mathrm{CCL}$ 
the entire catalyst layer and diffuses through the membrane. This would result in problems associated with reactant crossover and direct combustion of reactants, which are undesirable phenomena.

\subsection{Model Limitations}

One of the major assumptions made in this work pertains to Figure 3-3 (pp. 27), where it is assumed that all of the catalyst sites have been wetted by the phosphoric acid doped electrolyte. This means that reacting gases must first dissolve in the electrolyte before diffusing to the active catalyst sites. It has been observed that, in reality, there is a gas porosity in the catalyst layer, meaning that only some of the pores are wetted by the electrolyte, while others are not. Seland et al [127] have conducted SEM tests on PBI fuel cells and found the gas porosity of the catalyst layer to be between $20-67 \%$, yet conclude that, because of the PBI film "covering the catalyst", "oxygen and hydrogen have to dissolve into the [acid doped] PBI and diffuse towards the platinum" before reacting. This porosity in the catalyst layer may require in a combined diffusivity, which accounts for gaseous and aqueous diffusion. Considering that the diffusivity of reactant gases is 4 orders of magnitude higher in air than in phosphoric acid, this may significantly affect the catalyst utilization results presented in this work, especially at the anode, where the combined diffusivity of hydrogen becomes much higher than oxygen.

Another issue is the possibility of reactions occurring in the gaseous phase. This would entail a mixture of aqueous and gaseous kinetics, and in some cases, the aqueous contribution may be minimal. Then almost all of the reactions would occur in the gas phase since this becomes the path of least resistance. The exchange current density values 
will also have to be modified, since they may differ for gas phase reactions. Further, any catalyst not lined along the gas pores will be unutilized since it will be blocked by the electrolyte. Essentially, catalyst utilization would be identical to the gas porosity.

There are a number of other considerations. Firstly, the major reason why only some of the pores are wetted in Nafion ${ }^{\circledR}$ fuel cells, is that some are hydrophobic while others are hydrophilic in nature. By definition, the hydrophobic pores cannot be wetted by water - the main electrolyte species associated with $\mathrm{Nafion}^{\circledR}$. This is done deliberately to provide separate flow paths for water and oxygen, thus aiding in water removal. But to what extent are the hydrophobic sites affected when phosphoric acid (vs. water) is the main electrolyte species? Secondly, the electro-kinetic data, used in this work, is taken from Liu et al [101]. Their work assumed aqueous kinetics, but if their test cell did indeed contain a fraction of unwetted gas pores, then their results may have already incorporated combined diffusivity and exchange current density values, which would have accounted for any mixed gaseous and aqueous kinetics. However, it is difficult to say whether or not this actually was the case. Further research is needed to fully investigate this phenomenon. The model may have to be refined in the light of further knowledge.

Another assumption was that the concentration of phosphoric acid, absorbed in the membrane, remained constant. This value, in fact, depends on an equilibrium established between the water absorbed in the membrane and the gas humidity. There would also be variations along the gas channels, especially at the cathode, as the humidity increases due to water generation in the cell. Further work is needed to quantify this relationship between the membrane acid concentration and the ambient humidity. 


\section{CONCLUSIONS}

A two-phase three-dimensional model of an intermediate temperature PEM fuel cell was presented. This comprehensive transport model accounted for the two-phase electrical potential phenomenon, gas dissolution in the electrolyte phase, electrochemical reactions in the aqueous electrolyte phase, as well as mass, species and energy conservation. This was the first work on modeling of PEM fuel cells operating at intermediate temperatures and employing alternative membranes to Nafion ${ }^{(B)}$, in this case, acid doped PBI.

The model predictions matched well with experimental IV data, published independently by three authors. The results were also determined to be accurate, selfconsistent and in accordance with intuitive expectations. Reactant concentrations were found to decrease along the gas channels as they were consumed in electrochemical reactions, while temperature was found to increase as the generated heat was absorbed by the gas streams. The temperature variation in the cell (with minimal cooling) at base conditions was found to be $88 \mathrm{~K}$. Cooling strategies were simulated, which could reduce this variation to less than $20 \mathrm{~K}$.

The model painted a very detailed picture of transport processes occurring within the cell. It illustrated the potential variations and the path of proton diffusion across the membrane. In addition, it identified the most reactive regions within the cell. Our results showed that highest reaction rates occurred in the catalyst layers toward the entrance of the cell $(z \rightarrow 0)$, and in the catalyst regions under ( $x$-direction sense) the ribs rather than under the channels. 
The model addressed three prohibitive features, which deter the commercial development of intermediate temperature PEM fuel cells: 1) performance limitations, 2) catalyst utilization, and 3) material considerations.

The major factors affecting the performance of intermediate temperature PEM fuel cells were found to be the acid doping level, temperature of operation, and the transport properties of dissolved gases in the electrolyte. The performance is very sensitive to temperature and doping level, and generally improves as each of these parameters increases. There are however, upper limits for both parameters, since the acid in the membrane decomposes above $200{ }^{\circ} \mathrm{C}$, and the mechanical properties of the membrane begin to degrade as the acid doping level increases.

The performance of the fuel cell was found to be anode limiting. This was evidenced by the fact that the limiting performance improved significantly as the anode exchange current density was increased. The activation and ohmic IV performance, however, only improved slightly.

The catalyst utilization of the modeled fuel cell was predicted to be between 1 $2 \%$ for nominal operation. This represents major cost inefficiencies. Potential savings of over $90 \%$ of the cost of the catalyst are possible, without affecting the performance of the cell. But advanced catalyst deposition techniques must be identified, which would allow for a significant reduction in the eventual thickness of the catalyst layer, without compromising the mechanical integrity of the MEA. Such techniques may involve nanotechnological or electrochemical methods. These findings may be refined in the light of new knowledge regarding the possibility of gas phase electro-kinetics in this type of fuel cell. 
Significant performance improvements are predicted with the use of alternative doping agents to phosphoric acid. The transport limitations, associated with phosphoric acid systems, are responsible for the low catalyst utilizations. The model predicted that the IV performance can be improved by nearly $50 \%$ if alternative doping agents could be found, which afford better transport of dissolved gases, and a reduced tendency to adsorb onto the catalyst surface. A doping agent, with a 62.5 times higher diffusivity-solubility product, will result in an IV performance, which is equivalent to a 100-fold increase in catalytic activity.

It remains an issue for material scientists and chemists to identify or fabricate a suitable doping agent for intermediate temperature PEM fuel cells. This agent must be highly ionizing, thus allowing for high conductivity at the required temperatures. In addition, it must maintain its stability at the desired operating conditions, while affording higher solubility and diffusivity of oxygen and hydrogen than phosphoric acid. There should also be a reduced tendency of anions of the acid to adsorb onto the catalyst surface. Possible candidates are sulfuric acid and TFMSA. It is also possible that a modification of phosphoric acid may result in the desired properties. There is evidence that decreasing the acid concentration within the membrane (increasing its hydration) may result in enhanced conductivity and transport properties. The acid concentration is the result of an equilibrium established between the ambient humidity and the water content inside the membrane. So increasing the humidity of the gas streams may result in better acid properties. The model will also be improved if this factor were taken into account, but more work is needed to quantify this phenomenon. 
The experimental aspect of this work identified the need for an integrated approach to MEA assembly. Compatibility of materials is critical to the effective functioning of the fuel cell. The lack of repeatability of the intermediate temperature results indicates that compatibility issues may exist, especially due to uneven swelling or expansion, which limits the in-situ performance of the cell. DuPont ${ }^{\circledR}$ produces membranes and electrodes, which are compatible with each other, but are applicable for low temperature operation. A similar combination of membrane, electrodes, doping agents and catalyst materials are required for intermediate temperature operation, which are compatible with one another for the full range of expected operating conditions.

The model results have highlighted specific areas, which warrant further research in order to expedite the development of intermediate temperature PEM fuel cell technology - the need for advanced catalyst deposition techniques and for alternative doping agents. Most of the findings presented in this work are difficult to determine and quantify without mathematical modeling. Thus, the model serves as a tool to elicit a greater understanding of the transport phenomena occurring in the cell, the causes of performance limitations, and the areas where research should be focused. 


\section{REFERENCES}

1 K. Adamson, Hydrogen from renewable resources-the hundred year commitment, Energy Policy 32 (2004) 1231-1242.

2 N. Munroe, D. Cheddie, Perspectives on Fuelling Fuel Cells for Energy Systems in Developing Countries, Proceeds. Latin American and Caribbean Consortium of Engineering Institutions (LACCEI) 2004, Miami, FL.

3 N. Munroe, D. Cheddie, Fuelling Fuel Cells from Domestic Resources in Developing Countries, Presented at the Latin American and Caribbean Consortium of Engineering Institutions (LACCEI) 2005, Cartagena, Colombia.

4 D. Cheddie, N. Munroe, Strategies for Developing Nations in the Future Hydrogen Economy, Caribbean Studies Newsletter 2005; 32 (1): 2-5.

5 DOE, High temperature, low relative humidity polymer type membranes: DEPS36-05GO95020, Retrieved April 20, 2006, from http://www.eere.energy.gov/hydrogenandfuelcells/program_solicitations.html.

6 O. Savadogo, Emerging membranes for electrochemical systems part II. High temperature composite membranes for polymer electrolyte fuel cell (PEFC) applications, Journal of Power Sources 127 (2004) 135.

7 D. Cheddie, N. Munroe, Review and Comparison of Approaches to Proton Exchange Membrane Fuel Cell Modeling, J. Power Sources 147 (2005) 72.

8 D. Cheddie, N. Munroe, Mathematical model of a PEMFC using a PBI membrane, Energy Conversion and Management 47 (2006) 1490-1504.

9 D. Cheddie, N. Munroe, Parametric Model of an Intermediate Temperature PEMFC, J. Power Sources 156 (2006) 414-423.

10 D. Cheddie, N. Munroe, Two-dimensional Effects in Intermediate Temperature PEMFCs, Int. J. Transport Phenomena 8 (2006) 51-68.

11 D. Cheddie, N. Munroe, Three-dimensional Modeling of High Temperature PEMFCs, J. Power Sources, article in press.

12 D. Cheddie, N. Munroe, Analytical Correlations for Intermediate Temperature PEMFCs, J. Power Sources, article in press.

13 D. Cheddie, N. Munroe, A two phase model of an intermediate temperature PEM fuel cell, Int. J. Hydrogen Energy, Submitted for publication. 
14 D. Cheddie, N. Munroe, Modeling of High Temperature PEM Fuel Cells using FEMLAB, Comsol Multiphysics Conference 2005, Boston, MA.

15 D. Cheddie, N. Munroe, Mathematical Modeling of High Temperature PEM Fuel Cells, Presented at the Materials Congress 2006, London, UK.

16 D. Cheddie, N. Munroe, Modeling of PEM Fuel Cells using PBI Membranes, ASME Fuel Cell Conference 2006, Irvine, CA.

17 D. Cheddie, N. Munroe, Two Phase Modeling of a Phosphoric Acid Doped PEM Fuel Cell, ASME Joint U.S.-European Fluids Engineering Summer Meeting 2006, Miami, FL.

18 F. Standaert, K. Hemmes, N. Woudstra, Analytical fuel cell modeling, Journal of Power Source 63 (1996) 212-234.

19 F. Standaert, K. Hemmes, N. Woudstra, Analytical fuel cell modeling; nonisothermal fuel cells, J. Power Sources 70 (1998) 181-189.

20 E. Springer, T.A. Sawodzinski S. Gottesfeld, Polymer Electrolyte Fuel Cell Model, J. Electrochemical Society 138 (1991) 2334.

21 J.C. Amphlett, R.M. Baumert, R.F. Mann, B.A. Peppley, P.R. Roberge, Performance modeling of the Ballard Mark IV solid polymer electrolyte fuel cell I. Mechanistic model development, J. Electrochemical Society, 142:1 (1995) 1-8.

22 L. Pisani, G. Murgia, M. Valentín, B. D'Aguanno, A new semi-empirical approach to performance curves of polymer electrolyte fuel cells, J. Power Sources 108 (2002) 192-203.

23 G. Maggio, V. Recupero, L. Pino, Modeling polymer electrolyte fuel cells: an innovative approach, J. Power Sources 101 (2001) 275-286.

24 S.H. Chan, S.K. Goh, S.P. Jiang, A mathematical model of polymer electrolyte fuel cell with anode CO kinetics, Electrochimica Acta 48 (2003) 1905-1919.

25 C. N. Maxoulis, D. N. Tsinoglou, G. C. Koltsakis, Modeling of automotive fuel cell operation in driving cycles, Energy Conversion and Management 45 (2004) 559-573.

26 D. M. Bernardi, M.W. Verbrugge, Mathematical model of a gas diffusion electrode bonded to a polymer electrolyte, AIChE Journal 37:8 (1991) 1151-1163.

27 D. M. Bernardi, M.W. Verbrngge, A mathematical model of the solid-polymerelectrolyte fuel cell, J. Electrochemical Society 139:9 (1992) 2477-2491. 
28 J.J. Baschuk, Xianguo Li, Modelling of polymer electrolyte membrane fuel cells with variable degrees of water flooding, J. Power Sources 86 (2000) 181-196.

29 W.M. Yan, F. Chen, H.Y. Wu, C.Y. Soong, H.S. Chu, Analysis of thermal and water management with temperature-dependent diffusion effects in membrane of proton exchange membrane fuel cells, J. Power Sources 129 (2004) 127-137.

30 M. Wohr, K. Holwin, W. Schurnberger, M. Fischer, W. Neubrnad, G.

Eigenberger, Dynamic modeling and simulation of a polymer membrane fuel cell including mass transport limitation, Int. J. Hydrogen Energy 23:3 (1998) 213-218.

31 V. Gurau, H. Liu, S. Kakac, Two-dimensional model for proton exchange membrane fuel cells, AIChE Journal 44 (1998) 2410-2422.

32 C. Y. Wang, W. B. Gu, B. Y. Liaw, Micro-macroscopic coupled modeling of batteries and fuel cells, J. Electrochemical Society 145 (1998) 3407-3417.

33 T. Zhou, H. Liu, A general three-dimensional model for proton exchange membrane fuel cells, Int. J. Transport Phenomena, 3:3 (2001) 177-198.

34 S. V. Patankar, Numerical Heat Transfer and Fluid Flow, Hemisphere, Washington DC, 1980

35 S. Um, C.Y. Wang, K.S. Chen, Computational fluid dynamics modeling of proton exchange membrane fuel cells, J. Electrochemical Society 147:12 (2000) 4485-4493.

36 S. Ge, B Yi, A mathematical model for PEMFC in different flow modes, J. Power Sources 124 (2003) 1-11.

37 L. Wang, A. Husar, T. Zhou, H. Liu, A parametric study of PEM fuel cell performances, Int. J. Hydrogen Energy 28 (2003) 1263 - 1272.

38 T. Zhou, H. Liu, A 3D model for PEM fuel cells operated on reformate, J. Power Sources 138 (2004) 101-110.

39 T. Berning, D.M. Lu, N. Djilali, Three-dimensional computational analysis of transport phenomena in a PEM fuel cell, J. Power Sources 106 (2002) 284-294.

40 T. Berning, N. Djilali, Three-dimensional computational analysis of transport phenomena in a PEM fuel cell-a parametric study, J. Power Sources 124 (2003) $440-452$.

41 S. Dutta, S. Shimpalee, J.W. Van Zee, Numerical prediction of mass-exchange between cathode and anode channels in a PEM fuel cell, Int. J. Heat and Mass Transfer 44 (2001) 2029-2042. 

with serpentine gas flow channels, J. Power Sources 130 (2004) 149-157.

43 N.P. Siegel, M.W. Ellis, D.J. Nelson, M.R. von Spakovsky, A two-dimensional computational model of a PEMFC with liquid water transport, J. Power Sources 128 (2004) 173-184.

44 M. Hu, A. Gu, M. Wang, X. Zhu, L. Yu, Three dimensional, two phase flow mathematical model for PEM fuel cell: Part I. Model development, Energy Conversion and Management 45 (2004) 1861-1882.

45 W. Ying, T.H. Yang, W.Y. Lee, J. Ke, C.S. Kim, Three-dimensional analysis for effect of channel configuration on the performance of a small air-breathing proton exchange membrane fuel cell (PEMFC), J. Power Sources 145 (2005) 572-581.

46 A. Kumar, R.G. Reddy, Modeling of polymer electrolyte membrane fuel cell with metal foam in the flow-field of the bipolar/end plates, J. Power Sources 114 (2003) 54-62.

47 M. Hu, A. Gu, M. Wang, X. Zhu, L. Yu, Three dimensional, two phase flow mathematical model for PEM fuel cell: Part II. Analysis and discussion of the internal transport mechanisms, Energy Conversion and Management 45 (2004) $1883-1916$.

48 H. Sun, H. Liu, L.J. Guo, PEM fuel cell performance and its two-phase mass transport, J. Power Sources 143 (2005) 125-135.

49 M. Hogarth, X. Glipa, High temperature membranes for solid polymer fuel cells, ETSU F/02/00189/REP DTI/Pub URN 01/893, report prepared for Johnson Matthey Technology Centre, 2001.

50 H. Pu, Q. Liu, G. Liu, Methanol permeation and proton conductivity of aciddoped poly(N-ethylbenzimidazole) and poly( $\mathrm{N}$-methylbenzimidazole), Journal of Membrane Science 241 (2004) 169.

51 L. Jorissen, V. Gogel, J. Kerres, J. Garche, New membranes for direct methanol fuel cells, J. Power Sources 105 (2002) 267.

52 J.S. Wainright, J.T. Wang, D. Weng, R.F. Savinell, M. Litt, Acid-doped polybenzimidazole: a new polymer electrolyte, J. Electrochem. Soc. 142 (1995) L121.

53 C. Hasiotis, V. Deimede, C. Kontoyannis, New polymer electrolytes based on blends of sulfonated polysulfones with polybenzimidazole, Electrichimica Acta 46 (2001) 2401. 
54 S. Wasmus, A. Saunch, H. Moaddel, P.L. Rinaldi, M. Litt, C. Rogers, A. Valeriu, G.D. Mateescu, D.A. Tryk, R.F. Savinell, Ext. Abstract, No 466, 187th Electrochemical Society Meeting, Reno, NV, May 21-26 (1995).

55 J.T. Wang, J.S. Wainright, R.F. Savinell, M. Litt, A direct methanol fuel cell using acid-doped polybenzimidazole as polymer electrolyte, J. Applied Electrochemistry 26 (1996) 751.

56 J.S. Wainright, J.T. Wang, R.F. Savinell, Direct methanol fuel cells using acid doped polybenzimidazole as a polymer electrolyte, proceeds of the intersociety energy conversion engineering conference, Washington DC (1996) 1107.

57 D. Weng, J.S. Wainright, U. Landau, R.F. Savinell, Electro-osmotic drag coefficient of water and methanol in polymer electrolytes at elevated temperatures, J. Electrochemical Society 143 (1996) 1260.

58 H.A. Pohl, R.P. Chartoff, Carriers and unpaired spins in some organic semiconductors, J. Polymer Sci., Part A 2 (1964) 2787.

59 R. Savinell, E. Yeager, D. Tryk, U. Landau, J. Wainright, D. Weng, K. Luk, M. Litt, C. Rogers, A Polymer Electrolyte for Operation at Temperatures up to 200 OC, J. Electrochem. Soc, 141 (1994) LA6.

60 G.G. Scherer, E. Killer, D. Grman, Radiation grafted membranes: some structural investigations in relation to their behavior in ion-exchange-membrane water electrolysis cells, Int. J. Hydrogen Energy 17 (1992) 115.

61 S.R. Samms, S. Wasmus, R.F. Savinell, Thermal Stability of Proton Conducting Acid Doped Polybenzimidazole in Simulated Fuel Cell Environments, J. Electrochem. Soc. 143 (1996) 1225.

62 L. Qingfeng, R. He, J. Gao, J.O. Jensen, N.J. Bjerrum, The CO poisoning effect in PEMFCs operational at temperatures up to $200^{\circ} \mathrm{C}$, J. Electrochemical Society 150 (2003) A1599-A1605.

63 J. A. Asensio, B. Salvador, G.-R. Pedro, Enhanced conductivity in polyanioncontaining polybenzimidazoles. Improved materials for proton-exchange membranes and PEM fuel cells, Electrochemistry Communications 5 (2003) 967.

64 L. Qingfeng, H.A. Hjuler, N.J. Bjerrum, Phosphoric acid doped polybenzimidazole membranes: physiochemical characterization and fuel cell applications, J. Applied Electrochemistry 31 (2001) 773-779.

65 E. Fekete, Z. Peredy, E. Foldes, F.E. Karasz, B. Puanszky, Polymer Bulletin 39 (1997) 93. 

poly(2,5-benzimidazole) (ABPBI) and phosphoric acid prepared by direct acid casting, J. Membrane Science 241 (2004) 89.

67 S. Wasmus, J.T. Wang, R.F. Savinell, Real time mass spectrometric investigation of methanol oxidation in a direct methanol fuel cell, J. Electrochemical society 142 (1995) 3825.

68 R. Bouchet, S. Miller, M. Duclot, J.L. Souquet, A thermodynamic approach to proton conductivity in acid-doped polybenzimidazole, Solid State Ionics 145 (2001) 69-78.

69 O. Savadogo, B. Xing, Hydrogen/oxygen polymer electrolyte membrane fuel cell (PEMFC) based on acid-doped polybenzimidazole (PBI), J. New Materials for Electrochemical Systems 3 (2000) 345.

70 B. Xing, O. Savadogo, Hydrogen/oxygen polymer electrolyte membrane fuel cells (PEMFCs) based on alkaline-doped polybenzimidazole (PBI), Electrochemistry Communications 2 (2000) 697.

71 J. J. Fontanella, M. C.Wintersgill, J. S.Wainright, R. F. Savinell, M. Litt, High pressure electrical conductivity studies of acid doped polybenzimidazole, Electrochim. Acta 43 (1998) 1289.

72 J. M. Bae, I. Honma, M. Murata, T. Yamamoto, M. Rikukawa, N. Ogata, Properties of selected sulfonated polymers as proton-conducting electrolytes for polymer electrolyte fuel cells, Solid State Ionics 147 (2002) 189.

73 V. Deimede, G. A. Voyiatzis, J. K. Kallitsis, L. Qingfeng, N. J. Bjerrum, Macromolecules 33 (2000) 7609.

74 V. Deimede, C. Hasiotis, E. Stefanidaki, G. A. Voyiatzis, C. G. Kontoyannis, J. K. Kallitsis, Proceedings of the International George Papatheodorou Symposium, ICE:HTFORTH, 1999, Patras, pp.224-228.

75 A. Schechter, R. F. Savinell, Imidazole and 1-methyl imidazole in phosphoric acid doped polybenzimidazole, electrolyte for fuel cells, Solid State Ionics 147 (2002) 181 .

76 N. Gourdoupi, A.K. Andreopoulou, V. Deimede, J.K. Kallitsis, Novel protonconducting polyelectrolyte composed of an aromatic polyether containing mainchain pyridine units for fuel cell applications, Chem. Mater. 15 (2003) 5044.

77 M. K. Daletou, N. Gourdoup, J. K. Kallitsis, Proton conducting membranes based on blends of PBI with aromatic polyethers containing pyridine units, J. Membrane Science 252 (2005) 115. 

Madeira, S. Nunes, Performance and efficiency of a DMFC using non-fluorinated composite membranes operating at low/medium temperatures, J. Power Sources 145 (2005) 485 .

79 P. Staiti, M. Minutoli, Influence of composition and acid treatment on proton conduction of composite polybenzimidazole membranes, J. Power Sources 94 (2001) 9.

80 P. Staiti, A.S. Arico, S. Hocevar, V. Antonucci, Morphological variation of platinum catalysts in phosphotungstic acid fuel cell, J. Power Sources 70 (1998) 91.

81 P. Staiti, S. Hocevar, N. Giordano, Fuel cells with $\mathrm{H}_{3} \mathrm{PW}_{12} \mathrm{O}_{40} \cdot 29 \mathrm{H}_{2} \mathrm{O}$ as solid electrolyte, Int. J. Hydrogen Energy 22 (1997) 809.

82 T. Hattori, A. Ishiguro, Y. Murakami, Acidity of crystalline zirconium phosphate, J. Inorg. Nucl. Chem. 40 (1978) 1107.

83 S.E. Horsley, D.V. Nowell, The preparation and characterization of crystalline zirconium phosphate, J. Appl. Chem. Biotechnol. 23 (1973) 215.

84 H. Pu, W. H. Meyer, G. Wegner, Proton Transport in Polybenzimidazole Blended with $\mathrm{H}_{3} \mathrm{PO}_{4}$ or $\mathrm{H}_{2} \mathrm{SO}_{4}$, J. Polymer Science: Part B: Polymer Physics 40 (2002) 663.

85 M. Kawahara, J. Morita, M. Rikukuawa, K. Sanui, N. Ogata, Synthesis and proton conductivity of thermally stable polymer electrolyte: poly(benzimidazole) complexes with strong acid molecules, Electrochim. Acta 45 (2000) 1395.

86 C. A. Edmondson, M. G. Wintersgill, J. J. Fontanella, F. Gerace, B. Scrosati, S. G. Greenbaum, Solid State Ionics 85 (1996) 173.

87 J. J. Fontanella, M. C. Wintergill, M. K. Smith, J. Semancik, C. G. Andeen, Point defect activation volumes in the alkaline-earth fluorides, J. Phys. C: Solid State Physics 14 (1981) 2451.

88 J. J. Fontanella, M. C. Wintersgill, J. P. Calame, F. P. Purwl, D. R. Figueroa, C. G. Andeen, Effect of pressure on conductivity in poly(ethylene oxide) complexed with alkali metal salts, Solid State Ionics 9 (1983) 1139.

89 C.P. Buckley, D.R. Salem, high-temperature viscoelasticity and heat-setting of poly(ethylene terephthalate), Polymer 28 (1987) 69.

90 R. Bouchet, E. Siebert, Proton conduction in acid doped polybenzimidazole, Solid State Ionics 118 (1999) 287. 
91 L. Qingfeng, R. He, R.W. Berg, H.A. Hjuler, N.J. Bjerrum, Water uptake and acid doping of polybenzimidazoles as electrolyte membranes for fuel cells, Solid State Ionics 168 (2004) 177.

92 D. Weng, J.S. Wainright, U. Landau, R.F. Savinell, in Electrode Materials and Processes for Energy Conversion and Storage, S. Srinivasan, D.D. Macdonald, A.C. Khandkar (Eds.), The Electrochemical Society Proceedings Series, Pennington, NJ, 1994, p. 201.

93 Bozkurt, M. Ise, K.D. Kreuer, W.H. Meyer, G. Wegner, Proton-conducting polymer electrolytes based on phosphoric acid, Solid State Ionics 125 (1999) 225.

94 N. W. Brooks, R. A. Duckett, J. Rose, I. M. Ward, J. Clements, An n.m.r. study of absorbed water in polybenzimidazole, Polymer 34 (1993) 4038.

95 R. He, L. Qingfeng, G. Xiao, N. J. Bjerrum, Proton conductivity of phosphoric acid doped polybenzimidazole and its composites with inorganic proton conductors, J. Membrane Science 226 (2003) 169-184.

96 J.A. Asensio, S. Borros, P.G. Romero, Proton-conducting polymers based on benzimidazoles and sulfonated benzimidazoles, J. Polymer Science, Part A: Polymer Chemistry 40 (2002) 3703.

97 S.K. Zecevic, J.S. Wainright, M.H. Litt, S.L. Gojkovic, R.F. Savinell, Kinetics of $\mathrm{O} 2$ reduction on a $\mathrm{Pt}$ electrode covered with a thin film of solid polymer electrolyte, J. Electrochemical Society 144 (1997) 2973.

98 P. Zelenay, B.R. Scharifker, J. O'M Bockris, G. Gervasio, A Comparison of the Properties of $\mathrm{CF}_{3} \mathrm{SO}_{3} \mathrm{H}$ And $\mathrm{H}_{3} \mathrm{PO}_{4}$ in Relation to Fuel Cells, J. Electrochem. Soc. 133 (1986) 2262.

99 K.E. Gubbins, R.D. Walker Jr., The solubility and diffusivity of oxygen in electrolytic systems, J. Electrochemical Society 112 (1965) 469-471.

100 Z. Liu, J.S. Wainright, R.F. Savinell, High temperature polymer electrolytes for PEM fuel cells: study of the oxygen reduction reaction (ORR) at a Pt-polymer electrolyte interface, Chemical Engineering Science 59 (2004) 4833-4838.

101 Z. Liu, J.S. Wainright, M.H. Litt, R.F. Savinell, Study of the oxygen reduction reaction (ORR) at $\mathrm{Pt}$ interfaced with phosphoric acid doped polybenzimidazole at elevated temperature and low relative humidity, Electrochimica Acta, article in press.

102 J.T. Wang, R.F. Savinell, J. Wainright, M. Litt, H. Yu, A H2/O2 fuel cell using acid doped polybenzimidazole as polymer electrolyte, Electrochemica Acta 41 (1996) 193. 
103 L. Qingfeng, H. A. Hjuler, N. J. Bjerrum, Oxygen reduction on carbon supported platinum catalysts in high temperature polymer electrolytes, Electrochimica Acta 45 (2000) 4219.

104 L. Qingfeng, H.A. Hjuler, C. Hasiotis, J.K. Kallitsis, C.G. Kontoyannis, N.J. Bjerrum, A quasi-direct methanol fuel cell system based on blend polymer membrane electrolytes, Electrochemical and Solid State Letters 5 (2002) A125.

105 J. Wang, S. Wasmus R.F. Savinell, Evaluation of ethanol, 1-propanol, and 2propanol in a direct oxidation polymer-electrolyte fuel cell. A real-time mass spectrometry study, J. electrochemical society 142 (1995) 4218.

106 K. Wark, K. Wark Jr, Advanced thermodynamics for engineers, McGraw Hill, NY, 1994.

107 G.R. Hadley, Thermal Conductivity of Packed Metal Powders, Int. J. Heat and Mass Transfer 29 (1986) 909-920.

108 D.L. Koch, J.F. Brady, Dispersion in Fixed Beds, J. Fluid Mechanics 154 (1985) 399-427.

109 M. Kaviany, Principles of Heat Transfer in Porous Media, Springer-Verlag, NY, 1991.

110 J.R. Welty, C.E. Wicks, R.E. Wilson, Fundamentals of Momentum, Heat and Mass Transfer, Wiley, NY, 1969.

111 R.E. Meredith, C.W. Tobias, Conduction in Heterogeneous Systems, in: C.W. Tobias (Ed.), Advances in Electrochemistry and Electrochemical Engineering 2, Interscience Publishers, NY, 1962.

112 K. Klinedinst, J.A.S. Bett, J. Macdonald, P. Stonehart, Oxygen solubility and diffusivity in hot concentrated $\mathrm{H}_{3} \mathrm{PO}_{4}$, Electroanalytical Chemistry and Interfacial Electrochemistry 57 (1974) 281-289.

113 J.C. Huang, R.K. Sen, E. Yeager, Oxygen reduction on platinum in $85 \%$ orthophosphoric acid, J. Electrochemical Society 126 (1979) 768-792.

114 Z. Ogumi, Z. Takehara, S. Yoshizawa, Gas Permeation In SPE Method I. Oxygen Permeation through Nafion and Neosepta, J. Electrochemical Society 131 (1984) 769.

115 Boedeker Plastics, Inc., Celazole ${ }^{\otimes}$ PolyBenzImidazole Specifications, Retrieved June 15, 2005, from http://www.boedeker.com/celazo_p.htm.

116 University of California, San Diego (UCSD), Properties for Graphite, Retrieved June 15, 2005, from http://casl.ucsd.edu/data_analysis/carpet_plots.htm. 
117 T. A. Davis, A column pre-ordering strategy for the unsymmetric-pattern multifrontal method, ACM Trans. Math. Software 30 (2004) 165-195.

118 T. A. Davis, Algorithm 832: UMFPACK - an unsymmetric-pattern multifrontal method with a column pre-ordering strategy, ACM Trans. Math. Software 30 (2004) 196-199.

119 T. A. Davis, J. R. Gilbert, S. Larimore, E. Ng, An approximate column minimum degree ordering algorithm, ACM Trans. Math. Software 30 (2004) 353-376.

120 T. A. Davis, J. R. Gilbert, S. Larimore, E. Ng, Algorithm 836: COLAMD, an approximate column minimum degree ordering algorithm, ACM Trans. Math. Software 30 (2004) 377-380.

121 P. R. Amestoy, T. A. Davis, I. S. Duff, Algorithm 837: AMD, an approximate minimum degree ordering algorithm, ACM Trans. Math. Software 30 (2004) 381 388.

122 T. A. Davis, I. S. Duff, A combined unifrontal/multifrontal method for unsymmetric sparse matrices, ACM Trans. Math. Software 25 (1999) 1-19.

123 T. A. Davis, I. S. Duff, An unsymmetric-pattern multifrontal method for sparse LU factorization, SIAM J. Matrix Analysis and Applications 18 (1997) 140-158.

124 K.B. Wiles, C.M. de Diego, J. de Abajo, J.E. McGrath, Directly copolymerized partially fluorinated disulfonated poly (arylene ether sulfone) random copolymers for PEM fuel cell systems: synthesis, fabrication and characterization of membranes and membrane electrode assemblies for fuel cell applications, J. Membrane Science, submitted for publication.

125 M. Eikerling, A. Kornyshev, A Kulikovsky, Can theory help to improve fuel cells?, The Fuel Cell Review 2 (2005) 15-24.

126 H. Natter, R. Hempelmann, Tailor-made nanomaterials designed by electrochemical methods, Electrochimica Acta 49 (2003) 51-61.

127 F. Seland, T. Berning, B. Borresen, R. Tunold, Improving the performance of high-temperature PEM fuel cells based on PBI electrolyte, J. Power Sources, article in press. 
APPENDICES

134 


\section{APPENDIX A}

\section{Derivation of the Reactive Heat Generation Relation}

A thermodynamic approach may be used to derive the expression for the heat generation due to fuel cell reactions. Considering the fuel cell system as a closed thermodynamic system (Figure A-1), with the standard sign convention of positive heat transfers into the system and positive work out of the system, the following equations summarize the first law and second laws of thermodynamics.

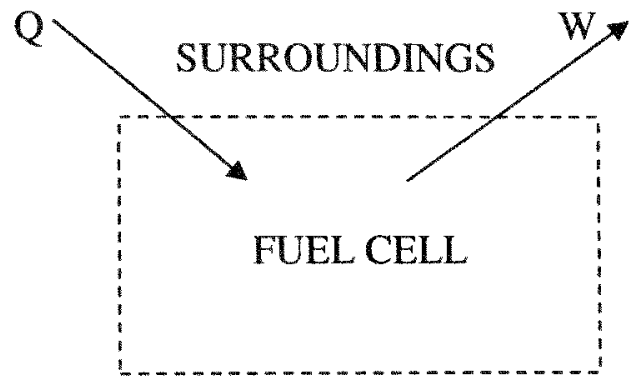

Figure A-1 Thermodynamic Schematic of the Fuel Cell

$$
\begin{aligned}
& Q-W_{\text {actual }}=\Delta H \\
& W_{\text {reversible }}=-(\Delta H-T \Delta S)
\end{aligned}
$$

Summing the two equations,

$$
\begin{aligned}
& Q-W_{\text {actual }}+W_{\text {reversible }}=T \Delta S \\
& \text { or } Q=-W_{\text {irreversible }}+T \Delta S
\end{aligned}
$$


With the sign convention of positive $Q$ into the system, the actual heat given off, which is equal to the heat generated (since there is no heat storage), is

$$
Q_{\text {gen }}=-Q=W_{\text {irreversible }}-T \Delta S
$$

This gives the total heat generation. The local heat generation rate can be obtained by converting the energy terms to voltage and current generation terms,

$$
\begin{aligned}
& Q_{\text {gen }}=-j\left(\frac{W_{\text {irreversible }}-T \Delta S}{n F}\right) \\
& Q_{g e n}=-j\left(\Delta V_{\text {irreversible }}-\frac{T \Delta S}{n F}\right) \\
& Q_{\text {gent }}=-j\left(\eta_{\text {electrode }}+\eta_{\text {ohmic }}-\frac{T \Delta S}{n F}\right)
\end{aligned}
$$

This can now be separated into the reactive heating term and the ohmic heating term, where the local heat of reaction is,

$$
Q_{r x n}=-j\left(\eta_{\text {electrode }}-\frac{T \Delta S}{n F}\right)
$$

This is identical to Equation (17). 


\section{APPENDIX B}

\section{Model Input File}

The input file below shows all the numerical values and equation settings used in the implementation of the model into FEMLAB 3.1i. The output file from the software is not included, since for over 80,000 finite elements, this would require over 2000 pages.

File name: 2 _. phase_3D.fl

Application modes and modules used in this model:

- Geoml (3D)

- Conductive Media DC

- Conductive Media DC

- Darcy's Law (Chemical Engineering Module)

- Maxwell-Stefan Diffusion and Convection (Chemical Engineering Module)

- Diffusion (Chemical Engineering Module)

- Convection and Conduction (Chemical Engineering Module)

\section{Model Properties}

Property Value

Saved date Jun 6, 2006 3:06:54 PM

Creation date Sep 14, 2005 10:43:55 AM

FEMLAB version FEMLAB 3.1.0.163

\section{Constants}

$\begin{array}{lll}\text { Name } & \text { Expression } & \text { Value } \\ \text { muO2 } & 27 \mathrm{e}-6 & 2.7 \mathrm{e}-5 \\ \mathrm{kp} & 1.8 \mathrm{e}-11 & 1.8 \mathrm{e}-11 \\ \text { epsi_d } & 0.4 & 0.4 \\ \mathrm{P0} & 1.013 \mathrm{e} 5 & 1.013 \mathrm{e} 5 \\ \mathrm{mH} 20 & 1 & 1 \\ \mathrm{mO2} 0 & 1 & 1 \\ \mathrm{MO} 2 & 32 \mathrm{e}-3 & 0.032 \\ \mathrm{MH2} & 2 \mathrm{e}-3 & 0.002 \\ \mathrm{~F} & 96487 & 96487 \\ \text { sigma_d } & 120 & 120 \\ \text { sigma_m } & (100 / \mathrm{TO}) * \exp (8.0219-(2605.6-70.1 * X P A) / \mathrm{TO}) & 4.251864 \\ \text { Vcell } & 0.4 & 0.4\end{array}$




\begin{tabular}{|c|c|c|}
\hline alphaa & 0.5 & 0.5 \\
\hline alphac & 1 & 1 \\
\hline $\mathrm{R}$ & 8.3143 & 8.3143 \\
\hline T0 & 423 & 423 \\
\hline aiOa & aioc* le8 & $7.690822 \mathrm{el} 1$ \\
\hline aioc & $a * i 0 c$ & 7690.821919 \\
\hline $\mathrm{MH} 2 \mathrm{O}$ & $18 \mathrm{e}-3$ & 0.018 \\
\hline $\mathrm{DH} 2 \_\mathrm{H} 2 \mathrm{O}$ & $14.4 \mathrm{e}-5$ & $1.44 e^{-4}$ \\
\hline $\mathrm{muH} 2$ & $11.3 \mathrm{e}-7$ & $1.13 \mathrm{e}-6$ \\
\hline $\mathrm{muH} 2 \mathrm{O}$ & $143.5 \mathrm{e}-7$ & $1.435 \mathrm{e}-5$ \\
\hline $\mathrm{cH} 2$ & 14450 & 14450 \\
\hline $\mathrm{cO} 2$ & 956 & 956 \\
\hline $\mathrm{cH} 2 \mathrm{O}$ & 1980 & 1980 \\
\hline $\mathrm{kO} 2$ & 0.0363 & 0.0363 \\
\hline $\mathrm{kH} 2 \mathrm{O}$ & 0.03 & 0.03 \\
\hline $\mathrm{kH} 2$ & 0.239 & 0.239 \\
\hline alphaO2 & $44.4 \mathrm{e}-6$ & $4.44 \mathrm{e}-5$ \\
\hline alphaH2O & $30.8 \mathrm{e}-6$ & $3.08 \mathrm{e}-5$ \\
\hline alphaH2 & $217 e-6$ & $2.17 \mathrm{e}-4$ \\
\hline $\mathrm{kd}$ & 1.15 & 1.15 \\
\hline $\mathrm{km}$ & 40 & 40 \\
\hline epsi_c & 0.2 & 0.2 \\
\hline epsi_mc & 1-epsi_dc-epsi_Pt & 0.577186 \\
\hline epsi_dc & epsi_Pt*rhoPurhoC/fPt & 0.401786 \\
\hline $\mathrm{MN} 2$ & $28.16 \mathrm{e}-3$ & 0.02816 \\
\hline $\mathrm{DO} 2 \_\mathrm{N} 2$ & $34.17 \mathrm{e}-6$ & $3.417 \mathrm{e}-5$ \\
\hline $\mathrm{DO} 2 \_\mathrm{H} 2 \mathrm{O}$ & $41.92 e-6$ & $4.192 \mathrm{e}-5$ \\
\hline $\mathrm{DN} 2 \_\mathrm{H} 2 \mathrm{O}$ & $49.24 e-6$ & $4.924 \mathrm{e}-5$ \\
\hline $\mathrm{cN} 2$ & 860 & 860 \\
\hline $\mathrm{muN} 2$ & $23 e-6$ & $2.3 e-5$ \\
\hline alphaN2 & $41 \mathrm{e}-6$ & $4.1 e-5$ \\
\hline $\mathrm{kN} 2$ & 0.034 & 0.034 \\
\hline $\mathrm{mN}_{2} \_0$ & 0 & 0 \\
\hline Vrev & $1.467-0.8111 * \mathrm{~T} 0 / 1000-0.1$ & 1.023905 \\
\hline delS & $-18.449-0.01283 * \mathrm{TO}$ & -23.87609 \\
\hline air & 0.219388 & 0.219388 \\
\hline oxy & 0.9627 & 0.9627 \\
\hline vo & flowrate & 0.32 \\
\hline flowrate & 0.32 & 0.32 \\
\hline CO2ref & $\mathrm{P} 0 / \mathrm{KO} 2$ & 0.763235 \\
\hline CH2ref & $\mathrm{P} 0 / \mathrm{KH}_{2}$ & 3.392156 \\
\hline $\mathrm{KO} 2$ & $\left(\operatorname{epsiPA}^{\wedge}(-1.945) /(1 / \mathrm{KO} 2 \mathrm{PA}+5.79 *(1-\mathrm{epsiPA}))\right)^{* P 0}$ & $1.327245 \mathrm{e} 5$ \\
\hline $\mathrm{KH} 2$ & $0.225 * \mathrm{KO} 2$ & 29863.015996 \\
\hline
\end{tabular}




\begin{tabular}{|c|c|c|}
\hline DO2 & DO2PA*(epsiPA*epsi mc $)^{\wedge} 1.8$ & $1.796647 \mathrm{e}-10$ \\
\hline $\mathrm{DH} 2$ & $2 * \mathrm{DO} 2$ & $3.593293 \mathrm{e}-10$ \\
\hline kch & $2.2 \mathrm{e}-8$ & $2.2 \mathrm{e}-8$ \\
\hline tcat & $10 e-6$ & $1 e-5$ \\
\hline $\mathrm{mPt}$ & $0.45 e-6 * 1 e 4$ & 0.0045 \\
\hline rhoPt & 21400 & 21400 \\
\hline rhoc & 5600 & 5600 \\
\hline $\mathrm{Pt}$ & 0.2 & 0.2 \\
\hline a & $3^{*} \mathrm{mPt} / \mathrm{rhoP} / \mathrm{rPt} / \mathrm{cat}$ available & $6.056075 \mathrm{e} 7$ \\
\hline $\mathrm{rPt}$ & $0.5 e-9$ & $5 e-10$ \\
\hline IOPA & $10^{\wedge}(-2193 / \mathrm{T} 0-0.491)^{*} \mathrm{le} 4$ & 0.021116 \\
\hline epsipA & $1 /(4.81 /(\mathrm{XPA}-2)+1)$ & 0.466149 \\
\hline XPA & 6.2 & 6.2 \\
\hline $\mathrm{i} 0 \mathrm{c}$ & iOPA $10^{\wedge}\left(4.16^{*}(1-\right.$ epsiPA $\left.)\right)$ & $1.269935 \mathrm{e}-4$ \\
\hline epsi_Pt & $\mathrm{mPt} / \mathrm{rhoP} / \mathrm{tcat}$ & 0.021028 \\
\hline DO2PA & $\exp (9.6195-3795.6 / \mathrm{T} 0) * 1 \mathrm{e}-9$ & $1.908753 \mathrm{e}-9$ \\
\hline KO2PA & $\exp (1.2467-958.4 / \mathrm{T} 0) * 10$ & 3.609481 \\
\hline theta & $-0.893^{*}(\text { Vcell-Vrev })^{\wedge} 2-1.714 *($ Vcell-Vrev $)$ & 0.721766 \\
\hline available & 0.48 & 0.48 \\
\hline
\end{tabular}

\section{Geom1}

Space dimensions: 3D

\subsection{Expressions}

\subsubsection{Subdomain Expressions}

1

2

jR

$\mathrm{mu} \quad \mathrm{mH2} \mathrm{O}^{*} \mathrm{mu} \mathrm{mH2} \mathrm{O}^{*} \mathrm{mu}$

$\mathrm{H} 2+(1-\quad \mathrm{H} 2+\mathrm{Cl}-$

$\left.\mathrm{mH2}(0) * \mathrm{mu} \mathrm{mH}_{2} \mathrm{0}\right)^{*} \mathrm{mu}$

$\mathrm{H} 2 \mathrm{O}^{-} \mathrm{H} 2 \mathrm{O}$

$\mathrm{kf}$
3.4

(1-

theta)*aiOa*

$\mathrm{CH} 2 / \mathrm{CH} 2 \mathrm{re}$

$f^{*}(\exp$ (alpha

$\mathrm{a}^{* \mathrm{~F} / \mathrm{R} / \mathrm{T} 0 *(}$

phis-phie))-

exp(-

alphaa*F/R/

$\mathrm{TO} 0^{*}$ (phis-

phie)))

\section{5}

6-7

8

9

(1-

theta)*aiOc*

$\mathrm{CO} 2 / \mathrm{CO} 2 \mathrm{re}$

$f^{*}(\exp$ (alpha

$\mathrm{C}^{*} \mathrm{~F} / \mathrm{R} / \mathrm{TO} 0^{*}($

phis-phie))-

exp(-

alphac*F/R/

T0*(phisphie)))

$$
\begin{aligned}
& \mathrm{mO2} 0 * \mathrm{mu} \mathrm{mO} 2 \_ \text {- } \mathrm{mu} \\
& \mathrm{O} 2+\mathrm{mN} 2002+\mathrm{mN}_{2} \mathrm{O} \\
& *^{\text {muN2 }}+\left(1-*^{*} \mathrm{muN} 2+(1-\right. \\
& \mathrm{mO} 2 \_0-\quad \mathrm{mO2}-0- \\
& \left.\mathrm{mN} 2{ }^{\circ}\right)^{*} \mathrm{mu} \mathrm{mN}_{2} 0 \text { ) } * \mathrm{~m} \\
& \mathrm{H} 2 \mathrm{O} \quad \mathrm{uH} 2 \mathrm{O} \\
& \mathrm{kO} 2 * \mathrm{mO}_{2}-\mathrm{kO}_{2} * \mathrm{mO}_{2} \\
& 0+\mathrm{kN} 2 * \mathrm{mN} \quad 0+\mathrm{kN} 2 * \mathrm{mN} \\
& 20+\mathrm{kH} 2 \mathrm{O}^{*} 2 \mathrm{O}+\mathrm{kH} 2 \mathrm{O}^{*} \\
& \text { (1-mO2 } 0-\text { (1-mO2_o- } \\
& \mathrm{mN2}-0) \quad \mathrm{mN2}-0)
\end{aligned}
$$




\begin{tabular}{|c|c|c|c|c|c|c|c|}
\hline alphaf & $\begin{array}{l}\text { alphaH } 2 * m \\
\mathrm{H} 2 \_0+\text { alpha } \\
\mathrm{H} 2 \mathrm{O}^{*}(1- \\
\mathrm{mH} 2 \ldots 0)\end{array}$ & $\begin{array}{l}\text { alphaH2*m } \\
\mathrm{H} 2 \_0+\text { alpha } \\
\mathrm{H} 2 \mathrm{O}^{*}(1- \\
\mathrm{mH} 2 \text { - } 0)\end{array}$ & & & & $\begin{array}{l}\text { alphaO2*m } \\
\text { O2_0+alpha } \\
\text { N2*mN2_0 } \\
+ \text { alphaH2O } \\
*\left(1-\mathrm{mO}_{2} \_0-\right. \\
\left.\mathrm{mN} 2 \_0\right)\end{array}$ & $\begin{array}{l}\text { alphaO2*m } \\
\mathrm{O} 2 \_0+\text { alpha } \\
\mathrm{N} 2 * \mathrm{mN} 2 \_0 \\
+ \text { alphaH2O } \\
{ }^{\prime}\left(1-\mathrm{mO} 2 \_0-\right. \\
\left.\mathrm{mN} 2 \_0\right)\end{array}$ \\
\hline $\mathrm{cpf}$ & $\begin{array}{l}\mathrm{cH}_{2} * \mathrm{mH}_{2} \\
0+\mathrm{cH}_{2} \mathrm{O} *(1- \\
\mathrm{mH} 2 \text { - }\end{array}$ & $\begin{array}{l}\mathrm{cH}_{2}^{*} \mathrm{mH}_{2} \\
0+\mathrm{cH}_{2} \mathrm{O}^{*}(1- \\
\left.\mathrm{mH}_{2} \_0\right)\end{array}$ & & & & $\begin{array}{l}\mathrm{cO}^{2} * \mathrm{mO}_{2}- \\
0+\mathrm{cN} 2 * \mathrm{mN} \\
2 \_0+\mathrm{cH} 2 \mathrm{O} * \\
\left(1-\mathrm{mO}_{2} \_-0-\right. \\
\left.\mathrm{mN} 2 \_0\right)\end{array}$ & $\begin{array}{l}\mathrm{cO}^{*} \mathrm{mO}^{2}- \\
0+\mathrm{cN} 2 * \mathrm{mN} \\
2 \_0+\mathrm{cH} 2 \mathrm{O}^{*} \\
\left(1-\mathrm{mO} 20_{-}\right. \\
\left.\mathrm{mN} 2 \_0\right)\end{array}$ \\
\hline $\mathrm{ks}$ & & $k d$ & $\mathrm{~km}$ & $\mathrm{~km}$ & $\mathrm{~km}$ & $\mathrm{kd}$ & \\
\hline keff & $\mathrm{kf}$ & 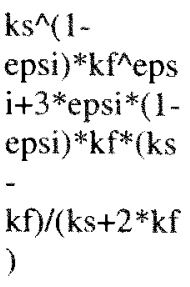 & ks & $\mathrm{ks}$ & $\mathrm{ks}$ & $\begin{array}{l}\mathrm{ks}^{\wedge}(1- \\
\text { epsi })^{*} \mathrm{kf} \text { eps } \\
\mathrm{i}+3^{*} \mathrm{epsi}(1- \\
\text { epsi })^{*} \mathrm{kf}(\mathrm{ks} \\
- \\
\mathrm{kf}) /\left(\mathrm{ks}+2^{*} \mathrm{kf}\right. \\
)\end{array}$ & $\mathrm{kf}$ \\
\hline Sohm & & $\begin{array}{l}\text { normli_soli } \\
\mathrm{d}^{\wedge} 2 / \text { sigmase } \\
\text { ff }\end{array}$ & $\begin{array}{l}\text { normli_soli } \\
\mathrm{d}^{\wedge} 2 / \text { sigmase } \\
\text { ff+normli_e } \\
\text { lectrolyte^ } 2 / \\
\text { sigmaeeff }\end{array}$ & $\begin{array}{l}\text { normJi_elec } \\
\text { trolyte }^{\prime} / \text { sig } \\
\text { maceff }\end{array}$ & $\begin{array}{l}\text { normJi_soli } \\
\mathrm{d}^{\wedge} 2 / \text { sigmase } \\
\mathrm{ff}^{\mathrm{n}} \text { normJi_e } \\
\text { lectrolyte } 2 / \\
\text { sigmaeeff }\end{array}$ & $\begin{array}{l}\text { normJi_soli } \\
d^{\wedge} 2 / \text { sigmase } \\
\text { ff }\end{array}$ & \\
\hline epsi & 1 & epsi_d & epsi_c & & epsi_c & epsi_d & 1 \\
\hline sigmaseff & & $\begin{array}{l}\text { sigma_d*(1- } \\
\text { epsi_d })^{\wedge} 1.5\end{array}$ & $\begin{array}{l}\text { sigma_d*ep } \\
\text { si_dc^1.5 }\end{array}$ & & $\begin{array}{l}\text { sigma_d }{ }^{*} e p \\
\text { si_dc^1.5 }\end{array}$ & $\begin{array}{l}\text { signa_d*(1- } \\
\text { epsi_d })^{\wedge} 1.5\end{array}$ & \\
\hline sigmaeeff & & & $\begin{array}{l}\text { sigma_m*ep } \\
\text { si_mc^1.5 }\end{array}$ & sigma_m & $\begin{array}{l}\text { sigma_m*ep } \\
\text { si } \mathrm{mc}^{\wedge} 1.5\end{array}$ & & \\
\hline Srxn & & & & & $\begin{array}{l}-j R^{*} \text { (phie- } \\
\text { phis- } \\
\text { To/F*delS) }\end{array}$ & & \\
\hline Qgen & & Sohm & Sohm & Sohm & Sohm+Srxn & Sohm & \\
\hline M & $\begin{array}{l}1 /\left(\mathrm{mH}_{2} \_0 /\right. \\
\mathrm{MH} 2+(1- \\
\left.\mathrm{mH} 2 \_0\right) / \mathrm{M} \\
\mathrm{H} 2 \mathrm{O})\end{array}$ & $\begin{array}{l}1 /\left(\mathrm{mH}_{2}-0 /\right. \\
\mathrm{MH} 2+(1- \\
\left.\mathrm{mH} 2 \_0\right) / \mathrm{M} \\
\mathrm{H} 2 \mathrm{O})\end{array}$ & & & & $\begin{array}{l}1 /\left(\mathrm{mi} / \mathrm{MO}^{2}+\right. \\
(1- \\
\mathrm{mi}) / \mathrm{MH} 2 \mathrm{O})\end{array}$ & $\begin{array}{l}1 /(\mathrm{mi} / \mathrm{MO} 2 \\
+(1- \\
\mathrm{mi}) / \mathrm{MH} 2 \mathrm{O})\end{array}$ \\
\hline rho & $\mathrm{PO} * \mathrm{M} / \mathrm{R} / \mathrm{TO}$ & $\mathrm{PO} * \mathrm{M} / \mathrm{R} / \mathrm{TO}$ & & & & $\mathrm{P} 0 * \mathrm{M} / \mathrm{R} / \mathrm{TO}$ & $\mathrm{P} 0 * \mathrm{M} / \mathrm{R} / \mathrm{T} 0$ \\
\hline $\mathrm{CH} 2$ & & & $\mathrm{Ci}$ & & & & \\
\hline $\mathrm{CO} 2$ & & & & & $\mathrm{Ci}$ & & \\
\hline
\end{tabular}

\subsection{Mesh}

\subsubsection{Extended mesh}

Number of degrees of freedom 461666

\subsubsection{Base mesh}

Number of edge elements $\quad 1118$

Number of boundary elements 18223

Number of elements 
Minimum element quality $\quad 0.0000$

\subsection{Application Mode: Conductive Media DC}

Application mode type: Conductive Media DC Application mode name: solid

\subsubsection{Application Mode Properties}

Property Value

Default element type Lagrange - Quadratic

Weak constraints Non-ideal

\subsubsection{Variables}

Dependent variables: phis

Independent variables: $x, y, z$

Shape functions: $\operatorname{shlag}(2, ' \mathrm{Iml})$, shlag(2,'phis')

Interior boundaries not active

\subsubsection{Boundary Settings}

\begin{tabular}{|c|c|c|c|c|}
\hline Boundary & 6 & \multicolumn{3}{|c|}{$7-11,13-16,18-22,27-31,33-36,38-41,4342$} \\
\hline Type & $\begin{array}{l}\text { Electric } \\
\text { potential }\end{array}$ & \multicolumn{2}{|l|}{ Electric insulation } & $\begin{array}{l}\text { Electric } \\
\text { potential }\end{array}$ \\
\hline Reference potential (Vref) & 0 & \multicolumn{2}{|l|}{0} & 0 \\
\hline Current density (J0) & $\{0 ; 0 ; 0\}$ & \multicolumn{2}{|l|}{$0 ; 0 ; 0$} & $\{0 ; 0 ; 0\}$ \\
\hline Conductivity (sigmabnd) & 0 & \multicolumn{2}{|l|}{0} & 0 \\
\hline Thickness (d) & 1 & \multicolumn{2}{|l|}{1} & 1 \\
\hline Normal current density (Jn) & 0 & \multicolumn{2}{|l|}{0} & 0 \\
\hline Electric potential (V0) & 0 & \multicolumn{2}{|l|}{0} & Vcell-Vrev \\
\hline weakconstr & 1 & \multicolumn{2}{|l|}{1} & 1 \\
\hline Shape functions (wcshape) & 1 & \multicolumn{2}{|l|}{1} & 1 \\
\hline $\begin{array}{l}\text { Integration order } \\
\text { (wcgporder) }\end{array}$ & 1 & \multicolumn{2}{|l|}{1} & 1 \\
\hline \multicolumn{5}{|l|}{ 3.3.4. Subdomain Settings } \\
\hline Subdomain & 2 & $3-4$ & $6-7$ & 8 \\
\hline Shape functions (shape) & 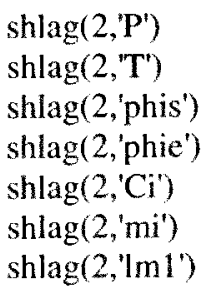 & $\begin{array}{l}\operatorname{shlag}\left(2, \mathrm{P}^{\prime}\right) \\
\operatorname{shlag}\left(2, \mathrm{~T}^{\prime}\right) \\
\operatorname{shlag}\left(2, \text { 'phis' }^{\prime}\right) \\
\operatorname{shlag}\left(2, \text { 'phie'}^{\prime}\right) \\
\operatorname{shlag}\left(2, \mathrm{Ci}^{\prime}\right) \\
\operatorname{shlag}\left(2, \mathrm{mi}^{\prime}\right) \\
\operatorname{shlag}\left(2, ' \operatorname{ml} \mathrm{I}^{\prime}\right)\end{array}$ & $\begin{array}{l}\operatorname{shlag}\left(2, \mathrm{P}^{\prime}\right) \\
\operatorname{shlag}\left(2, \mathrm{~T}^{\prime}\right) \\
\text { shlag(2,'phis') } \\
\text { shlag(2,'phie') } \\
\text { shlag(2,'Ci') } \\
\text { shlag(2,'mi') } \\
\text { shlag(2,'Iml') }\end{array}$ & $\begin{array}{l}\operatorname{shlag}\left(2, \mathrm{P}^{\prime}\right) \\
\operatorname{shlag}\left(2, \mathrm{~T}^{\prime}\right) \\
\text { shlag(2,'phis') } \\
\text { shlag(2,'phie') } \\
\text { shlag }\left(2, \mathrm{Ci}^{\prime}\right) \\
\text { shlag }\left(2, \mathrm{mi}^{\prime}\right) \\
\text { shlag(2,'Iml') }\end{array}$ \\
\hline Integration order (gporder) & 4 & 4 & 4 & 4 \\
\hline Constraint order (cporder) & 2 & 2 & 2 & 2 \\
\hline Conductivity (sigma) & sigmaseff & sigmaseff & sigmaseff & sigmaseff \\
\hline \multicolumn{5}{|l|}{ Conductivity (sigmatensor) } \\
\hline sigtype & iso & iso & iso & iso \\
\hline External current density (Je) & $\{0 ; 0 ; 0\}$ & $\{0 ; 0 ; 0\}$ & $\{0 ; 0 ; 0\}$ & $\{0 ; 0 ; 0\}$ \\
\hline
\end{tabular}




$\begin{array}{lllll}\text { Current source (Qj) } & 0 & -\mathrm{jR} & -\mathrm{jR} & 0 \\ \text { Initial value (phis) } & 0 & 0 & 0 & 0\end{array}$

\subsection{Application Mode: Conductive Media DC}

Application mode type: Conductive Media DC

Application mode name: electrolyte

\subsubsection{Application Mode Properties}

Property Value

Default element type Lagrange - Quadratic

Weak constraints Off

\subsubsection{Variables}

Dependent variables: phie Independent variables: $x, y, z$

Shape functions: shlag(2,'phie')

Interior boundaries not active

\subsubsection{Boundary Settings}

Boundary

Type

Reference potential (Vref)

Current density (J0)

Conductivity (sigmabnd)

Thickness (d)

Normal current density (Jn) 0

Electric potential (Vo) 0

weakconstr

Integration order (wcgporder) 2
$12-16,18-21,23-26,28-31,33-37$

Electric insulation

0

$\{0 ; 0 ; 0\}$

0

1

1

\subsubsection{Subdomain Settings}

\begin{tabular}{|c|c|c|c|}
\hline Subdomain & $3-4$ & 5 & $6-7$ \\
\hline $\begin{array}{l}\text { Shape functions } \\
\text { (shape) }\end{array}$ & $\begin{array}{l}\text { shlag }\left(2, \mathrm{P}^{\prime}\right) \operatorname{shlag}\left(2, \mathrm{~T}^{\prime}\right) \\
\operatorname{shlag}\left(2, \text { 'phis' }^{\prime}\right) \operatorname{shlag}\left(2, \text { 'phie' }^{\prime}\right) \\
\text { shlag(2,'Ci') shlag(2,'mi') } \\
\text { shlag(2,'Iml') }\end{array}$ & $\begin{array}{l}\text { shlag }\left(2, \mathrm{P}^{\prime}\right) \operatorname{shlag}\left(2, \mathrm{~T}^{\prime}\right) \\
\text { shlag(2,'phis') } \operatorname{shlag}\left(2, \text { 'phie' }^{\prime}\right) \\
\text { shlag(2,'Ci') shlag(2,'mi') } \\
\text { shlag(2,'Im1') }\end{array}$ & 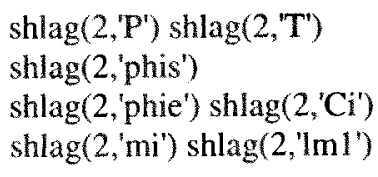 \\
\hline $\begin{array}{l}\text { Integration order } \\
\text { (gporder) }\end{array}$ & 4 & 4 & 4 \\
\hline $\begin{array}{l}\text { Constraint order } \\
\text { (cporder) }\end{array}$ & 2 & 2 & 2 \\
\hline $\begin{array}{l}\text { Conductivity } \\
\text { (sigma) }\end{array}$ & sigmaeeff & sigmaeeff & sigmaeeff \\
\hline \multicolumn{4}{|l|}{$\begin{array}{l}\text { Conductivity } \\
\text { (sigmatensor) }\end{array}$} \\
\hline sigtype & iso & iso & iso \\
\hline $\begin{array}{l}\text { External current } \\
\text { density (Je) }\end{array}$ & $\{0 ; 0 ; 0\}$ & $\{0 ; 0 ; 0\}$ & $\{0 ; 0 ; 0\}$ \\
\hline
\end{tabular}


Current source (Qj) jR

Initial value (phie) 0

\subsection{Application Mode: Non-Isothermal Flow}

Application mode type: Non-Isothermal Flow (Chemical Engineering Module)

Application mode name: NSE

\subsubsection{Application Mode Properties}

Property Value

Default element type Lagrange - Quadratic

Analysis type Stationary

Weak constraints Off

\subsubsection{Variables}

Dependent variables: $u, v, w, P$

Independent variables: $x, y, z$

Shape functions: shlag(2,'P')

Interior boundaries not active

\subsubsection{Boundary Settings}

\begin{tabular}{|c|c|c|c|c|c|}
\hline Boundary & $\begin{array}{l}1-2,5-9,11,38-42 \\
44,47-48\end{array}$ & 3,45 & 4,46 & 12 & 37 \\
\hline Type & Insulation/Symmetry & Flux & $\begin{array}{l}\text { Pressure } \\
\text { condition }\end{array}$ & Flux & Flux \\
\hline Pressure $(p 0)$ & 0 & 0 & $\mathrm{PO}$ & 0 & 0 \\
\hline Inward flux $(N)$ & 0 & vo & 0 & $\begin{array}{l}\mathrm{MH} 2 * \mathrm{DH} 2 / \\
\text { rho* Cix }\end{array}$ & $\begin{array}{l}(2 * \mathrm{MH} 2 \mathrm{O} \\
\mathrm{MO} 2) * \mathrm{DO} 2 / \mathrm{rho}^{*} \mathrm{Cix}\end{array}$ \\
\hline weakconstr & 1 & 1 & 1 & 1 & 1 \\
\hline $\begin{array}{l}\text { Integration order } \\
\text { (wcgporder) }\end{array}$ & 2 & 2 & 2 & 2 & 2 \\
\hline
\end{tabular}

\subsubsection{Subdomain Settings}

\begin{tabular}{|c|c|c|}
\hline Subdomain & 1,9 & 2,8 \\
\hline $\begin{array}{l}\text { Shape functions } \\
\text { (shape) }\end{array}$ & $\begin{array}{l}\operatorname{shlag}\left(2, \mathrm{P}^{\prime}\right) \operatorname{shlag}\left(2, \mathrm{~T}^{\prime}\right) \text { shlag }\left(2, \text { 'phis' }^{\prime}\right) \\
\text { shlag(2,'phie') } \operatorname{shlag}\left(2, \mathrm{Ci}^{\prime}\right) \operatorname{shlag}\left(2, \mathrm{mi}^{\prime}\right) \\
\text { shlag(2,'Iml') }\end{array}$ & $\begin{array}{l}\text { shlag(2,'P') shlag(2,'T') shlag(2,'phis') } \\
\text { shlag(2,'phie') shlag(2,'Ci') shlag(2,'mi') } \\
\text { shlag(2,'Iml') }\end{array}$ \\
\hline $\begin{array}{l}\text { Integration order } \\
\text { (gporder) }\end{array}$ & 4 & 4 \\
\hline $\begin{array}{l}\text { Constraint order } \\
\text { (cporder) }\end{array}$ & 2 & 2 \\
\hline Density (rho) & rho & rho \\
\hline $\begin{array}{l}\text { Time-scaling } \\
\text { coefficient (Dts) }\end{array}$ & 1 & 1 \\
\hline $\begin{array}{l}\text { Volume fraction } \\
\text { (epsilon) }\end{array}$ & 1 & 1 \\
\hline Permeability (k) & 0 & $\mathrm{kp}$ \\
\hline $\begin{array}{l}\text { Dynamic viscosity } \\
\text { (eta) }\end{array}$ & $\mathrm{mu}$ & $\mathrm{mu}$ \\
\hline
\end{tabular}


Source term $(\mathbf{F}) \quad 0$

Initial value $(\mathrm{P}) \quad \mathrm{P} 0$

P0

\subsection{Application Mode: Maxwell-Stefan Diffusion and Convection}

Application mode type: Maxwell-Stefan Diffusion and Convection (Chemical Engineering Module)

Application mode name: species

\subsubsection{Application Mode Properties}

Property Value

Default element type Lagrange - Quadratic

Equation form Non-conservative

Weak constraints Off

\subsubsection{Variables}

Dependent variables: $\mathrm{mi}, \mathrm{mj}$

Independent variables: $x, y, z$

Shape functions: shlag(2,'mi')

Interior boundaries not active

\subsubsection{Boundary Settings}

Boundary 37

Type Flux

$38-42,44,47-48 \quad 45 \quad 46$

Mass fraction (w0)

$0 \quad 0$

Insulation/Symmetry Mass fraction Convective flux

Inward mass flux $(\mathrm{N})$

$-\mathrm{MO} 2 * \mathrm{DO} 2 * \mathrm{Cix} 0$

weakconstr

1

Integration order (wcgporder) 2

0

1

2

\subsubsection{Subdomain Settings}

Subdomain

Shape functions (shape)

Integration order (gporder)

Constraint order (cporder) 2

Maxwell-Stefan diffusion coefficient (Dij)

Molecular weight (M)

Reaction rate $(R)$

Temperature (T)

Density (rho)

Pressure (P)

Dts

\#-velocity (u)

\#-velocity (v)

$\#$-velocity (w)

Initial value $(\mathrm{mi})$

\section{8}

shlag(2,'P') shlag(2,'T") shlag(2,'phis') shlag(2,'phie') shlag(2,'Ci') shlag (2,'mi') shlag( $\left.2, ' \mathrm{ml} \mathbf{l}^{\prime}\right)$

\section{4}

$\left\{1, \mathrm{DO} 2 \_\mathrm{H} 2 \mathrm{O} * 2 * \mathrm{epsi} /(3-\mathrm{epsi}) ; 1,1\right\}$

\section{$\left\{\mathrm{MO}^{\prime} ; \mathrm{MH} 2 \mathrm{O}\right.$ \}}

0

T0

rho

PO

\section{1}

u

$\mathrm{v}$

w

$1 / 2$
9

$\operatorname{shlag}\left(2\right.$, P'$\left.^{\prime}\right) \operatorname{shlag}\left(2, \mathrm{~T}^{\prime}\right) \operatorname{shlag}(2$, 'phis') shlag(2, phie') $\operatorname{shlag}\left(2,{ }^{\prime} \mathrm{Ci}^{\prime}\right)$ shlag(2,'mi') shlag(2,'/m1') 4

2

$\left\{1, \mathrm{DO} 2 \_\mathrm{H} 2 \mathrm{O}^{\prime} ; 1,1\right\}$

['MO2';'MH2O'\}

0

T0

rho

P0

\section{1}

u

$\mathrm{v}$

W

$1 / 2$ 


\subsection{Application Mode: Diffusion}

Application mode type: Diffusion (Chemical Engineering Module)

Application mode name: reactants

\subsubsection{Application Mode Properties}

Property Value

Default element type Lagrange - Quadratic

Weak constraints off

\subsubsection{Variables}

Dependent variables: $\mathrm{Ci}$

Independent variables: $\mathrm{x}, \mathrm{y}, \mathrm{z}$

Shape functions: $\operatorname{shlag}\left(2,{ }^{\prime} i^{\prime}\right)$

Interior boundaries not active

\subsubsection{Boundary Settings}

$\begin{array}{llll}\text { Boundary } & 12 & 13-16,18-22,27-31,33-3637 \\ \text { Type } & \text { Concentration } & \text { Insulation/Symmetry } & \text { Concentration } \\ \text { Inward flux (N) } & 0 & 0 & 0 \\ \text { Mass transfer coefficient (kc) } & 0 & 0 & 0 \\ \text { Bulk concentration (cb) } & 0 & 0 & 0 \\ \text { Concentration (c0) } & \mathrm{P} 0 / \mathrm{KH} 2 & 0 & \text { x_mi_species*P0/KO2 } \\ \text { weakconstr } & 1 & 1 & 1 \\ \text { Integration order (wcgporder) } & 2 & 2 & 2 \\ \text { Initial value (wcinit) } & 0 & 0 & 0\end{array}$

\subsubsection{Subdomain Settings}

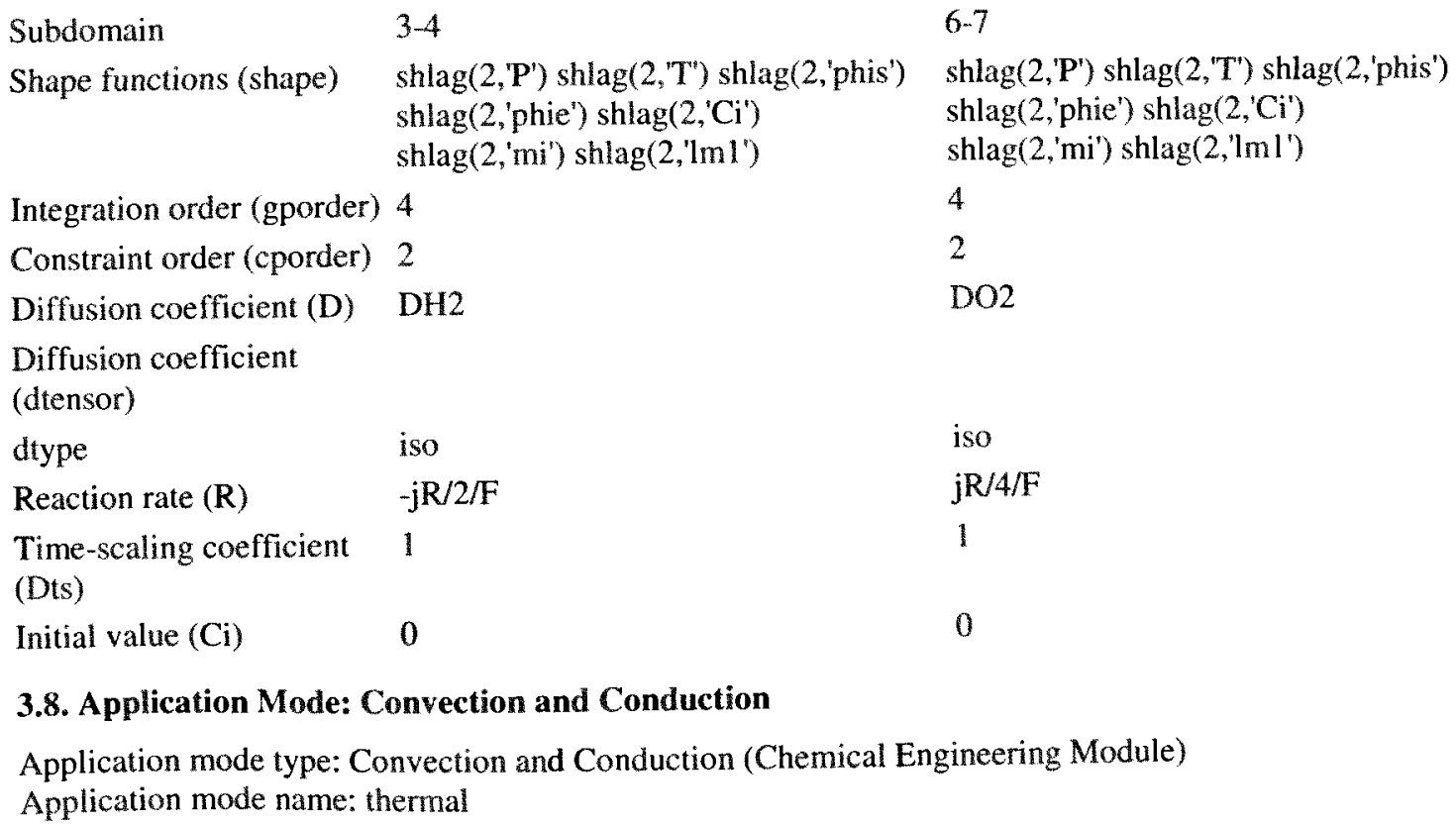

\subsubsection{Application Mode Properties}


Property Value

Default element type Lagrange - Quadratic

Equation form Non-conservative

Weak constraints off

\subsubsection{Variables}

Dependent variables: $T$

Independent variables: $x, y, z$

Shape functions: $\operatorname{shlag}(2, \mathrm{~T})$

Interior boundaries not active

\subsubsection{Boundary Settings}

$\begin{array}{lllll}\text { Boundary } & 2,5,7-9,11,13-16,18- & 3,45 & 4,46 & 1,6,42,48 \\ & 21,23-26,28-31,33-36, & & \\ \text { Type } & 38-41,44,47 & & & \\ & \text { Thermal insulation } & \text { Temperature } & \text { Convective flux } & \text { Heat flux } \\ \text { Inward heat flux (q0) } & 0 & 0 & 0 & -10 *(\mathrm{~T}-298) \\ \text { Temperature (T0) } & 0 & \text { T0 } & 0 & 0 \\ \text { weakconstr } & 1 & 1 & 1 & 1 \\ \text { Integration order (wcgporder) } & 2 & 2 & 2 & 2 \\ \text { Initial value (wcinit) } & 0 & 0 & 0 & 0\end{array}$

\subsubsection{Subdomain Settings}

\begin{tabular}{|c|c|c|c|}
\hline Subdomain & 1,9 & 2,8 & 3-7 \\
\hline Shape functions (shape) & $\begin{array}{l}\operatorname{shlag}\left(2, \mathrm{P}^{\prime}\right) \operatorname{shlag}\left(2, \mathrm{~T}^{\prime}\right) \\
\operatorname{shlag}\left(2, \text { 'phis' }^{\prime}\right) \\
\operatorname{shlag}\left(2, \text { 'phie' }^{\prime}\right) \\
\operatorname{shlag}\left(2, \mathrm{Ci}^{\prime}\right) \\
\operatorname{shlag}\left(2, \mathrm{mi}^{\prime}\right) \\
\operatorname{shlag}(2, \operatorname{ml})\end{array}$ & 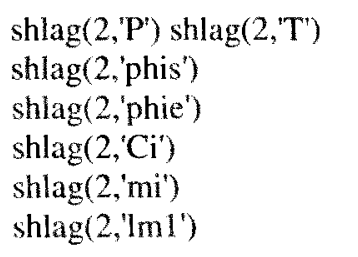 & $\begin{array}{l}\operatorname{shlag}\left(2, \mathrm{P}^{\prime}\right) \operatorname{shlag}\left(2, \mathrm{~T}^{\prime}\right) \\
\text { shlag(2,'phis') } \\
\text { shlag(2,'phie') } \\
\text { shlag(2,'Ci') } \\
\operatorname{shlag}\left(2, \mathrm{mi}^{\prime}\right) \\
\operatorname{shlag}\left(2, \mathrm{Iml}^{\prime}\right)\end{array}$ \\
\hline Integration order (gporder) & 4 & 4 & 4 \\
\hline Constraint order (cporder) & 2 & 2 & 2 \\
\hline Thermal conductivity $(\mathrm{k})$ & keff & keff & keff \\
\hline $\begin{array}{l}\text { Thermal conductivity } \\
\text { (ktensor) }\end{array}$ & $\begin{array}{l}\{0.025,0,0 ; 0,0.025,0 ; 0,0 \\
0.025\}\end{array}$ & $\begin{array}{l}\{0.025,0,0 ; 0,0.025,0 ; 0,0 \\
, 0.025\}\end{array}$ & $\begin{array}{l}\{0.025,0,0 ; 0,0.025,0 ; 0,0 \\
, 0.025\}\end{array}$ \\
\hline ktype & iso & iso & iso \\
\hline Time-scaling coefficient (Dts) & 1 & 1 & 1 \\
\hline Density (rho) & rho & rho & 1 \\
\hline Heat capacity $(\mathrm{C})$ & $\operatorname{cpf}$ & $\operatorname{cpf}$ & 1000 \\
\hline Heat source (Q) & 0 & Qgen & Qgen \\
\hline$x$-velocity (u) & $\mathrm{u}$ & $u$ & 0 \\
\hline$y$-velocity $(v)$ & $\mathrm{v}$ & $\mathrm{v}$ & 0 \\
\hline$z$-velocity (w) & $w$ & $\mathrm{w}$ & 0 \\
\hline Tuning parameter (delid) & 0.5 & 0.5 & 0.5 \\
\hline Tuning parameter (delsd) & 0.25 & 0.25 & 0.25 \\
\hline Tuning parameter (delcd) & 0.35 & 0.35 & 0.35 \\
\hline
\end{tabular}




\section{Solver Settings}

Solve using a script: off

Auto select solver on

Solver Stationary nonlinear

Solution form general

Symmetric off

Adaption off

\subsection{Direct (UMFPACK)}

Solver type: Linear system solver

Parameter Value

Pivot threshold $\quad 0.1$

Memory allocation factor 0.7

\subsection{Nonlinear}

$\begin{array}{ll}\text { Parameter } & \text { Value } \\ \text { Relative tolerance } & 1.0 \mathrm{e}-6 \\ \text { Maximum number of iterations } & 500 \\ \text { Manual tuning of damping parameters } & \text { Off } \\ \text { Highly nonlinear problem } & \text { Off } \\ \text { Initial damping factor } & 1.0 \\ \text { Minimum damping factor } & 1.0 \mathrm{e}-4 \\ \text { Restriction for step size update } & 10.0\end{array}$

\subsection{Advanced}

Parameter Value

Constraint handling method Eliminate

Null-space function Auto

Assembly block size $\quad 5000$

Use Hermitian transpose On

Use complex functions with real input Off

Type of scaling Auto

Manual scaling

Row equilibration On

Manual control of reassembly Off

Load constant On

Constraint constant On

Mass constant On

Jacobian constant On

Constraint Jacobian constant On 


\section{APPENDIX C}

\section{The Effect of Catalyst Layer Thickness on Catalyst Utilization}

In this work, the thickness of the catalyst layer was taken to be $10 \mu \mathrm{m}$, and it was found that for nominal operation, between $1-2 \%$ of the catalyst was actually used. In some other works on fuel cell modeling, thicker catalyst layers have been reported, up to $50 \mu \mathrm{m}$. The question arises: How does distributing the same catalyst loading $(0.5 \mathrm{mg}$ $\mathrm{cm}^{-2}$ ) over a thicker layer affect the catalyst utilization?

According to Equation (35), increasing the catalyst thickness reduces the effective surface area/volume parameter, $a$. Physically, spreading the catalyst over a thicker region results in less dense packing, and hence lower reaction rates. Changes in porosity due to the less dense packing have a small effect on gas diffusivity. So if the catalyst thickness increases by a factor of 5 , then the catalyst activity decreases by the same factor. Consider the ID Fick's law:

$$
\frac{d^{2} C}{d x^{2}}-k^{2} C=0
$$

The term $k^{2} C$ represents the species consumption term, $k^{2}$ chosen just to ensure a positive co-efficient. This term actually is a function of the overpotential, but for simplicity, in this analysis, it is taken as a constant.

With the boundary conditions,

$$
C=C_{0} \quad \text { at } \quad x=0 \text { and } \frac{d C}{d x}=0 \quad \text { at } \quad x=t_{c a t}
$$

the approximate analytical solution, assuming that the concentration falls rapidly, is, 


$$
\frac{C}{C_{0}}=\exp (-k x)
$$

Theoretically the concentration never falls to zero, however practically, the concentration could be considered zero when the LHS is sufficiently small, say of value, $\delta$. The value of $x, \chi$, at which the concentration falls below this low value

$$
\chi=\frac{\ln (1 / \delta)}{k}
$$

So the active thickness of the catalyst layer, $\chi$, (that thickness for which the concentration is practically non-zero), is inversely proportional to the square root the of reaction co-efficient, $k^{2}$.

Now, if the catalyst thickness is increased by a factor of 5 , with the catalyst loading unchanged, then $k^{2}$ deceases by a factor of 5 , hence $\chi$ increases by a factor of $\sqrt{5}$. Thus the active catalyst thickness increases, due to the lower reaction rates. However, the fraction of the catalyst layer thickness, which is active, $\chi / L$ decreases by a factor of $\sqrt{5}$. In other words, if the catalyst utilization for a thickness of $10 \mu \mathrm{m}$ is $1-2 \%$, then this utilization decreases to $0.45-0.90 \%$ as the catalyst layer thickness increases to $50 \mu \mathrm{m}$ i.e. the catalyst utilization becomes worse. This under girds the case for thinner catalyst layers. 


\section{DENVER FARON CHEDDIE}

1995

B. Sc. Mechanical Engineering

The University of the West Indies

St. Augustine, Trinidad

2004

M. Phil. Mechanical Engineering

The University of the West Indies

St. Augustine, Trinidad

\section{PUBLICATIONS AND PRESENTATIONS}

D. Cheddie, N. Munroe, Review and Comparison of Approaches to Proton Exchange Membrane Fuel Cell Modeling, Journal of Power Sources 147 (2005) 72-84.

D. Cheddie, N. Munroe, Mathematical Model of a PEMFC using a PBI Membrane, Energy Conversion and Management 47 (2006) 1490-1504.

D. Cheddie, N. Munroe, Parametric Model of an Intermediate Temperature PEMFC, Journal of Power Sources 156 (2006) 414-423.

D. Cheddie, N. Munroe, Two-dimensional Effects in Intermediate Temperature PEMFCs, International Journal of Transport Phenomena 8 (2006) 51-68.

D. Cheddie, N. Munroe, Three-dimensional Modeling of High Temperature PEMFCs, Journal of Power Sources, Article in Press.

D. Cheddie, N. Munroe, Analytical Correlations for Intermediate Temperature PEMFCs, Journal of Power Sources, Article in Press.

D. Cheddie, N. Munroe, A two phase model of an intermediate temperature PEM fuel cell, International Journal of Hydrogen Energy, Submitted for publication.

D. Cheddie, N. Munroe, Modeling of PEM Fuel Cells using PBI Membranes, ASME Fuel Cell Conference 2006, Irvine, CA.

D. Cheddie, N. Munroe, Two Phase Modeling of a Phosphoric Acid Doped PEM Fuel Cell, ASME Joint U.S.-European Fluids Engineering Summer Meeting 2006, Miami, FL.

D. Cheddie, N. Munroe, Modeling of High Temperature PEM Fuel Cells using FEMLAB, Comsol Multiphysics Conference 2005, Boston, MA. 
D. Cheddie, N. Munroe, Mathematical Modeling of High Temperature PEM Fuel Cells, Materials Congress 2006, London, UK.

N. Munroe, D. Cheddie, Perspectives on Fuelling Fuel Cells for Energy Systems in Developing Countries, Latin American and Caribbean Consortium of Engineering Institutions (LACCEI) 2004, Miami, FL.

N. Munroe, D. Cheddie, Fuelling Fuel Cells from Domestic Resources in Developing Countries, Latin American and Caribbean Consortium of Engineering Institutions (LACCEI) 2005, Cartagena, Colombia.

D. Cheddie, N. Munroe, Strategies for Developing Nations in the Future Hydrogen Economy, Caribbean Studies Newsletter 32 (2005) 2-5.

\section{REVIEWER}

Journal of Power Sources

International Journal of Hydrogen Energy 